INSTITUTO DE PESQUISAS ENERGÉTICAS E NUCLEARES Autarquia Associada à Universidade de São Paulo

\title{
METODOLOGIA DE MONITORAÇÃO E DIAGNÓSTICO AUTOMATIZADO DE ROLAMENTOS UTILIZANDO LÓGICA PARACONSISTENTE, TRANSFORMADA DE WAVELET E PROCESSAMENTO DE SINAIS DIGITAIS
}

\author{
Paulo Henrique Ferraz Masotti
}

Tese apresentada como parte dos requisitos para a obtenção do grau de Doutor em Ciências na Área de Tecnologia Nuclear - Reatores

Orientador:

Dr. Daniel Kao Sun Ting

\author{
SÃO PAULO \\ 2006
}


Á esposa e filho, Rosa e Alexandre e a meu irmão e meus pais César, Neimer e Antonieta. 


\section{Agradecimentos}

Ao Dr. Daniel Kao Sun Ting, pela orientação da tese, pelas discussões e soluções técnicas encontradas, abordando com detalhes vários itens deste trabalho o que contribuiu muito para a sua qualidade final.

Ao Instituto de Pesquisas Energéticas e Nucleares (IPEN/CNEN-SP), e ao Centro de Engenharia Nuclear (CEN) pela infra-estrutura fornecida e pela oportunidade concedida.

Ao Dr Belle R. Upadhyaya e Dr J. Wesley Hines do Departamento de Engenharia Nuclear da Universidade do Tennessee, pelas trocas de informações na fase inicial deste trabalho.

À colega M.Sc. Rosani Maria L da Penha, pelas sugestões e valiosos comentários técnicos efetuados no decorrer deste trabalho.

Ao colega M.Sc. Nicolau Dyrjawoj pelo desenvolvimento de um dos amplificadores utilizados neste trabalho.

À colega Dra. Iraci Martinez P. Gonçalves pelas discussões técnicas e pelo apoio constante.

Aos colegas do Centro de Engenharia Nuclear, em especial aos colegas do Grupo de Monitoração de Diagnóstico.

E a todos aqueles que de alguma forma colaboraram com a realização deste trabalho. 


\title{
METODOLOGIA DE MONITORAÇÃO E DIAGNÓSTICO AUTOMATIZADO DE ROLAMENTOS UTILIZANDO LÓGICA PARACONSISTENTE, TRANSFORMADA DE WAVELET E PROCESSAMENTO DE SINAIS DIGITAIS
}

\author{
Paulo Henrique Ferraz Masotti
}

\section{RESUMO}

A área de monitoração e diagnóstico vem apresentando um acentuado desenvolvimento nos últimos anos com a introdução de novas técnicas de diagnóstico bem como vem contando com a contribuição dos computadores no processamento das informações e das técnicas de diagnósticos. A contribuição da inteligência artificial na automatização do diagnóstico de defeito vem se desenvolvendo continuamente e a crescente automação na indústria vêm de encontro a estas novas técnicas.

$\mathrm{Na}$ área nuclear, é crescente a preocupação com a segurança nas instalações, e têm sido procuradas técnicas mais eficazes para aumentar o nível de segurança [59]. Algumas usinas nucleares já possuem instaladas, em algumas máquinas, sensores que permitem a verificação de suas condições operacionais. Desta forma, este trabalho também pode colaborar nesta área, ajudando no diagnóstico das condições de operação das máquinas, mais especificamente, no diagnóstico das condições dos rolamentos.

O principal objetivo deste trabalho é detectar e classificar os tipos de defeitos apresentados pelos rolamentos analisados e para tal desenvolveutse uma nova técnica de extração de característica dos sinais de aceleração, baseando-se no Zero Crossing da Transformada de Wavelet contribuindo com o desenvolvimento desta dinâmica área.

Como técnica de inteligência artificial foi utilizada a Lógica Paraconsistente Anotada com dois valores (LPA2v), oferecendo a sua contribuição na automação do diagnóstico de defeitos, pois esta lógica pode tratar inclusive de resultados contraditórios que as técnicas de extração de características possam apresentar.

Foi desenvolvido um programa de computador onde varias técnicas de extração de características foram utilizadas para realização de diagnóstico das condições de operação dos rolamentos. Este programa foi testado através de dados experimentais obtidas em uma bancada de ensaios para rolamentos onde defeitos previamente conhecidos foram utilizados para avaliar o desempenho das novas técnicas utilizadas. 
Este trabalho também se concentrou na identificação de defeitos em sua fase inicial procurando utilizar acelerômetros, pois são sensores robustos, de baixo custo e facilmente encontrados na indústria em geral.

Os resultados deste trabalho foram obtidos através da utilização de um banco de dados experimental e verificoutse que os resultados de diagnósticos de defeitos mostraramse bons para defeitos em fase inicial. 


\title{
METHODOLOGY FOR MONITORING AND AUTOMATED DIAGNOSIS OF BALL BEARINGS USING PARACONSISTENT LOGIC, WAVELET TRANSFORM AND DIGITAL SIGNAL PROCESSING
}

\begin{abstract}
The monitoring and diagnosis area is presenting an impressive development in recent years with the introduction of new diagnosis techniques as well as with the use the computers in the processing of the information and of the diagnosis techniques. The contribution of the artificial intelligence in the automation of the defect diagnosis is developing continually and the growing automation in the industry meets this new techniques.

In the nuclear area, the growing concern with the safety in the facilities requires more effective techniques that have been sought to increase the safety level. Some nuclear power stations have already installed in some machines, sensors that allow the verification of their operational conditions. In this way, the present work can also collaborate in this area, helping in the diagnosis of the operational condition of the machines.

This work presents a new technique for characteristic extraction based on the Zero Crossing of Wavelet Transform, contributing with the development of this dynamic area.

The technique of artificial intelligence was used in this work the Paraconsistente Logic of Annotation with Two values (LPA2v), contributing with the automation of the diagnosis of defects, because this logic can deal with contradictory results that the techniques of feature extraction can present.

This work also concentrated on the identification of defects in its initial phase trying to use accelerometers, because they are robust sensors, of low cost and can be easily found the industry in general.

The results obtained in this work were accomplished through the use of an experimental database, and it was observed that the results of diagnoses of defects shown good results for defects in their initial phase.
\end{abstract}




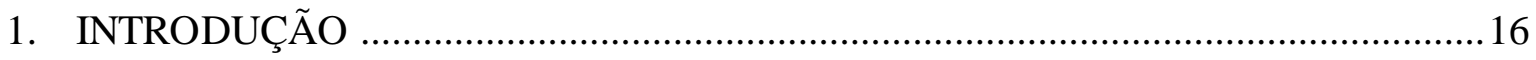

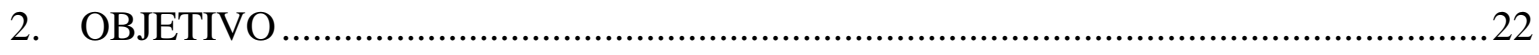

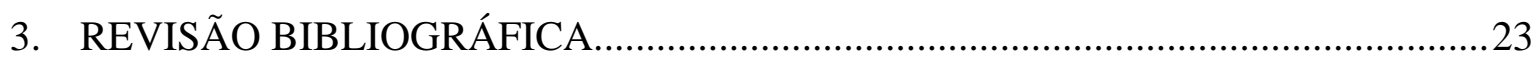

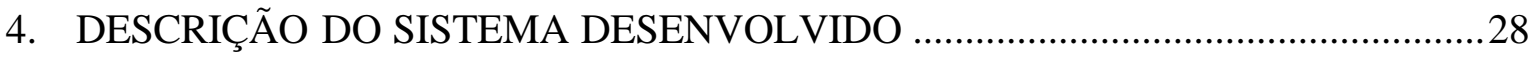

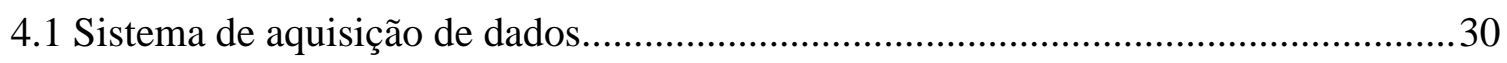

4.1.1 Detalhamento da sequiência da elaboração do banco de dados ...............................30

4.1.2 Diagrama de blocos do sistema desenvolvido.........................................................33

4.1.2.1 Bloco de pré-processamento de sinal............................................................34

4.1.2.2 Extração de características ..............................................................................34

4.1.2.3 Lógica Nebulosa Paraconsistente ……………………………………….......34

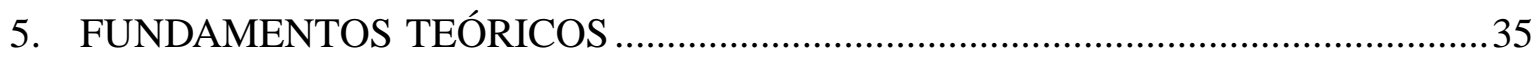

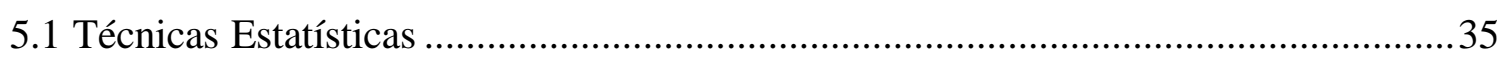

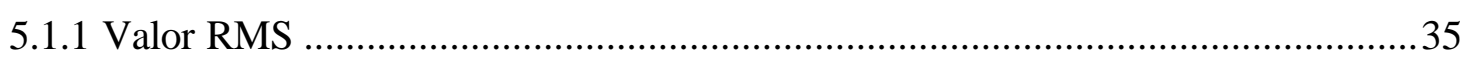

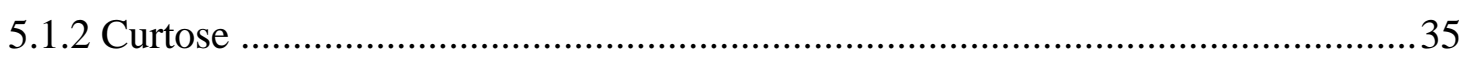

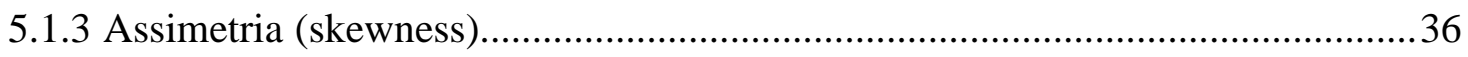

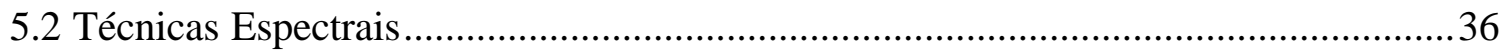

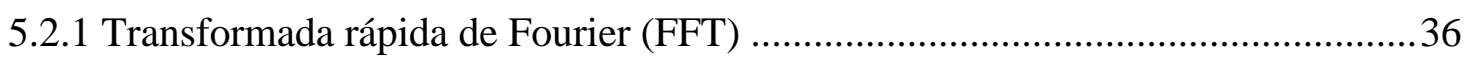

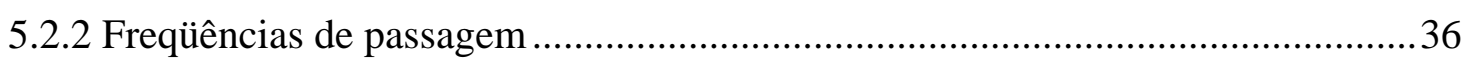

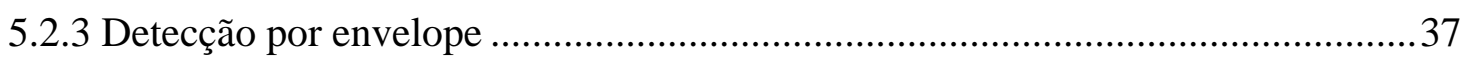

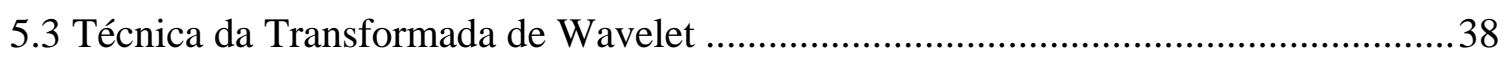

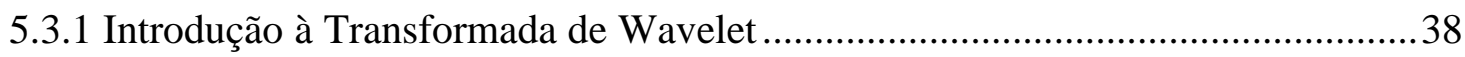

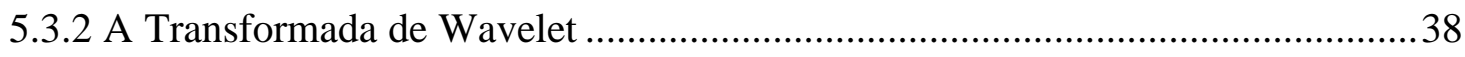

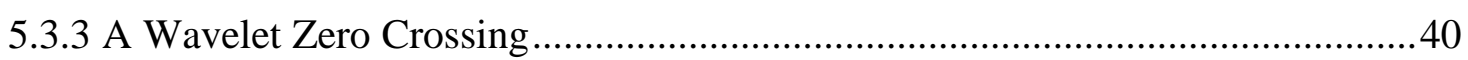

5.3.4. Zero crossing da transformada de wavelet.......................................................4

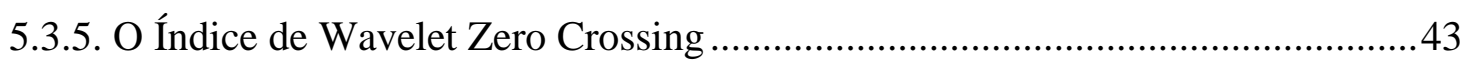

5.3.6 A utilização da Transformada de Wavelet ...........................................................4

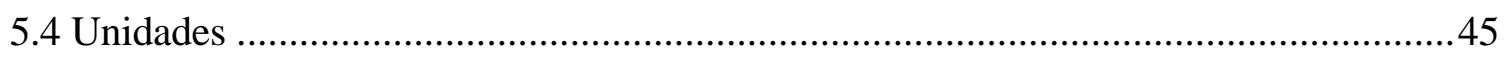




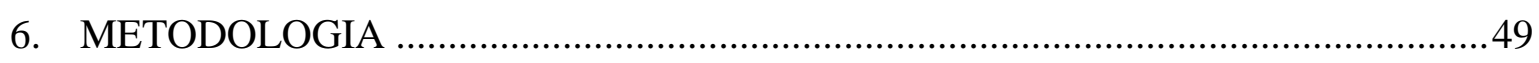

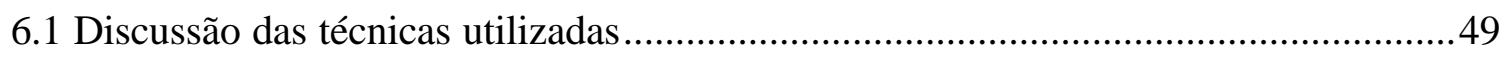

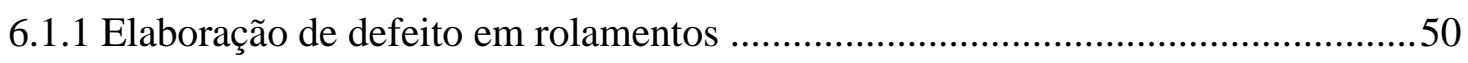

6.1.2 Condições de referência do rolamento sem defeito .............................................51

6.1.3 Estudos da aplicação da Transformada de Wavelet............................................52

6.1.3.1 A metodologia para cálculo do Índice de Wavelet Zero Crossing .................53

6.1.4 Aplicação da Lógica Nebulosa Paraconsistente ..................................................60

6.2 Programa de Análise e Diagnóstico de Defeitos em Rolamentos ..............................72

6.2.1 Diagrama de blocos do programa desenvolvido .............................................. 73

6.2.2 Descrição das telas do subprograma de extração de características......................75

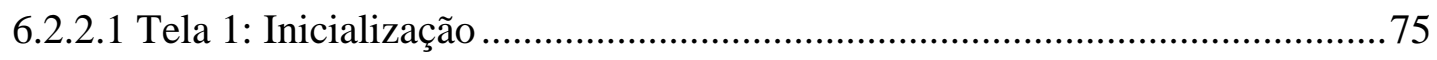

6.2.2.2 Tela 2: Especificação do rolamento .............................................................75

6.2.2.3 Tela 3: Características dos sinais de aceleração.............................................78

6.2.2.4 Tela 4: Características dos sinais de velocidade ...........................................78

6.2.2.5 Tela 5: Parâmetros estatísticos avançados .................................................... 81

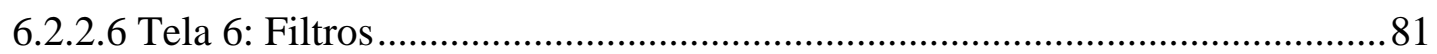

6.2.2.7 Tela 7: Zero Crossing da Transformada de Wavelet (análise por nível) .......81

6.2.2.8 Tela 8: Zero Crossing da Transformada de Wavelet (10 níveis) ....................81

6.3 Descrição das telas do subprograma de diagnósticos ................................................. 86

6.3.1 Tela 9: Comparação entre os sinais sem defeito e com defeito ............................86

6.3.2 Tela 10: Curvas de IWZC em função do limiar..................................................... 86

6.3.3 Tela 11: Comparação de parâmetros estatísticos ...............................................89

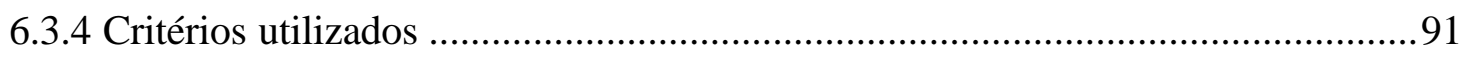

6.3.5 Tela dos resultados de extração de características ............................................94

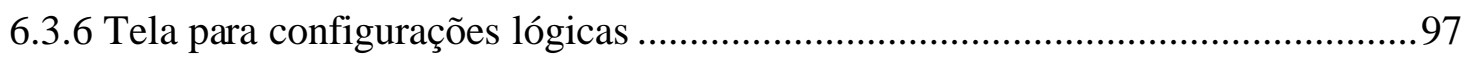

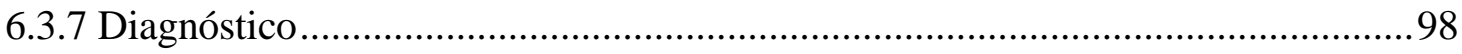

6.4 Visualização das extrações de características já realizadas .......................................98

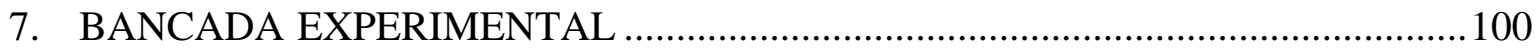

7.1 Determinação das condições de referência de um rolamento sem defeito ................100

7.2 Procedimento de montagem dos rolamentos na máquina de ensaios ....................... 101

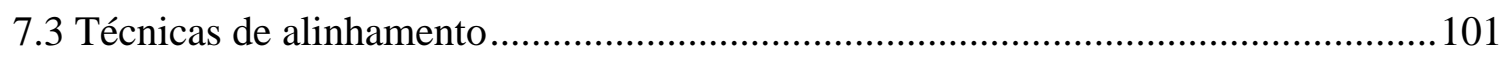

7.3.1 Alinhamento utilizando relógio apalpador e comparador................................ 102 
7.3.2 Alinhamento utilizando-se a DEP 103

7.4 Algumas características do rolamento utilizado e das condições de ensaio 103

7.5 Graxa lubrificante utilizada 104

7.6 Localização dos defeitos 104

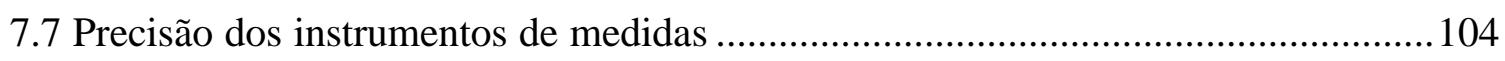

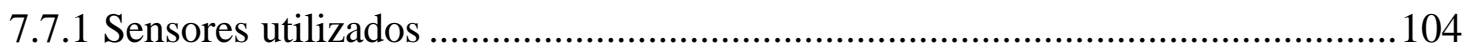

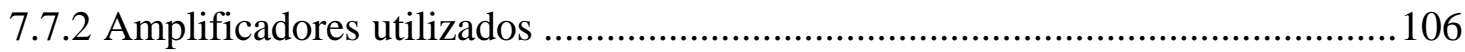

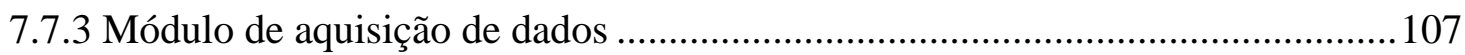

7.7.4 Conexões elétricas, aterramento e blindagem eletromagnética .........................109

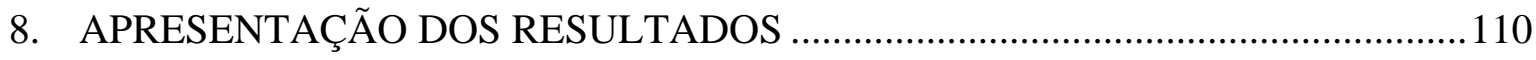

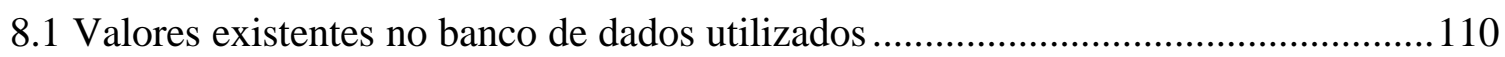

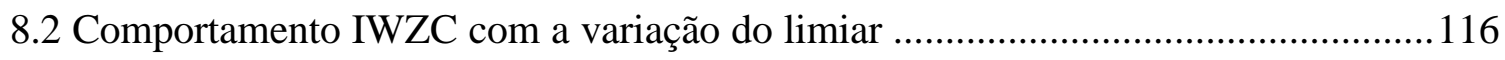

8.3 Obtenção dos critérios para RMS 5, 6 e 7 ................................................................. 121

8.4 Resultado dos diagnósticos realizados do banco de dados ......................................123

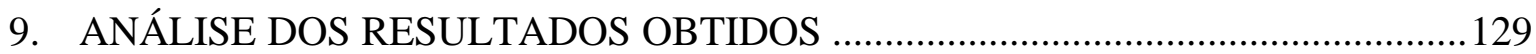

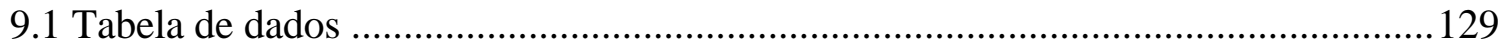

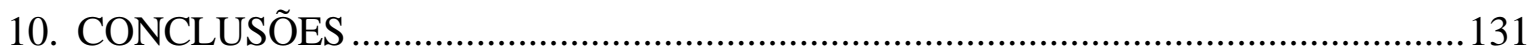

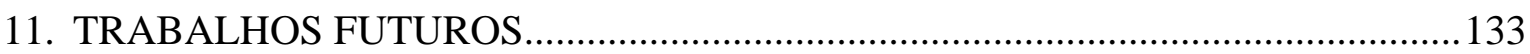

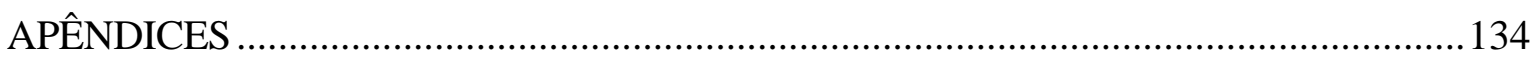

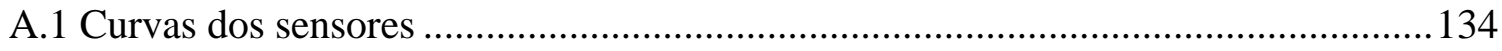

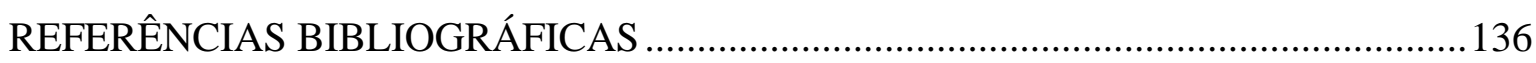




\section{LISTA DE TABELA}

TABELA 5.1. Conversão do sinal de entrada para as várias unidades disponíveis .............45

TABELA 6.1. Valores do banco de dados dos rolamentos sem defeito ...............................51

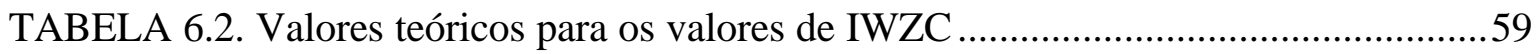

TABELA 6.3. Nomes das condições lógicas extremas .......................................................67

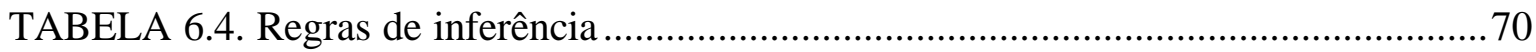

TABELA 6.5. Lista das variáveis de entrada com seus critérios........................................95

TABELA 8.1. Significado dos códigos dos defeitos utilizados ....................................... 110

TABELA 8.2. Código do RMS do sinal de velocidade e o defeito associado .................... 112

TABELA 8.3. Código da curtose da Aceleração e o defeito associado .............................. 114

TABELA 8.4. Resultados para os rolamentos sem defeito ............................................. 123

TABELA 8.5. Análise estatística para os rolamentos sem defeitos em porcentagem........ 124

TABELA 8.6. Resultados para rolamentos com defeito distribuído tipo corrosão ............124

TABELA 8.7. Análise estatística de defeito distribuído (corrosão), em porcentagem...... 125

TABELA 8.8. Resultados para rolamentos com defeito distribuído tipo riscado .............. 126

TABELA 8.9. Análise estatística de defeitos distribuídos (riscados), em porcentagem... 126

TABELA 8.10. Resultados para os rolamentos com defeito localizado tipo furo.............. 127

TABELA 8.11. Análise estatística de defeitos localizado (furo), em porcentagem.......... 128

TABELA 9.1. Taxa de acerto dos resultados obtidos.......................................................129

TABELA 9.2. Resultados dos estados lógicos de saída por proposição ........................... 130 


\section{LISTA DE FIGURAS}

FIGURA 4.1. Diagrama das etapas necessárias para a obtenção do diagnóstico .. 29

FIGURA 4.2. Diagrama de blocos para elaboração de um banco de dados 30

FIGURA 4.3. Foto mostrando o rolamento "montado". 32

FIGURA 4.4. Foto mostrando o rolamento desmontado. 32

FIGURA 4.5. Diagrama de blocos do sistema de diagnóstico 33

FIGURA 5.1. Representação esquemática do ângulo $\phi$ e do "pitch diameter". 37

FIGURA 5.2. RZCTW para um sinal senoidal.

FIGURA 5.3. Reticulado de Hasse - domínio valores verdades - forma cartesiana [27] ....47

FIGURA 5.4. O domínio lógico representado pelo gef e pelo gec..... .48

FIGURA 6.1. Máquina para ensaio de rolamentos e o sistema de aquisição de dados

FIGURA 6.2. Diferença da representação do zero crossing da transformada de wavelet ...54

FIGURA 6.3. Módulo da representação do zc da transformada de wavelet para nível D4 .55

FIGURA 6.4. Curva IWZC..... .56

FIGURA 6.5. Sinal senoidal de freqüência conhecida 57

FIGURA 6.6. Função de pertinência para característica RMS 62

FIGURA 6.7. Etapas para a aplicação da lógica nebulosa paraconsistente. .63

FIGURA 6.8. Diagrama lógico mostrando as etapas para diagnóstico 65

FIGURA 6.9. Diagrama informando se a DEP ou ENV detectaram o defeito. 65

FIGURA 6.10. Diagnóstico para classificação de defeitos 66

FIGURA 6.11. Diagrama de blocos da aplicação da Lógica Nebulosa Paraconsistente .....68

FIGURA 6.12. Funções de pertinência de entrada do grau de evidência favorável. 69

FIGURA 6.13. Funções de pertinência de entrada do grau evidência contrária 69

FIGURA 6.14. Representação gráfica dos estados lógicos da saída. . .71

FIGURA 6.15. Funções de pertinência de saída. 72

FIGURA 6.16. Diagrama de blocos das telas de extração de características .73

FIGURA 6.17. Diagrama de blocos das telas de diagnóstico 74

FIGURA 6.18. Tela Inicialização. 76

FIGURA 6.19. Tela apresentando a especificação do rolamento. 77 
FIGURA 6.20. Característica do sinal de aceleração.

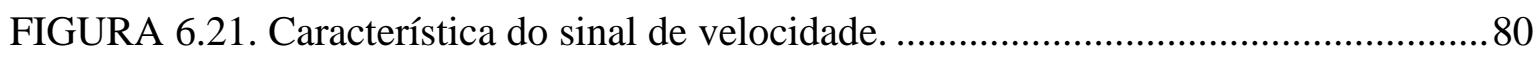

FIGURA 6.22. Parâmetros estatísticos avançados. ......................................................... 82

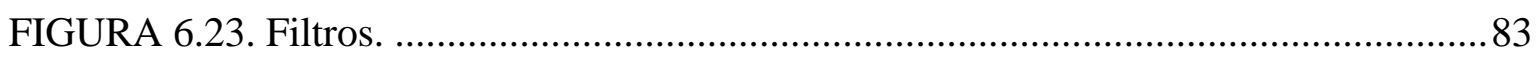

FIGURA 6.24. Zero Crossing da Transformada de Wavelet (análise por nível). ................84

FIGURA 6.25. Zero Crossing da Transformada de Wavelet (10 níveis). ...........................85

FIGURA 6.26. Comparação entre os sinais sem defeito e com defeito. ..............................87

FIGURA 6.27. Curvas de IWZC em função do limiar. ....................................................... 88

FIGURA 6.28. Comparação de Parâmetros estatísticos. ...................................................... 90

FIGURA 6.29. Sinal de aceleração, antes da redução de ruídos .........................................92

FIGURA 6.30. Detalhe do sinal de aceleração, antes da redução de ruídos........................93

FIGURA 6.31. Sinal de aceleração, após a redução de ruídos ............................................93

FIGURA 6.32. Detalhe do sinal de aceleração, após da redução de ruídos .........................94

FIGURA 6.33. Variáveis utilizadas para a avaliação das condições do rolamento..............96

FIGURA 6.34. Blocos lógicos para a obtenção dos valores gef e gec. ...............................98

FIGURA 6.35. Diagnóstico da condição do rolamento analisado ......................................98

FIGURA 6.36. Principais resultados dos parâmetros analisados. .......................................99

FIGURA 7.1. Ângulos utilizados nas medidas de desalinhamento do eixo ........................ 102

FIGURA 7.2. Detalhe mostrando os acelerômetros no mancal do rolamento sob ensaio .105

FIGURA 7.3. Amplificadores utilizados para os acelerômetros de carga .......................... 106

FIGURA 7.4. Conjunto de amplificadores utilizados para acelerômetros ICP ................. 107

FIGURA 7.5. Programa preexistente adaptado para os sinais de acelerômetros................ 108

FIGURA 8.1. Grau de severidade dos defeitos pelo valor RMS. .................................... 111

FIGURA 8.2. Grau de severidade dos defeitos pela curtose. ........................................... 113

FIGURA 8.3. DEP de um sinal do tipo localizado ........................................................... 115

FIGURA 8.4. Envelope de um sinal do tipo localizado ................................................. 115

FIGURA 8.5. Tela mostrando as DEP para os vários níveis da transforma de wavelet....117

FIGURA 8.6. Curvas IWZC de um rolamento sem defeito ............................................119

FIGURA 8.7. Curva IWZC de um rolamento com defeito distribuído .............................119

FIGURA 8.8. Curva IWZC de um rolamento com defeito localizado (furo) .....................120

FIGURA 8.9. Agrupamentos dos dados para obtenção do critério RMS 5, 6 e 7 ............. 122 


\section{LISTA DE DEFINIÇÕES E ABREVIATURAS}

$\mu_{\mathrm{A}}=$ grau de pertinência da variável de entrada $\mathrm{A}$.

$\mu_{\mathrm{B}}=$ grau de pertinência da variável de entrada $\mathrm{B}$.

$\mu_{1}=\mu_{\mathrm{A}}$, grau de evidência favorável (gef).

$\mu_{2}=1-\mu_{\mathrm{B}}$, grau de evidência contrária (gec).

$\mathrm{A} / \mathrm{D}=$ analogic digital converter

$\mathrm{BPFI}=$ ball pass frequency inner race

$\mathrm{BPFO}=$ ball pass frequency outer race

$\mathrm{BSF}=$ ball spin frequency

$\mathrm{BSF}=$ freqüência de passagem das esferas.

ct $=$ centróide.

$\mathrm{DEP}=$ densidade espectral de potência (PSD - inglês).

DEP E = freqüências de passagem da pista externa detectadas pela técnica DEP

DEP I = freqüências de passagem da pista externa detectadas pela técnica DEP

Diâmetro pitch $=$ diâmetro primitivo

EA $=$ emissão acús tica

$\mathrm{ENV} E=$ freqüências de passagem da pista externa detectadas pela técnica envelope

ENV I = frequiências de passagem da pista interna detectadas pela técnica envelope

$\mathrm{F}=$ falso

$\mathrm{f}_{0}=$ freqüência fundamental

$\mathrm{fa}=$ freqüência de amostragem.

$\mathrm{ffb}=$ freqüência de final da banda

FFT $=$ Fast Fourier Transform

fib $=$ freqüência de inicio da banda

fo $=$ freqüência do eixo

$\mathrm{fp}=$ freqüência de passagem $(\mathrm{p}=1,2,3,4$,

Freqüência de passagem $=$ freqüências de defeitos dos rolamentos

$\mathrm{FTF}=$ fundamental train frequency

$\mathrm{Gc}=$ grau de certeza. 
Gct $=$ grau de contradição

gec $=$ grau de evidência contrária

gef $=$ grau de evidência favorável

HFRT $=$ high frequency resonance technique

$\mathrm{I}=$ inconsistência

$\mathrm{ICP}=$ acelerômetro - integrated circuit piezoelectric da marca registrada PCB inc.

$\mathrm{IRF}=$ frequiência de passagem da pista interna.

IWZC = índice de wavelet zero crossing.

Kurt $=$ curtose

LPA = lógica paraconsistente aplicada

LPA2v = Lógica Paraconsistente Anotada com dois valores

mps = média dos picos dos sinais (módulo da representação da ZCTW)

$\mathrm{Ms} / \mathrm{s}=$ mega amostragens por segundo

$\mathrm{n}=$ níveis da transformada de wavelet.

NFNI = nível baixo de falsidade e nível baixo de inconsistência

NFNP = nível baixo de falsidade e nível baixo de paracompleteza

NVNP = nível baixo de verdade e nível baixo de paracompleteza

NVNI = nível baixo de verdade e nível baixo de inconsistência

nzc $=$ número de zero crossing

$\mathrm{ORF}=$ freqüência de passagem da pista externa.

$\mathrm{P}=$ paracompleto

$\mathrm{P} 1=$ proposição 1

paracompleto $=$ dual de inconsistente.

ppf $=$ ponto do plano da fronteira

$\mathrm{QFI}=$ quase falso tendendo inconsistência

$\mathrm{QFP}=$ quase falso tendendo paracompleto

QIF = quase inconsistência tendendo falsidade

QIV = quase inconsistência tendendo verdade

$\mathrm{QPF}=$ quase paracompleto tendendo falsidade

$\mathrm{QPV}=$ quase paracompleto tendendo verdade

QVI = quase verdade tendendo inconsistência

$\mathrm{QVP}=$ quase verdade tendendo paracompleto

rcd = rolamento com defeito 
RMS = root mean square (raiz média quadrática)

RMS 5, 6, 7 = valor RMS da tw para os níveis 5, 6 e 7

$\mathrm{rpm}=$ rotações por minuto

rsd = rolamento sem defeito

rzctw $=$ representação do zero crossing da transformada de wavelet

$\mathrm{SAD}=$ Sistema de aquisição de dados

sd $=$ sem defeito

$\mathrm{SEE}=$ Spectral Emitted Energy (SEE ${ }^{\mathrm{TM}}$ Technology) (SKF Group)

Tal IWZC1 = valor do coeficiente de decaimento da curva IWZC no nível 1

$\mathrm{tf}=$ transformada de Fourier

Thc = limiar crítico. Valor a partir do qual ocorre uma rápida variação na curva IWZC com o aumento do valor do limiar

The 10 = limiar crítico para a curva IWZC no nível 10

The 8 = limiar crítico para a curva IWZC no nível 8

Thc 9 = limiar crítico para a curva IWZC no nível 9

Thmax $=$ o máximo valor do limiar para que o IWZC apresente $0 \mathrm{zc} / \mathrm{s}$.

Thmax 6 = máximo valor do limiar para a curva IWZC no nível 6

Thmax 7 = máximo valor do limiar para a curva IWZC no nível 7

$\mathrm{tw}=$ transformada de wavelet.

uc $=$ união dos centróides

$\mathrm{V}=$ verdade

$\mathrm{wzc}=$ wavelet zero crossing .

$\mathrm{zc}=$ zero crossing .

$\mathrm{zc} / \mathrm{s}=$ zero crossing por segundo 


\section{INTRODUÇÃO}

Máquinas rotativas são componentes essenciais em qualquer planta nuclear e industrial. Para que tais máquinas possam operar de modo eficiente, seguro e com baixo custo operacional, a monitoração preditiva se apresenta como um importante elemento, pois permite que a máquina se mantenha dentro dos padrões estabelecidos pelo fabricante ou projetista, garantindo assim o seu perfeito funcionamento. Em usinas nucleares, a implantação da monitoração da vibração permite, entre outras coisas, colaborar com a extensão da vida útil da instalação ("ageing"). A monitoração de vibração em usinas nucleares pode ser utilizada principalmente em máquinas rotativas tais como, motores, bombas do circuito primário, bombas do circuito secundário, bombas do circuito terciário, ventiladores, exaustores e turbinas. Estes sinais monitorados fornecem informações às equipes de manutenção, para que os reparos possam ser realizados no momento adequado, impedindo que estas máquinas operem fora das condições de operação estabelecidas pelo fabricante. Desta forma, essas máquinas podem ter a sua vida útil estendida. Além disso, nas modernas instalações nucleares, as máquinas consideradas críticas, já possuem instaladas pelo próprio fabricante, sensores, que embora não façam parte da cadeia de segurança, permitem constatar as condições de operação o que, conseqüentemente, aumenta a segurança da instalação, sendo que na atualidade o seu uso vem se tornando cada vez mais comum [42].

Existem várias técnicas para se avaliar as condições de funcionamento das máquinas rotativas. Por exemplo, a análise de seu sinal de vibração, de seus sinais acústicos e a análise química do lubrificante. No entanto, a técnica que tem se mostrado mais eficaz e mais utilizada na detecção de defeitos em máquinas rotativas é a análise de sinais de vibração [1].

Nas pesquisas bibliográficas realizadas sobre a monitoração das máquinas rotativas encontramos uma citação [2] que demonstra que na atualidade continuam os estudos para desenvolver novos métodos que melhorem os índices de acertos dos diagnósticos de falhas em máquinas rotativas: "Na atualidade, extensos trabalhos de pesquisa estão sendo 
realizados no campo de diagnóstico, processamento de dados e controle de máquinas”. E, além disso, em [37] é destacado a importância das análises das condições do rolamento para o diagnóstico de máquinas rotativas: "Os rolamentos são os componentes mais comuns de todas as plantas industriais. A confiabilidade do rolamento é, portanto, o ponto mais crítico em todas as situações industriais. Desta forma, embora os rolamentos sejam relativamente baratos, eles podem causar custosos desligamentos de importantes sistemas, levando a significativa perda de produção”.

Com relação aos defeitos que podem ocorrer em rolamentos, a referência [7] salienta que podem ocorrer defeitos na pista interna, na pista externa, na gaiola e nas esferas ou roletes, além de combinações destes entre si.

Algumas das causas que podem levar os rolamentos a apresentarem defeitos são [7]:

1- Sobrecarga;

2- Desbalanceamento;

3- Variações bruscas de temperatura, fora do especificado;

4- Lubrificação inadequada;

5- Partículas abrasivas ou corrosivas no lubrificante, contaminantes;

6- Erro de projeto;

7- Desgaste pelo uso (fadiga do material);

8- Equipamento que permaneceu estacionado durante longos períodos;

9- Erros de montagens.

Ao se identificar que um mesmo tipo de falha está se repetindo, podemos chegar a pelo menos uma das quatro possibilidades mostradas a seguir e propor soluções adequadas para cada caso. As possibilidades são:

a) Houve uma falha no projeto da máquina;

b) O operador não a está usando dentro de suas especificações operacionais;

c) A máquina está instalada em local inadequado;

d) As condições de lubrificação são inadequadas.

Uma das maneiras de se evitar que os rolamentos apresentem falhas é a realização da manutenção preditiva, que busca assegurar que um equipamento opere de modo eficiente, com segurança e baixo custo operacional, assegurando que a máquina esteja 
dentro dos padrões estabelecidos pelo fabricante ou projetista. Entre as vantagens da monitoração preditiva pode-se destacar os seguintes itens:

a) Diminuição do número de falhas e paradas da máquina, aumentando a disponibilidade da instalação;

b) Redução do custo de manutenção;

c) Aumento de sua vida útil;

d) Aumento na confiabilidade e segurança na operação.

Além disso, os rolamentos devem estar sempre devidamente lubrificados. Com relação a este item podemos citar [6]: "Para lubrificar rolamentos, a graxa lubrificante é inferior ao óleo em alguns aspectos, pois ela não é tão adequada para operar a altas velocidades devido a sua baixa fluidez. Mas quando a graxa é usada como lubrificante de rolamento, a estrutura do rolamento pode ser simplificada. A lubrificação com graxa é conveniente para máquinas ou equipamentos pequenos e leves, é de fácil manipulação, e a poluição causada por vazamento de óleo é reduzida. Por estas razões mais de $80 \%$ dos rolamentos são lubrificados com graxa”. Assim, tomando por base estas informações, este trabalho se concentrou nos rolamentos lubrificados com graxa.

A grande maioria dos sistemas de monitoração de falhas em rolamentos [3, 4, 5] não são capazes de classificar qual é o tipo de defeito existente em um rolamento, detectando apenas se estes apresentam falhas ou não. Existem, porém alguns sistemas que informam se o defeito existente está na pista interna, na externa ou nas esferas [5]. Alguns poucos [3] procuram identificar qual o tipo de defeito estes rolamentos apresentam o que não é simples. Estas técnicas levam em conta a descrição dos defeitos ou falhas observadas.

Neste trabalho, procurou-se concentrar o estudo na possibilidade da detecção de falhas em rolamentos procurando localizar a parte do rolamento onde ocorreu à falha, isto é, na pista interna ou na pista externa. Procurourse identificar também se os defeitos são dos tipos localizado ou distribuído. Foi também definido que a região dos defeitos incipientes, ou seja, defeitos em sua fase inicial é que seria estudada por este trabalho.

Nesse trabalho adotou-se e definiu-se defeitos incipientes tomando-se por base o valor RMS que é normalizado [30]. Esta norma define, para rolamentos em boas condições, os níveis de vibrações entre 0,28 e $0,71(\mathrm{~mm} / \mathrm{s})$, e entre 0,71 e 1,8 (mm/s) para rolamentos em condições aceitáveis de operação. Os dados obtidos tanto para os 
rolamentos sem defeito, como os que foram tomados como tendo defeito, estão dentro da região de rolamentos que ainda são considerados bons ou em condições aceitáveis segundo a norma.

Uma lista com os tipos de defeitos efetuados e sua classificação segundo os valores RMS está apresentada na figura 8.1 e na tabela 8.2.

A detecção dos defeitos incipientes é bastante complexa porque estes defeitos iniciais se confundem com ruídos e outros tipos de sinais, levando o analista a ter grande dificuldade para detectar a existência do defeito em seu início. Nestas condições é comum existir dificuldades na realização do diagnóstico, isto é: existe defeito ou não? Para responder a esta questão fez-se uso de várias técnicas de extração de características do sinal, tais como (valor RMS, curtose, densidade espectral de potência, técnica do envelope, etc.). Algumas técnicas de extração de características poderão indicar que "sim", apresenta defeito, outras técnicas poderão indicar que não apresenta defeito. Esta contradição pode ser tratada de modo adequado através da lógica denominada Lógica Paraconsistente, que foi desenvolvida entre outras razões para tratar de condições onde existem contradições, como na resposta à proposição citada, existe defeito ou não?

Para a implementação e integração de todas estas técnicas desenvolveutse um programa, tomando-se por base a plataforma Matlab. Este programa permitiu a análise de dados previamente adquiridos e que após o carregamento dos dados, se realizassem os cálculos dos vários parâmetros estatísticos, espectrais e das transformadas de wavelet. Finalmente, a lógica paraconsistente aplicada combinada com a lógica nebulosa, realiza o diagnóstico da condição do rolamento. Se estas análises forem realizadas e armazenadas periodicamente, isto permitirá a realização do histórico da evolução das condições operacionais e de defeitos da máquina, registrando de modo padronizado, todos os parâmetros utilizados para avaliar o seu desempenho. Todas estas análises podem ser feitas, em um programa instalado em microcomputador ou "laptop".

Este trabalho possui ampla utilização, podendo ser aplicado a inúmeras áreas, tais como: plantas de geração elétrica nuclear ou convencional, indústria automobilística e instalações químicas e petroquímicas. No campo nuclear, principalmente na monitoração de máquinas rotativas tais como, bombas do circuito primário, secundário, terciário, nas turbinas, nos sistemas auxiliares, nos sistemas de ventilação e exaustão, vem se tornando cada vez mais importante, porque permitem saber quais são as suas reais condições de operação. Desta forma, durante as paradas programadas da usina, o programa de 
manutenção preditiva existente receberá mais informações sobre as condições destas máquinas permitindo uma manutenção mais eficiente, ajudando a garantir que em condições de emergência, estes sistemas venham a funcionar adequadamente.

Como originalidade deste trabalho pode-se destacar:

A proposição de uma nova metodologia para detectar a existência de falhas incipiente em rolamentos, estendendo os estudos objetivando a localização do defeito (pista interna, externa) e a classificação do tipo de falha que este apresenta, o que difere da abordagem tradicional, normalmente limitada apenas à detecção de defeito no rolamento.

A proposição de uma nova técnica de extração de característica baseado na Transformada de Wavelet (Índice de Wavelet Zero Crossing).

A automatização do diagnóstico, utilizando para isto a Lógica Nebulosa Paraconsistente associada a cada uma das técnicas de extração de características, aproveitando o que cada uma das técnicas apresenta de melhor, na identificação de cada tipo de falha.

A utilização de um programa de computador que permita capturar raias (raias do eixo, por exemplo), facilitando o diagnóstico das condições do rolamento em locais onde existam ruídos, quando da aquisição dos dados.

Como principais contribuições podem-se destacar:

a) Desenvolvimento de uma nova metodologia implementada através de um programa de computador para diagnóstico integrado das condições de operação dos rolamentos;

b) Desenvolvimento de uma nova técnica para extração de característica de defeitos em rolamentos (Índice de Wavelet Zero Crossing);

c) Utilização da Lógica Paraconsistente Aplicada;

d) Detecção de defe itos incipientes nos rolamentos;

e) Criação de um banco de dados com falhas previamente conhecidas que será utilizado no desenvolvimento de programas para detectar falhas em rolamento;

f) Utilização de método de diagnóstico que permite.

I- Possibilidade de monitoramento contínuo das condições de rolamentos;

II- Não interferência na operação da máquina; 
III- Facilidade no planejamento de programa de manutenção preditiva através da utilização do programa desenvolvido. Isso proporciona uma diminuição no custo de manutenção, no custo da produção e no tempo de reparo, dando mais segurança e proteção ao sistema em que estiver instalado;

IV- Aumento da vida útil, não somente do rolamento, como também do equipamento no qual ele está instalado;

V- Identificação do tipo de defeito apresentado pelo rolamento;

VI- Formação de um histórico do rolamento;

VII- Localização do defeito (pista interna, externa). 


\section{OBJETIVO}

Desenvolver, demonstrando a viabilidade com dados experimentais laboratoriais, uma metodologia que combinando as várias técnicas de extração de características permita monitorar e diagnosticar as condições de operação de rolamentos, detectando $e$ classificando automaticamente, falhas incipientes em sua estrutura.

Os principais objetivos desta metodologia podem ser resumidos como:

a) - Detecção de falhas incipientes;

b) - Localização da posição do defeito incipiente: pista interna ou pista externa;

c) - Identificação do tipo de defeito ocorrido: distribuído ou localizado;

d) - Classificação do defeito: incipiente e severo;

e) - Programa de computador que implemente a metodologia proposta.

Para atingir este objetivo as seguintes atividades deverão ser cumpridas:

- Construir um banco de dados experimental, composto por sinais obtidos de rolamentos com defeitos incipientes implantados de forma controlada;

- Implementar e aplicar as várias técnicas já conhecidas de extração de características dos sinais de rolamentos e utilizá-las para analisar os defeitos em sua fase inicial (defeitos incipientes);

- Pesquisar novas técnicas de extração de características dos sinais de rolamento, tais como, a Transformada de Wavelet e o Zero Crossing da Transformada de Wavelet;

- Automação do diagnóstico utilizando um sistema de inferência baseada em Lógica Nebulosa Paraconsistente, que combine os resultados individuais das várias técnicas utilizadas, possibilitando um diagnóstico final mais robusto. 


\section{REVISÃO BIBLIOGRÁFICA}

Foi feito um levantamento bibliográfico e entre os artigos pesquisados, localizourse "A Review of Vibrations and Acoustic Measurements Methods for the Detection of Defects in Rolling Element Bearing" [1]. Esta revisão serviu de base para apresentar o estado da arte sobre este tema de trabalho, pois algumas das técnicas que estamos utilizando, tais como, curtose e densidade espectral de potência são abordadas nesta revisão fornecendo o estado da arte nesta área, além de informações sobre outras técnicas de extração de características. A seguir, nas próximas páginas, apresentaremos alguns dos pontos principais do artigo citado.

Inúmeros estudos têm sido realizados para explicar o mecanismo de geração de vibrações e ruídos em rolamentos. O que se notou é que a presença de defeitos nos rolamentos causa um aumento significativo nos níveis de vibrações.

Estes defeitos em rolamentos podem ser categorizados como distribuídos ou localizados:

- Os defeitos distribuídos incluem as superfícies rugosas, ondulações, pistas desalinhadas e elementos rolantes fora do tamanho. São causados por erros de fabricação, instalação inadequada ou uso abrasivo.

- Os defeitos localizados incluem trincas, furos e lascas nas superfícies rolantes. O defeito mais comum é o lascamento das pistas ("spalling") ou dos elementos rolantes originados quando, por fadiga, uma "lasca" se inicia abaixo da superfície do metal e se propaga em direção à superfície, até que um pedaço do metal se quebre, provocando um pequeno furo ou lasca. Falhas por fadiga podem ser geradas por sobrecargas ou pancadas repetitivas no rolamento durante a sua operação ou instalação.

Os sinais de vibração podem ser tratados tanto no domínio do tempo como no domínio da freqüência. Uma característica simples no domínio do tempo é medir o valor RMS da aceleração e o fator de crista (“Crest Factor”), ou seja, a razão do valor de pico da aceleração pelo valor RMS da aceleração. Este método tem sido aplicado com limitado 
sucesso para detecção de defeitos localizados. Alguns parâmetros estatísticos, tais como a densidade de probabilidade e a curtose, foram propostos para a detecção de defeitos de rolamentos. Para um rolamento sem dano, o valor de curtose pode chegar até 4 . Um valor maior que 4 é considerado por si mesmo como indicação de falha iminente e nenhum histórico anterior é requerido. Contudo, uma desvantagem deste método é que quando o dano é avançado, o valor de curtose pode voltar ao nível correspondente a de um rolamento sem defeito. Portanto, tem-se sugerido medir a curtose em bandas selecionadas de freqüências. Vários outros estudos também mostram a efetividade da curtose na detecção de defeitos em rolamentos, mas em alguns casos, o método não pode detectar efetivamente o dano incipiente. Porém, mesmo assim a curtose não tem se tornado um método muito popular para monitorar as condições dos rolamentos.

Os defeitos locais também podem ser detectados pela visualização do sinal de vibração no domínio do tempo, em um osciloscópio ou em um registrador gráfico onde se procura observar a presença de picos periódicos, devido ao impacto dos elementos rolantes defeituosos. Alguns autores propuseram um método de detecção de defeitos baseados no número de picos que ultrapassaram um nível de detecção pré-ajustado.

A análise do sinal de vibração no domínio da frequiência ou a sua análise espectral é talvez a técnica mais usada para detectar defeitos em rolamentos. O surgimento dos analisadores de Transformada Rápida de Fourier, "Fast Fourier Transform" (FFT) tem tornado o trabalho de se obter o espectro de banda estreita mais fácil e mais eficiente, e tanto a faixa de alta freqüência como a de baixa freqüência, do espectro de vibração, são de interesse na avaliação das condições do rolamento.

As interações dos elementos rolantes defeituosos de um rolamento produzem pulsos de curta duração, sempre que os defeitos produzirem golpes nas esferas devido ao movimento rotacional do sistema. Esses pulsos excitam a freqüência natural dos rolamentos e das estruturas, resultando em um aumento m energia de vibração nas altas frequiências. As freqüências de ressonâncias dos elementos dos rolamentos também podem ser calculadas teoricamente. Portanto, monitorar o aumento no nível de vibrações na faixa da alta freqüência do espectro é um método efetivo para predizer a condição dos elementos rolantes do rolamento (esferas, pista interna, externa e gaiola) e tem sido usado com êxito por vários investigadores. 
O estudo do Cepstrum de potência mostrou-se como sendo uma técnica efetiva de diagnóstico. Outros autores tinham reportado que o Cepstrum pode efetivamente detectar defeitos na pista externa, mas falhou para detecção de defeitos na pista interna.

Detecção de envelope ou técnica de ressonância de alta freqüência (HFRT) é outra técnica importante de processamento de sinal, que ajuda na identificação de defeitos em rolamentos, pela extração de características das freqüências de passagem dos defeitos, do sinal de vibração do rolamento defeituoso. Esta técnica foi revista por vários autores e é bastante utilizada e o seu sucesso demonstrado por vários investigadores. O envelope fornece uma advertência antecipada da deterioração da condição mecânica do rolamento.

Recentemente, o método da transformada de Wavelet foi sugerido para extrair sinais transitórios para os quais a FFT torna-se ineficiente. A Transformada de Wavelet fornece uma distribuição tempo-freqüência de resolução variável, que possibilita a detecção de impulsos repetitivos, geradas pela passagem de cada elemento rolante sobre o defeito [51, 56, 57, 65]. As diferentes resoluções no domínio tempo-freqüência da transformada de Wavelet a torna superior em relação à FFT. Desta forma a Transformada de Wavelet tem-se mostrado adequada para a detecção de impulsos repetitivos, e pode ser aplicada onde a FFT tem se mostrado de baixa eficiência, isto é, na análise de sinais transitórios e descontínuos.

Alguns pesquisadores têm usado os transdutores de proximidade para monitorar as condições dos elementos rolantes do rolamento. Nesses estudos, o transdutor detecta o deslocamento diretamente na pista externa dos elementos rolantes ao passar sobre ela. Desta forma, as vibrações da estrutura são reduzidas ou eliminadas e a relação sinal ruído é melhorada. Contudo, é difícil a instalação deste sensor que não somente envolve furos e rosqueamentos na caixa do rolamento, mas também o ajuste fino do intervalo entre o sensor e a pista externa, o qual pode mudar devido às condições de vibração, poeira, dilatação, etc. Esta técnica de monitoração é comumente conhecida como REBAM (Rolling Element Bearing Activity Monitor).

Ainda segundo [1], a emissão acústica (EA), que é o fenômeno de geração de transiente de onda elástica devida à rápida liberação de energia por esforços causados por uma alteração estrutural em um material sólido sob esforços mecânicos ou térmicos pode ser utilizada. A vantagem da emissão acústica sobre monitoração da vibração é que a EA pode detectar o crescimento da trinca sob a superfície, enquanto que os sinais de vibração são detectáveis somente quando eles aparecem na superfície. Outros investigadores 
mostraram que características dos sinais de aceleração medidos por EA podem detectar defeitos antes de eles aparecerem na faixa de freqüências dos acelerômetros piezelétricos e também podem detectar as possíveis fontes de geração de EA durante o teste de fadiga de rolamento.

Medidas de ruído acústico também são utilizadas para detecção de defeitos em rolamentos. Essas medidas são normalmente realizadas de dois modos: pressão do som e intensidade do som. A pressão do som gerada por rolamentos sem defeitos foi estudada por vários pesquisadores, no entanto, pouca literatura está disponível para medição do som como uma técnica de identificação de defeito. Medida de intensidade do som é uma técnica comparativamente recente e têm sido feitas sucessivas tentativas para detecção de defeitos de elementos rolantes de rolamento.

Têm surgido outras técnicas para a detecção de defeitos em rolamento. Entre estas novas técnicas, tem-se a SEE [8,9], que é uma nova tecnologia para detecção de falha. Este método usa a alta freqüência de emissão acústica, $(250.000 \mathrm{~Hz}$ a $350.000 \mathrm{~Hz})$ que a define fora da faixa de freqüência das análises normais de vibrações de 0 até $20 \mathrm{kHz}$ e da faixa de outras técnicas de envelope, de $5 \mathrm{kHz}$ até $60 \mathrm{kHz}$. O transdutor de emissão acústica é sensível ao contato metal-metal que ocorre quando os elementos dos rolamentos rolam sob uma pista sem uma camada de lubrificante. O transdutor emite um sinal de alta freqüência, um pulso de voltagem, que dá evidência ao evento defeituoso. Esta tecnologia, tal como o envelope, fornece uma advertência antecipada da deterioração da condição mecânica.

Em 1989, alguns investigadores propuseram um esquema de monitoramento baseado no reconhecimento de padrões e também um sistema automático para diagnóstico de falhas em rolamentos, baseado no processamento de assinaturas no domínio do tempo e técnicas de reconhecimento de padrão. Atualmente, as redes neurais artificiais têm emergido como as ferramentas mais populares para processamento de sinais $\mathrm{e}$ reconhecimento de padrões, e são convenientes para programas de monitoramento das condições de operação do equipamento.

Atualmente, a quantidade de dados coletados nos instrumentos digitais são tão vastas que torna-se necessário um sistema automatizado que forneça uma avaliação concisa e confiável das condições da máquina. Isto é igualmente verdadeiro para os rolamentos. 
Finalmente, na conclusão deste artigo [1] é observado que para a detecção de defeitos em rolamentos, a ênfase atual está sendo dada para o método de "medida de vibração", provavelmente em função do custo beneficio que esta técnica apresenta bem como de sua simplicidade e eficiência.

A técnica da Transformada de Wavelet é utilizada em diversas áreas de monitoração de vibração e no estudo dos vários tipos de defeitos em máquinas rotativas $[16,18,19,21,22]$. Neste trabalho a Representação do Zero Crossing da Transforma de Wavelet que foi utilizada, possui semelhanças com a Representação de Zero Crossing desenvolvido por Mallat [20] e que serviu para criar um novo índice que foi chamado de Índice de Wavelet Zero Crosssing (IWZC).

A Wavelet Zero Crossing tem aplicações principalmente na utilização da técnica de detecção de defeitos conhecida como corrente parasita "Eddy Current". Podem-se citar como exemplo os trabalhos desenvolvidos na Universidade do Tennessee em Knoxville nos EUA, pelo Dr. B. Upadhyaya [23, 40], para a identificação de defeitos em tubos (trincas, corrosão, furos). O uso do Zero Crossing da Transformada de Wavelet, como no item 5.3.4, para diagnóstico de defeitos em rolamentos, pelas pesquisas bibliográficas realizadas, é inédita.

Uma outra técnica de diagnóstico proposta é a utilização da Lógica Paraconsistente Aplicada. Esta lógica foi criada simultânea e independentemente pelo lógico polonês S. Jáskowski e pelo lógico brasileiro N.C.A. Da Costa [25]. Tem sido aplicada na área de engenharia desde 1999 [33] por Da Silva Filho [27] que a utilizou em sua tese de doutorado, para o controle de um robô e posteriormente foi modificada por um segundo pesquisador para controlar um segundo robô [41]. Sua aplicação para detecção de defeitos em rolamento, pelas pesquisas bibliográficas efetuadas, mostrou ser inédita.

As pesquisas bibliográficas mostraram que existem alguns programas que realizam análise de sinais de rolamentos, utilizando a linguagem Labview [3] e outras linguagens [43, 44, 45, 46]; porém o programa que foi desenvolvido neste trabalho agrega outras vantagens, tais como, a inclusão de varias técnicas de extração de características, a utilização da Lógica Paraconsistente Anotada e filtros de largura de banda bastante estreita, que permitem capturar "raias", facilitando o diagnóstico de defeitos em rolamentos.

Pelo que foi apresentado acima, as várias técnicas para extração de características dos rolamentos, unidas por meio da Lógica Paraconsistente Aplicada se apresentam como uma nova metodologia de diagnóstico para detecção de defeitos incipientes. 


\section{DESCRIÇÃO DO SISTEMA DESENVOLVIDO}

O sistema desenvolvido utilizou-se de um programa de computador para reunir as várias técnicas de extração de características cujas informações foram levadas à etapa de diagnóstico que realizou uma avaliação das condições do rolamento analisado.

As técnicas de extração de características que foram utilizadas são: o cálculo do RMS (Root Mean Square), já bastante tradicional na área de máquinas e rolamentos, a transformada de "Fourier", a detecção por envelope, e outras que se constituem como uma nova proposta, que são as Transformadas de Wavelets onde se inclui o Zero Crossing da Transformada de Wavelet.

Após a etapa de extração de características os resultados de cada uma destas técnicas, geraram funções de pertinência de um sistema especialista, que combinado com regras de inferência, permite a construção de um sistema de diagnóstico baseado na Lógica Nebulosa Paraconsistente.

Quando as regras de inferências estiverem devidamente estabelecidas e as funções de pertinência da Lógica Nebulosa Paraconsistente devidamente ajustadas, o programa de computador desenvolvido poderá realizar de modo automático, o diagnóstico do rolamento sob análise com grande precisão para os tipos de defeitos programados.

Toda a metodologia desenvolvida teve por base o programa "Matlab" e os seus “toolboxes” [10, 66, 67]: "processamento de sinais digitais”, "Wavelet”, "Fuzzy Logic” e o "Guide".

Para validar esta metodologia e estabelecer a relação causa-efeito, foram realizados experimentos em laboratório sob diferentes condições de rotação com a utilização de defeitos previamente introduzidos de forma controlada (furos, corrosões, riscos). É importante destacar que os defeitos do tipo localizado (furo), foram criados com grau de severidade crescente, o mesmo é válido para os defeitos do tipo distribuído (corrosão), com um grau de corrosão crescente. Desta forma, é possível avaliar o grau de sensibilidade, ou seja, de incipiência que o conjunto, banco de dados e o programa desenvolvido, são capazes de captar, e como os valores obtidos são absolutos, isto é, possuem unidades de engenharia. 
$\mathrm{Na}$ criação do banco de dados, a graxa lubrificante utilizada foi àquela recomendada pelo fabricante dos rolamentos. Foram utilizados apenas rolamentos do tipo esfera e de uma única classe. Outros bancos de dados para rolamentos também podem ser utilizados pelo programa desenvolvido.

A figura 4.1 ilustra as várias etapas do programa de computador que foi desenvolvido para o diagnóstico de falhas de rolamentos e que serão apresentadas a seguir.

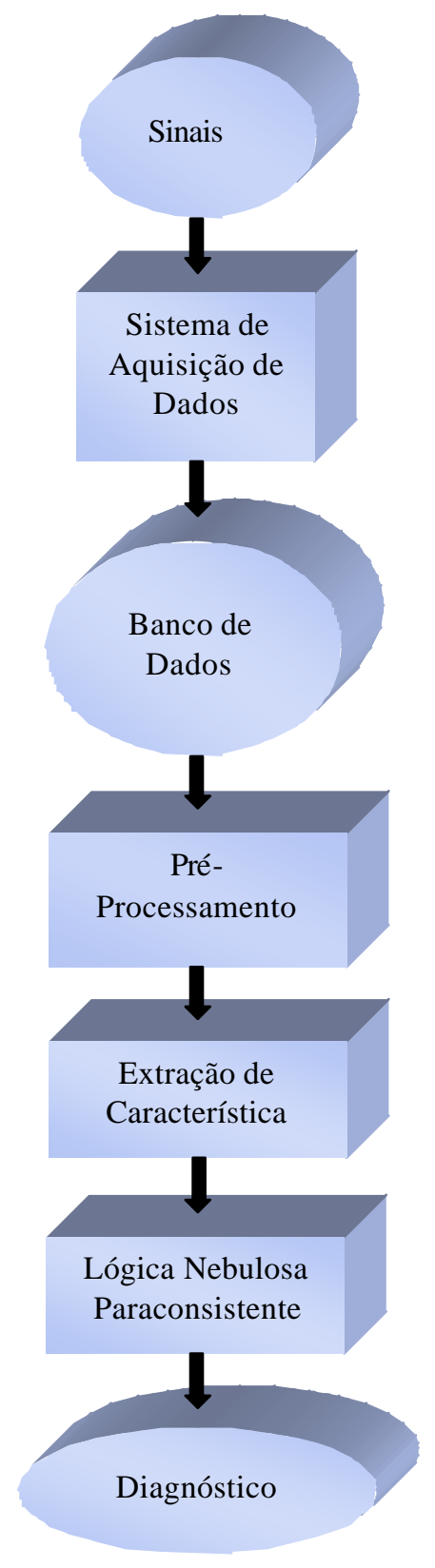

FIGURA 4.1. Diagrama das etapas necessárias para a obtenção do diagnóstico 


\subsection{Sistema de aquisição de dados}

Na figura 4.2 está detalhado o diagrama de blocos do sistema de aquisição de dados utilizado; os sinais captados pelos acelerômetros são processados pelos sistemas de aquisição de dados e a seguir salvo para posterior análise.

\subsubsection{Detalhamento da seqüência da elaboração do banco de dados}

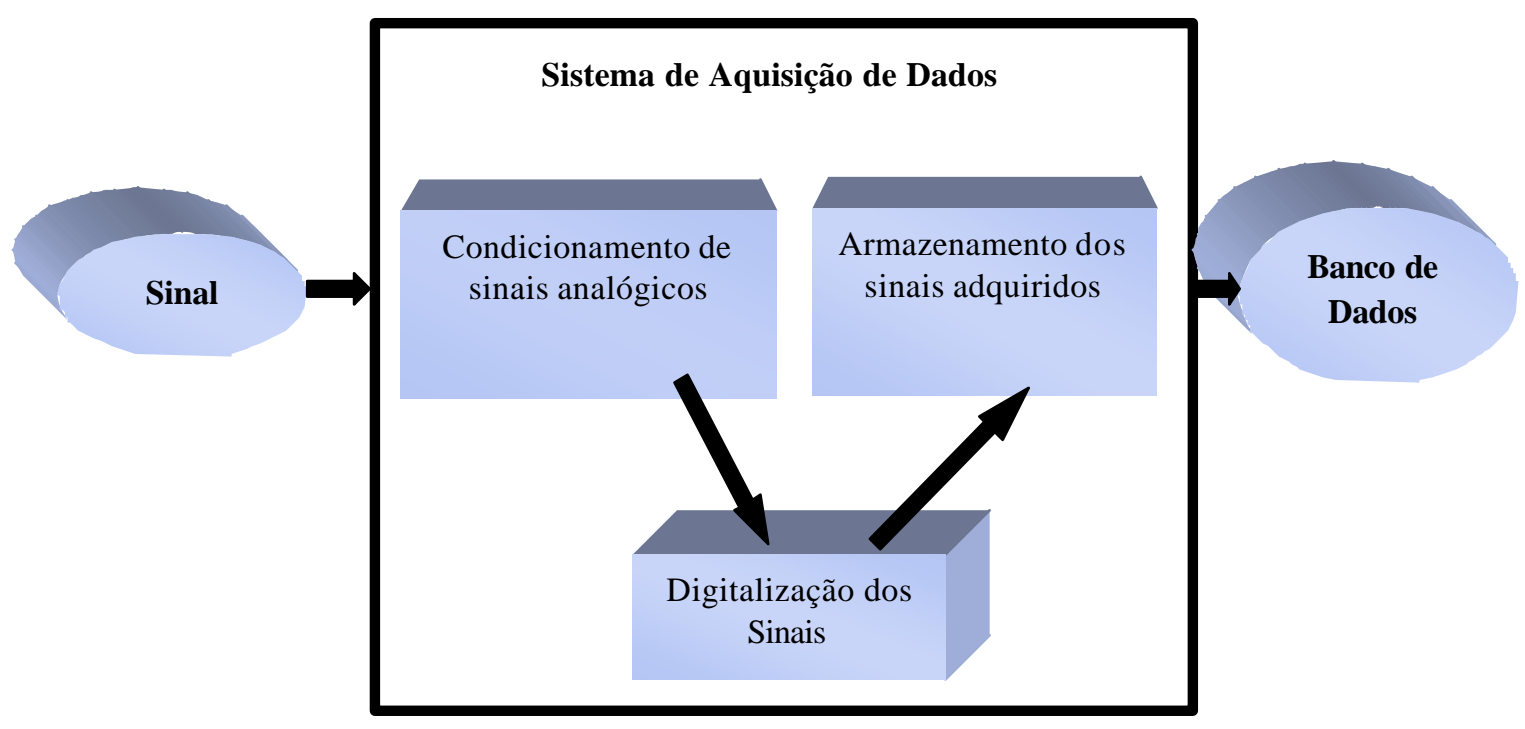

FIGURA 4.2. Diagrama de blocos para elaboração de um banco de dados

No diagrama de blocos da figura 4.2, temos o "sinal" que representa a aceleração obtida de sensores do tipo acelerômetro piezoelétrico que estão fixados aos mancais de uma bancada de "Simulação de Defeitos em Máquinas Rotativas" [26]. Estes sinais são enviados ao subconjunto de nome, Sistema de Aquisição de Dados (SAD), que é constituído pelo módulo de hardware para condicionamento de sinais analógicos, um módulo (placa) de conversão A/D, por um microcomputador de mesa, ou "laptop", e que são controlados um programa de computador que controla os blocos, digitalização dos sinais e gravação dos sinais adquiridos. As descrições detalhadas destes componentes estão no capítulo 7.

Bloco "Condicionamento de sinais analógicos":

Realiza a amplificação e a filtrage m analógica dos sinais captados pelos sensores de vibração, estabelecendo uma freqüência de corte fixa para estes sinais e também atua como um filtro "anti-aliasing", evitando que ocorram erros associados à taxa de amostragem. Os 
dois próximos blocos são controlados por um programa desenvolvido na plataforma "Labview".

Bloco "Digitalização dos sinais":

Foi instalada dentro de um microcomputador de mesa (desktop) uma placa conversora analógico-digital (A/D) fabricada pela National Instruments, que realiza a digitalização dos sinais vindos dos amplificadores.

Este bloco foi controlado por um programa de aquisição de dados baseados no LABVIEW já existente, e que foi desenvolvido no IPEN. A este programa foram acrescidas novas funções tais como: funções estatísticas (RMS, curtose, assimetria, histograma), funções para análise espectral (densidade espectral de potência) e uma função para visualização de até três sinais de acelerometria, tanto no domínio do tempo como no domínio da freqüência. Há também a possibilidade de visualização em três dimensões (3D) de três sinais de acelerômetros, simultaneamente, no domínio do tempo. Desta forma, este programa permite uma pré-avaliação da qualidade do sinal que está sendo adquirido, porém, como nos concentramos na detecção de defeitos em sua fase inicial, este programa, como foi desenvolvido, permite apenas uma pré-avaliação dos sinais, e não uma análise conclusiva sobre a qualidade do sinal.

Bloco "Armazenamento dos sinais adquiridos":

Estes sinais digitalizados pela etapa anterior são salvos em arquivos sob o formato texto (*.txt). Os sinais salvos sob a forma de texto, ao serem organizados por rotação, tipo de defeito, carga, etc., formam o banco de dados cujos dados serão posteriormente analisados.

O banco de dados foi criado no Laboratório de Vibrações do IPEN, utilizando-se uma máquina que foi adquirida da empresa "Spectra Quest", que desenvolve equipamentos para estudos de vários tipos de sistemas mecânicos (rolamentos, engrenagens, poliacorreia, mancais, eixos, etc.) [26].

Inicialmente foram criados defeitos bem definidos que serviram de base para a avaliação da máquina e do sistema de aquisição de dados utilizado. A seguir teve inicio a criação dos defeitos, criados em uma escala decrescente de severidade, iniciando-se desde os mais fáceis de serem detectados até os mais difíceis. Na criação de defeitos foram criados dois tipos de defeitos. Os defeitos que foram chamados de localizados, isto é, defeitos que estão circunscritos a uma pequena área, tais como, furos e pequenos 
lascamentos, e os defeitos chamados de distribuídos, que se estendem além da metade do curso da pista de rolagem das esferas, e que incluem as corrosões, e riscos.

Para a construção do banco de dados seguiram-se os seguintes passos:

Escolheu-se um rolamento com certo tipo de defeito (localizado ou distribuído) e este foi montado na máquina de ensaios de rolamentos e submetido a diferentes rotações: $15 \mathrm{~Hz}(900 \mathrm{rpm}), 30 \mathrm{~Hz}(1800 \mathrm{rpm})$ e $50 \mathrm{~Hz}(3000 \mathrm{rpm})$ e para dois valores de carga $5,9 \mathrm{~kg}$ e $1 \mathrm{~kg}$. Os sinais obtidos dos acelerômetros foram enviados ao bloco "sistema de aquisição de dados" da figura 4.2, de onde saíram digitalizados. A seguir, um outro tipo de defeito é escolhido e repete-se o ciclo até completar o banco de dados com todos os tipos de defeitos programados.

Nas figuras 4.3 e 4.4 são mostrados o rolamento do tipo desmontável escolhido para a construção do banco de dados que é o modelo E20, fabricado pela FAG.

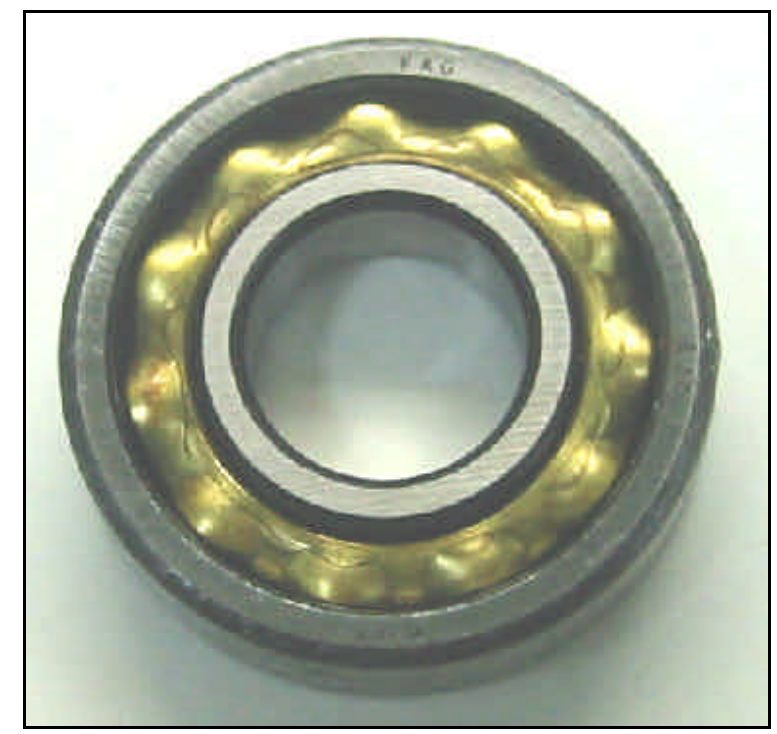

FIGURA 4.3. Foto mostrando o rolamento "montado"

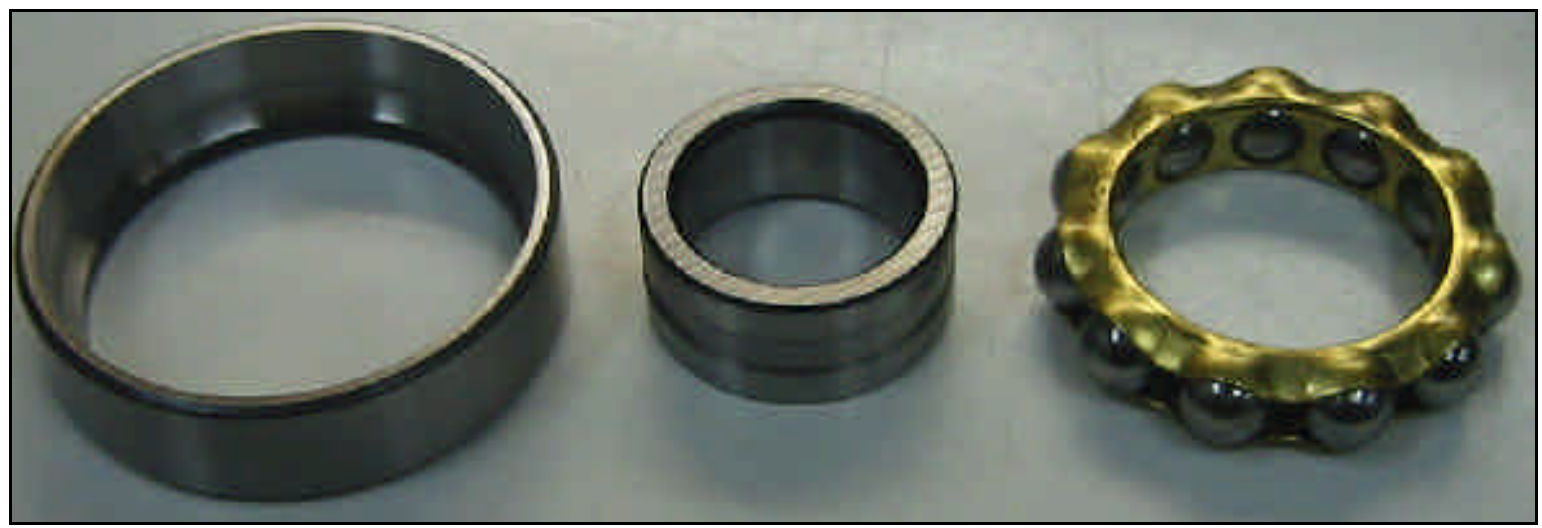

FIGURA 4.4. Foto mostrando o rola mento desmontado 


\subsubsection{Diagrama de blocos do sistema desenvolvido}

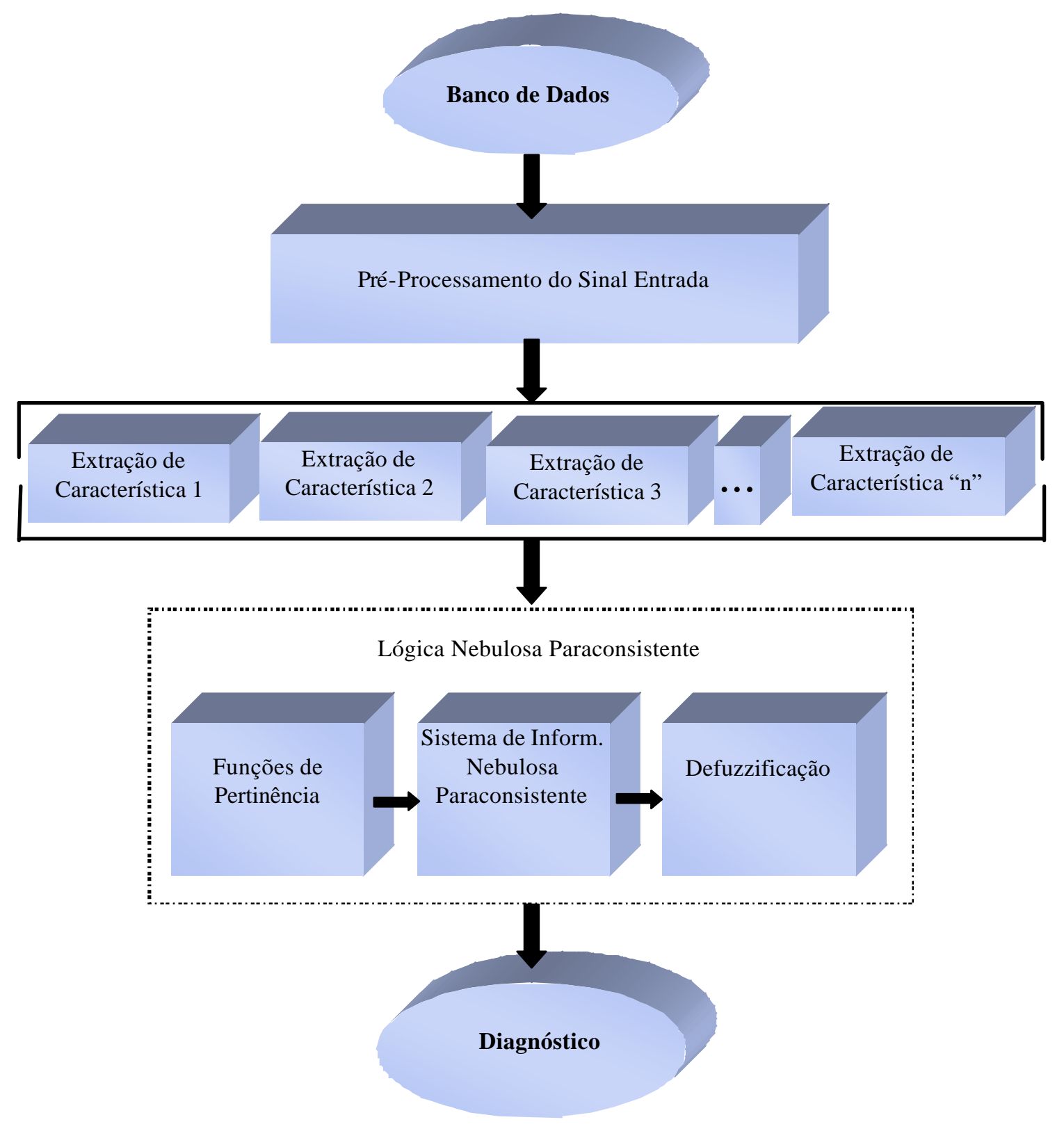

FIGURA 4.5. Diagrama de blocos do sistema de diagnóstico

Analisaremos agora as etapas que compõem o diagrama de blocos da figure 4.5, as quais tratam os sinais dinâmicos de rolamento, armazenados sob a forma de arquivos texto, que compõem o banco de dados. Cabe destacar que podem ser analisados sinais não apenas da bancada de teste do IPEN, mas de quaisquer outras instalações tais como: das usinas 
nucleares (Angra I ou II), indústrias petroquímicas, usinas de geração de energia hidroelétricas, indústria automobilística, companhia siderúrgicas e outras.

\subsubsection{Bloco de pré-processamento de sinal}

Geralmente os sinais obtidos do "campo" contêm ruídos e pode ser necessário atenuá-los ou eliminá-los para que se possa realizar a análise destes sinais através dos métodos de extração de características. Desta forma, esta etapa conta com filtros de ruídos (denoising), que podem permitir uma análise mais detalhada do sinal analisado.

\subsubsection{Extração de características}

Nesta etapa será realizada a extração de características do sinal, obtendo-se valores que permitam obter informações a respeito do rolamento sob análise. Podem-se extrair várias características dos sinais de rolamento através da utilização de várias técnicas.

\subsubsection{Lógica Nebulosa Paraconsistente}

A Lógica Nebulosa Paraconsistente é utilizada para avaliar os valores obtidos por cada uma das técnicas de extração de características, pois podem ocorrer que os resultados obtidos por cada uma destas técnicas sejam contraditórios com relação às condições de operação do rolamento analisado, desta forma como esta lógica foi desenvolvida para tratar de situações onde ocorram contradições, esta pode ajudar a definir as reais condições operacionais do rolamento. 


\section{FUNDAMENTOS TEÓRICOS}

\subsection{Técnicas Estatísticas}

Com as técnicas estatísticas obtêm-se características globais do sinal, perdendo-se a dependência temporal e da freqüência.

\subsubsection{Valor RMS}

Este parâmetro mede a energia do sinal e é usado como padrão há vários anos na indústria para identificação de defeitos em rolamentos [30, 31]. É um parâmetro normalizado e seu uso já está consolidado, o que permite realizar uma análise das condições gerais do funcionamento do rolamento.

O valor RMS é definido como:

$$
R M S=\frac{\operatorname{norma}(A)}{\sqrt{(n)}}
$$

onde: $A$ é um vetor de $n$ elementos e norma o maior valor singular de $A$

\subsubsection{Curtose}

É uma técnica utilizada na monitoração de máquinas rotativas, principalmente na identificação de defeitos em rolamentos [1].

$$
\mathrm{k}=\frac{E \cdot(x-\mu)^{4}}{\sigma^{4}}
$$

onde: $\sigma=$ desvio padrão de $x$ e $\mu=$ é a média de $x$ 


\subsubsection{Assimetria (skewness)}

Esta técnica será utilizada em conjunto com a curtose na detecção de defeitos em rolamentos.

$$
\mathrm{y}=\frac{E \cdot(x-\mu)^{3}}{\sigma^{3}}
$$

onde: $\sigma=$ desvio padrão de $x$ e $\mu=$ é a média de $x$

\subsection{Técnicas Espectrais}

\subsubsection{Transformada rápida de Fourier (FFT)}

Outra técnica já consolidada industrialmente embora ainda não normalizada é a análise do sinal no domínio da freqüência obtida pela transformada de Fourier:

$$
\mathrm{F}(\mathrm{j} \omega)=\int_{-\infty}^{+\infty} f(t) e^{-j \omega t} d t
$$

onde: $\omega=2 \pi \mathrm{f}$ e $\mathrm{f}=$ freqüência

Na análise dos defeitos foi utilizado a Densidade Espectral de Potência pelo método de Welch que é baseada na função FFT.

\subsubsection{Freqüências de passagem}

São parâmetros que permitem identificar a presença de um defeito singular nas freqüências de passagem das esferas. As principais freqüências relacionadas ao rolamento são: freqüência de passagem da pista externa, BPFO "Ball pass frequency outer race", freqüência de passagem da pista interna, BPFI "Ball pass frequency inner race", freqüência de passagem das esferas, BSF "Ball spin frequency" e freqüência fundamental (gaiola), FTF "Fundamental train frequency" [11].

Estas freqüências são definidas pelas equações a seguir e cujos parâmetros são mostrados na figura 5.1 . 


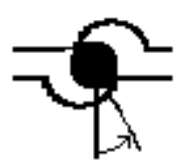

Ângulo $\phi$

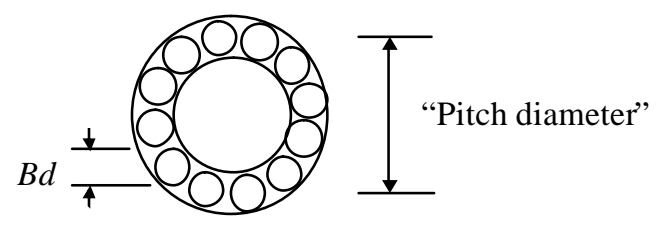

FIGURA 5.1. Representação esquemática do ângulo $\phi$ e do "pitch diameter".

$$
\begin{aligned}
& B P F O=\frac{n}{2} \frac{R P M}{60}\left(1-\frac{B d}{P d} \cos \phi\right) \\
& B P F I=\frac{n}{2} \frac{R P M}{60}\left(1+\frac{B d}{P d} \cos \phi\right) \\
& B S F=\frac{P d}{2 B d} \frac{R P M}{60}\left[1-\left(\frac{B d}{P d}\right)^{2} \cos ^{2} \phi\right] \\
& F T F=\frac{1}{2} \frac{R P M}{60}\left(1-\frac{B d}{P d} \cos \phi\right)
\end{aligned}
$$

Onde: $P d=$ "pitch diameter", $B d=$ diâmetro da esfera, $n=$ número de esferas,

$\phi=$ ângulo de contato e $R P M$ é o número de rotações por minuto, do eixo.

\subsubsection{Detecção por envelope}

A detecção por envelope ou técnica de ressonância de alta freqüência (HFRT) [1] é uma importante técnica de processamento de sinal na identificação de defeitos em rolamentos, através da extração de características das freqüências de defeitos do sinal de vibração do rolamento defeituoso.

Na prática o sinal é filtrado pelo filtro passabanda ao redor de uma das frequiências de ressonância, eliminando assim muitos sinais de vibração indesejados vindos de outras fontes. Este sinal filtrado é então demodulado por um detector de envelope que o retifica e o suaviza por meio de um filtro passabaixa, eliminando-se assim a portadora ou freqüência de ressonância. A seguir é efetuado o espectro no domínio da frequiência, do sinal de 
envelope, para se obter as freqüências do sinal de defeito, analisando-se, a seguir, as condições do rolamento [1].

\subsection{Técnica da Transformada de Wavelet}

A seguir serão apresentadas a transformada de wavelet, a wavelet zero crossing e a sua representação. Também serão descritos o zero crossing da transformada de wavelet, a sua representação, além do novo índice criado que foi chamado de Índice de Wavelet Zero Crossing (IWZC).

\subsubsection{Introdução à Transformada de Wavelet}

Uma das novas transformadas tempo-freqüência que surgiu foi à Transformada de Wavelet $[12,13,14,15,16]$ que pode ser definida como a filtragem de um sinal por meio do filtro de quadratura e convoluído por uma forma de onda de duração limitada (Wavelet) e que possui um valor médio de zero, sendo aplicável a sinais transientes e não harmônicos.

A título de comparação com a análise de "Fourier" que é limitado a sinais estacionários, pode-se dizer que a análise de Fourier consiste em decompor um sinal em ondas senoidais de várias frequiências. Ao passo que a transformada de Wavelet é uma decomposição do sinal utilizando-se uma única Wavelet que pode ser expandida ou compactada e que se desloca no eixo do tempo, cobrindo todo o sinal analisado.

A análise de Wavelet é capaz de revelar aspectos dos dados que outras técnicas de análise de sinais não conseguem, tais como tendências e descontinuidades. Além disso, como favorece uma visão diferente dos dados em relação a aquelas apresentadas pelas técnicas tradicionais, a análise de Wavelet pode comprimir um sinal e também retirar ruídos (“denoise”) $[10,18,19]$ de um sinal sem que haja uma degradação apreciável.

\subsubsection{A Transformada de Wavelet}

A função $\psi(x)$ conhecida como Wavelet mãe é definida no domínio do tempo e da freqüência e que pode ser usada para criar uma família de Wavelet $\psi_{a, b}(x)[20,21,68]$. A Wavelet pode se apresentar sob duas formas: contínua e discreta.

Para a Wavelet na forma Contínua temos: 


$$
\psi_{\mathrm{a}, \mathrm{b}}(\mathrm{x})=|\mathrm{a}|^{-\frac{1}{2}} \psi\left(\frac{\mathrm{x}-\mathrm{b}}{\mathrm{a}}\right)
$$

sendo $a$ o parâmetro chamado de escala e $b$ o parâmetro chamado de deslocamento, onde ( $a, b$ são valores reais).

Para o sinal digital $\mathrm{f}(\mathrm{k})$, onde $\mathrm{k}=0,1,2, \ldots$, pode ser usada a transformada discreta [22]. Os valores diádicos são os mais utilizados para os parâmetros "escala" e "deslocamento" da Transformada de Wavelet, isto é, para o parâmetro "escala" temos: $a=2^{j}$ e para o parâmetro "deslocamento" temos: $b=k a=k 2$. O índice "j" representa o número de níveis da Transformada Discreta de Wavelet. Então para a Wavelet na forma Discreta podemos escrever:

$$
\psi_{\mathrm{a}, \mathrm{b}}(\mathrm{x})=2^{\mathrm{j} / 2} \psi\left(2^{\mathrm{j}} \mathrm{x}-\mathrm{k}\right)
$$

onde $\psi=$ Wavelet mãe, $\mathrm{a}=2^{\mathrm{j}}$ define a escala e $\mathrm{b}=\mathrm{ka}=\mathrm{k} 2^{\mathrm{j}}$ define o deslocamento.

A Transformada de Wavelet também pode ser obtida pelas seguintes integrais [10]:

Temos a seguinte equação para a Wavelet Contínua:

$$
W f_{a, b}=\frac{1}{\sqrt{a}} \int_{-\infty}^{\infty} f(x) \psi\left(\frac{x-b}{a}\right) d x
$$

onde: $\mathrm{a} \in \boldsymbol{R}-\{0\}, \mathrm{b} \in \boldsymbol{R}$

Para a Wavelet Discreta:

$$
W f_{a, b}=\frac{1}{\sqrt{a}} \int_{-\infty}^{\infty} f(x) \psi\left(\frac{x-b}{a}\right) d x
$$

onde: $\mathrm{a}=2^{\mathrm{j}}, \mathrm{b}=\mathrm{k} 2^{\mathrm{j}},(\mathrm{j}, \mathrm{k}) \in \mathrm{Z}^{2}$.

O coeficiente $W f_{a, b}$ da Transformada Discreta pode ainda ser dividido em duas partes [22]: Um é o coeficiente de aproximação e a outra é o coeficiente de detalhe. O 
coeficiente de aproximação está associado à escala alta, captando os componentes de baixa frequiência do sinal $\mathrm{f}(\mathrm{x})$, enquanto que os coeficientes de detalhes estão associados à escala baixa, correspondendo aos componentes de alta freqüência do sinal $f(x)$. Os coeficientes de aproximação $\left(\mathrm{A}_{\mathrm{j}}\right)$ da Transformada Discreta de Wavelet, para um sinal digital $\mathrm{f}(\mathrm{x})$, no nível j, podem ser expressos como:

$$
A_{j}=\sum_{n=0}^{\infty} f(n) \phi_{j, k}(n)=\sum_{n=0}^{\infty} f(n) \frac{1}{\sqrt{2^{j}}} \phi\left(\frac{n-k 2^{j}}{2^{j}}\right)
$$

onde $\phi_{\mathrm{j}, \mathrm{k}}(\mathrm{n})$ é a função escala associada com a função de Wavelet $\psi_{\mathrm{a}, \mathrm{b}}(\mathrm{x})$.

De modo semelhante os coeficientes de detalhe $\left(D_{j}\right)$ da Transformada Discreta de Wavelet para um sinal digital $\mathrm{f}(\mathrm{x})$ no nível j pode ser expressa como:

$$
D_{j}=\sum_{n=0}^{\infty} f(n) \psi_{j, k}(n)=\sum_{n=0}^{\infty} f(n) \frac{1}{\sqrt{2^{j}}} \psi\left(\frac{n-k 2^{j}}{2^{j}}\right)
$$

Desta forma, ao se escolher uma escala "diádica" [23] e um valor adequado para a translação no tempo, temos a Transformada Discreta de Wavelet, em que se obtêm os coeficientes da Transformada de Wavelet mais rapidamente.

\subsubsection{A Wavelet Zero Crossing}

Mallat [20] propôs chamar de função de suavização a resposta a um impulso de um filtro passa baixa. A convolução da função $f(x)$, com a função de suavização atenua parte das altas freqüências sem modificar a baixas freqüências e, portanto suaviza $f(x)$. Vamos mostrar que se a wavelet é a segunda derivada de uma função suavização o Zero-Crossing da Transformada de Wavelet indica a localização de pontos de forte variação no sinal

Seja $\theta(x)$ a função de suavização e

$$
\psi(x)=\frac{d^{2} \theta(x)}{d x^{2}}
$$

denotamos a dilatação de $\theta(x)$ por um fator $s$ por: $\theta_{s}(x)=\frac{1}{s} \theta\left(\frac{x}{s}\right)$ 
desde que $W_{s} f(x)=f^{*} \psi_{s}(x)$, nós derivamos que:

$$
W_{s} f(x)=f *\left(s^{2} \frac{d^{2} \theta_{s}}{d x^{2}}\right)(x)=s^{2} \frac{d^{2}}{d x^{2}}\left(f * \theta_{s}\right)(x)
$$

portanto: $W_{s} f(x)$ é proporcional à segunda derivada de $f(x)$ suavizada por $\theta_{s}(x)$. Os Zeros Crossings de $W_{s} f(x)$ correspondem aos pontos de inflexão de $f * \theta_{s}(x)$ [23] e que será denominado por wzc.

A Representação de Zero Crossing [20] pode ser obtida através das seguintes etapas:

Seja $f(x) \in L^{2}$ e $\left(W_{2}^{j} f(x)\right)_{j \in z}[20,23]$ uma transformada de wavelet diádica. Para quaisquer pares consecutivos de zeros crossings de $W_{2}^{j} f(x)$, cujas abscissas são $\left(z_{n-1}, z_{n}\right)$, calcula-se a integral:

$$
e_{n}=\int_{z_{n-1}}^{z_{n}} w_{2^{j}} f(x) d x
$$

Da equação 18, pode-se escrever:

$$
w_{2^{l}} f(x)=2^{2^{j}} \frac{d^{2}}{d x^{2}}\left(f * \theta_{2^{j}}\right)(x)
$$

desde que, $z_{n-1}, z_{n}$, são dois zero-crossings de $W_{2}^{j} f(x)$, as abscissa correspondem a dois pontos consecutivos de $(d / d x)\left(f * \theta_{2} j\right)(x)$. As 2 equações acima levam a seguinte equação:

$$
e_{n}=2^{2^{j}}\left(\frac{d}{d x}\left(f * \theta_{2} j\right)\left(z_{n}\right)-\frac{d}{d x}\left(f * \theta_{2} j\right)\left(z_{n-1}\right)\right)
$$

A integral $e_{n}$ é proporcional à diferença entre dois extremos consecutivos da derivada de $f(x)$ suavizada na escala $2^{j}$.

Para qualquer função $W_{2}^{j} f(x)$, na posição dos zero-crossings $\left(\mathrm{z}_{\mathrm{n}}\right)_{\mathrm{n} \in \mathrm{z}} \mathrm{e}$ o valor da integral $\left(e_{n}\right)_{\mathrm{n} \in \mathrm{z}}$ podem ser representados pela função $z_{2}^{j} f(x)$ definida por: 


$$
z_{2^{j}} f(x)=\frac{e_{n}}{z_{n}-z_{n-1}}
$$

para, $x \in\left[z_{n-1}, z_{n}\right]$

\subsubsection{Zero crossing da transformada de wavelet}

Para caracterização do sinal de aceleração num primeiro momento foi aplicada a técnica de wavelet zero crossing desenvolvida por Mallat [20] utilizando a wavelet proposta por ele. Esta técnica não apresentou resultados satisfatórios para os sinais de aceleração disponíveis no banco de dados. Como a Wavelet de Meyer, na sua forma discreta (dmey), apresentou melhores resultados, esta foi utilizada para o cálculo da transformada de wavelet. Após o sinal ser reconstruído no nível desejado, a caracterização é feita através dos seus valores de máximos e mínimos e os seus cruzamentos por zero (figura 6.3), obtendo-se uma representação semelhante à utilizada por Mallat. Neste sinal reconstruído, os pontos de zero crossing indicam os pontos onde a aceleração se anula e a amplitude da representação do zero crossing da transformada de wavelet corresponde à amplitude média do sinal reconstruído.

Sejam as funções $f(x) \in L^{2}$ e $\left(W_{2}^{j} f(x)\right)_{j \in z}[20,23]$ uma transformada de wavelet diádica. Para quaisquer pares consecutivos de zeros crossings de $W_{2}^{j} f(x)$, cujas abscissas são respectivamente $\left(z_{n-1}, z_{n}\right)$, calcula-se a integral:

$$
e_{n}=\int_{z_{n-1}}^{z_{n}} w_{2^{j}} f(x) d x
$$

A representação do zero crossing da transformada de wavelet é dada pela função $Z_{2}^{j} f(x)$ que é definida pelo valor da integral $e_{n}$ nas posições $\left(z_{n-1}, z_{n}\right)_{n \in Z}$.

$$
z_{2^{j}} f(x)=\frac{e_{n}}{z_{n}-z_{n-1}}
$$

para $x \in\left[z_{n-1}, z_{n}\right]$

Os resultados mostraram- se satisfatórios e estão apresentados neste trabalho. Com base nesta representação do zero crossing da transformada de wavelet foi definido o Índice apresentado no item [5.3.5] 


\subsubsection{O Índice de Wavelet Zero Crossing}

Foi criado um novo índice, que foi chamado de índice de wavelet zero crossing e que foi definido como:

$$
I W Z C=\left(\frac{N Z C}{\Delta l}\right) * f_{a}
$$

onde:

IWZC = Índice de wavelet zero crossing

$\mathrm{NZC}=$ número de zero crossings do sinal

$\Delta \mathrm{l}=$ tamanho do arquivo em número de pontos

$\mathrm{f}_{\mathrm{a}}=$ freqüência de amostragem

Este índice (IWZC) representa o número de vezes que o sinal cruzou o zero num dado intervalo de tempo. A definição do índice desta forma tem se mostrado adequado, pois como os sinais são periódicos, esta divisão pelo tamanho do arquivo permite estabelecer um índice independente do tamanho do arquivo e a sua multiplicação pela frequiência de amostragem permite obter um valor associado ao tempo, pois a freqüência de amostragem tem a unidade de $1 / \mathrm{s}$.

Este índice é função de duas variáveis: limiar ("threshold") e aos níveis de decomposição da transformada discreta de "wavelet" e ambos podem ser variados.

Para ilustrar, a seguir será apresentado um sinal senoidal na figura 5.2 onde se pode estudar o comportamento teórico para o cálculo do IWZC. Foi calculado o IWZC de um sinal senoidal de $80 \mathrm{~Hz}$ e freqüência de amostragem de $5000 \mathrm{~Hz}$ durante um período de 0,512s. É possível se observar em verde à função seno, em vermelho a transformada inversa da Transformada de Wavelet e que está com seu sinal reconstruído no domínio do tempo através dos seus coeficientes, no caso o nível 5 , pois a frequiência de amostragem $f_{a}$ $=5000$ para um seno com freqüência de $80 \mathrm{~Hz}$ corresponde ao nível 5 e em azul observa-se à Representação de Zero Crossing da Transformada de Wavelet, item 5.3.4, cruzando o eixo do zero 8 vezes (nzc) (desconsiderar o primeiro ponto), resultando em um IWZC de $160(\mathrm{zc} / \mathrm{s})$. 


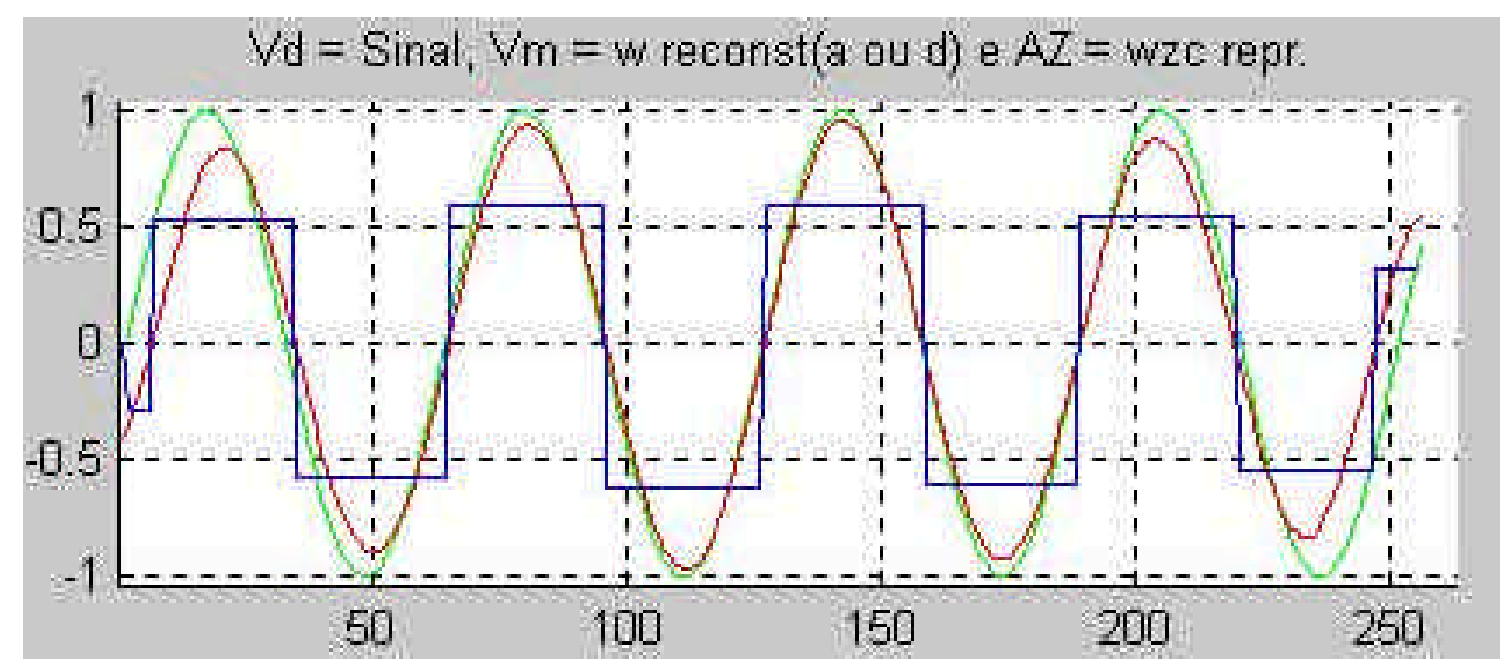

FIGURA 5.2. RZCTW para um sinal senoidal

\subsubsection{A utilização da Transformada de Wavelet}

Nesta tese, a utilização do Zero Crossing da Transformada de Wavelet, item 5.3.4, surgiu quando se realizavam as pesquisas bibliográficas. Observou-se durante estas pesquisas que era necessário procurar uma nova técnica de diagnóstico que facilitasse o diagnóstico de defeitos em sua fase incipiente e que permitisse detectar se o defeito é do tipo distribuído ou localizado. Existem trabalhos que utilizam a Transformada de Wavelet para diagnóstico de defeitos em rolamentos, porém a sua utilização para diagnóstico de defeitos incipientes, já não se mostrava muito fácil em função da dificuldade da escolha de quais níveis de decomposição e que wavelet utilizar. Isto dificultava a sua aplicação, além disso, os resultados obtidos em cada nível eram na forma vetorial, o que dificulta a sua aplicação prática, e os resultados obtidos eram difíceis de serem interpretados ou calculados.

Desta forma, procurou-se utilizar uma técnica que se mostrasse promissora no diagnóstico de defeitos em rolamentos, preferencialmente na linha das Transformada de Wavelet, pois as possibilidades oferecidas pela Transformada de Wavelet de decompor um sinal em várias bandas, e de reapresentar o sinal resultante (filtrado) em vários níveis, permitiria uma análise detalhada destes sinais. A possibilidade de reconstrução do sinal original, a partir dos vários níveis de sinais em que estes foram decompostos, permite uma grande flexibilidade de análise destes sinais. Nesta linha de raciocínio, adotou-se o Zero Crossing da Transformada de Wavelet, item 5.3.4, que ao ser aplicada à análise de defeitos em rolamentos permite analisar quando a aceleração muda de sinal (sentido). Como $\mathrm{F}=$ 
m.a é possível supor-se que a massa for constante é como se observasse através do sinal de aceleração, a força mudando de direção em cada instante.

Este raciocínio permite associar às forças presentes nos rolamentos aos defeitos existentes. Além disso, procurou-se associar os resultados vetoriais obtidos, nos vários níveis, a um índice que foi chamado de Índice de Wavelet Zero Crossing (IWZC). Desta forma a aplicação do Zero Crossing da Transformada de Wavelet, na análise de defeito em rolamentos, torna-se uma nova técnica de diagnóstico, pois não localizamos na bibliografia pesquisada, nenhuma aplicação desta técnica no diagnóstico de defeitos em rolamentos.

\subsection{Unidades}

A seguir, apresenta-se uma tabela onde se pode observar as unidades utilizadas nas várias técnicas para extração de características tais como, o envelope e as DEP de aceleração e velocidade e o IWZC. A unidade 1 é a mais comumente encontrada, a unidade 2 é uma nova proposta de definição destas unidades, que se está apresentado, cujo objetivo é estabelecer uma unidade com significado físico do fenômeno.

TABELA 5.1. Conversão do sinal de entrada para as várias unidades disponíveis

\begin{tabular}{|c|c|c|c|c|}
\hline $\begin{array}{c}\text { Sinal entr. } \\
\text { acel ou veloc }\end{array}$ & Técnica & Símbolo & Unidade 1 & Unidade 2 \\
\hline $\mathrm{m} / \mathrm{s}^{2}$ & DEP p/ Aceler. & $\mathrm{a}$ & $\left(\mathrm{m}^{2} / \mathrm{s}^{4}\right) / \mathrm{Hz}$ & $\mathrm{w} / \mathrm{kg}$. \\
\hline $\mathrm{m} / \mathrm{s}^{2}$ & Envelope & $\mathrm{e}$ & $\left(\mathrm{m}^{2} / \mathrm{s}^{4}\right) / \mathrm{Hz}$ & $\mathrm{w} / \mathrm{kg}$. \\
\hline $\mathrm{m} / \mathrm{s}$ & DEP p/ Velocid. & $\mathrm{v}$ & $\left(\mathrm{m}^{2} / \mathrm{s}\right) / \mathrm{Hz}$ & $\mathrm{m}^{2} / \mathrm{s}$ \\
\hline $\mathrm{m} / \mathrm{s}^{2}$ & Indice de WZC & IWZC & $\mathrm{zc} / \mathrm{s}$ & $\mathrm{Hz}$ \\
\hline
\end{tabular}

Poderíamos, como proposição, especular que o espectro de um sinal de aceleração representa a potência específica das forças envolvidas, enquanto que espectro da velocidade representa a difusividade da quantidade de movimento. Já o IWZC representa a freqüência com que o sinal de aceleração (força) inverte o seu sentido. 


\subsection{Lógica Nebulosa Paraconsistente}

As premissas básicas que formam o fundamento da Lógica Nebulosa e que também são uma limitação da Lógica Clássica Booleana é que se um elemento "x" do universo de discurso "X" é escolhido como sendo parte do conjunto "nebuloso A", este elemento " $x$ " é considerado válido e consistente a "priori”. Aúnica quantificação associada a ele é o grau de relevância deste elemento ao conjunto "nebuloso A", expresso através da função de pertinência $\mu_{\mathrm{A}}(\mathrm{x})$. Existem dificuldades para quantificar ou verificar a validade ou credibilidade da informação e da sua consistência posteriormente, tendo-se como saída apenas o conjunto $[0,1]$ representando todos os estados possíveis entre o verdadeiro e o falso.

Na década de 50, uma nova lógica não clássica foi introduzida, denominada Lógica Paraconsistente, que é uma evolução da Lógica Clássica Boleana e sua forma "nebulosa". Esta nova lógica foi criada simultaneamente e independentemente pelo lógico polonês Jáskowski (1904-1965) e pelo lógico brasileiro Da Costa [25]. Posteriormente outros pesquisadores como Abe e Da Silva Filho [27, 28, 29, 54] introduziram outros itens que permitiram a sua aplicação na área de engenharia de modo mais fácil. Este trabalho toma por base o trabalho desses dois pesquisadores, com as alterações necessárias para o diagnóstico das condições de operação de rolamentos.

Será utilizada a Lógica Paraconsistente Anotada com dois valores. Uma dada proposição $\mathbf{P}$ é associada com o par $\left(\mu_{1}, \mu_{2}\right)$ onde $0 \leq \mu_{1} \leq 1$ significa o grau de evidência favorável em $\mathbf{P}$ enquanto o grau de evidência contrária em $\mathbf{P}$ é $0 \leq \mu_{2} \leq 1$. O domínio definido pelo par é denominado reticulado de valores verdades. Neste reticulado, $(1,0 ; 0,0)$ indica "evidência favorável total", $(0,0 ; 1,0)$ indica "evidência desfavorável total", $(1,0$; $1,0)$ indica "evidências totalmente inconsistentes" e $(0,0 ; 0,0)$ indica ausência de evidências. O domínio do reticulado dos valores verdades pode ser representado pelo reticulado de Hasse conforme a Figura 5.3: 

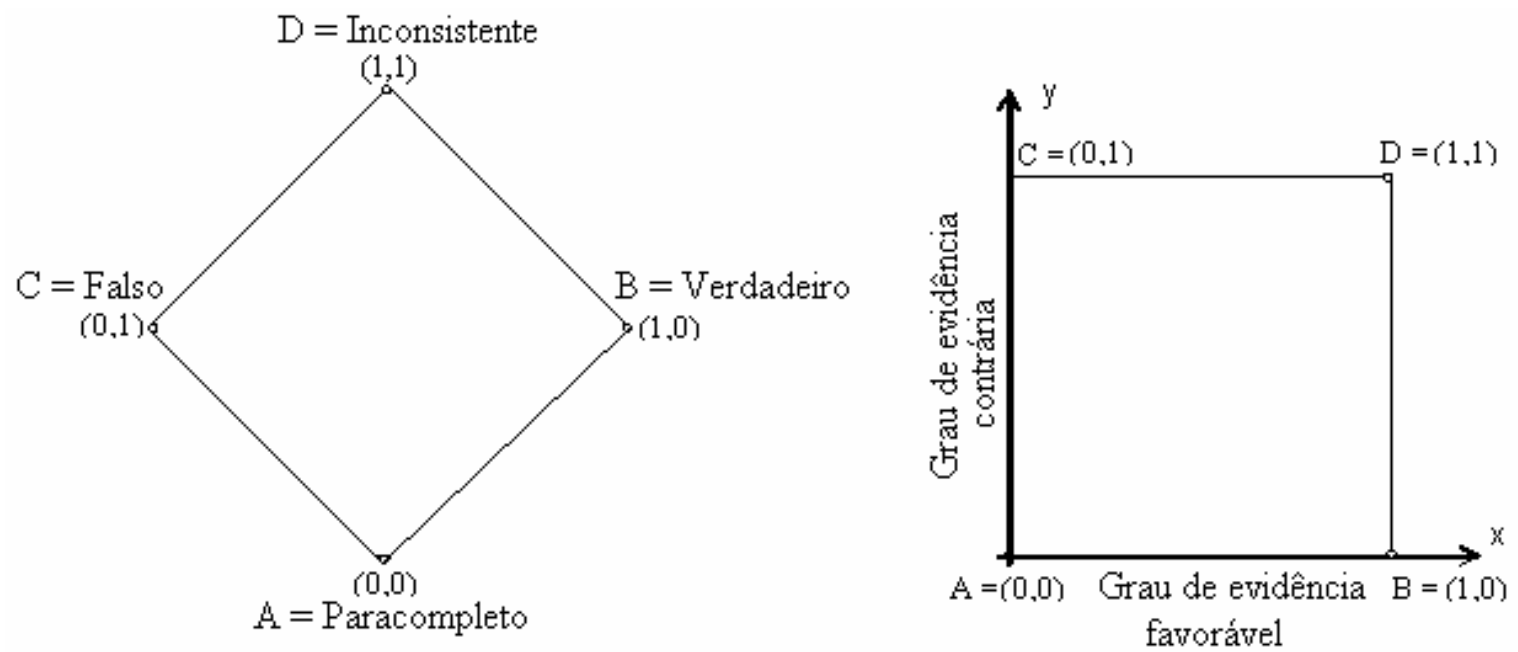

FIGURA 5.3. Reticulado de Hasse - domínio valores verdades - forma cartesiana [27]

Combinando adequadamente as variáveis $\mu_{1}$ e $\mu_{2}$ são definidas duas novas variáveis que trazem o conceito do grau de contradição e do grau de certeza a proposição em questão.

Um reticulado mais representativo pode ser obtido através da seguinte definição das novas variáveis $\mathbf{G r a u}$ de Contradição $\boldsymbol{G}_{\boldsymbol{c} t}$ e o $\mathbf{G r a u}$ de Certeza $\boldsymbol{G}_{\boldsymbol{c}}$. A transformação das variáveis é realizada pelas seguintes equações:

- Grau de contradição: $\mathrm{G}_{\mathrm{ct}}=\mu_{1}+\mu_{2}-1 \quad$ onde $-1 \leq \mathrm{G}_{\mathrm{ct}} \leq 1$

- Grau de certeza: $\quad \mathrm{G}_{\mathrm{c}}=\mu_{1}-\mu_{2} \quad$ onde $-1 \leq \mathrm{G}_{\mathrm{c}} \leq 1$

A Figura 5.4 ilustra como exemplo o reticulado representativo da lógica paraconsistente anotada, subdividido em 12 regiões, utilizando-se das variáveis, grau de certeza e grau de contradição [27, 28, 29]. 


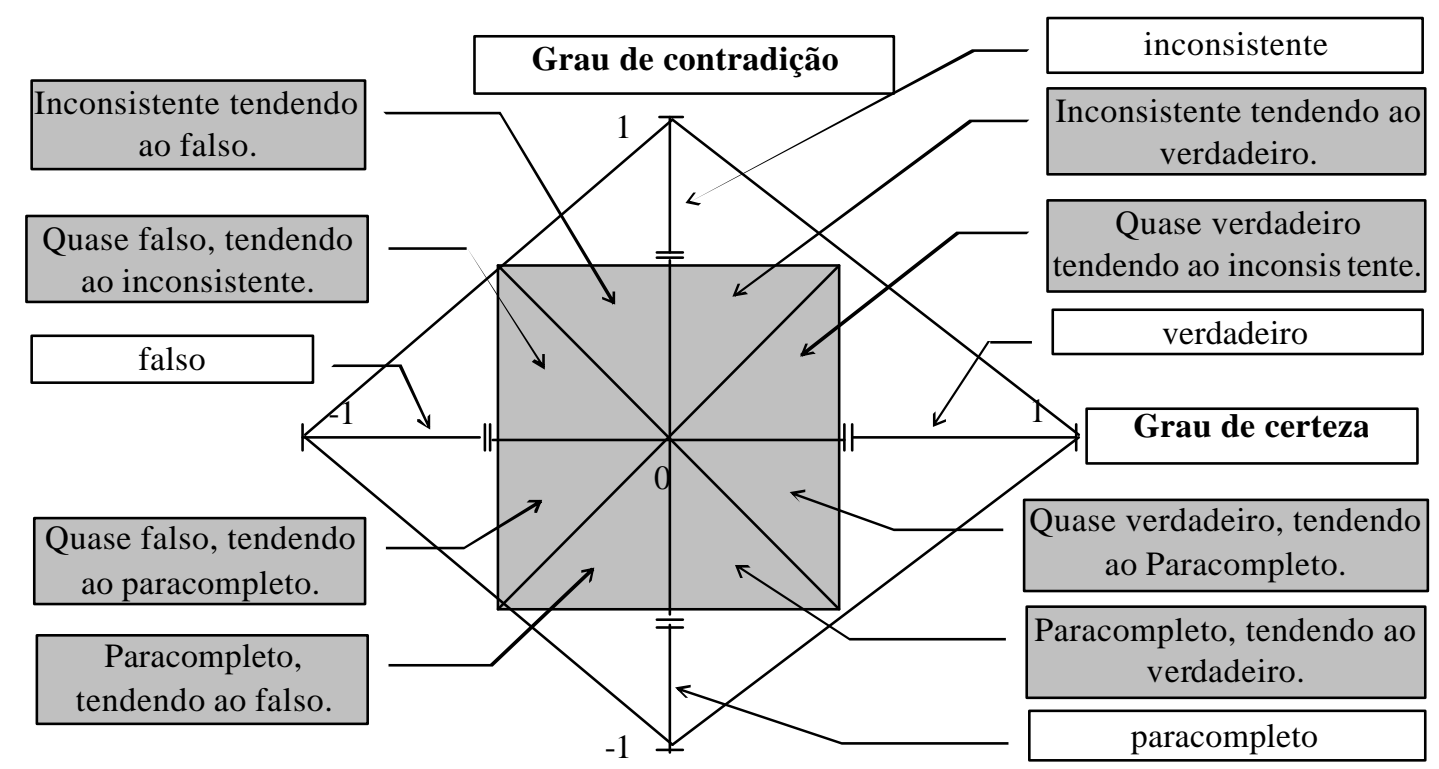

FIGURA 5.4. O domínio lógico representado pelo gef e pelo gec

$\mathrm{Na}$ teoria de conjuntos nebulosos, um elemento $\mathrm{x}$ do universo de discurso $\mathrm{X}$ está associado ao conjunto "nebuloso A" através da função de pertinência $\mu_{A}(\mathrm{x})$ que tem valores no intervalo $[0,1]$. Na sua forma contínua o conjunto A pode ser representado por:

$$
A=\int_{X} \mu_{A}\left(x_{i}\right) / x_{i}
$$

Considerando a Lógica Paraconsistente onde uma dada proposição é caracterizada por um par de funções de pertinência $\left[\mu_{A}(x), \mu_{B}(x)\right]$, pode-se demonstrar que o conjunto "nebuloso" A pode ser representado por:

$$
A=\int_{X}\left(\mu_{A}\left(x_{i}\right) / x_{i}+\mu_{B}\left(x_{i}\right) / x_{i}\right)
$$

O símbolo "+" assim representa tanto a operação "E” ou a operação "OU”. A implementação desta última equação (29) pode ser realizada utilizando-se o "Toolbox Fuzzy", do programa MATLAB [67]. 


\section{METODOLOGIA}

Para a aquisição dos dados, como já mencionado, foi feito uso da bancada apresentada na figura 6.1. Nesta foto é possível observar a máquina onde os rolamentos são montados para os ensaios programados, bem como o sistema de aquisição de dados.

No capítulo 7, informações mais detalhadas sobre a bancada e do seu uso, são apresentadas.

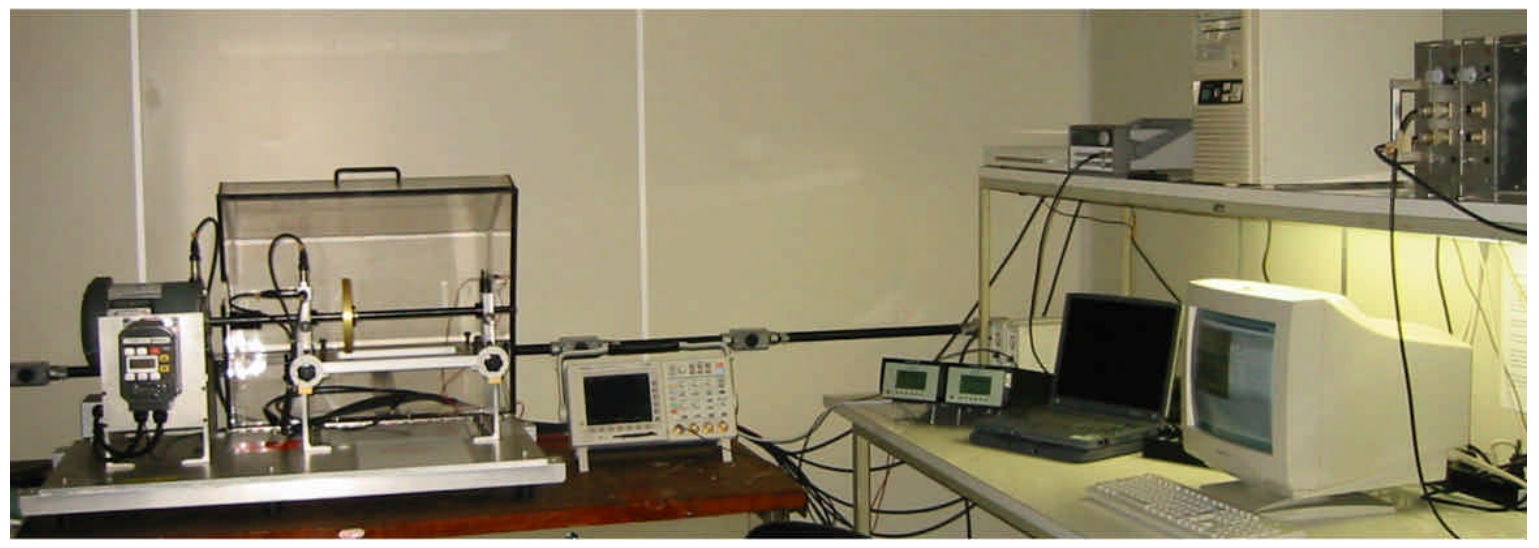

FIGURA 6.1. Máquina para ensaio de rolamentos e o sistema de aquisição de dados

\subsection{Discussão das técnicas utilizadas}

A metodologia desenvolvida está dividida em três etapas e pode ser apresentada da seguinte forma:

A primeira etapa foi à criação de um banco de dados experimental de defeitos previamente definidos em rolamentos do tipo esfera. Para tanto, foram criados nos rolamentos sob análise, os defeitos do tipo localizado (furos, pequenos lascamentos) na pista interna e na pista externa, e os defeitos distribuídos (corrosões e riscos) na pista externa do rolamento. Posteriormente estes rolamentos foram montados na máquina de ensaio para se obter os sinais dos rolamentos com defeitos. Iniciaram-se os estudos analisando-se os rolamentos com defeitos mais severos até os mais incipientes, sempre com a rotação no eixo de 1800RPM e os defeitos localizados na pista externa. A seguir estes sinais foram armazenados sob forma digital, formando o banco de dados. 
A parte do banco de dados utilizados neste trabalho possui um número total de 100 arquivos de defeitos em rolamentos, com a rotação de 1800RPM. Estes defeitos foram criados de forma controlada m pista externa e na pista interna, sendo 70 arquivos com defeito na pista externa ( 35 defeitos do tipo localizado e 35 defeitos do tipo distribuído) e 30 arquivos com defeito tipo localizado na pista interna. Os arquivos dos rolamentos sem defeitos são 15. Existem alguns arquivos que foram obtidos de rolamentos com defeitos do tipo riscado. A carga aplicada ao eixo foi adotada como sendo de $5,9 \mathrm{~kg}$.

A segunda etapa foi a extração das características dos vários sinais armazenados no banco de dados. Para isto utilizaram-se as várias técnicas de extração de características conhecidas (envelope, DEP do sinal de aceleração, DEP do sinal de velocidade, valor RMS, curtose, etc.), descritas no capítulo anterior.

A terceira etapa foi combiná-las de forma adequada através da Lógica Nebulosa Paraconsistente obtendo-se um diagnóstico automatizado dos defeitos no rolamento.

O programa que foi desenvolvido realiza as 3 etapas descritas acima e está detalhado na secção 6.2.

\subsubsection{Elaboração de defeito em rolamentos}

Os defeitos do tipo distribuído como corossão, foram mergulhados em uma solução de HCL, por 12 horas, e levados à máquina de ensaios, outros rolamentos foram deixados por mais tempo, desde 16 até 41 horas. Isto permitiu a criação de uma escala de defeitos do tipo corrosão que abrangesse desde as corrosões mais suaves até as mais severas. Para a criação dos defeitos do tipo riscado, riscos foram efetuados na pista externa do rolamento com broca com ponta de diamante, porém o controle das condições para se criar este tipo de defeito, mostrou-se bastante complexa não se conseguindo bons resultados no controle dos defeitos criados.

Os defeitos do tipo localizados foram realizados através de brocas com pontas de diamante, onde se efetuaram danos que atravessaram a pis ta no sentido axial, com profundidades e larguras diferentes, além disso, defeitos do tipo furo e pequenos lascamentos também foram criados, porém os resultados para este trabalho, que se concentra na identificação de defeitos do tipo localizados ou distribuídos, não apresenta diferenças significativas, pois furos e pequenos lascamentos foram tratados como defeitos localizados. Os vários defeitos criados com brocas, com profundidades diferentes, tinham por objetivo simular os vários graus de severidade de defeitos, desde os mais suaves, 
portanto mais difíceis de serem detectados até os mais severos, criando também uma escala crescente de defeitos do tipo localizado.

\subsubsection{Condições de referência do rolamento sem defeito}

Um dos primeiros passos foi estabelecer os valores de referência para os rolamentos sem defeito. Para tanto, foram realizados ensaios com onze rolamentos sem defeito. Analisando-se as faixas de valores apresentadas por cada variável (rms, curtose, envelope, etc.) obtiveram-se os valores máximos e mínimos destas variáveis, que definem os valores das características a partir dos quais um rolamento será classificado como tendo defeito.

A tabela 6.1 mostra os resultados obtidos para os rolamentos sem defeito e que serviram de base para estabelecer os critérios de separação entre os sinais de rolamentos com defeitos e os sinais de rolamentos sem defeitos.

Nessa tabela, os números em negrito na frente da palavra "variável", representam a identificação de cada um dos arquivos utilizados.

TABELA 6.1. Valores do banco de dados dos rolamentos sem defeito

\begin{tabular}{||c||c|c|c|c|c|c|c|c|c|c|c||}
\hline Variável & $\mathbf{1 7 2 9 1 0}$ & $\mathbf{1 7 2 5 4 4}$ & $\mathbf{1 7 1 9 4 2}$ & $\mathbf{1 3 2 7 0 0}$ & $\mathbf{1 7 5 7 3 2}$ & $\mathbf{1 8 2 3 1 8}$ & $\mathbf{2 0 5 6 5 4}$ & $\mathbf{1 7 1 4 2 4}$ & $\mathbf{1 2 1 8 4 6}$ & $\mathbf{1 2 3 5 0 0}$ & $\mathbf{1 6 4 9 0 6}$ \\
\hline \hline RMS & 0.0004 & 0.0004 & 0.0005 & 0.0007 & 0.0009 & 0.0006 & 0.0009 & 0.0005 & 0.0005 & 0.0004 & 0.0005 \\
\hline KURT & 5.5185 & 5.343 & 5.5308 & 5.6455 & 3.7427 & 4.9 & 3.9019 & 5.6229 & 6.0928 & 6.1476 & 5.9655 \\
\hline DEP E & 0.0036 & 0.0042 & 0.0045 & 0.0003 & 0.0211 & 0.0305 & 0.0127 & 0.0047 & 0.0032 & 0.0052 & 0.0008 \\
\hline DEP I & 0.0005 & 0.0003 & 0.0002 & 0.0001 & 0.0007 & 0.001 & 0.0002 & 0.0044 & 0.001 & 0.0009 & 0.0009 \\
\hline ENV E & 0.0142 & 0.005 & 0.0071 & 0.0018 & 0.0134 & 0.0012 & 0.0015 & 0.0064 & 0.0058 & 0.0041 & 0.0038 \\
\hline ENV I & 0.0325 & 0.035 & 0.0192 & 0.038 & 0.017 & 0.0097 & 0.0062 & 0.0214 & 0.0078 & 0.0166 & 0.0264 \\
\hline TAL IWZC 1 & 2.613 & 3.2984 & 2.2129 & 2.8268 & 2.9836 & 3.9884 & 2.9956 & 2.2182 & 2.5 & 2.452 & 1.5353 \\
\hline Thmax 6 & 0.32 & 0.28 & 0.29 & 0.26 & 0.52 & 0.46 & 0.16 & 0.93 & 0.88 & 0.4 & 0.32 \\
\hline RMS 5 & 0.0288 & 0.032 & 0.0302 & 0.0398 & 0.0441 & 0.0399 & 0.0605 & 0.0544 & 0.0412 & 0.0359 & 0.0459 \\
\hline RMS 6 & 0.0584 & 0.0648 & 0.0656 & 0.0686 & 0.0963 & 0.099 & 0.0477 & 0.0788 & 0.0859 & 0.0875 & 0.0841 \\
\hline RMS 7 & 0.0847 & 0.0665 & 0.0669 & 0.0484 & 0.1285 & 0.1483 & 0.0727 & 0.0767 & 0.0858 & 0.1005 & 0.0961 \\
\hline thmax 7 & 0.36 & 0.33 & 0.39 & 0.14 & 0.49 & 0.49 & 0.18 & 0.27 & 0.39 & 0.48 & 0.3 \\
\hline
\end{tabular}

onde:

RMS - Valor rms do sinal analisado.

Kurt - Curtose do sinal analisado. 
DEP E - Densidade Espectral de Potência do sinal, nas freqüências de passagem da pista externa.

DEP I - Densidade Espectral de Potrência do sinal, nas freqüências de passagem da pista interna.

ENV E - Envelope do sinal nas freqüências de passagem da pista externa.

ENV I - Envelope do sinal nas freqüências de passagem da pista interna.

As variáveis abaixo serão melhor apresentadas no decorrer deste trabalho.

Tal IWZC 1 - Constante de decaimento do nível 1 do gráfico IWZC vs limiar.

RMS 5, 67 - Valor rms dos níveis 5, 6 e 7 do gráfico IWZC vs limiar.

Thmax 6 - Máximo valor do limiar, para o nível 6 do gráfico IWZC vs limiar.

Thmax 7 - Máximo valor do limiar, para o nível 7 do gráfico IWZC vs limiar.

Thc8, Thc9 e Thc10 - Máximo valor de limiar, para os níveis 8, 9 e 10 do gráfico IWZC vs limiar.

\subsubsection{Estudos da aplicação da Transformada de Wavelet}

Para a utilização da transformada de wavelet é necessária a escolha de uma wavelet, chamada de wavelet mãe, de um conjunto de wavelets mãe preexistente ou desenvolver uma wavelet própria, para que a transformada de wavelet possa realizar os seus cálculos. Para a análise dos sinais de rolamento do banco de dados obtido, a wavelet mãe chamada de "dmey" e que é uma abreviatura de "discrete meyer wavelet", foi a que apresentou melhor desempenho. Desta forma, esta wavelet foi adotada para todas as análises onde se utilizou o zero crossing da transformada de wavelet. Esta escolha foi feita após testarem-se várias wavelets mães, por exemplo, da família das Daubechies, Haar, Symlets, Coiflets, biortogonal spline, biortogonal reversa [60] e a que apresentou melhor fidelidade na reconstrução do sinal original foi a "dmey". 


\subsubsection{A metodologia para cálculo do Índice de Wavelet Zero Crossing}

Para um dado sinal, obtido de um sensor do tipo acelerômetro, aplica-se à transformada de wavelet (definida pela eq. 12), decompondo-o nos níveis (bandas de freqüências) desejados $(1,2,3$, etc) obtendo-se desta forma os coeficientes da transformada de wavelet; a próxima etapa é reconstruir este sinal no domínio do tempo, realizando a transformada inversa de wavelet, na banda de freqüência desejada, onde os zeros crossings indicam os pontos onde a aceleração se anula. O próximo passo é obter a Representação do Zero Crossing da Transformada de Wavelet (rzctw), utilizando-se a equação (eq 24). Esta equação define, nos pontos onde ocorreram os zc, a amplitude da representação do zero crossing da transformada de wavelt. Existem duas formas de calcular a amplitude do Zero Crossing (zc): a) utilizando a diferença das amplitudes da representação do zero crossing da transformada de wavelet b) ou utilizando a diferença do módulo das amplitudes da representação do zero crossing da transformada de wavelt, vide figuras 6.2 e 6.3 .

Desta forma, tem-se na figura 6.2, os seguintes códigos indicados na legenda da figura:

- em vermelho o sinal reconstruído no tempo, de um sinal de aceleração;

- na cor preta, visualiza-se a representação do zero crossing da transformada de wavelet;

- em azul os pontos onde ocorreram os zeros crossings e sua amplitude foi calculada com base na diferença entre as amplitudes da representação do zero crossing da transformada de wavelet, nos pontos de zero crossing. 


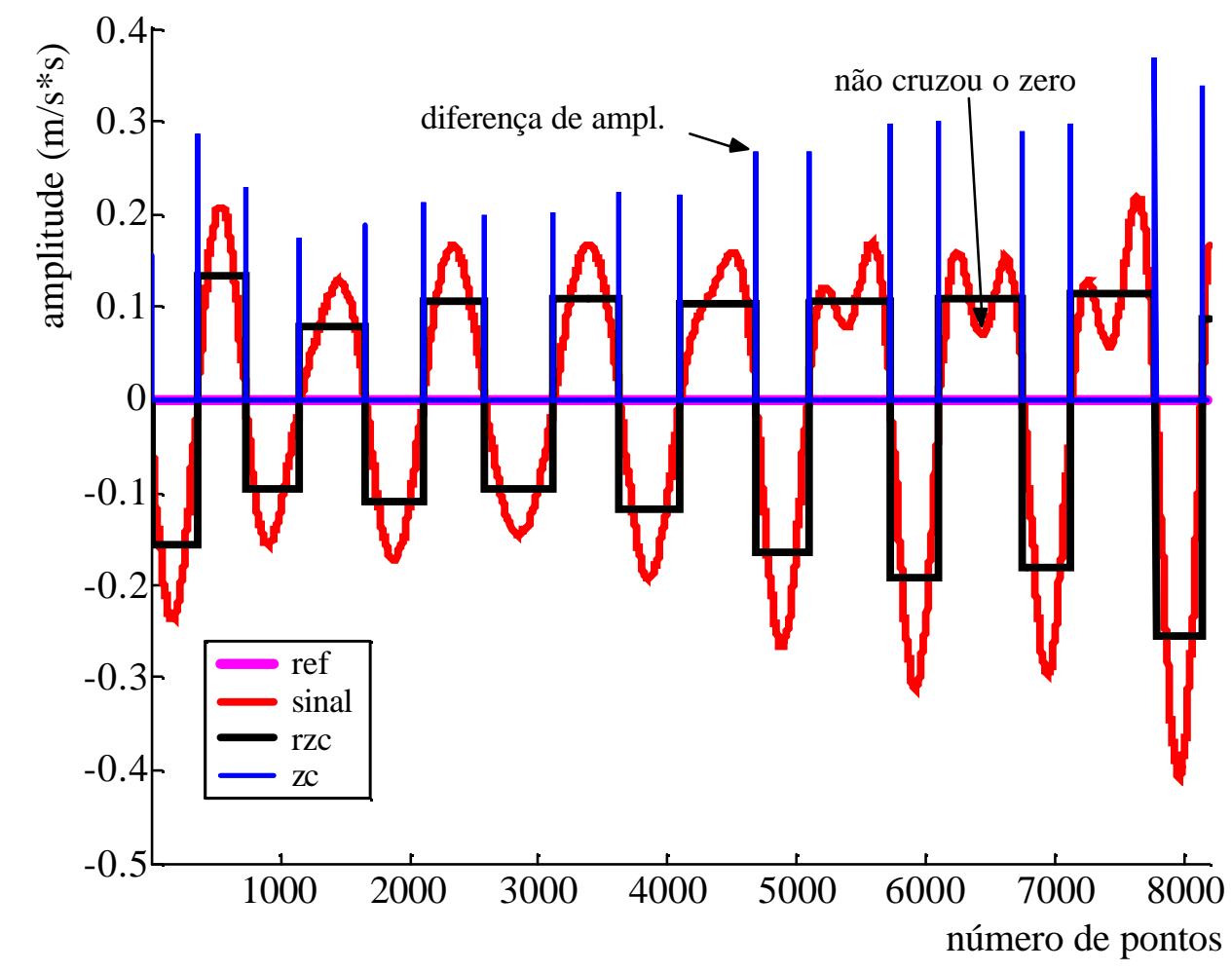

FIGURA 6.2. Diferença da representação do zero crossing da transformada de wavelet

e na figura 6.3, tem-se os seguintes códigos indicados na legenda da figura:

- em vermelho o sinal reconstruído no tempo, de um sinal de aceleração;

- na cor preta, visualiza-se a representação do zero crossings da transformada de wavelet;

- em verde o módulo da representação do zero crossing da transformada de wavelet;

- e em azul os pontos onde ocorreram os zeros crossing e suas amplitudes foram calculadas com base no módulo das amplitudes da representação do zero crossing da transformada de wavelet (mps). 


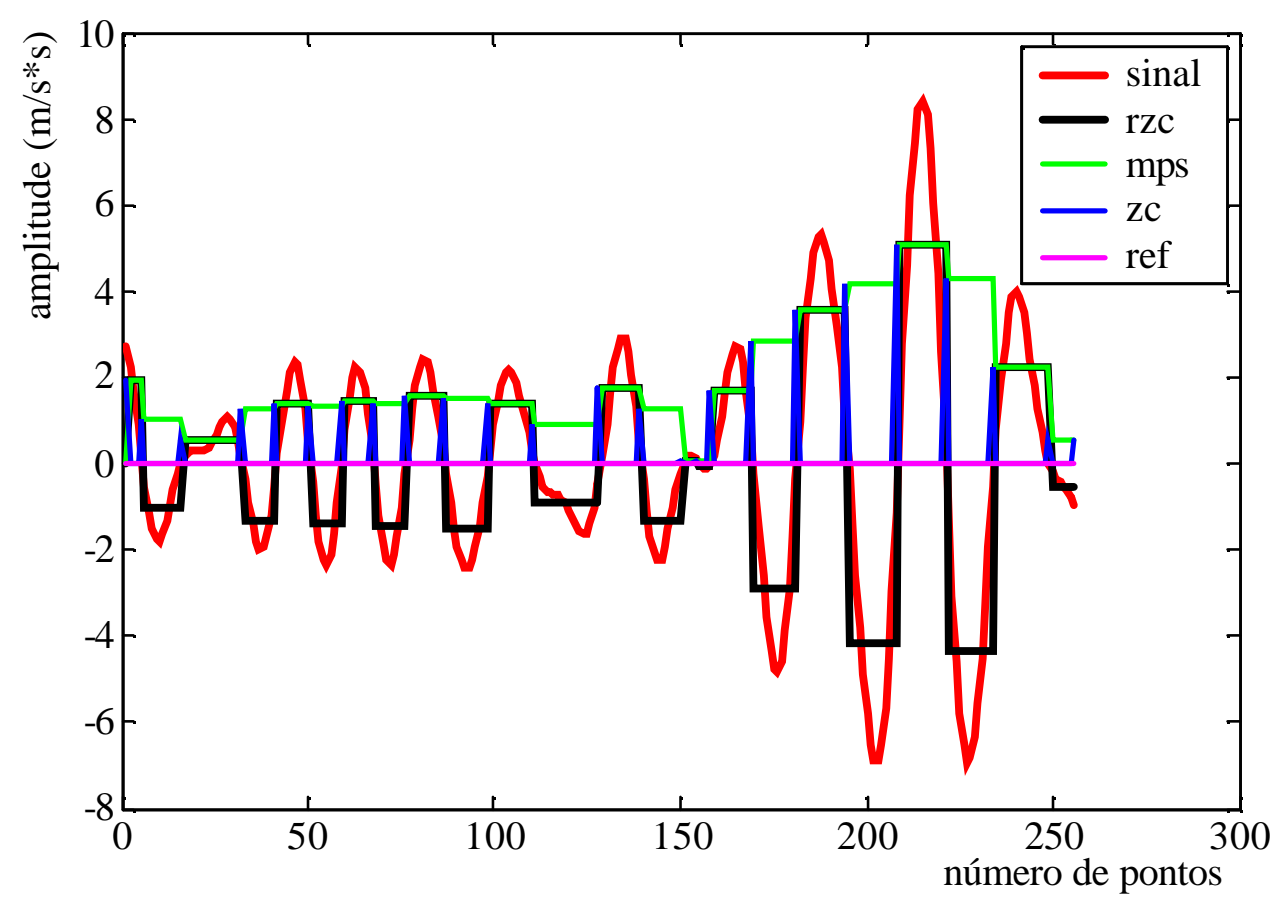

FIGURA 6.3. Módulo da representação do zc da transformada de wavelet para nível D4

O módulo da representação do zero crossing da transformada de wavelet, figura (6.3), apresentou um comportamento mais próximo da forma do sinal e foi adotado neste trabalho para as análises envolvendo o IWZC.

Como o IWZC conta o número de vezes que a representação do zero crossing da transformada de wavelet (rzctw) cruzou por zero no tempo, uma das análises realizadas foi a de se variar o valor do limiar, de zero até que não se obtivesse mais nenhum valor para IWZC, figura 6.4 obtendo-se assim, o máximo valor do limiar (amplitude). Desta forma, é possível avaliar o comportamento do sinal com relação à variação da sua amplitude em relação ao IWZC (freqüência).

$\mathrm{Na}$ figura 64 têm-se os valores de n1 até n10 que correspondem aos níveis da transformada de wavelet e para cada nível foi associada uma cor. E pode-se observar que apresenta um comportamento semelhante a um de um filtro linear de primeira ordem em cada nível de freqüência com uma constante de decaimento e um limiar crítico. A este tipo de gráfico deno minaremos de curva de IWZC. 


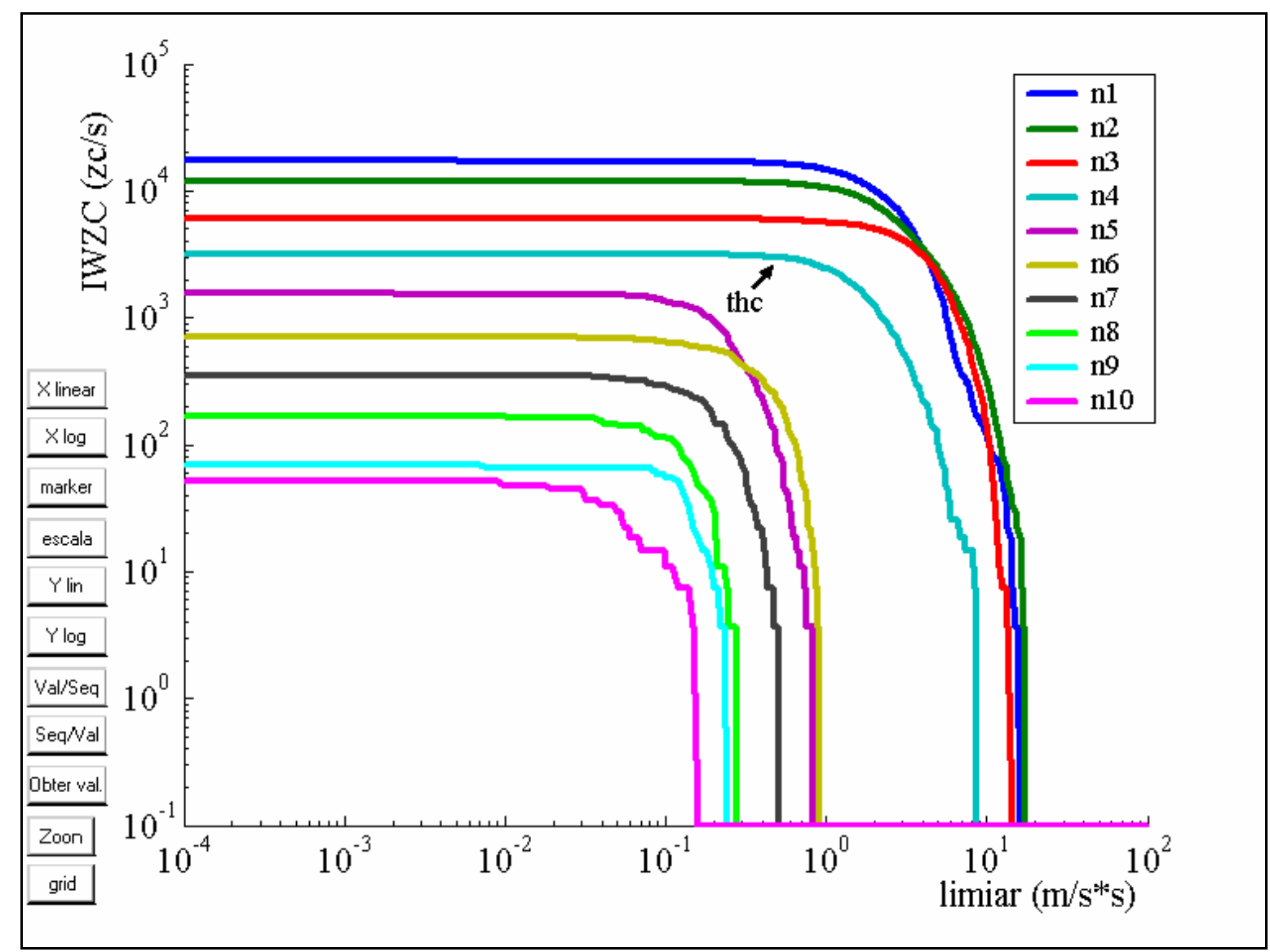

FIGURA 6.4. Curva IWZC

Para uma utilização correta do IWZC é necessário que se determine um valor de limiar mínimo (crítico), a partir do qual os "ruídos" não estão mais sendo computados. Isto pode ser feito através de critérios estabelecidos para a determinação do ponto onde a derivada da função exponencial ajustada, comece a apresentar um rápido decaimento no IWZC. Este parâmetro recebeu o nome de thc.

Por sua vez, a constante de decaimento (Tal IWZCx, onde x é o número do nível) representa uma taxa de decaimento do valor do IWZC, ou seja, a queda na amplitude do sinal de "Representação do Zero Crossing da Transformada de Wavelet". Portanto, para quedas rápidas, o coeficiente de decaimento corresponde a uma variação rápida do sinal, já para quedas lentas, correspondem a lentas variações nas amplitudes do sinal.

O Thmax é o máximo valor do limiar para que o IWZC apresente $0 \mathrm{zc} / \mathrm{s}$

No domínio da freqüência, os defeitos em rolamentos são caracterizados por freqüências de passagem e suas harmônicas. A determinação do IWZC para sinais senoidais torna-se, portanto importante. O IWZC, figura 65, para um sinal senoidal de 
uma determinada freqüência possui um valor de IWZC que é obtido através da seguinte fórmula: IWZC = freqüência do seno *2. Por exemplo, para um sinal senoidal de freqüência de $250 \mathrm{~Hz}$ tem-se um valor de IWZC de $250 * 2=500 \mathrm{zc} / \mathrm{s}$.

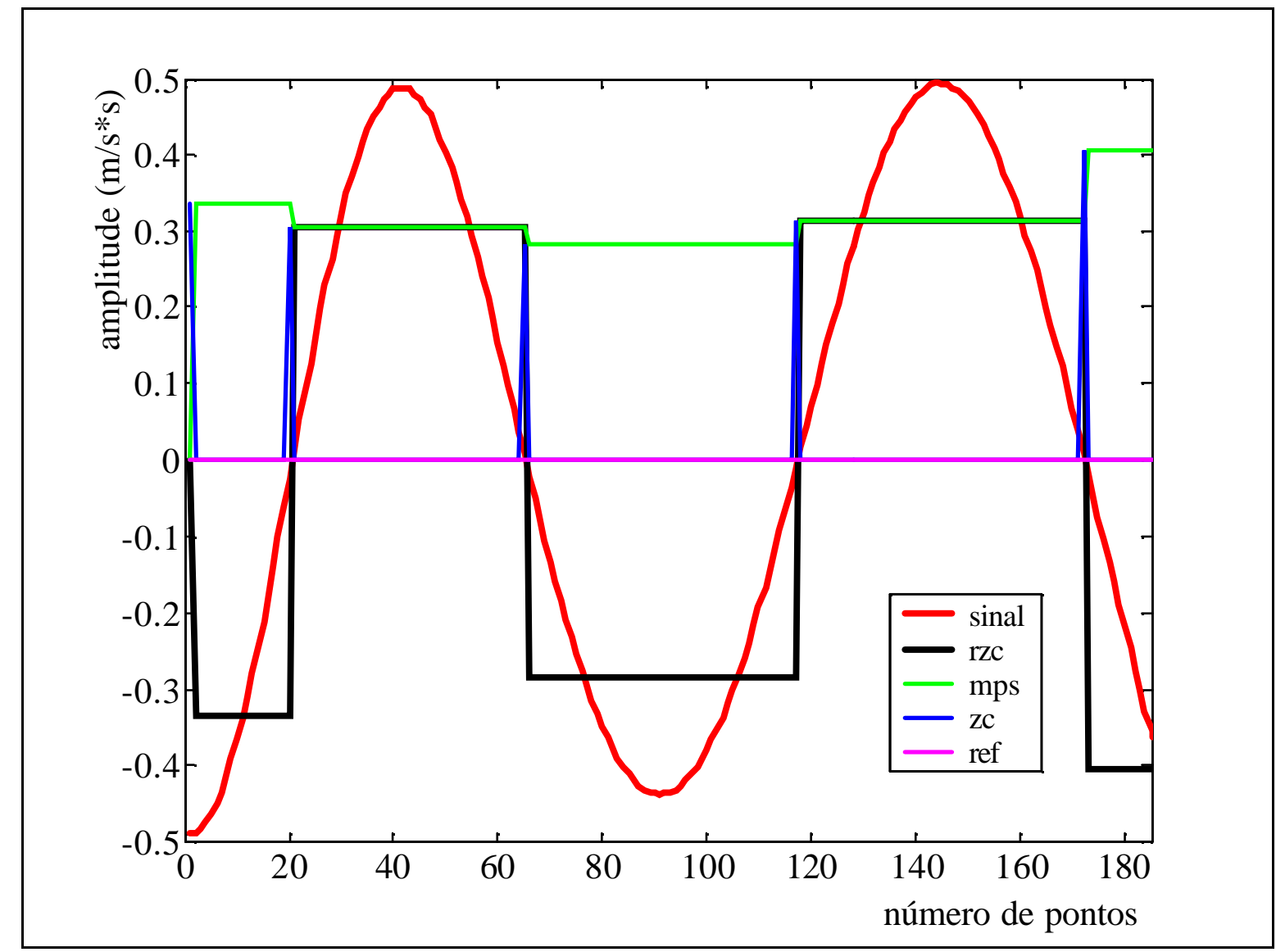

FIGURA 6.5. Sinal senoidal de freqüência conhecida

O cálculo teórico do índice wavelet zero crossing para um seno pode ser realizado considerando $\mathrm{f}_{0}$, a freqüência fundamental de rotação de um determinado do eixo, e o sinal de aceleração teórico provocado por este defeito que será:

$$
\mathrm{a}=\mathrm{A}_{0} \operatorname{sen}\left(2 * \mathrm{pi}^{*} \mathrm{f}_{0} * \mathrm{t}\right)
$$

Em cada período a função seno cruza o eixo do tempo duas vezes, como ilustrado na figura 6.5, ou seja, a aceleração muda de sentido duas vezes a cada período, portanto:

$$
\mathrm{IWZC}=4 * \mathrm{pi}^{*} \mathrm{f}_{0}
$$

Desta forma, para um eixo de um motor girando a freqüência $f_{0}$ de $10 \mathrm{~Hz}$, tem-se: 
- Para sinais de aceleração onde existam desbalanceamento e sabendo-se apenas a freqüência fundamental, pode-se calcular o zc/s pela equação:

$4 * \mathrm{pi}^{*} \mathrm{f}_{0}=4 * \mathrm{pi}^{*} 10=125,66(\mathrm{zc} / \mathrm{s})$. Corresponderia a um desbalanceamento do eixo.

- Para sinais do tipo desalinhamento tem-se além da freqüência fundamental do eixo, as suas harmônicas. Assim, por exemplo, calculando para a frequiência fundamental e a segunda harmônica da freqüência do eixo tem-se:

$4 * \mathrm{pi}^{*} 10+8 * \mathrm{pi} * 10=376,99(\mathrm{zc} / \mathrm{s})$ ou $12 * \mathrm{pi} * 10=376,99(\mathrm{zc} / \mathrm{s})$ que corresponderia a um desalinhamento do eixo.

Mais dois exemplos serão apresentados: no primeiro caso, considere um eixo de um motor girando a freqüência $f_{0}=10 \mathrm{~Hz}$, e que na pista externa possua um defeito com uma frequiência de passagem $\mathrm{f}_{\mathrm{i}}$ e no segundo caso, um defeito na pista interna que possua uma freqüência de passagem $\mathrm{f}_{2}$.

Para os sinais relativos aos defeitos da pista externa, tem-se a freqüência fundamental e as suas harmônicas, se a fundamental $\mathrm{fl}$ for $42 \mathrm{~Hz}$ tem-se:

$4 * \mathrm{pi}^{*} 42+8 * \mathrm{pi} * 42+12 * \mathrm{pi} * 42=3166,7(\mathrm{zc} / \mathrm{s})$ que corresponderia a um defeito na pista externa.

O mesmo procedimento se repete para a pista interna, porém, com uma freqüência f2 e o mesmo para as esferas, com uma freqüência f3. Na tabela 6.2 estes resultados são resumidos. 
TABELA 6.2. Valores teóricos para os valores de IWZC

\begin{tabular}{|c|c|c|}
\hline Defeito & Freqüîncia & IWZC (zc/s) \\
\hline Desbalanceamento & $\mathrm{f}_{0}$ & $4^{*} \mathrm{pi}^{*} \mathrm{f}_{0}$ \\
\hline Desalinhamento & $\mathrm{f}_{0}+$ harmônicas & $4^{*} \mathrm{pi}^{*} \mathrm{f}_{0}+8 * \mathrm{pi}^{*} \mathrm{f}_{0}+\ldots$ \\
\hline Pista externa & $\mathrm{f}_{1}+$ harmônicas & $4^{*} \mathrm{pi}^{*} \mathrm{f}_{1}+8 * \mathrm{pi}^{*} \mathrm{f}_{1}+\ldots$ \\
\hline Pista interna & $\mathrm{f}_{2}+$ harmônicas & $4 * \mathrm{pi}^{*} \mathrm{f}_{2}+8 * \mathrm{pi}^{*} \mathrm{f}_{2}+\ldots$ \\
\hline Esferas & $\mathrm{f}_{3}+$ harmônicas & $4 * \mathrm{pi}^{*} \mathrm{f}_{3}+8 * \mathrm{pi}^{*} \mathrm{f}_{3}+\ldots$ \\
\hline
\end{tabular}

Além disso, para um dado número de níveis em que a transformada de wavelet decompõe o sinal, a banda de freqüência de cada nível decomposto apresenta a seguinte relação:

Para aproximação:

$$
\begin{aligned}
& \text { fib }=0 \\
& \mathrm{ffb}=\mathrm{fa} / 2^{\mathrm{n}} \\
& 0
\end{aligned}
$$

Para detalhe:

$$
\begin{aligned}
& \mathrm{fib}=\mathrm{fa} / 2^{\mathrm{n}} \\
& \mathrm{ffb}=\mathrm{fa} / 2^{\mathrm{n}-1} \\
& \mathrm{fa} / 2^{\mathrm{n}} \quad \mathrm{fa} / 2^{\mathrm{n}-1} \\
& \text { e são múltiplos da freqüência de amostragem divido por } 2 \text {, ou seja, fa/2. }
\end{aligned}
$$

Por exemplo:

Para o nível 1, tem-se a faixa de frequiências para o nível de Aproximação de 0 até fa/4 e para o nível de Detalhe de fa/4 até fa/2.

Para o nível 2, tem-se a faixa de freqüências para o nível de Aproximação de 0 até fa/8 e para o nível de Detalhe de fa/8 até fa/4, etc.

Desta forma, quando se deseja analisar uma determinada banda de frequiência, conhecendo-se a faixa de freqüência que cada nível da transformada de wavelet oferece, é possível escolher adequadamente qual nível deverá ser utilizado. 


\subsubsection{Aplicação da Lógica Nebulosa Pa raconsistente}

O diagrama de blocos apresentado na figura 6.7 indica as transformações que uma variável de entrada, que pode ser um das características extraídas do sinal tais como: RMS, Curtose, DEP, etc. e que estão listadas na tabela 6.1, passam até se chegar a um diagnóstico.

A lógica nebulosa paraconsistente como já descrito na teoria apresentada no item 5.5, analisa uma dada proposição, que chamaremos de Proposição 1 (P1).

No quadro indicado da figura 6.7 pelo número romano I, é mostrado um gráfico onde a característica 1 , que pode ser o RMS, ou curtose, ou DEP E, etc. é representado no eixo das abscissas. A função de pertinência indicada na figura transfere o valor da abscissa para um correspondente valor no eixo das ordenadas, que é chamado de grau de pertinência $\mu_{\mathrm{A}}$. Esta variável pode assumir valores num intervalo de 0 a 1 .

O mesmo vale para o quadro indicado pelo número romano II, porém para outra característica 2.

No quadro III, para a aplicação da Lógica Paraconsistente se estabelece uma relação matemática, entre o grau de evidência favorável (gef) $\left(\mu_{1}\right)$ ou e o grau de pertinência $\left(\mu_{\mathrm{A}}\right)$, que é apresentada a seguir:

$$
\mu_{1}=\mu_{\mathrm{A}}
$$

e no quadro de número IV estabelece a relação, entre o grau de evidência contrária (gec) $\left(\mu_{2}\right)$ e o grau de pertinência $\left(\mu_{\mathrm{B}}\right)$. Observa-se que $\mu_{2}$ é o complemento de $\mu_{\mathrm{B}}$.

$$
\mu_{2}=1-\mu_{\mathrm{B}}
$$

Na próxima etapa, no quadro $\mathrm{V}$, calcula-se o grau de certeza $(\mathrm{Gc})$ que é definida de acordo com a equação abaixo:

$$
\mathrm{Gc}=\mu_{1}-\mu_{2}
$$


Desta forma pode-se observar que o grau de certeza (Gc) varia entre -1 e 1. Observa-se que o valor nulo está agora incluído no domínio.

Á região dos valores positivos do grau de certeza Gc denominados de região de verdade e a região dos valores negativos, chamados de região de falsidade.

Similarmente, o grau de contradição Gct é definido pela seguinte equação:

$$
\mathrm{Gct}=\mu_{1}+\mu_{2}-1
$$

As mesmas considerações são válidas para o Gct, mostrado no quadro VI. Pode-se observar que o grau de contradição (Gct) varia entre - 1 e 1, e que o valor nulo também esta incluído no domínio. O nome do eixo de Gct para valores positivos é denominado de região de indeterminação, e a região para valores negativos, é chamada de região paracompleta.

Fazendo agora o raciocínio inverso, se Gc é igual a zero, para valores de $\mu_{1}$ e $\mu_{2}$ iguais a 0,5 e $\mu_{1}=\mu_{\mathrm{A}}$, tem-se para os valores acima de 0,5 a indicação de que a proposição P1 é verdadeira, e para valores menores que 0,5 que P1 é falsa, como apresentado no quadro I, pelas setas e pela linha tracejada que passa pelo valor 0,5 de $\mu_{\mathrm{A}}$. Um raciocínio semelhante é realizado para o Gct.

As funções de pertinência apresentadas nos quadros I e II foram escolhidas em função das análises do comportamento das técnicas de extração de características utilizadas. Neste trabalho, todas as características puderam ser representadas por um único tipo de função, como sendo o de uma função rampa. Assim, os valores $\mu_{\mathrm{A}}$ a partir de 0,5 entram na região de verdade e os valores abaixo de 0,5 entram na região de falsidade.

No quadro VII da figura 67, estão representados os dois eixos, o do Grau de Certeza e o de Contradição, com os seus limites e com as suas funções de pertinência correspondentes.

Estas funções são combinadas às funções de pertinência de saída através das regras de inferência, gerando um estado de saída no gráfico do quadro VIII. Este gráfico está divido em regiões, às quais se atribuem nomes (verdadeiro, quase verdadeiro, falso, quase falso, etc). 
A seguir, figura 6.6, será apresentado um exemplo de como os valores de uma das características de defeito, por exemplo, o valor RMS foi utilizado para se obter o grau de pertinência $\mu_{\mathrm{A}}$, através de uma função de pertinência do tipo rampa.

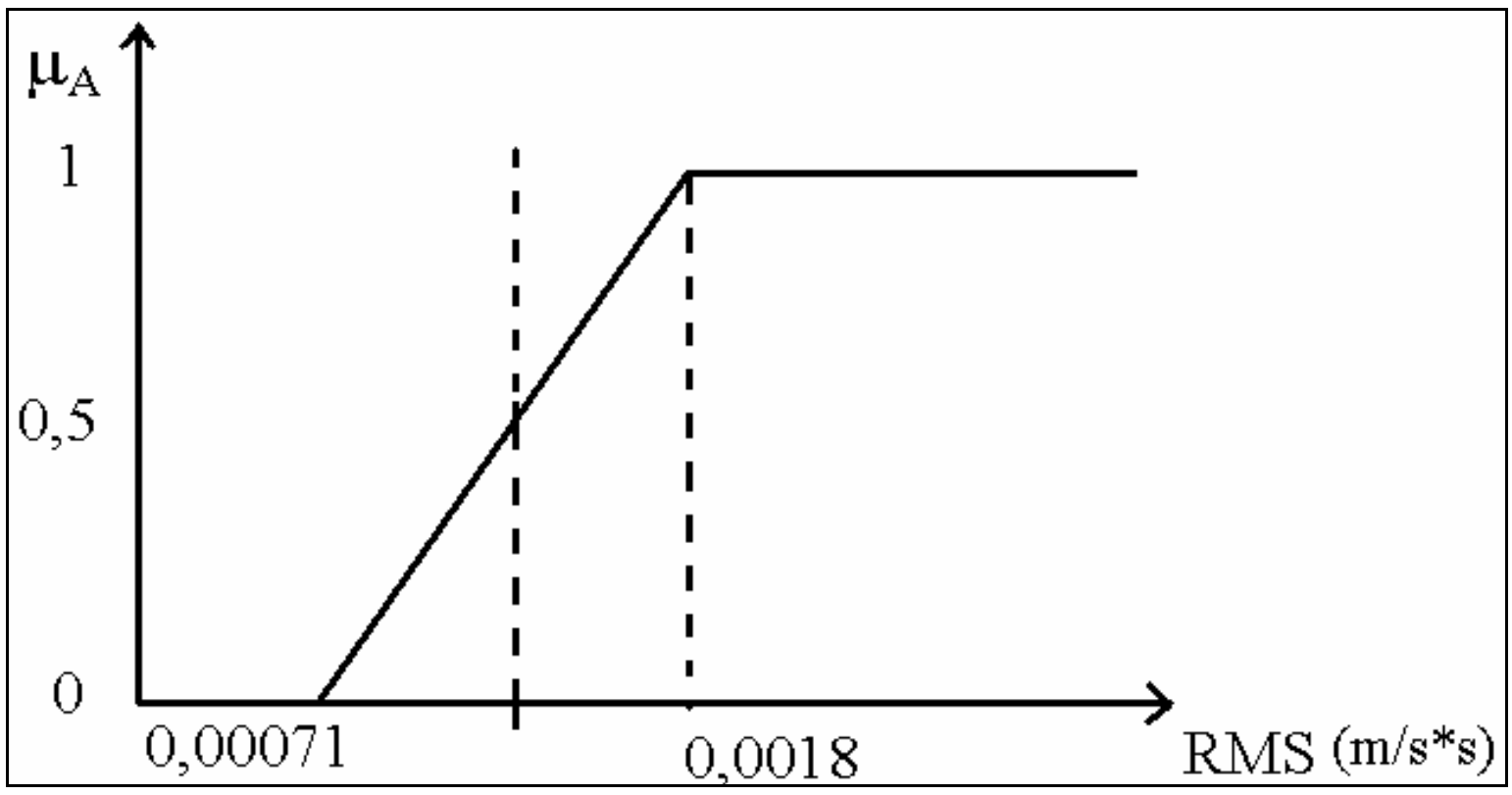

FIGURA 6.6. Função de pertinência para característica RMS

Para as outras características, as suas respectivas funções de pertinências estão apresentadas na figura 6.33 e seguem todos o mesmo tipo de função rampa. Nesta tela pode-se verificar que o menor valor da variável foi chamado de critério 1 e o maior valor de critério 2.

Estes valores é que determinam a função rampa no quadro I e II de $\mu_{\mathrm{A}}$ e $\mu_{\mathrm{B}}$. 


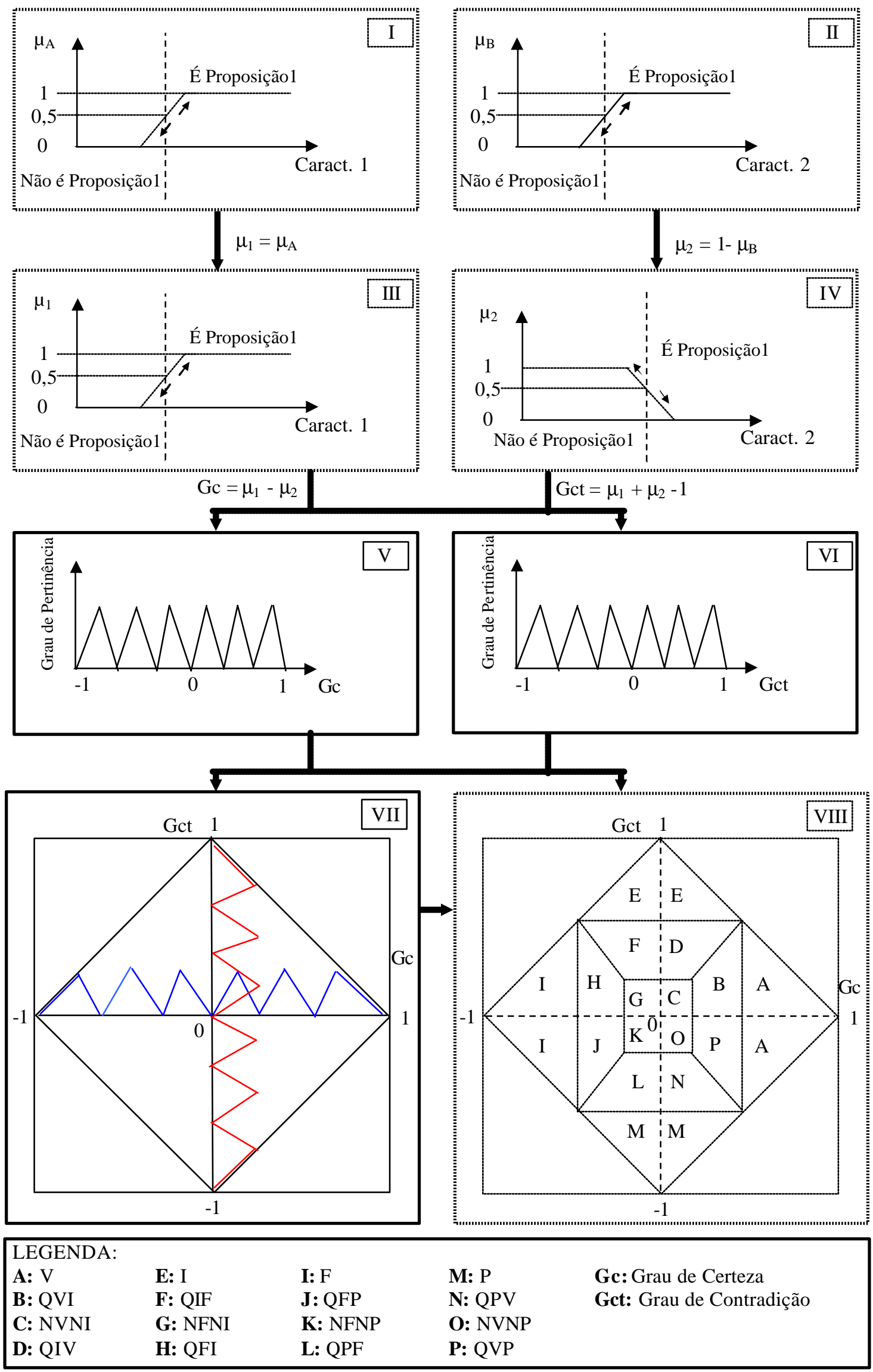

FIGURA 6.7. Etapas para a aplicação da lógica nebulosa paraconsistente 


\subsubsection{Implementação da lógica de decisão com a Lógica nebulosa paraconsistente}

Entre várias arvores lógicas possíveis, para demonstrar a viabilidade do método, e baseado na experiência experimental, propusemos a arvore lógica para decisão apresentada na figura 6.8 .

No bloco lógico mostrado na figura 6.8, a lógica paraconsistente é utilizada para responder as seguintes proposições que são os diagnósticos procurados:

1- Tem defeito ou não?, para responder a esta proposição, quatro características (RMS, Curt, ENV E, ENV I, tabela 6.1) são utilizadas para a definição do grau de pertinência $\mu_{\mathrm{A}}$ através de uma porta "OR" da Lógica Nebulosa. Da mesma forma, para estabelecer o contraditório, quatro outras características (Thmax6, DEP I, Thmax7, DEP E) são utilizadas para estabelecer o grau de pertinência $\mu_{\mathrm{B}}$. Como já definido anteriormente o grau de pertinência $\mu_{\mathrm{A}}$ gerará o grau de evidência favorável, e por sua vez $\mu_{\mathrm{B}}$ gerará o grau de evidência contrária. A partir de $\mu_{\mathrm{A}}$ e $\mu_{\mathrm{B}}$ assim obtidos, utilizando-se as etapas III, IV, V, VI, VII e VIII do diagrama da figura 6.7, obtêm-se a resposta à proposição inicial que é o diagnóstico procurado;

2- O defeito localiza-se na pista externa? Para esta proposição são utilizadas DEP E ou ENV E, como grau de evidência favorável e DEP I ou ENV I como grau de evidência contrária;

3- O defeito detectado é severo? Nesta proposição são utilizados RMS como grau de evidência favorável e curtose como grau de evidência contrária;

4- As variáveis utilizadas nesta figura possuem a possibilidade de ter seus pesos alterados, figura 6.33, conforme se aumenta o conhecimento sobre o comportamento de cada uma destas variáveis, permitindo assim que o diagnóstico se torne mais preciso. 


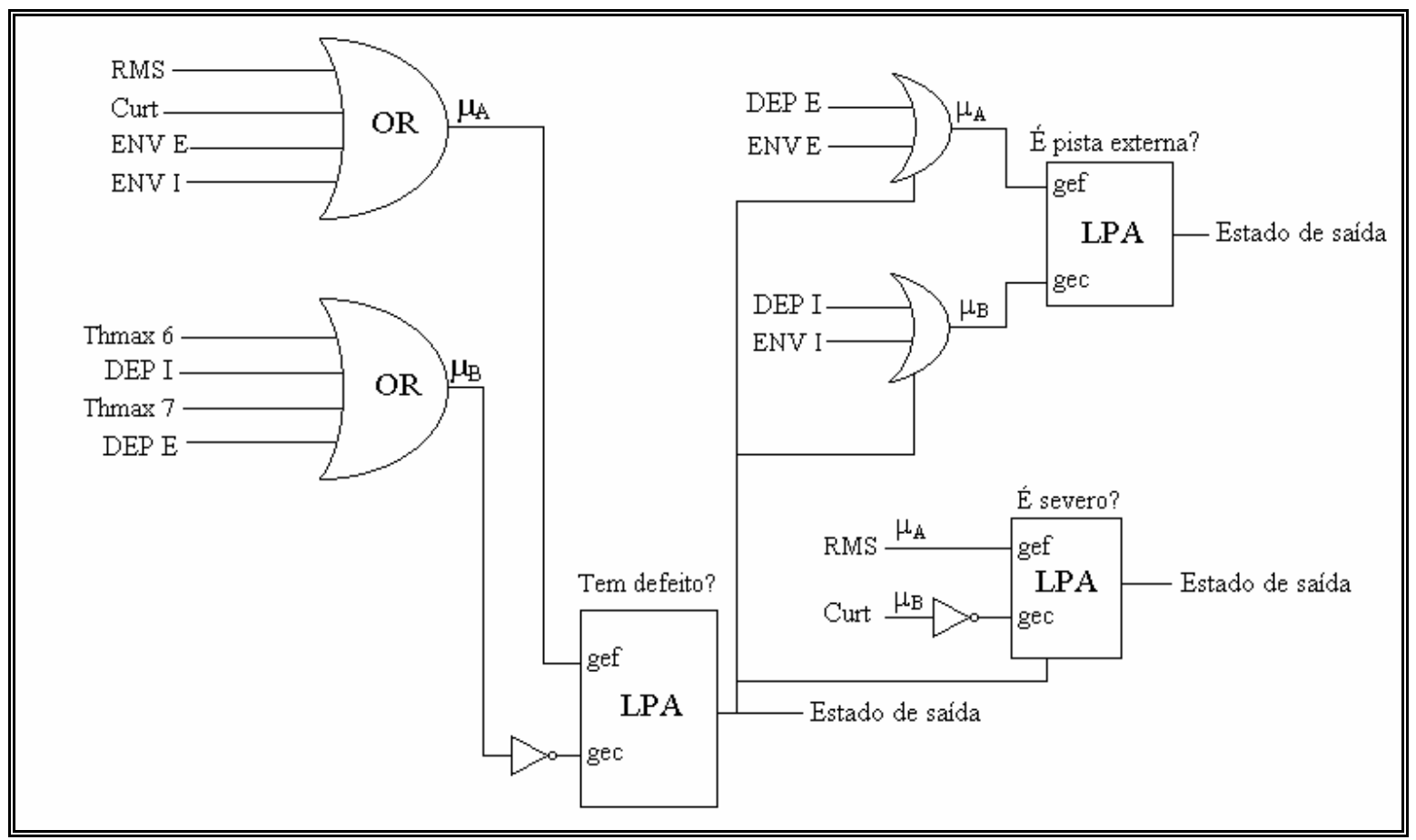

FIGURA 6.8. Diagrama lógico mostrando as etapas para diagnóstico

Além da identificação se o defeito ocorreu na pista interna ou externa, é possível também identificar quem informou que ocorria defeito na pista externa, se o envelope ou a densidade espectral de potência. Com este objetivo, foi implementado um bloco utilizando a Lógica nebulosa paraconsistente. Este bloco está mostrado na figura a seguir 6.9.

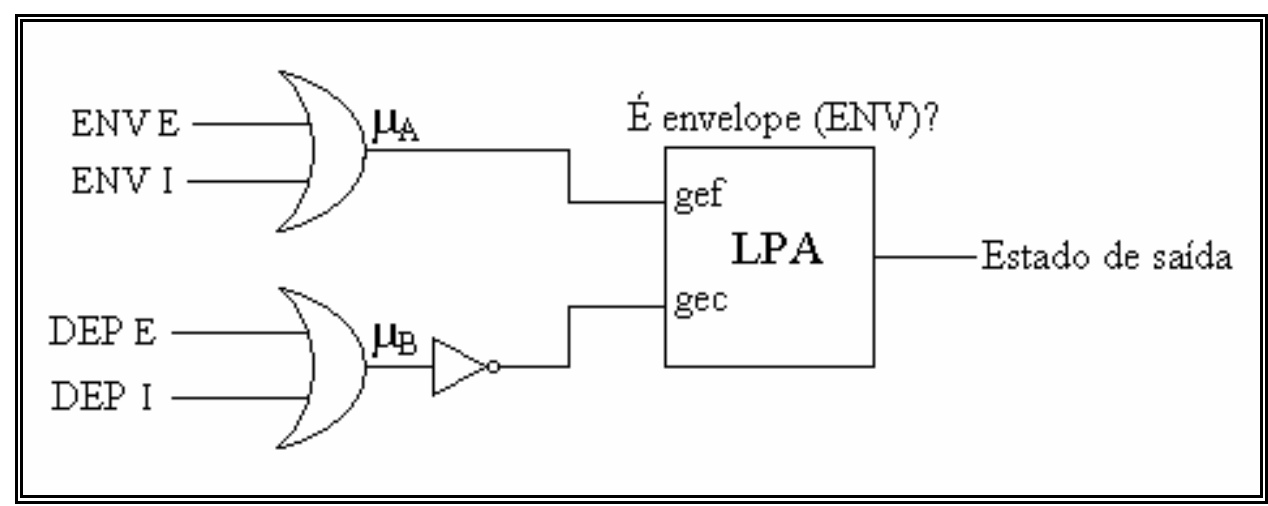

FIGURA 6.9. Diagrama informando se a DEP ou ENV detectaram o defeito

Os parâmetros calculados com base na transformada de wavelet se mostraram eficientes na classificação do tipo de defeito, ou seja, localizado ou distribuído. Estes parâmetros foram: o Tal IWZC 1 e o RMS 5, 6 e 7. O Tal IWZC 1 é o coeficiente de 
decaimento da curva IWZC para o nível 1. Este coeficiente apresenta valor baixo quando o tipo de defeito é localizado.

Os RMS 5, 6 e 7 são definidos pelos valores RMS do sinal reconstruído da Transformada de Wavelet dos níveis 5, 6 e 7 do sinal de vibração, respectivamente. Estes três níveis de frequiências $(5,6$ e 7) são os que contêm as principais raias de frequiências de passagem dos defeitos. Esse parâmetro apresenta valores altos quando o tipo defeito é distribuído.

Os critérios para os valores de Tal IWZC 1 e RMS 5, 6 e 7 foram definidos através dos dados obtidos para os rolamentos sem defeitos, e de uma amostra dos rolamentos do banco de dados, para defeitos localizados e defeitos distribuídos. Os resultados quantitativos serão apresentados no capítulo 8. Para a identificação se o defeito é do tipo localizado ou distribuído utiliza-se o bloco lógico indicado na figura 6.10.

Inicialmente, verifica-se se o valor de Tal IWZC 1 apresenta um valor de gef maior que o critério 1 da figura 6.10. No caso afirmativo o defeito é do tipo localizado. Se for menor, é realizada a avaliação do valor RMS 5, 6 e 7. Se é maior que o critério 2, o defeito é distribuído. Caso não se confirme, existe a possibilidade do defeito estar ainda em uma fase inicial. Os critério 1 e critérios 2 estão definidos na figura 6.33

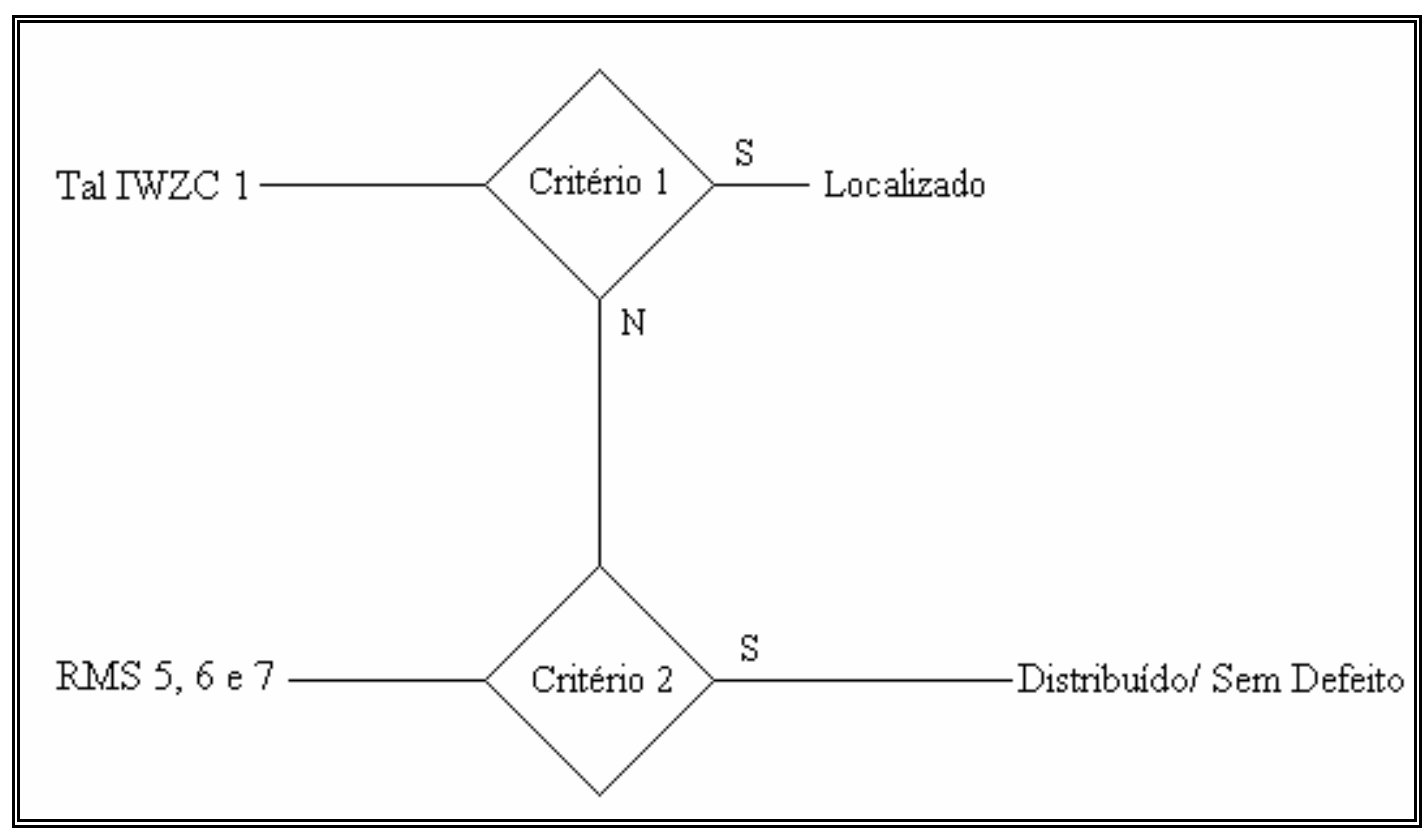

FIGURA 6.10. Diagnóstico para classificação de defeitos 
Aos estados extremos da lógica foram atribuídos nomes a estes estados, que está apresentado na tabela 6.3.

TABELA 6.3. Nomes das condições lógicas extremas

\begin{tabular}{|c||c|c||}
\hline Gc & Gct & Nome do estado lógico \\
\hline \hline 0 & 0 & Paracompleto \\
\hline \hline 0 & 1 & Falso \\
\hline \hline 1 & 0 & Verdadeiro \\
\hline \hline 1 & 1 & Inconsistente \\
\hline
\end{tabular}

Assim para uma dada proposição tem-se associado pela Lógica nebulosa paraconsistente algumas designações de estado de saída que podem facilitar a utilização desta lógica. Para as aplicações em engenharia, estas designações dos estados lógicos definidos pela lógica paraconsistente devem ser ajustadas à aplicação desejada. Por exemplo, caso a saída da lógica estivesse orientando o movimento de um robô, como já foi realizado em outros trabalhos $[27,28,29,41]$, os estados lógicos podem significar para o robô: verdadeiro - "vá em frente", inconsistente - "vire para a esquerda", paracompleto "volte", etc. No nosso caso dependendo da proposição, o estado de saída paracompleta pode ser um resultado desejado ou não, como na pergunta Tem Defeito? As combinações lógicas das variáveis de entrada podem indicar que a resposta desejada seja paracompleta, ou seja, nenhuma das características de entrada constatou defeito, ou seja, estiveram próximos a zero e $\mu_{1}$ e $\mu_{2}$ com valores próximos a zero indica uma saída paracompleta, neste caso a resposta desejada.

Na figura 6.11 é apresentado um diagrama de blocos onde se podem ver o bloco de funções de pertinência (neste caso 6) para o grau de evidência favorável, figura 6.12, e o bloco de funções de pertinência (neste caso também 6) para o grau de evidência contrária, figura 6.13, e que através das regras de inferência, apresentadas na tabela 6.4, se pode associar as funções de pertinência de entrada a uma das 17 funções de pertinência de saída. 


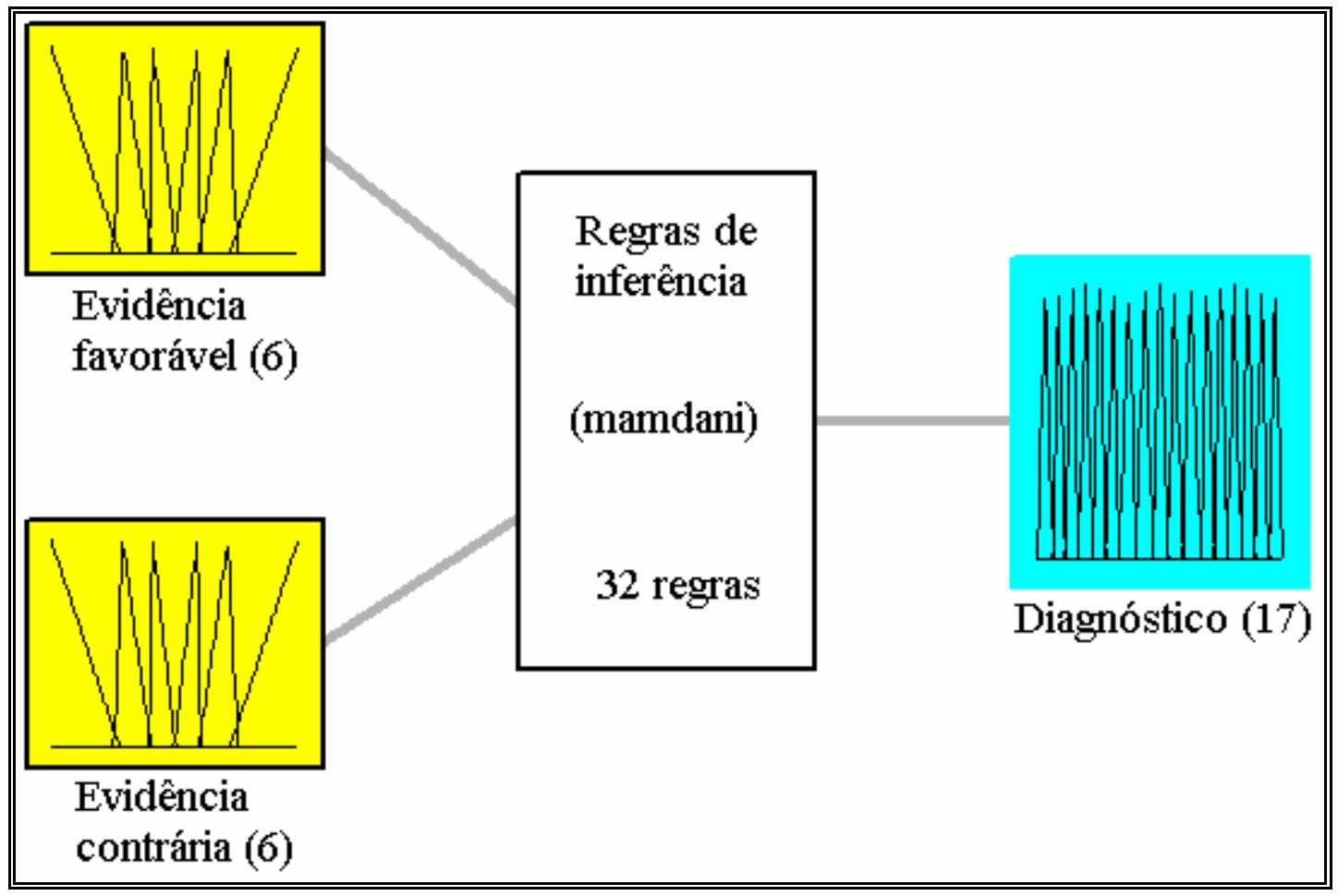

FIGURA 6.11. Diagrama de blocos da aplicação da Lógica Nebulosa Paraconsistente

Para o grau de evidência favorável, a cada uma das funções de pertinência para será atribuído os seguintes nomes:

V - Verdade, QV - Quase Verdade, NBV - Nível Baixo de Verdade.

F - Falsidade, QF - Quase Falso, NBF - Nível Baixo de Falsidade.

Para o grau de evidência contrária temos as seguintes funções de pertinência:

I - Inconsistente, QI - Quase Inconsistente, NBI - Nível Baixo de Inconsistência.

P - Paracompleto, QP - Quase Paracompleto, NBP - Nível Baixo de Paracompleto. 


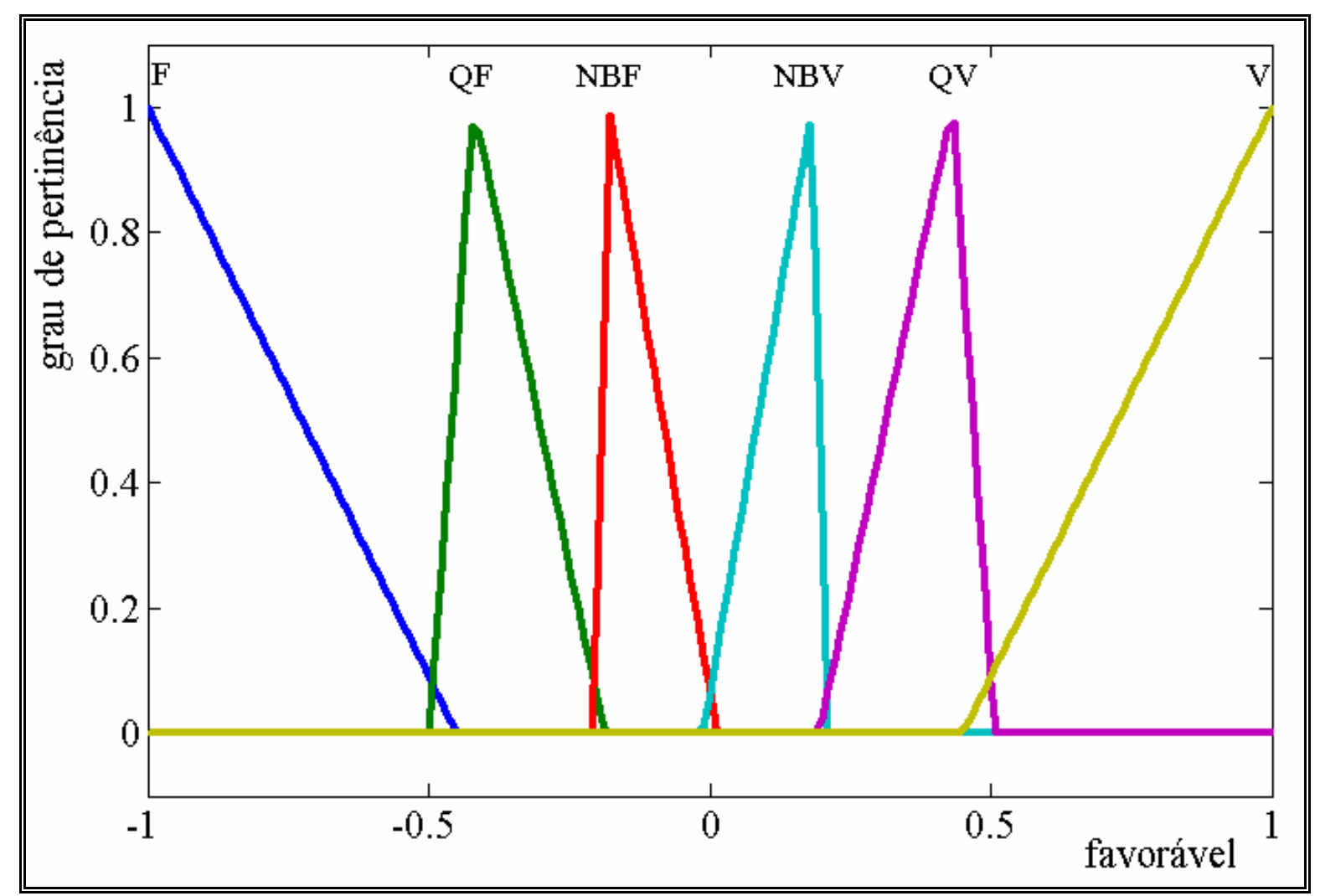

FIGURA 6.12. Funções de pertinência de entrada do grau de evidência favorável

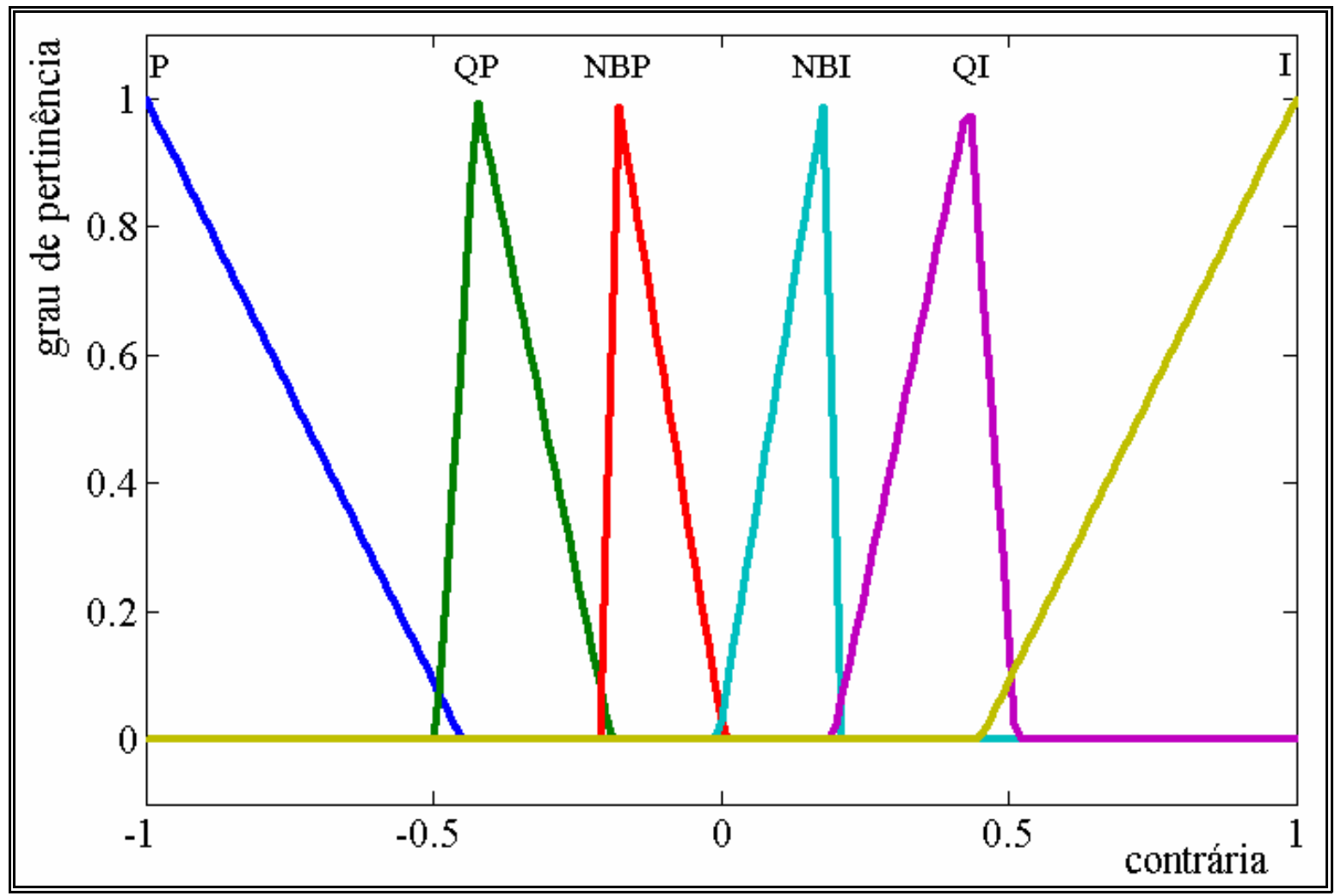

FIGURA 6.13. Funções de pertinência de entrada do grau evidência contrária 
Utilizando o programa "Matlab" foi desenvolvido um programa que ao ser executado faz uso da tabela 6.4 que combina as regras de inferências com as funções de pertinência de entrada e saída, permitindo um diagnóstico das condições do rolamento.

Os estados lógicos de saída estarão entre uma das situações descritas abaixo e podem ser visualizadas nas figuras 6.14 e 6.15. A figura 6.14 mostra as regiões lógicas de saída para diagnósticos, vide tabela 6.4, e a figura 6.15 mostra as funções de pertinência de saída que são utilizadas no programa desenvolvido, na parte da lógica nebulosa paraconsistente, para realizar o diagnóstico automático de defeitos.

TABELA 6.4. Regras de inferência

\begin{tabular}{|c|c|c|c|c|c|c||}
\hline Gct Gc & F & QF & NBF & NBV & QV & V \\
\hline I & ${ }^{*}$ & I & I & I & I & ${ }^{*}$ \\
\hline QI & F & QFI & QIF & QIV & QVI & V \\
\hline NBI & F & QFI & NFNI & NVNI & QVI & V \\
\hline NBP & F & QFP & NFNP & NVNP & QVP & V \\
\hline QP & F & QFP & QPF & QPV & QVP & V \\
\hline P & $\star$ & P & P & P & P & $*$ \\
\hline
\end{tabular}

A tabela 6.4 apresenta as combinações entre o grau de certeza e ou grau de contradição, definindo regiões que foram denominadas pelas siglas indicadas nas células e que estão definidas na figura seguinte (6.14). 


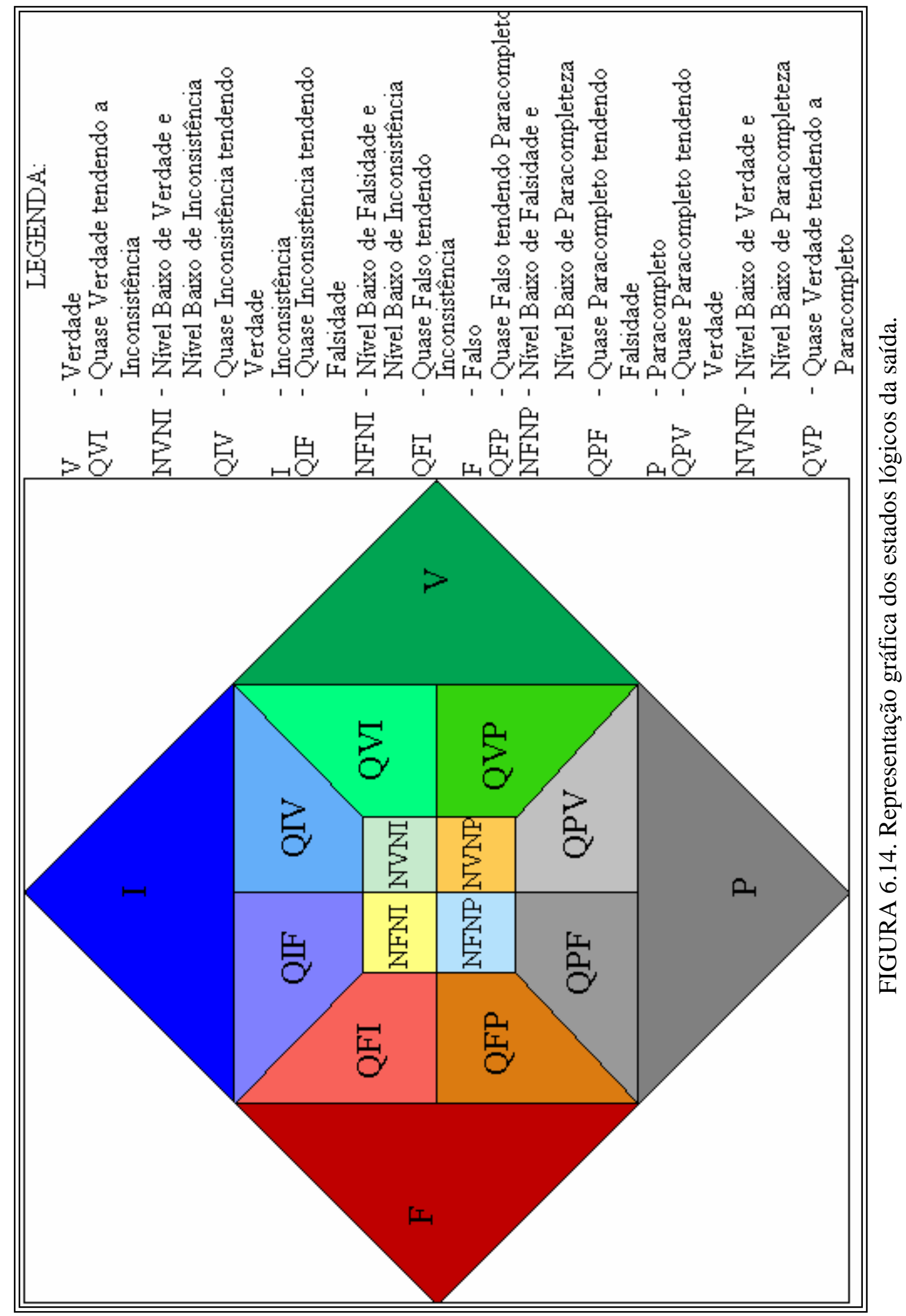




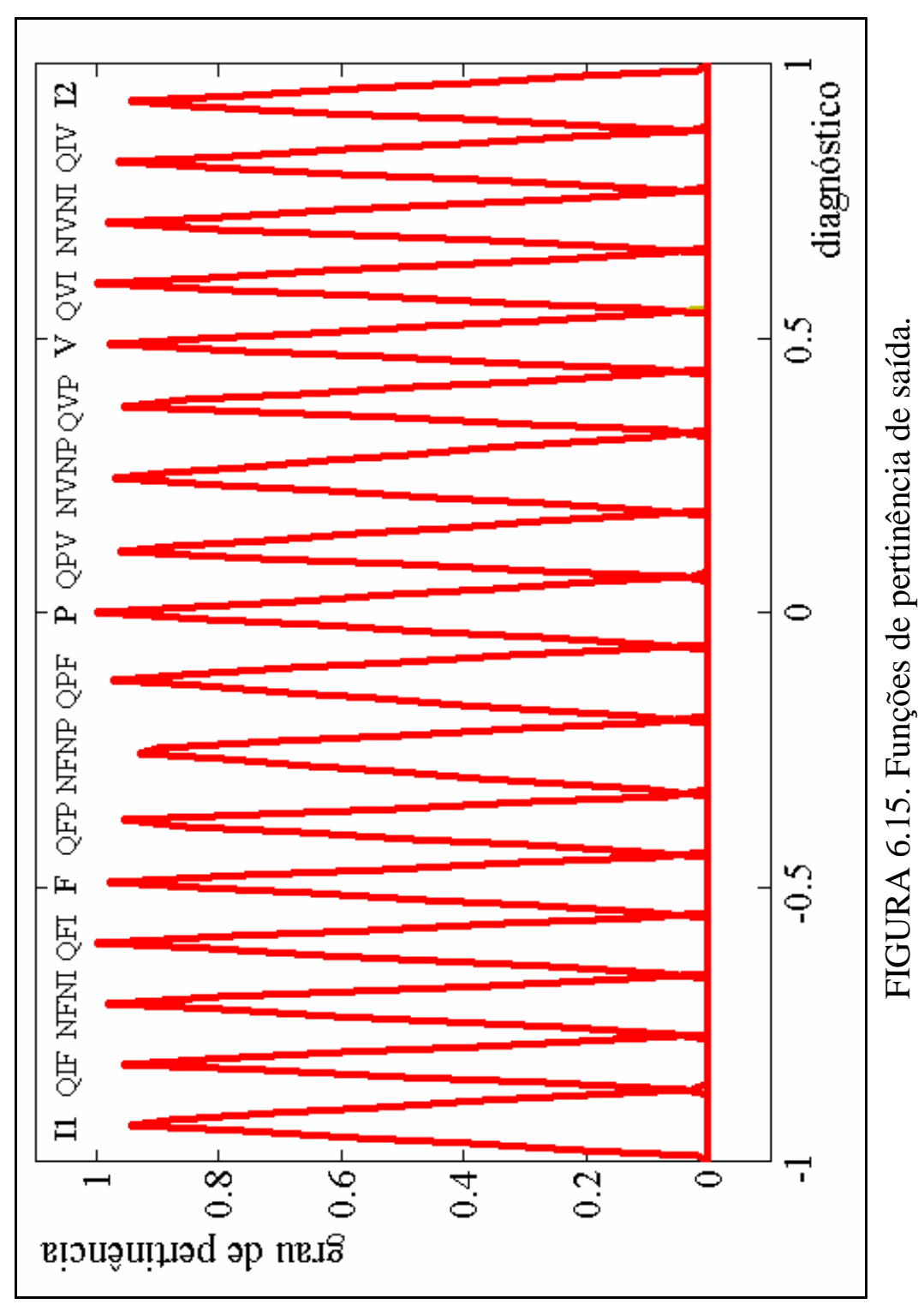

\subsection{Programa de Análise e Diagnóstico de Defeitos em Rolamentos}

O programa desenvolvido é dividido em dois subprogramas. O primeiro é composto de funções de extração de características que pode ser visto no diagrama de blocos da figura 6.16. O segundo subprograma está mostrado m diagrama de blocos da figura 6.17 e contém as rotinas de diagnósticos automáticos de defeitos divididos em 6 telas.

Uma das vantagens da utilização de um programa para diagnóstico é que permite a sistematização na entrada de dados, evitando que etapas possam ser esquecidas, isto cria uma padronização além de rapidez nas análises realizadas. 


\subsubsection{Diagrama de blocos do programa desenvolvido}

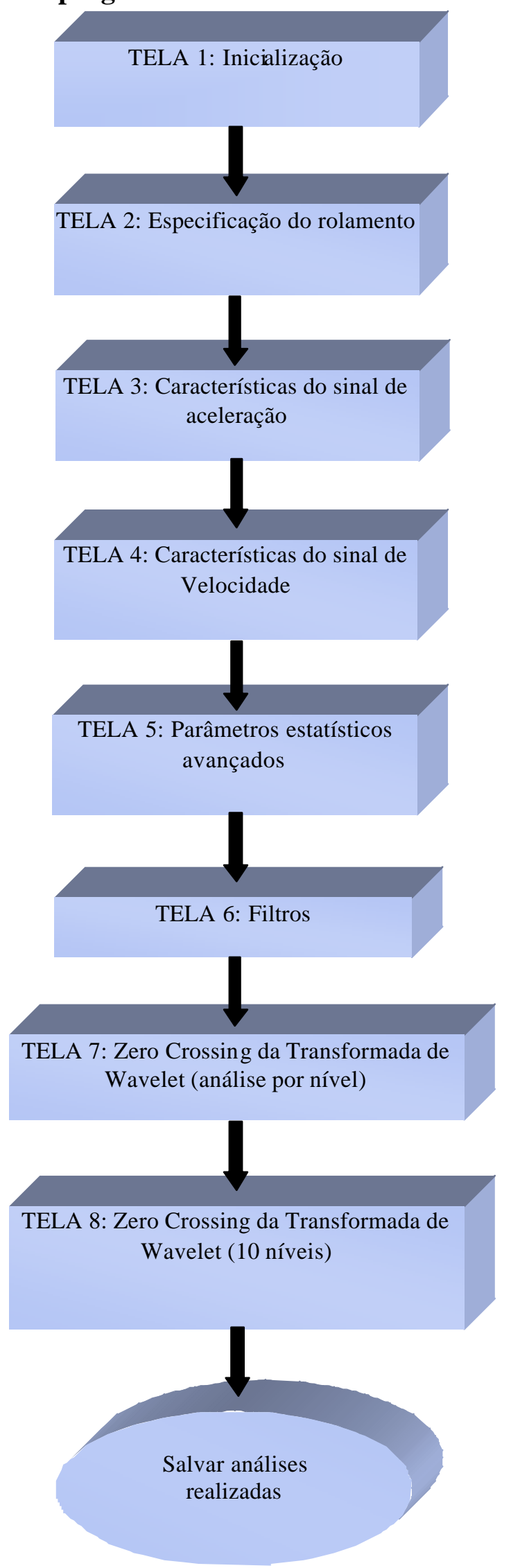

FIGURA 6.16. Diagrama de blocos das telas de extração de características 


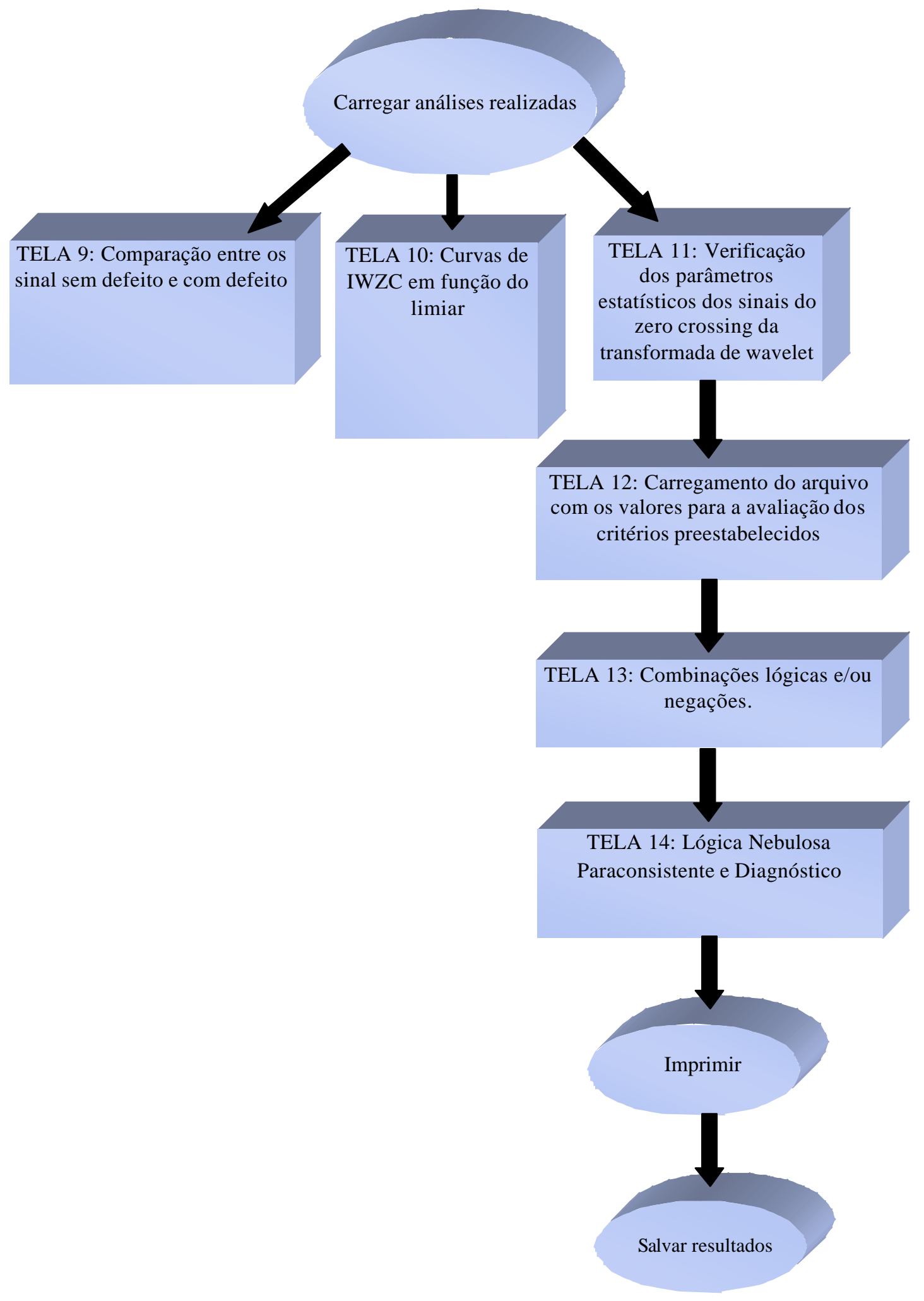

FIGURA 6.17. Diagrama de blocos das telas de diagnóstico 


\subsubsection{Descrição das telas do subprograma de extração de características}

Serão descritas abaixo, as funções que cada uma das telas deste subprograma executa.

\subsubsection{Tela 1: Inicialização}

Esta tela esta apresentada na figura 618, e tem por função, carregar o sinal de aceleração em formato texto, (*.txt) ou (*.mat), no formato próprio do Matlab, compensar os ganhos do sistema de aquisição de dados, confirmar o tamanho e data do arquivo, informar a posição do sensor de aquisição de sinais na máquina de ensaios, a frequiência de amostragem e realizar uma visualização prévia do sinal no domínio do tempo e da freqüência. Caso o arquivo carregado possua sinais de mais de um sensor, estes são mostrados à esquerda da tela que possui capacidade de mostrar até seis sinais simultaneamente.

\subsubsection{Tela 2: Especificação do rolamento}

A tela da figura 6.19 calcula as frequiências de passagem até a oitava harmônica para os vários tipos de rolamentos, cujas características geométricas já estão pré-definidas (E20, M20, E25, MB 204, etc.). Nesta tela, pode-se alterar a unidade da rotação do eixo, que pode ser fornecida em Hz ou RPM e também informar o ângulo de contato (figura 5.1). Se for selecionada no campo a opção "modelo do rolamento" e a posição “customizar", é possível simular outras condições utilizando valores não padronizados para o diâmetro "pitch", o número de esferas, o diâmetro das esferas, o ângulo de contato e a rotação do eixo. 


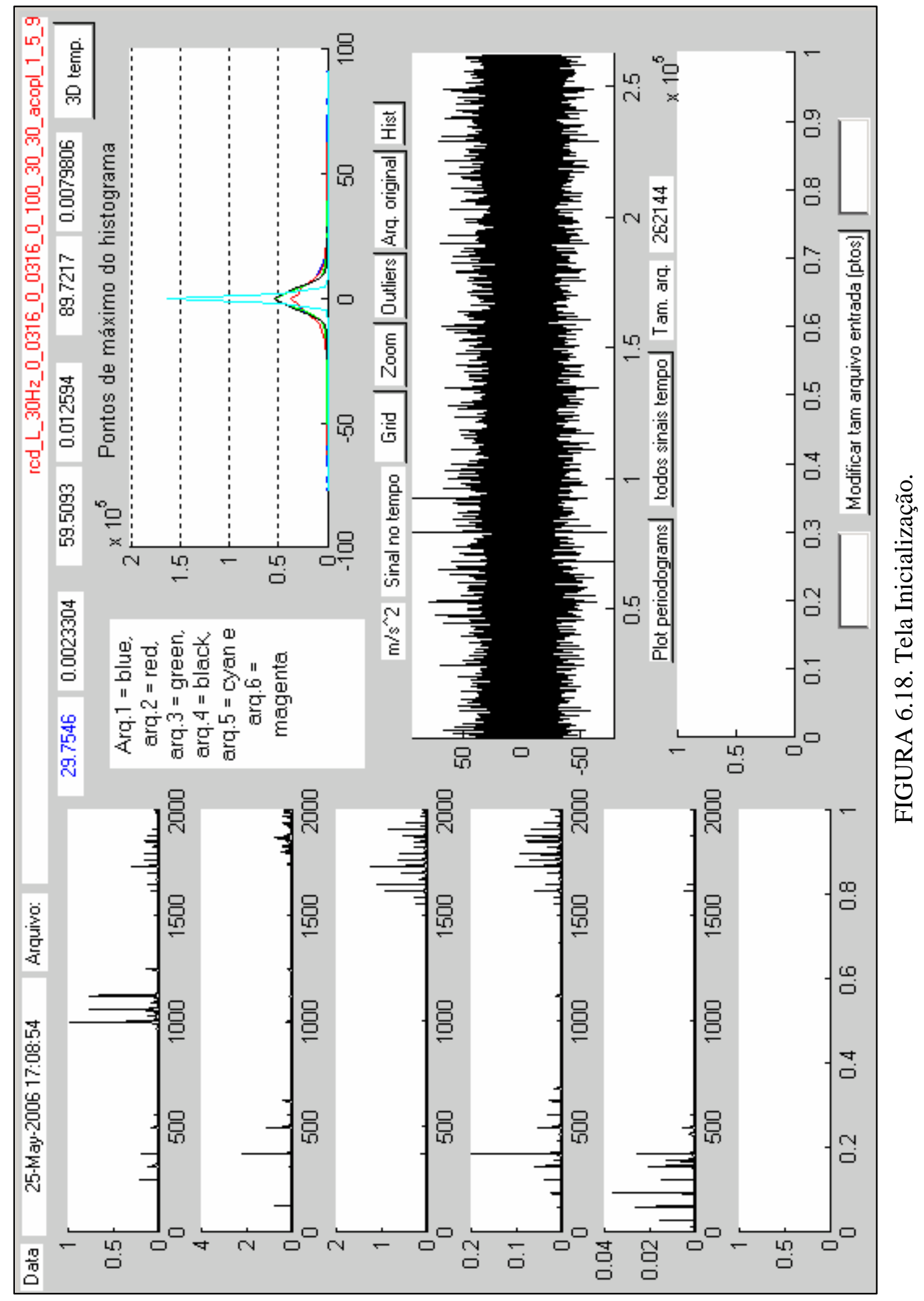




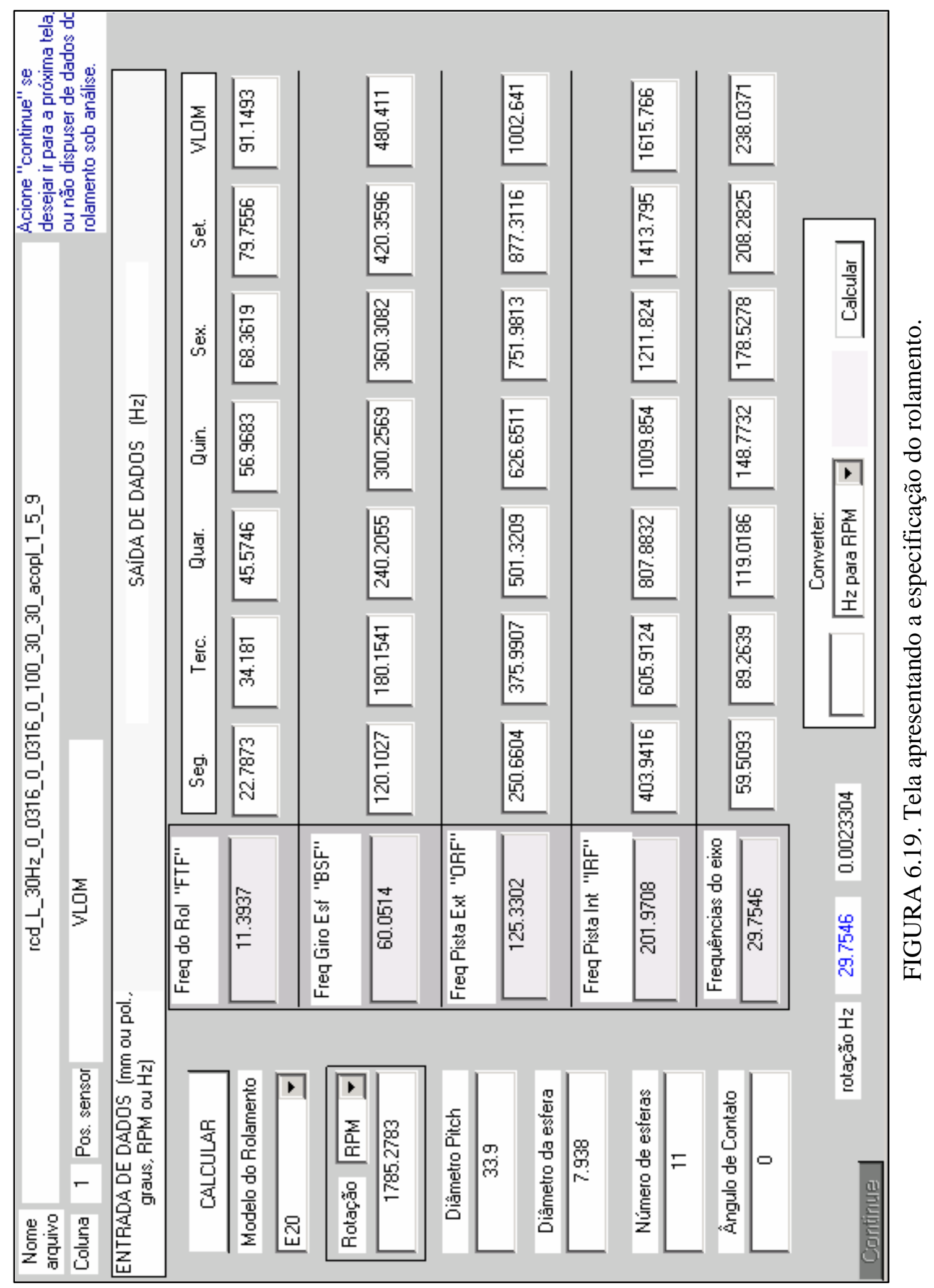




\subsubsection{Tela 3: Características dos sinais de aceleração}

Na tela da figura 6.20, é possível realizar a extração das características e as análises das condições do rolamento para sinais de aceleração. Esta tela fornece parâmetros estatísticos tais como, o valor RMS, curtose, assimetria (skewness), média e desvio padrão. Pode-se observar também o sinal analisado no domínio do tempo, a sua DEP e o envelope do sinal. Para facilitar a análise dos resultados, são apresentadas janelas laterais com a indicação através de pequenos símbolos de cor vermelha (+), indicando as freqüências de passagem.

Acima dos gráficos de DEP e envelope existem espaços para se posicionar o cursor e alterar o valor dos eixos $\mathrm{x}$ e $\mathrm{y}$.

\subsubsection{Tela 4: Características dos sinais de velocidade}

$\mathrm{Na}$ tela da figura 6.21, são calculadas as características e analisadas os sinais de velocidade. Pode-se observar neste gráfico a existência de um filtro, onde se pode alterar a freqüência de corte inferior permitindo que os sinais de baixa frequiência destacados pelo processo de integração do sinal de aceleração não seja amplificado demasiadamente podendo vir a distorcer as análises realizadas.

Parâmetros estatísticos tais como o valor RMS, curtose e assimetria também são apresentados. Pode-se observar os valores, através de um gráfico, da DEP do sinal de aceleração. Como na tela anterior, janelas laterais mostram em detalhe as freqüências de passagem calculadas para o rolamento sob análise. 


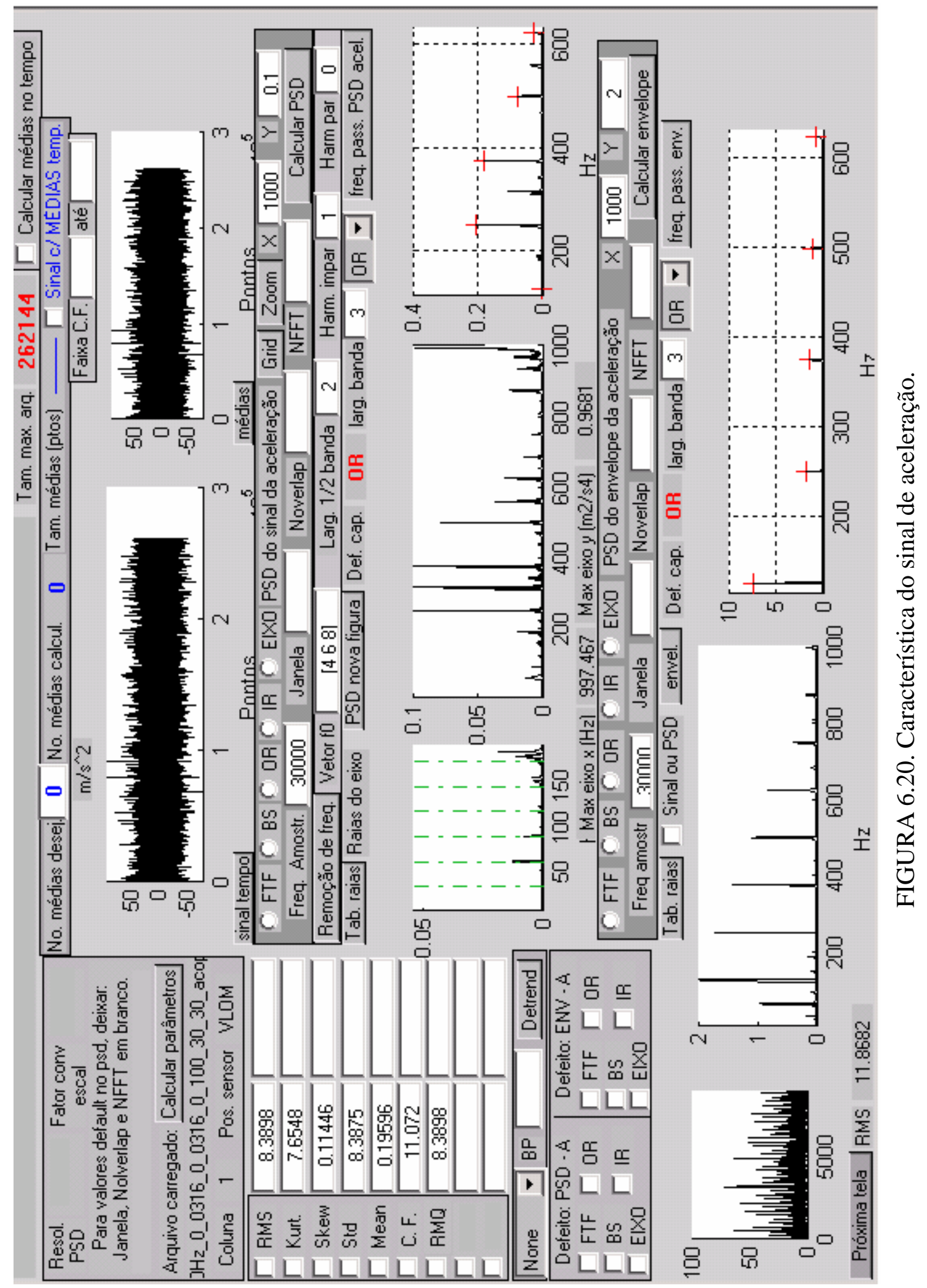




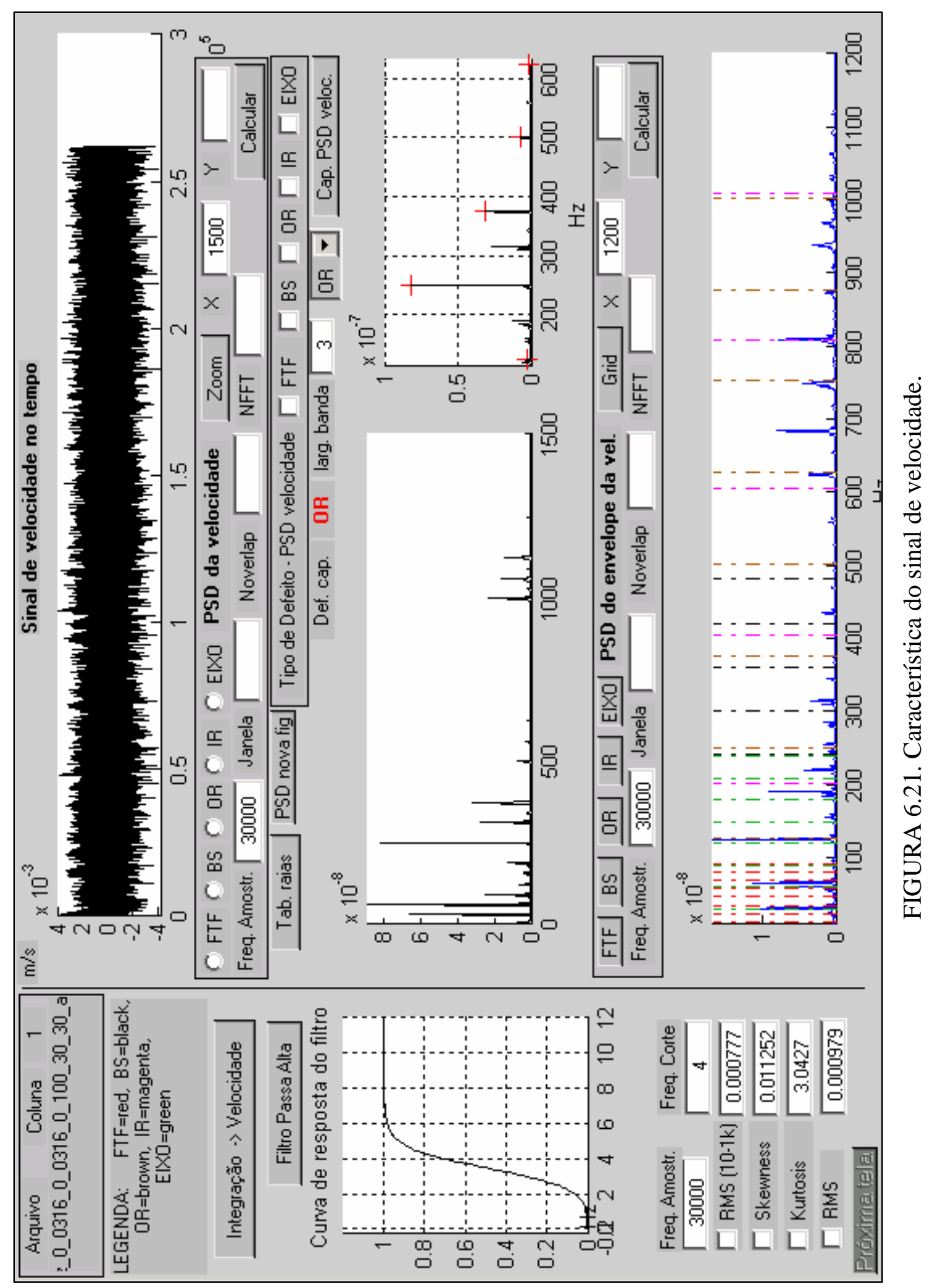




\subsubsection{Tela 5: Parâmetros estatísticos avançados}

Na tela da figura 6.22, são calculadas e apresentadas funções estatísticas avançadas tais como o Cepstrum, a Autocorrelação do sinal e o Crest Factor do sinal através de uma janela deslizante.

\subsubsection{Tela 6: Filtros}

A seguir, tem-se a tela na figura 6.23 que possui comandos para filtrar os sinais de entrada para as etapas de análise pelo Zero Crossing da Transformada de Wavelet, cortando as frequiências deste sinal que estejam acima de $10 \mathrm{kHz}$ e, se for necessário, realizar o remoção de ruídos (“denoising”) neste sinal, utilizando a Transformada de Wavelet.

Várias telas mostram as possíveis alterações do sinal durante as etapas de filtragem ou "denoising", o que permite um controle visual destas alterações após a filtragem. Esta tela também permite definir o tamanho do sinal que será utilizado pelas etapas de analise pelo Zero Crossing da Transformada de Wavelet.

\subsubsection{Tela 7: Zero Crossing da Transformada de Wavelet (análise por nível)}

A etapa a seguir, apresentada na tela da figura 6.24, permite que se realize uma análise "manual" do Zero Crossing da Transformada de Wavelet, podendo se escolher o nível de decomposição desejado, o tipo de wavelet, o valor de limiar desejado, pois a partir deste valor tem-se o início da contagem do número de Zero Crossing. Além disso, permite a opção de se analisar o sinal de detalhe.

\subsubsection{Tela 8: Zero Crossing da Transformada de Wavelet (10 níveis)}

A tela da figura 6.25 mostra o cálculo do IWZC para 10 níveis de decomposição do Zero Crossing da Transformada de Wavelet do sinal de forma automática, e a sua variação com o limiar. Podem-se observar alguns botões que permitem calcular outras variáveis, mas de interesse secundário para o objetivo da tela em questão. 


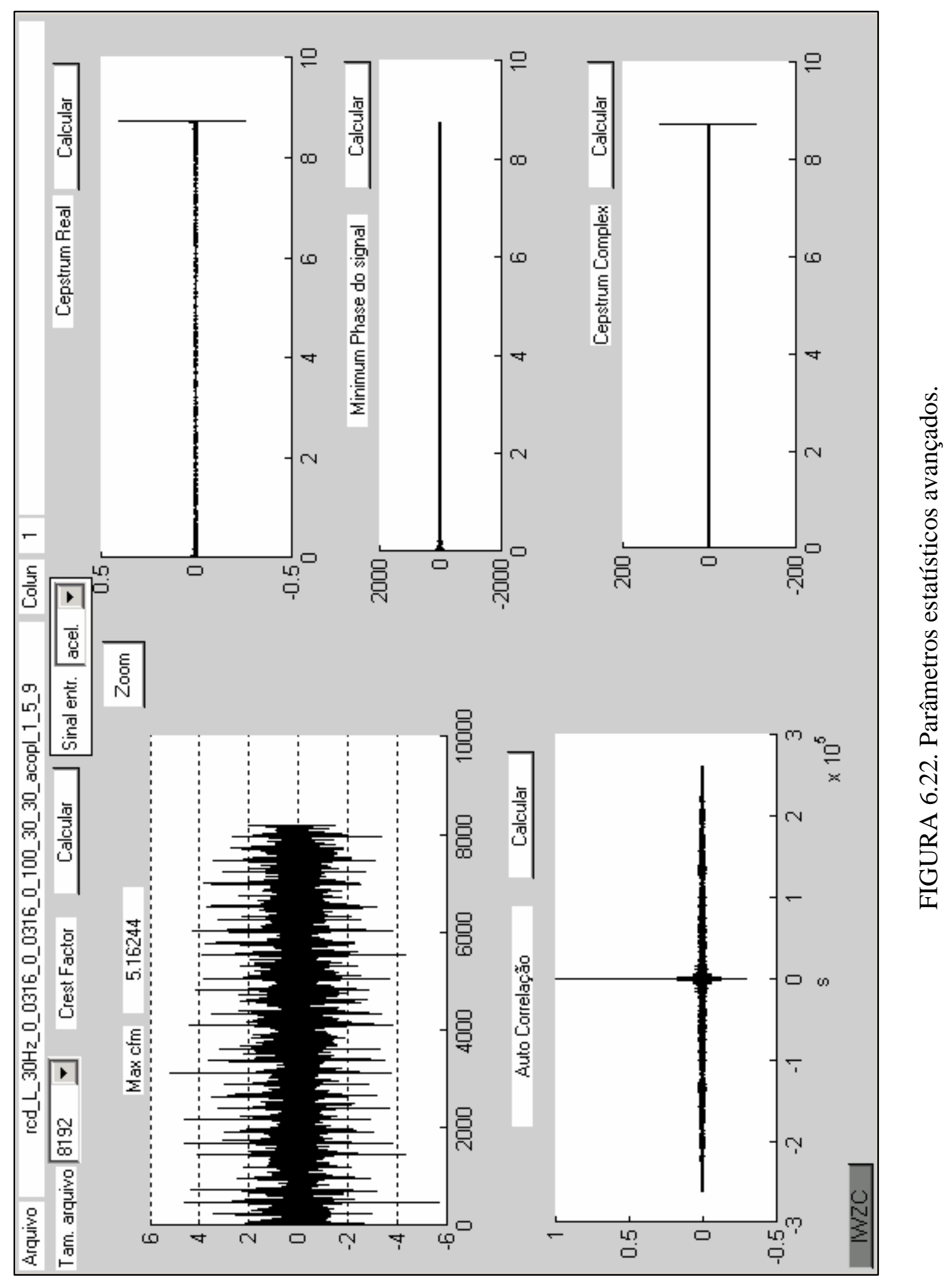




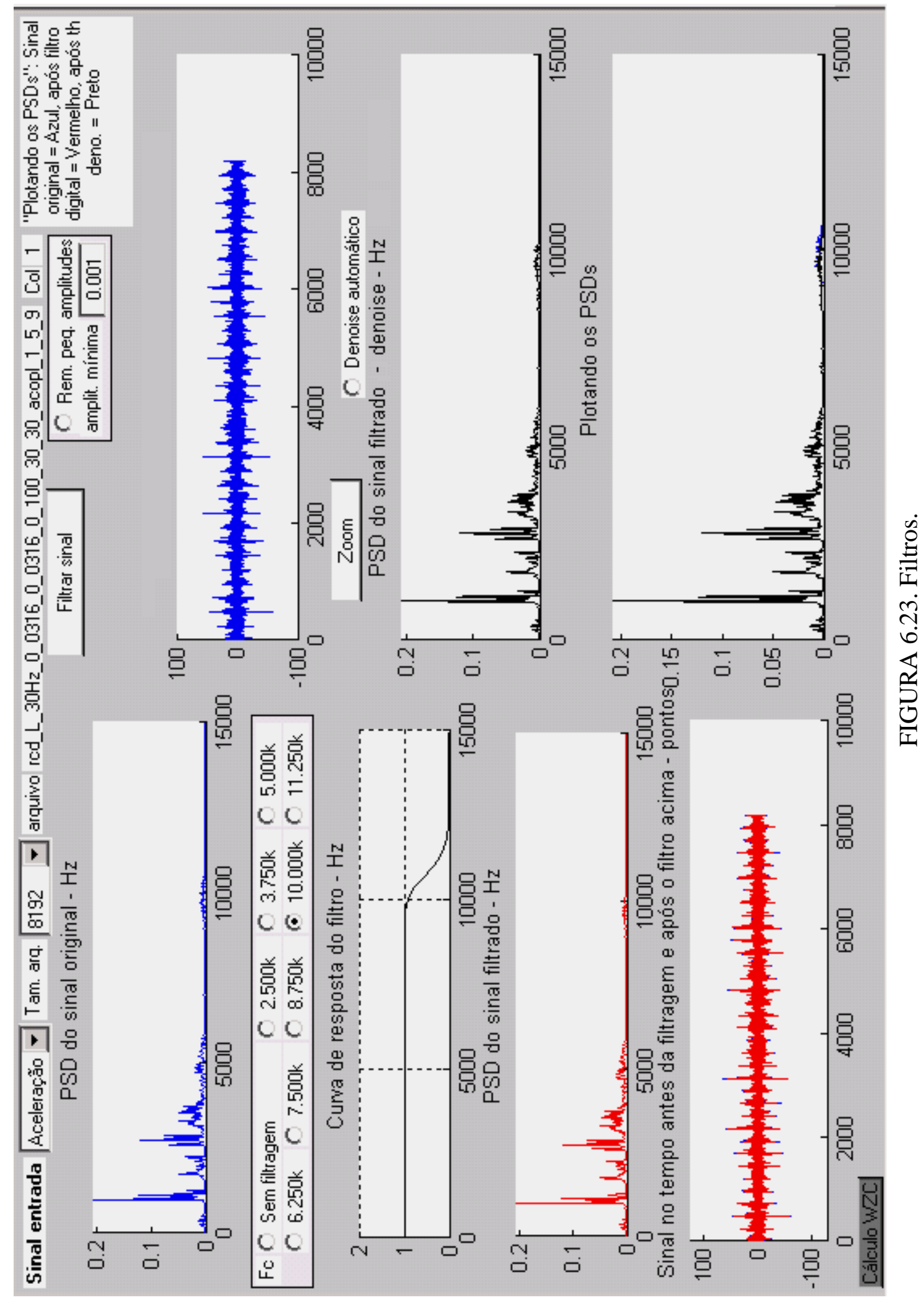




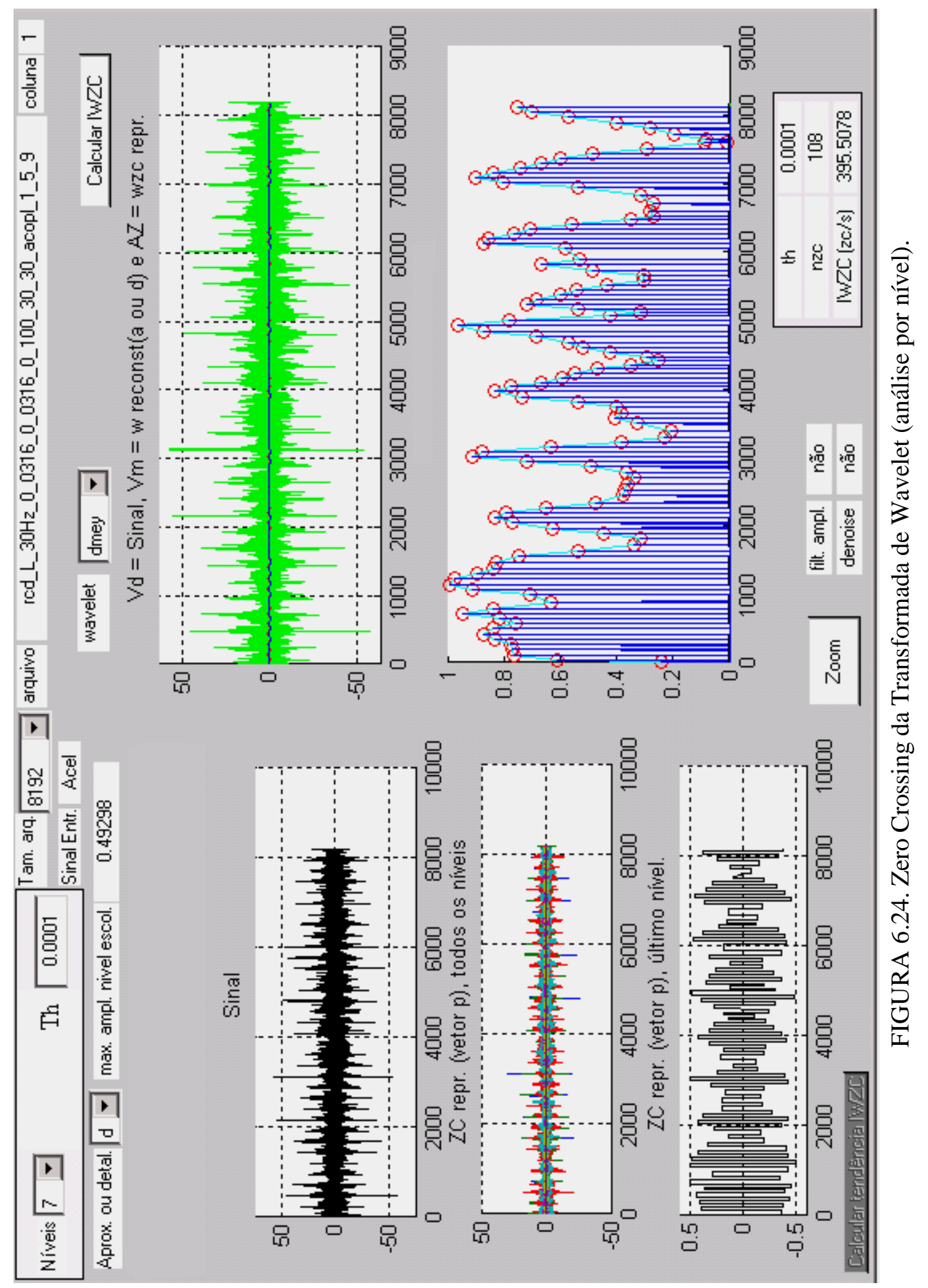




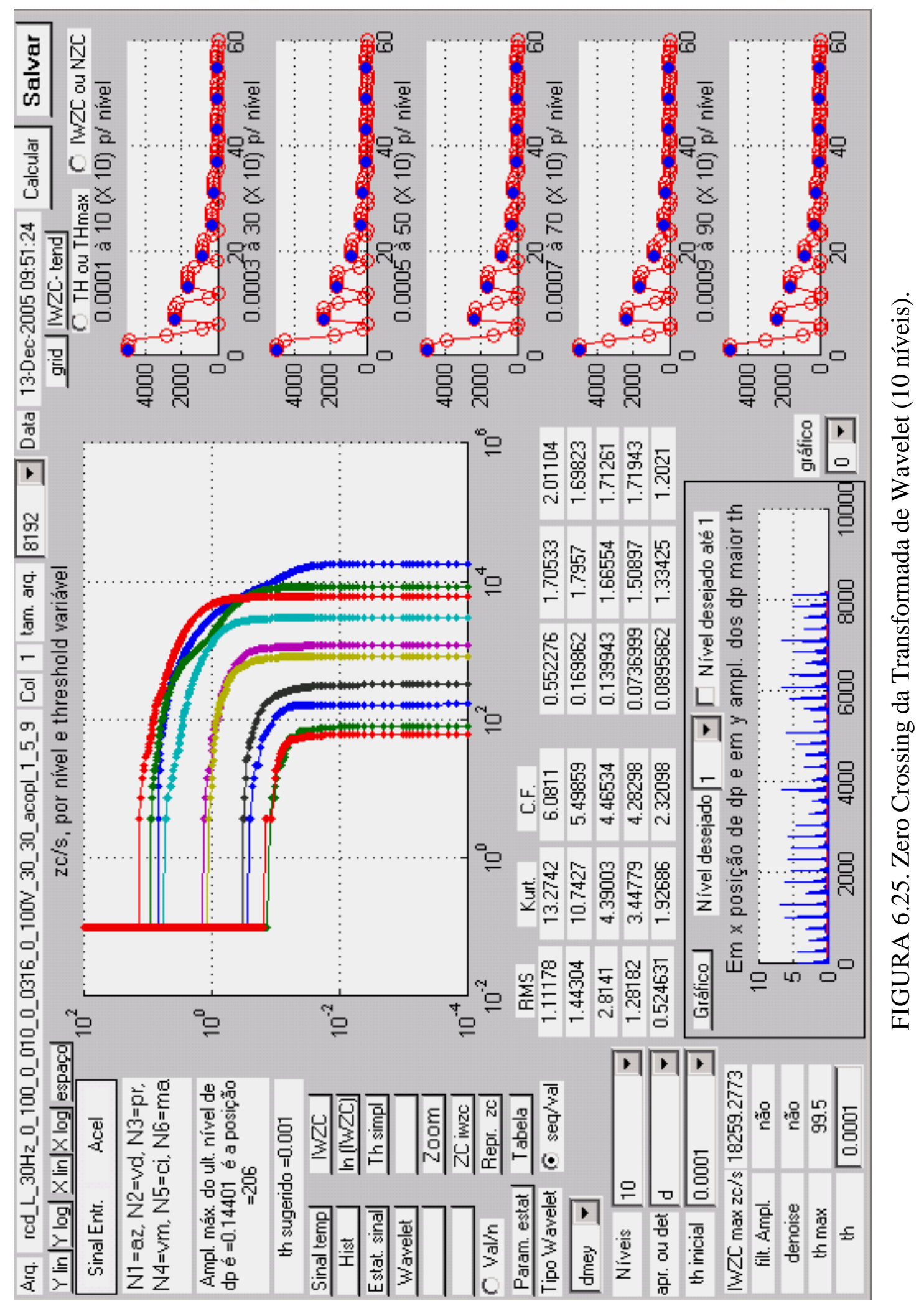




\subsection{Descrição das telas do subprograma de diagnósticos}

Serão descritas abaixo as telas que compõem as rotinas que realizam o diagnóstico de defeito a partir das características obtidas no programa anterior.

\subsubsection{Tela 9: Comparação entre os sinais sem defeito e com defeito}

A tela 9 da figura 6.26 permite comparar um sinal sem defeito e um sinal com defeito [53]. Para fins comparativos, nesta tela é possível se observar os vários níveis do zero crossing da transformada de wavelet em uma mesma escala de amplitude, de forma normalizada. Pode-se notar que os gráficos apresentados à direita da tela possuem uma amplitude do sinal bem maior com a ocorrência de vários pulsos, indicando defeitos no rolamento analisado. Esta indicação de defeito pode ser observada nos 7 níveis, o que não se observa nos sinais do rolamento sem defeito apresentado no lado esquerdo.

Assim, através de uma análise visual pode-se observar preliminarmente o que ocorre com o rolamento quando surge um defeito, neste caso um defeito na pista externa, indicando antes das análises mais detalhadas que serão executadas nas telas seguintes se os números de níveis de decomposição estão adequados e quais os níveis de maior interesse.

\subsubsection{Tela 10: Curvas de IWZC em função do limiar}

A tela 10 , mostrada na figura 6.27 , pode ser utilizada para avaliar o comportamento do coeficiente de decaimento de IWZC em função de limiar de amplitude de duas maneiras:

1 - visualizar o comportamento de IWZC em função do liminar para um dado nível fixo (por exemplo, nível 6), podendo ser carregados até 5 sinais de diferentes arquivos para comparações entre eles.

2 - avaliar o comportamento de IWZC em função do limiar para vários níveis, desde 1 até 10 simultaneamente, para até 5 sinais. 


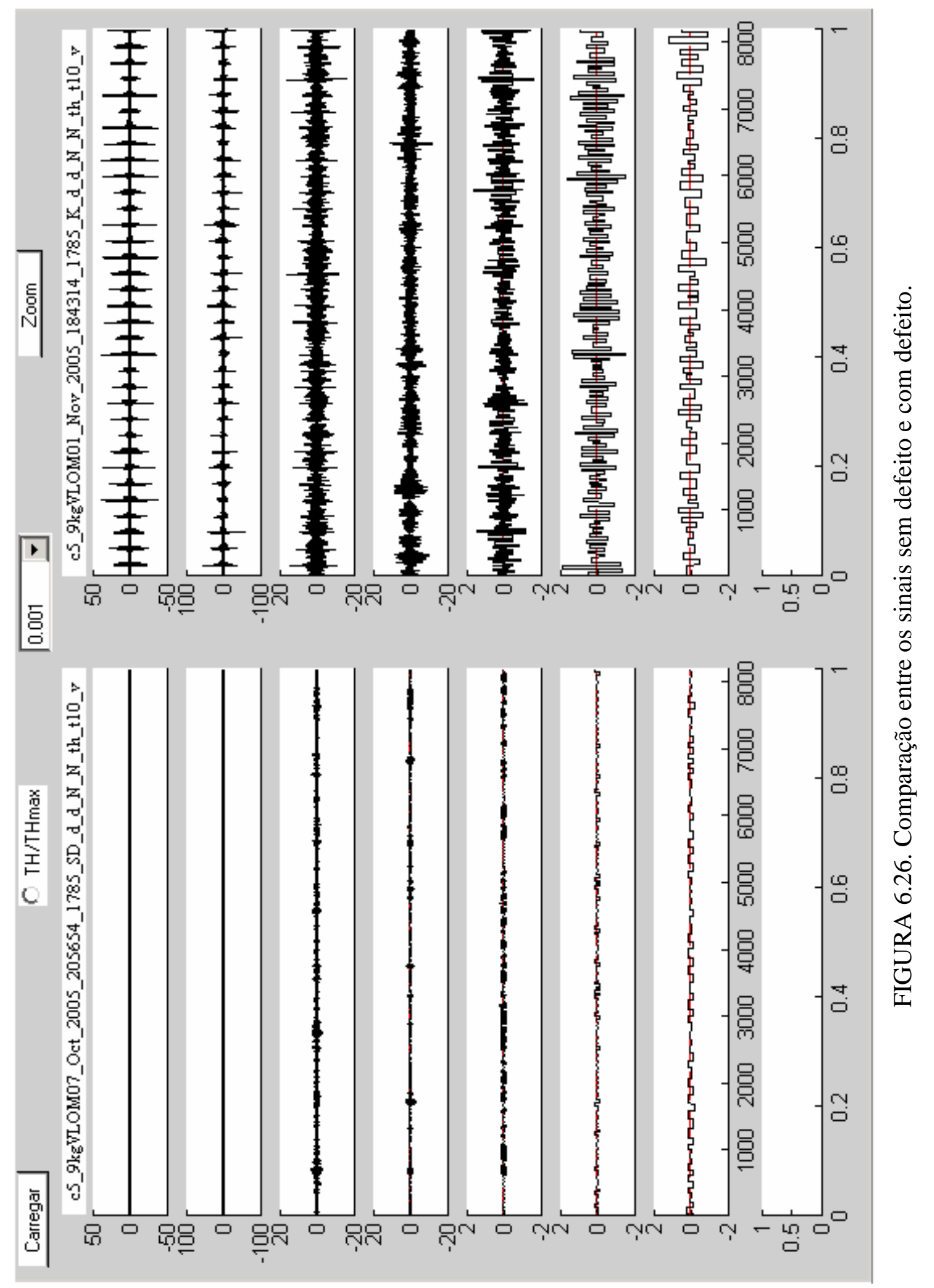




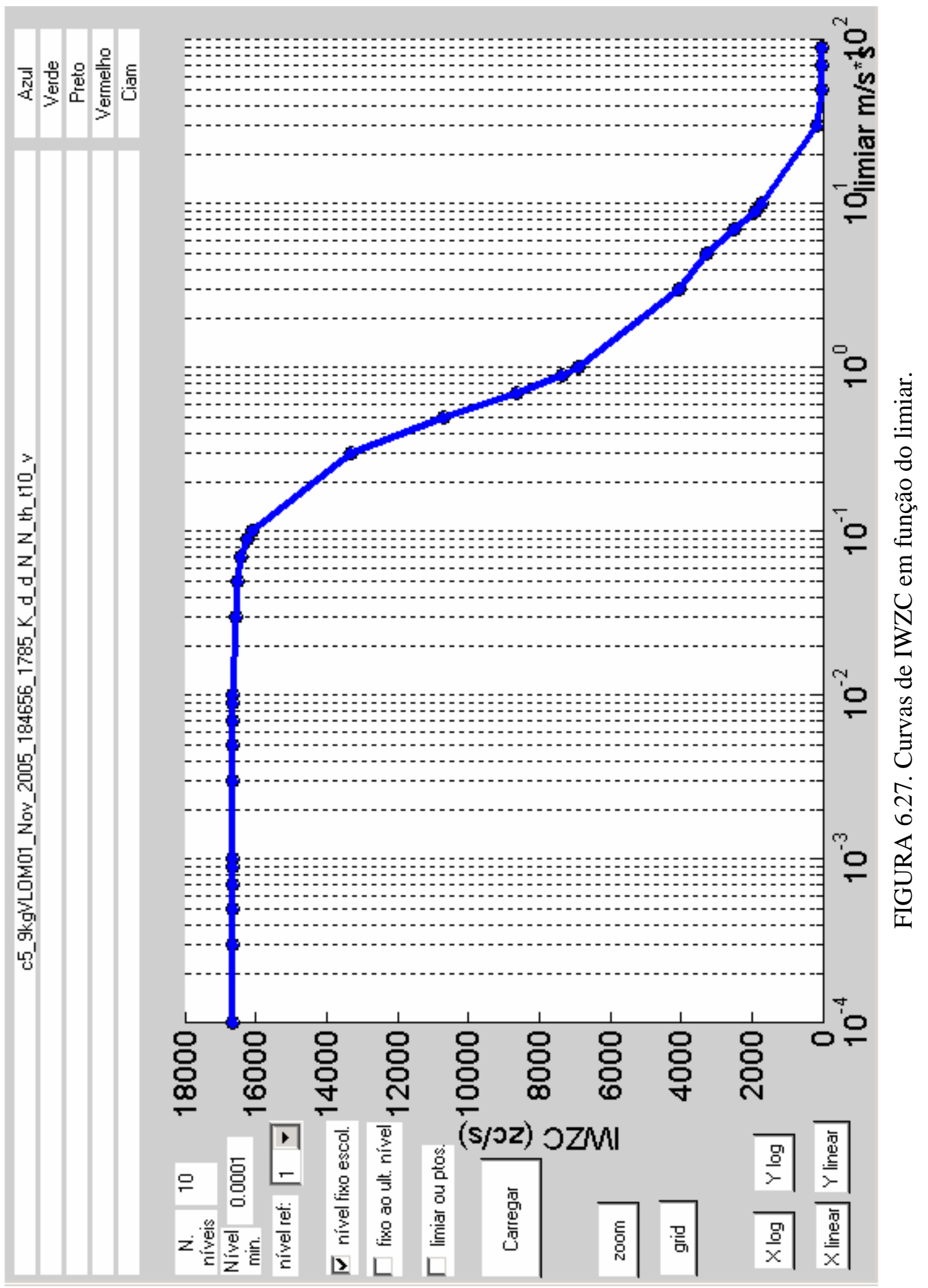




\subsubsection{Tela 11: Comparação de parâmetros estatísticos}

A tela 11 da figura 6.28 possibilita uma comparação entre os parâmetros estatísticos de um sinal decomposto pelo zero crossing da transformada de wavelet de um rolamento sem defeito e de um com defeito, para cada nível [53].

À esquerda da tela são apresentadas as propriedades estatísticas de um sinal decomposto de um rolamento sem defeito e a da direita correspondentemente a um sinal de um rolamento com defeito, decomposto em até 10 .

Para uma comparação das condições de operação dos rolamentos é realizada entre os dois lados da tabela, uma divisão do valor RMS de um rolamento sem defeito com um rolamento de condições desconhecidas, para cada um dos seus 10 níveis.

Os valores de RMS1 / RMS2 próximos a 1 mostram que os valores RMS dos dois arquivos são iguais, se forem iguais para os 10 níveis pode-se dizer são de um rolamento sem defeito. 


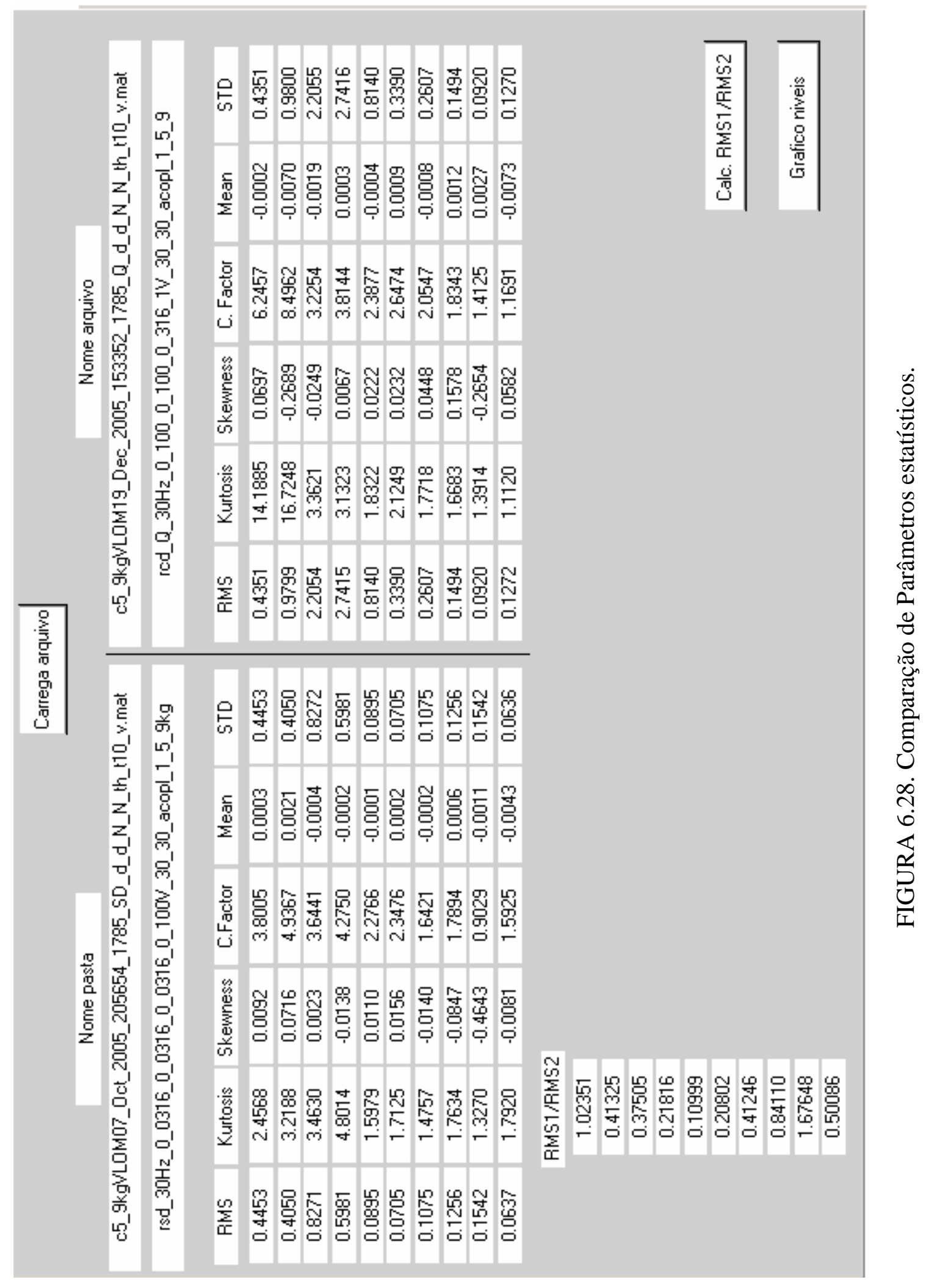




\subsubsection{Critérios utilizados}

Na tela 6.33 existem valores que estão disponíveis na literatura, como por exemplo, as normas para o valor RMS, e que serviram como critérios para diagnóstico dos rolamentos.

Os critérios para transformar os valores obtidos das técnicas de extração de características, em valores num intervalo de 0 a 1 , foram obtidos das funções de pertinências. Estes valores serão aplicados a combinações lógicas do tipo "e" "ou" e serão entregues a lógica nebulosa paraconsistente.

Para as funções novas, tais como o Thmax, o critério foi baseado na análise dos dados disponíveis, analisando as informações relativas à condição, sem defeito e com defeito, definiram-se valores que foram adotados como critério para verificar a existência ou não de defeitos.

Para técnica do Envelope, utilizou-se o critério de se verificar se alguma das sete primeiras raias de defeitos ultrapassava os valores daqueles que foram estabelecidos para as raias dos rolamentos sem defeitos. Caso alguma das raias de defeitos ultrapasse este limite estabelecido para um rolamento sem defeito, tem-se uma indicação de defeito.

O mesmo critério foi estabelecido para a DEP, porém o número de raias ficou limitado em 5, em função das frequiências de ressonância de nossa maquina de ensaios.

Para um rolamento sem defeito o valor da curtose que foi adotado como limiar foi o valor 6 a partir do qual se teria um rolamento com defeito. Porém na pesquisa bibliográfica realizada [60], informou-se que a curtose como um indicativo de defeito, pode iniciar com um valor de 4 e pode atingir valores de até 45. Desta forma, o valor 6 já seria uma indicação de defeito. Para identificar as possíveis causas desta discrepância, podem ocorrer as seguintes possibilidades.

O cálculo da curtose para os rolamentos sem defeitos do banco de dados utilizado foi calculado em toda a banda do sinal ( 1 até $15 \mathrm{kHz}$ ) e não em uma determinada banda, por exemplo, na faixa de $10 \mathrm{~Hz}$ a $1 \mathrm{KHz}$, como a que é recomendada pela norma para o cálculo dos valores do RMS.

Como um dos focos deste trabalho é a detecção de defeitos em sua fase inicial, procurou-se reduzir os ruídos eletrônicos e as interferências eletromagnéticas. Isto pode ter causado diferença entre os valores da curtose antes e depois da redução dos ruídos da bancada de ensaios, pois não se conseguiu reduzir as amplitudes das freqüências de 
passagem do eixo. Desta forma ao se calcular a curtose, os valores anteriores à redução de ruído estavam entre 3.9 e 4.1 e após a redução de ruídos ficaram entre 5.5 e 6.

Comparando-se a figura 6.29 com a figura 6.31, pode-se observar a influência do ruído nos sinais de aceleração de um rolamento sem defeito. As figuras 6.30 e 6.32 mostram detalhes das figuras 6.29 e 6.31 para melhor visualização.

Desta forma analisando os sinais antes e depois da redução do ruído, pode-se observar nas figuras mostradas, que a amplitude das frequiências de passagem do eixo permaneceram as mesmas, porém o ruído diminuiu. Isto evidenciou estes picos que se tornaram mais "visíveis" e foram devidamente captados pela curtose.

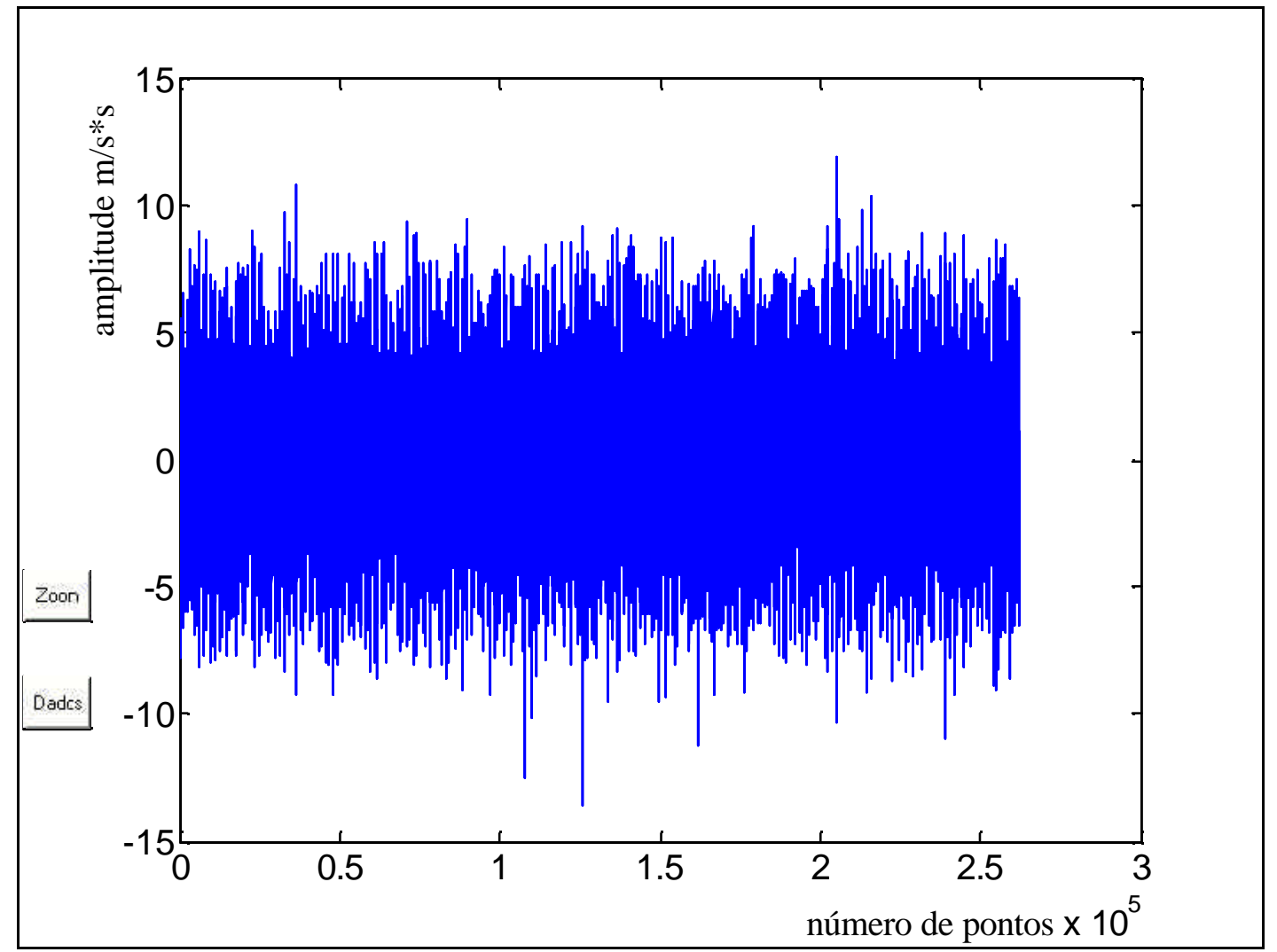

FIGURA 6.29. Sinal de aceleração, antes da redução de ruídos 


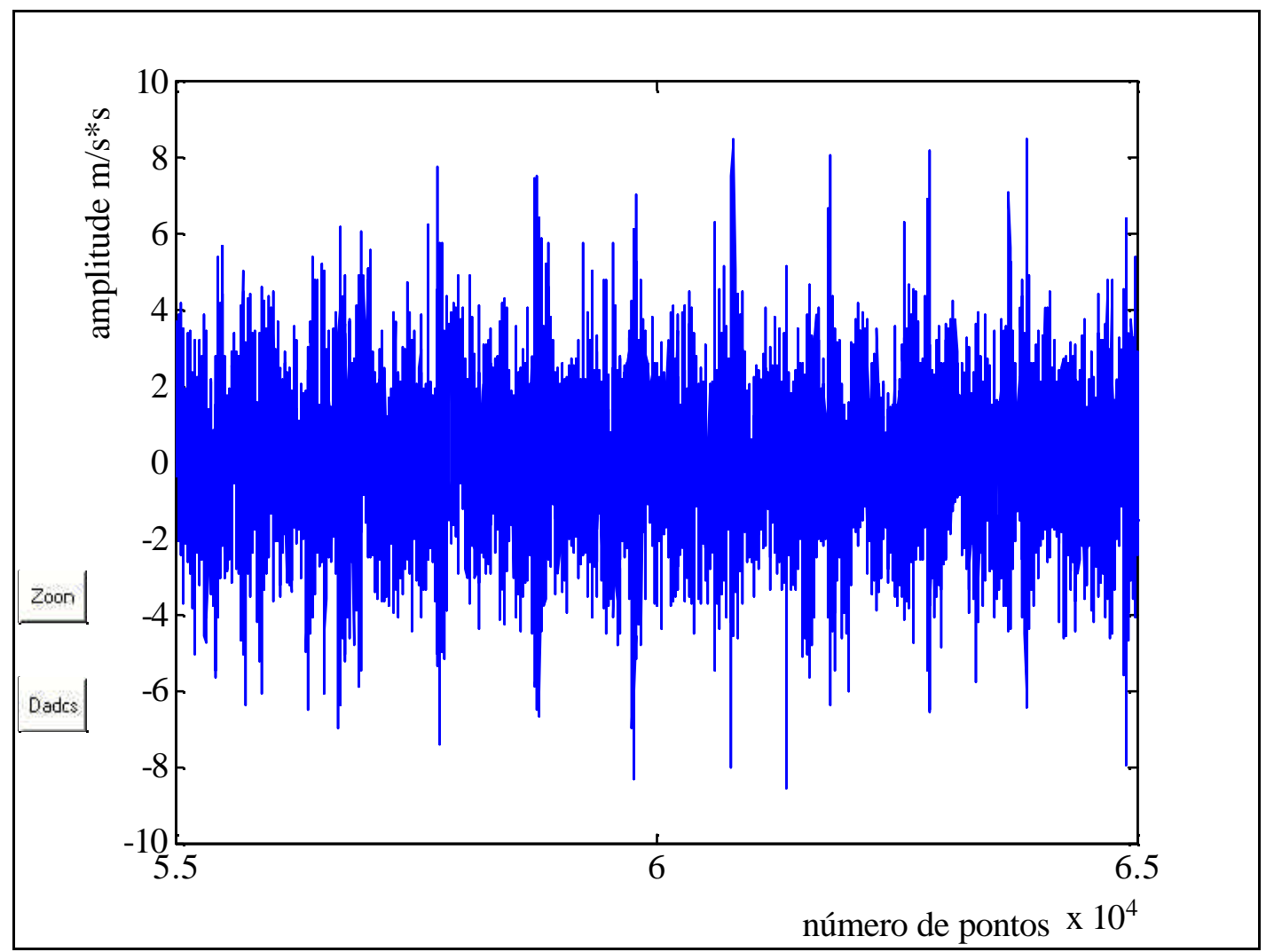

FIGURA 6.30. Detalhe do sinal de aceleração, antes da redução de ruídos

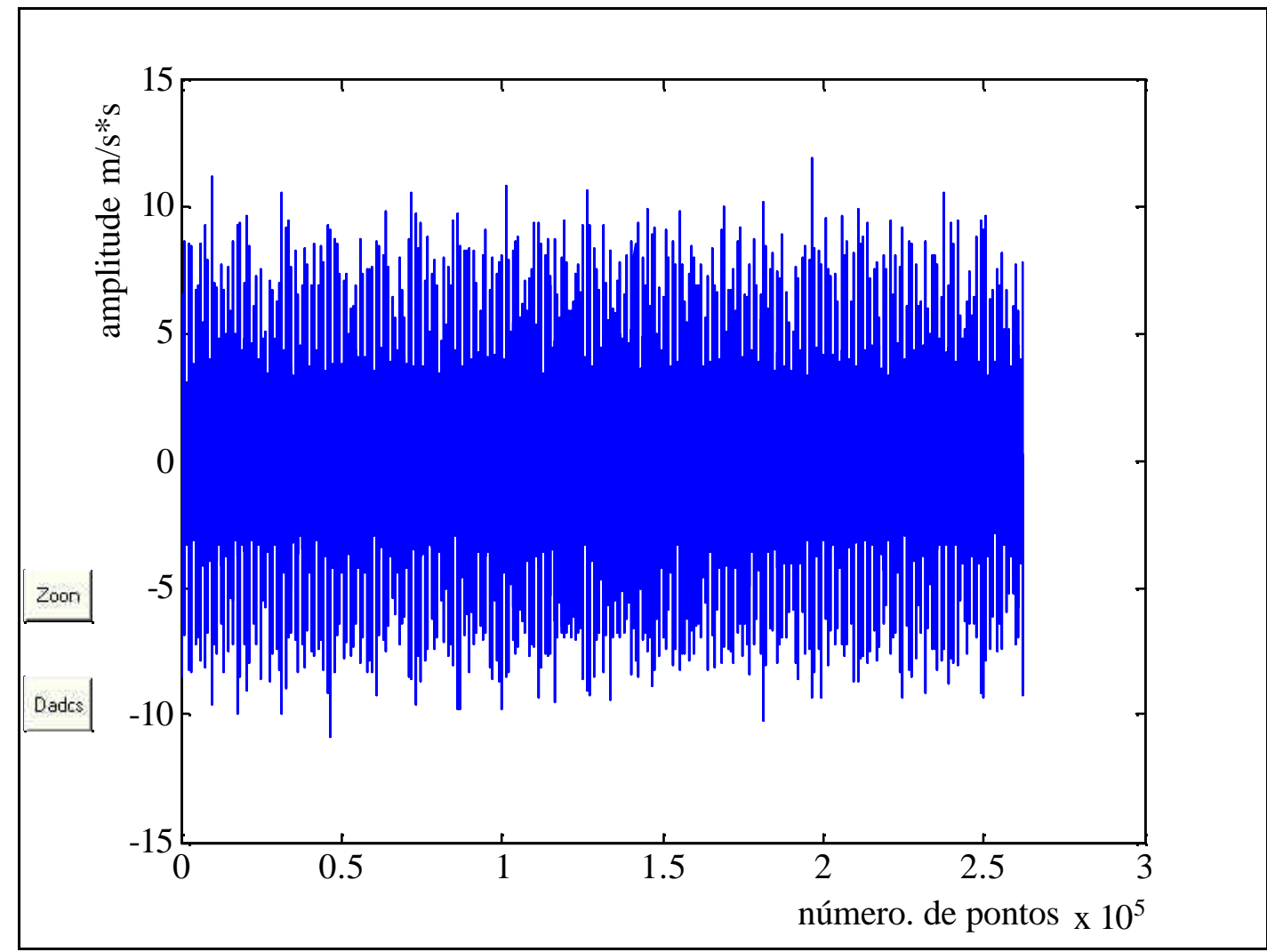

FIGURA 6.31. Sinal de aceleração, após a redução de ruídos 


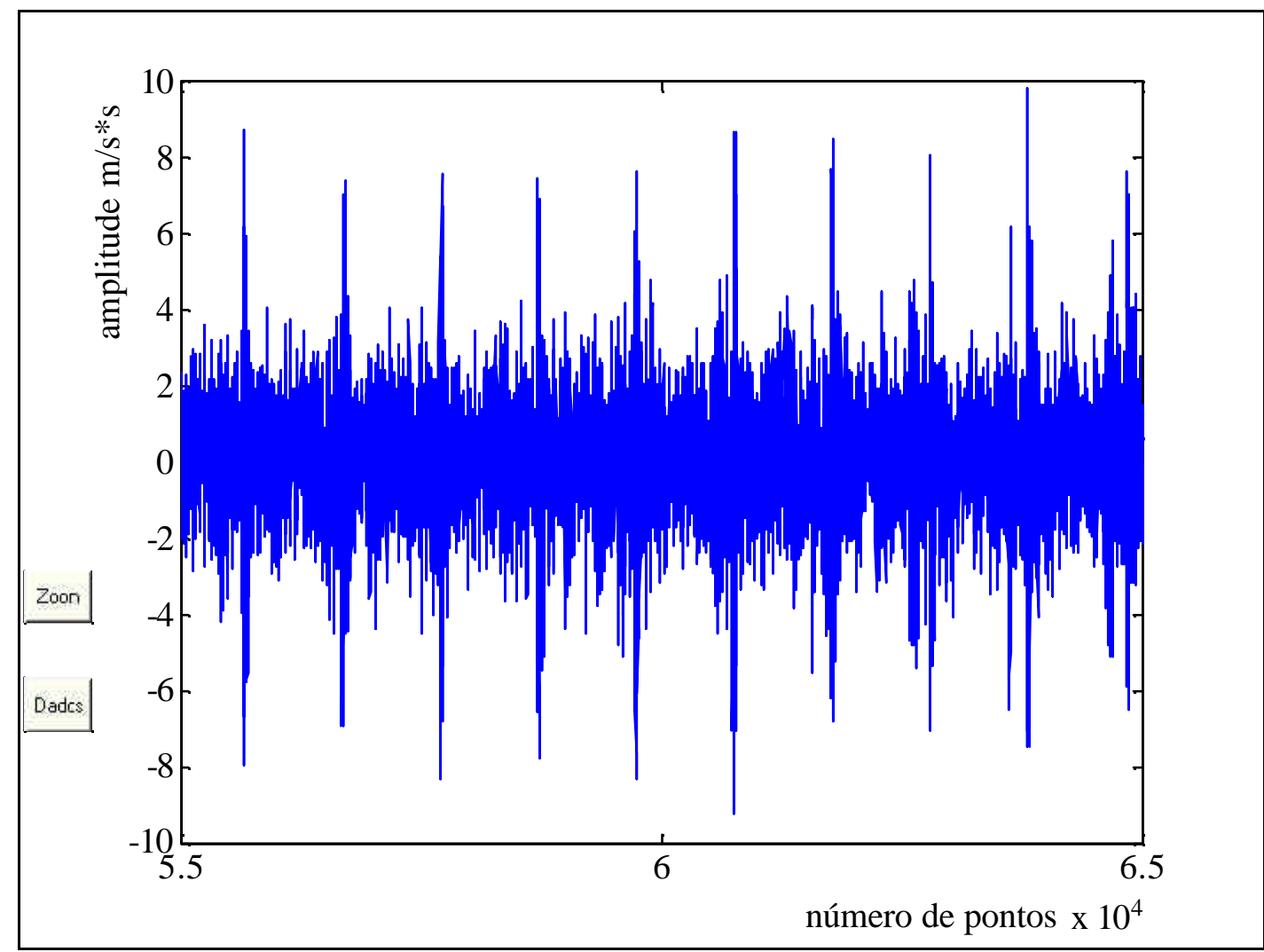

FIGURA 6.32. Detalhe do sinal de aceleração, após da redução de ruídos

\subsubsection{Tela dos resultados de extração de características}

A primeira tela de diagnóstico apresenta os valores individualmente obtidos pelas várias técnicas de extração de características, o critério utilizado, a função de pertinência e os valores do grau de evidência favorável e o grau de evidência contrária (gef e gec), para cada uma das técnicas utilizadas.

Os arquivos utilizados nas análises também são listados permitindo que seja impressos em papel caso desejado.

A tabela 6.5 apresenta uma lista dos nomes das variáveis de entrada obtida das técnicas de extração de características com os seus respectivos critérios, onde o critério 1 apresenta os valores correspondentes à condição "totalmente" sem defeito e o critério 2 os valores correspondentes à condição "totalmente" com defeito.

Os critérios foram estabelecidos através do banco de dados utilizado, com exceção do valor RMS que é normalizado.

Para se obter os valores do critério 1, para as variáveis, Kurt, DEP E, ENV E, Thmax 6, etc, tomou-se por base, os valores máximos obtidos de um rolamento sem defeito. Para se obter os valores do critério 2, foram utilizados os valores médios obtidos 
por estas variáveis para os rolamentos com defeito. Estes valores foram extraídos dos sinais pertencentes ao banco de dados utilizado.

A figura 6.33 possui uma coluna denominada "peso", que para os valores RMS e Curt podem assumir valores de 0,9 e 0,95. Esses pesos foram utilizados, pois essas se mostraram sensíveis aos parâmetros desbalanceamento e desalinhamento. Desta forma, esses pesos procuram reduzir a influência destes dois parâmetros nessas variáveis.

TABELA 6.5. Lista das variáveis de entrada com seus critérios

\begin{tabular}{|c|c|c||}
\hline \hline Nome da variável & Critério 1 & Critério 2 \\
\hline \hline RMS & 0,00071 & 0,0018 \\
\hline \hline Curt & 3 & 9 \\
\hline \hline DEP E & 0,001 & 0,062 \\
\hline \hline DEP I & 0,0001 & 0,009 \\
\hline \hline ENV E & 0,0014 & 0,0285 \\
\hline \hline ENV I & 0,0012 & 0,076 \\
\hline \hline TAL IWZC 1 & 0,636 & 3,57 \\
\hline \hline Thmax 6 & 0,05 & 1,86 \\
\hline \hline RMS 5, 6, 7 & $0,0480,0660,062$ & 0,98 \\
\hline \hline Thmax 7 & 0,04 & 0,018 \\
\hline \hline Thc 8 & 0,0004 & 0,008 \\
\hline \hline Thc 9 & 0,0015 & 0,004 \\
\hline \hline Thc 10 & 0,0015 & - \\
\hline \hline
\end{tabular}




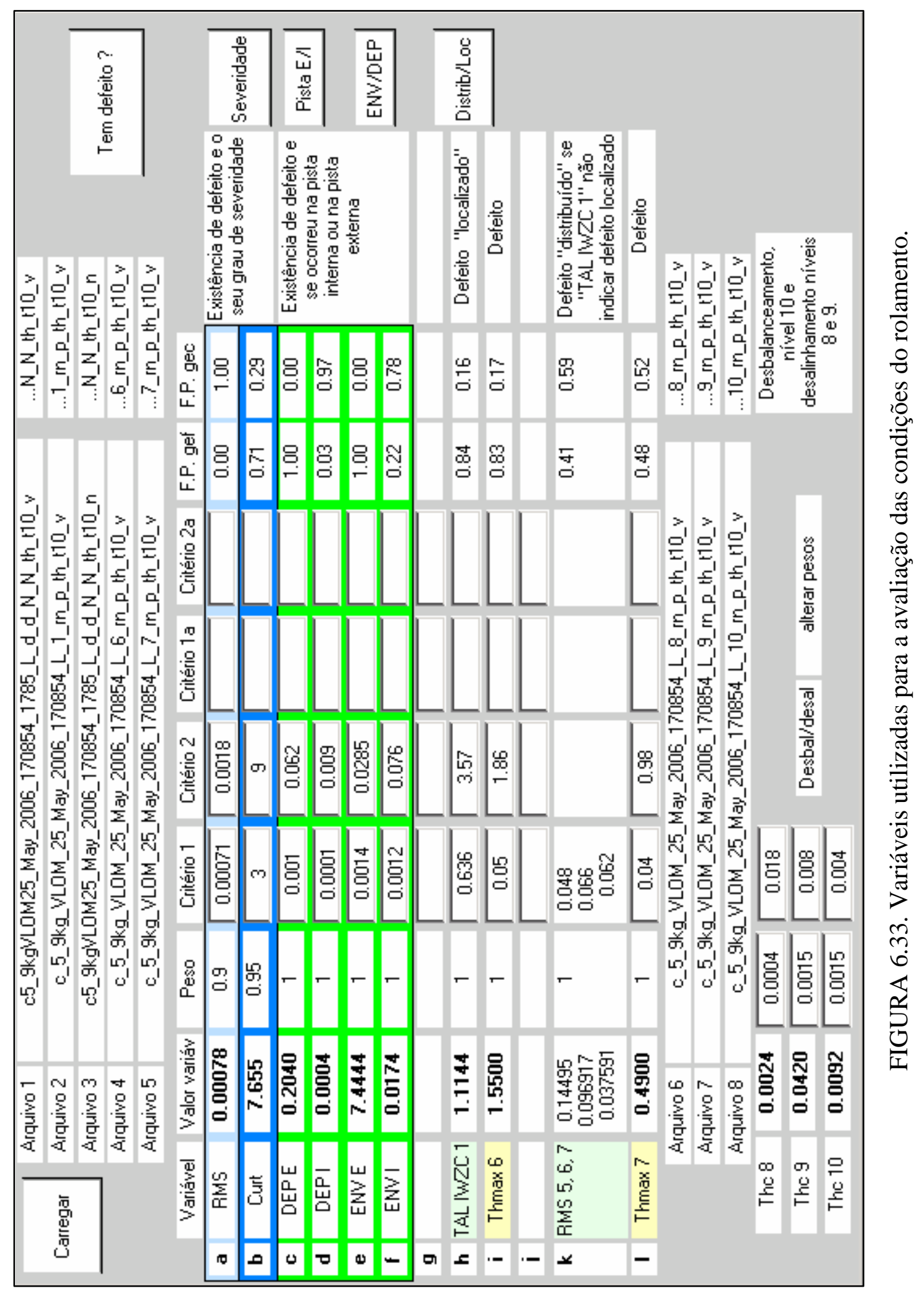




\subsubsection{Tela para configurações lógicas}

A próxima tela, figura 634 permite que se realize uma combinação através da lógica nebulosa entre as variáveis de entrada podendo escolher em cada linha, o modo desejado de análise, seja pela média dos valores das variáveis, pelo critério lógico "E", pelo critério "OU" e o estado lógico de negação. O conectivo "OU” executa a operação de máximo, o conectivo "E" executa a operação de mínimo, a média realiza a operação de média simples. Os valores de entrada são valores contínuos dentro de um intervalo de 0 a 1.

Cada linha da tela permite a escolha de um dos modos desejado de análise.

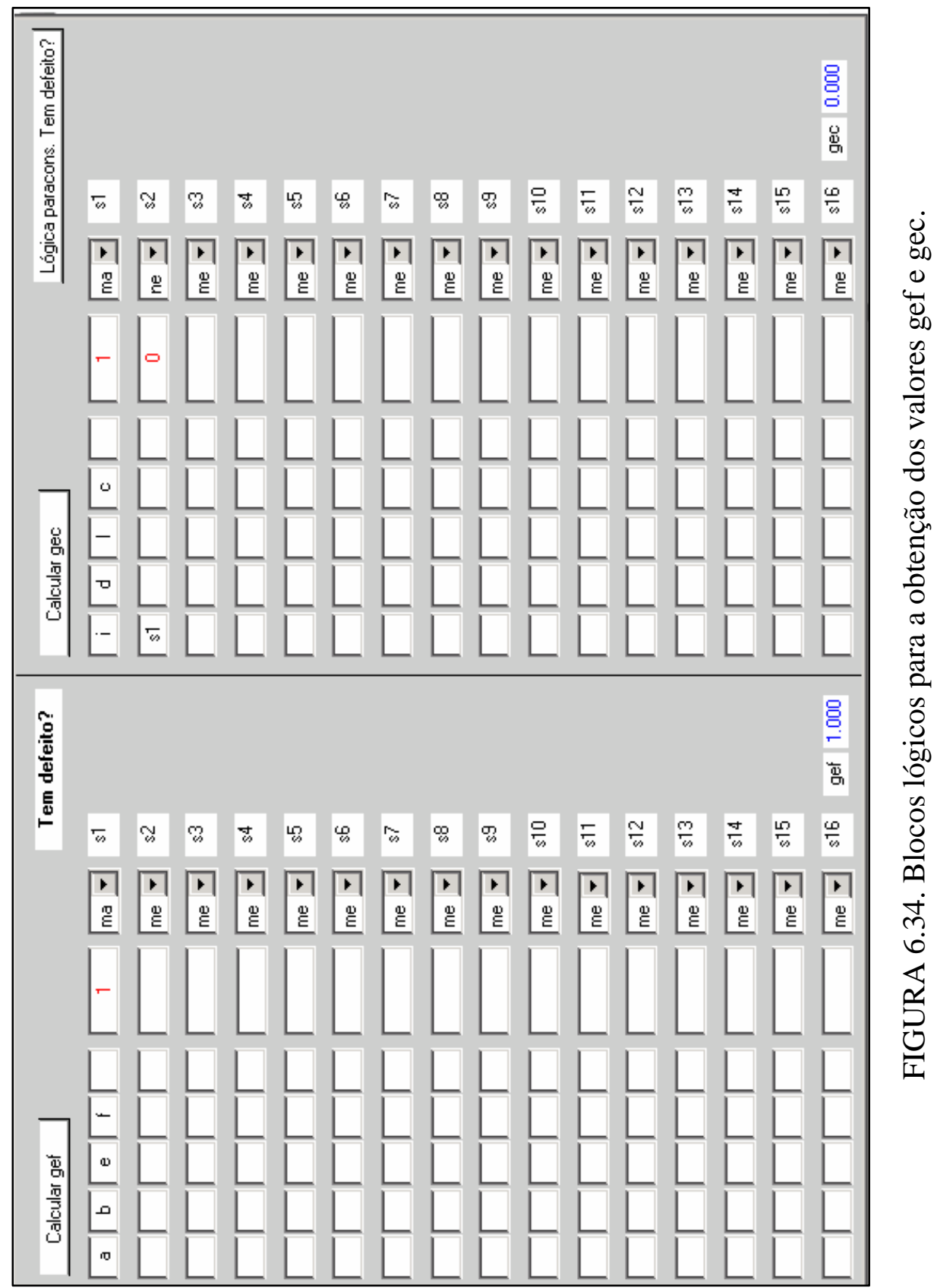


Os resultados apresentados nesta tela foram implementados utilizando-se a Lógica nebulosa paraconsistente.

\subsubsection{Diagnóstico}

Na tela, figura 6.35, é possível visualizar no quadro branco que se localiza na parte inferior da tela, o diagnóstico final, que nesse caso, para a proposição tem defeito, apresenta como resposta "Afirmativa Verdadeira (V)", que de acordo com a lógica nebulosa paraconsistente utilizada para a detecção de defeitos em rolamentos significa Verdade.

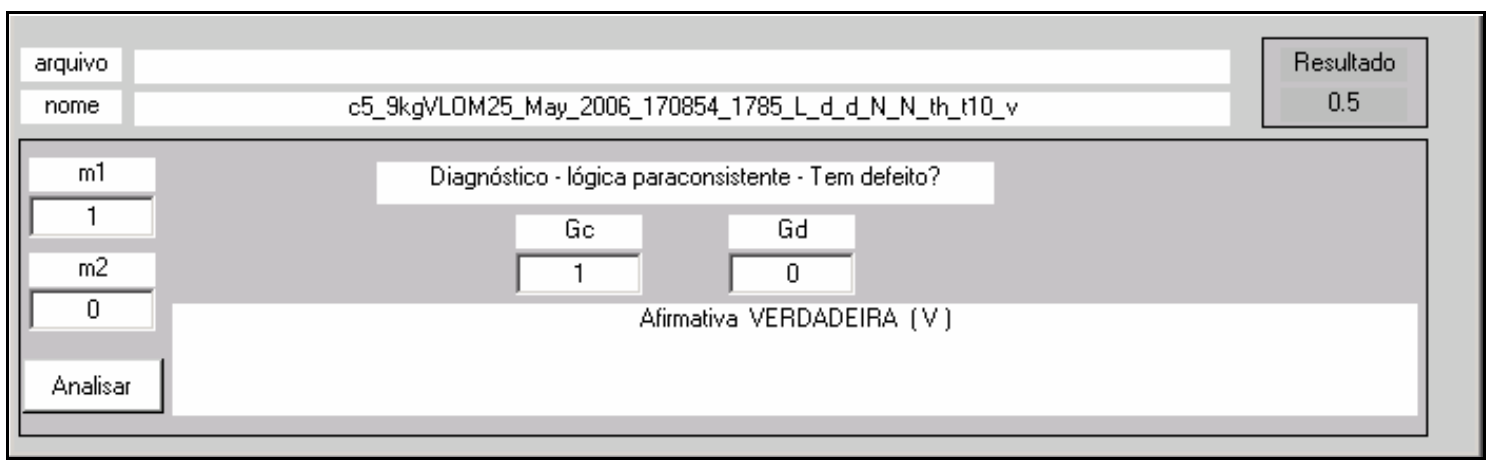

FIGURA 6.35. Diagnóstico da condição do rolamento analisado

\subsection{Visualização das extrações de características já realizadas}

Tela da figura 6.36, que reúne os principais resultados das análises realizadas pelas telas de extração de características. 


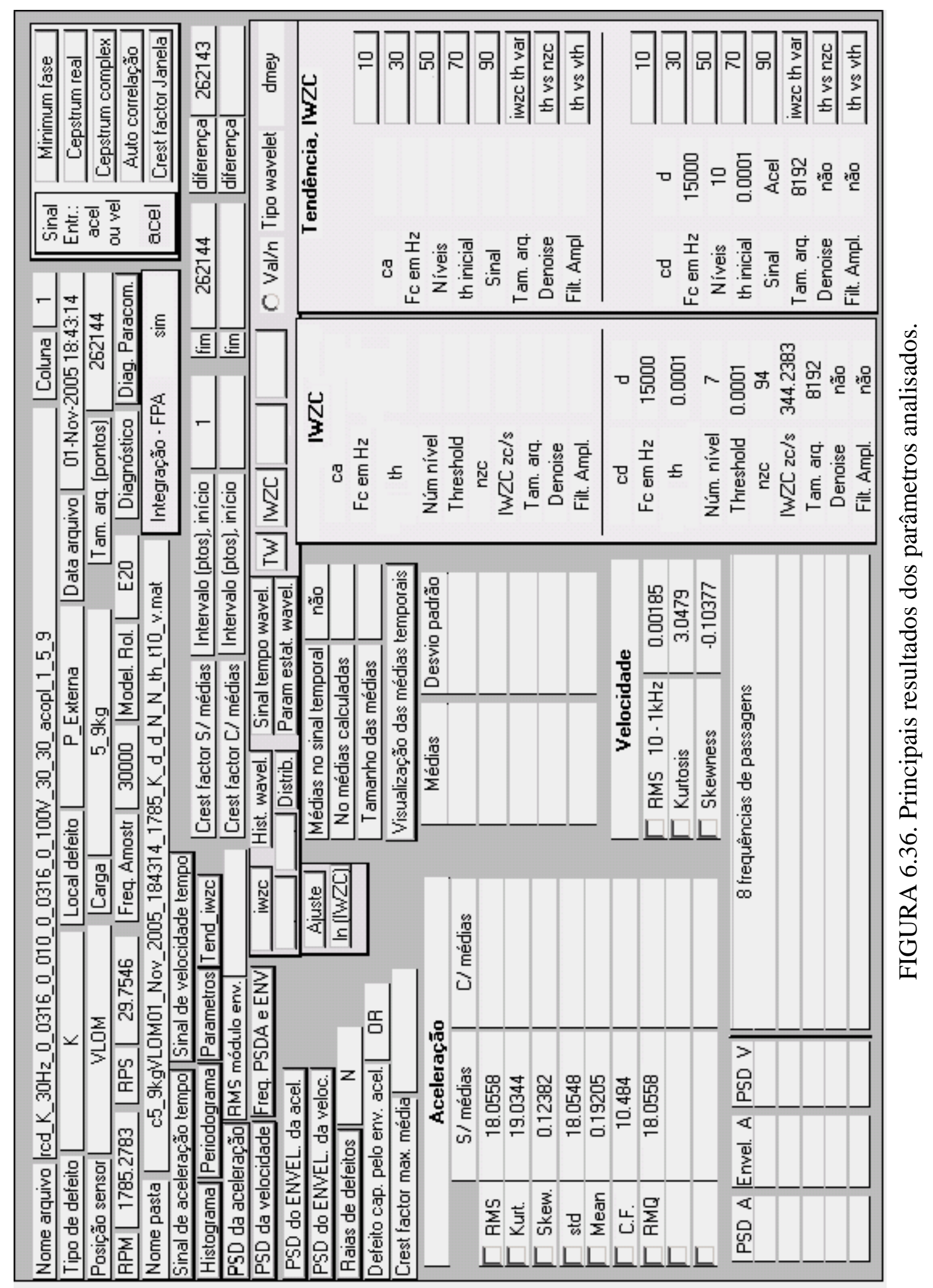




\section{BANCADA EXPERIMENTAL}

\subsection{Determinação das condições de referência de um rolamento sem defeito}

Para se estabelecer uma referência dos sinais de acelerometria (baseline), para um rolamento em condições normais nesta bancada de ensaios, fixou-se um rolamento sem defeito no mancal da máquina onde seriam fixados posteriormente os rolamentos com defeitos e fizeram-se várias medidas de aceleração, onde se procurava verificar a repetibilidade dos resultados obtidos. Para tanto, montourse e desmontourse o rolamento do mancal várias vezes e em cada montagem e desmontagem realizoutse pelo menos 3 medidas. Através do estudo destas medidas verificou-se que a repetibilidade ocorria, porém não dentro de um determinado valor, mas dentro de um intervalo de valores. Desta forma, foi possível se determinar um intervalo de valores de acelerações para os rolamentos do tipo desmontáveis de esferas que não possuíam defeitos. Os ensaios com rolamentos foram realizados no mancal mais distante do motor e do acoplamento, procurando minimizar possíveis influências destes elementos.

Os principais problemas ocorridos com este rolamento ao ser montado na máquina de ensaios com as alterações mencionadas foram estudados e serão apresentados a seguir.

Os rolamentos do tipo desmontável são separáveis em três conjuntos: A pista interna, a pista externa e a gaiola com as esferas. A pista interna é fixada rigidamente no eixo apresentando um bom acoplamento com o eixo da máquina não apresentando problemas de alinhamento ou balanceamento. A pista externa embora esteja fixada no mancal, pode apresentar problemas de alinhamento com relação ao conjunto eixo-mancal. A gaiola, por ser uma das partes móveis, procura se ajustar ao conjunto pista internaexterna o que pode levar a um ajuste que evidencie os problemas de desalinhamento da pista externa. Desta forma, um ajuste cuidadoso da pista externa deve ser realizado, para evitar as dificuldades citadas.

Um dos itens mais importantes em máquinas é o alinhamento do conjunto mancaleixo-motor. Desta forma, para a obtenção de um banco de dados, deve-se assegurar que o conjunto esteja alinhado. Através da densidade espectral de potência é possível se verificar o desalinhamento do eixo através da análise do espectro obtido. Um outro item de grande importância é o balanceamento do eixo. Este também pode ser verificado através do 
espectro da densidade espectral de potência. Para a obtenção do baseline estes rolamentos foram lubrificados com graxa recomendada pelos fabricantes e da forma como estes recomendam.

Para se obter a referência dos sinais (baseline) para um rolamento desmontável fixado na máquina de ensaios, os cuidados que foram citados permitiram que se estabelecesse uma linha de base precisa o que permitiu a análise das condições de defeitos incipientes, pois uma das informações principais na detecção dos defeitos é sabermos onde se encontra a linha de base.

\subsection{Procedimento de montagem dos rolamentos na máquina de ensaios}

1- Lubrificar com graxa o rolamento que será montado no mancal;

2- Montar a pista interna no suporte desenvolvido para ser acoplado ao eixo;

3- Montar a gaiola com as esferana pista interna;

4- Montar a pista externa do rolamento (nesse instante o rolamento está "montado");

5- Montar o rolamento no mancal;

6- Ajustar o conjunto eixo, mancal, rolamento para que as esferas encostem-se à borda lateral da pista externa do rolamento;

7- Apertar os mancais;

8- Verificar a fixação do acoplamento flexível;

9- Verificar a fixação dos sensores;

10- Verificar o balanceamento do eixo;

11- Verificar o alinhamento do eixo e do rolamento no eixo;

12- Medir a rotação com o tacômetro digital;

13- Verificar o ga nho dos amplificadores, confirmando que não existe saturação;

14- Iniciar as aquisições de dados.

\subsection{Técnicas de alinhamento}

Para a verificação e alinhamento dos eixos foram utilizadas duas técnicas. Uma utilizando relógio comparador e relógio apalpador e a segunda utilizando a DEP para verificação do alinhamento do eixo da máquina. 


\subsubsection{Alinhamento utilizando relógio apalpador e comparador}

Para o alinhamento do eixo da maquina de ensaio [62, 63], foram usinados dois dispositivos. Um permitia que se fixassem o relógio comparador ou apalpador ao eixo do motor e o outro era um disco que se fixava ao eixo onde se encontravam os rolamentos sob análises. Estes dispositivos, após serem devidamente centrados facilitavam o processo de alinhamento, bem como aumentavam a precisão das medidas efetuadas.

Utilizando-se os relógios comparador e apalpador seguiu-se o seguinte procedimento: Fixava-se o relógio em um eixo e comparava-o com o eixo seguinte anotando os valores obtidos para em cada uma das posições da figura 7.1, tomando-se o cuidado de descontar o sag do instrumento, para evitar erros nas medidas.

Precisão dos instrumentos utilizados:

Relógio Comparador 1/1000 mm

Pedestal para fixação do relógio comparador

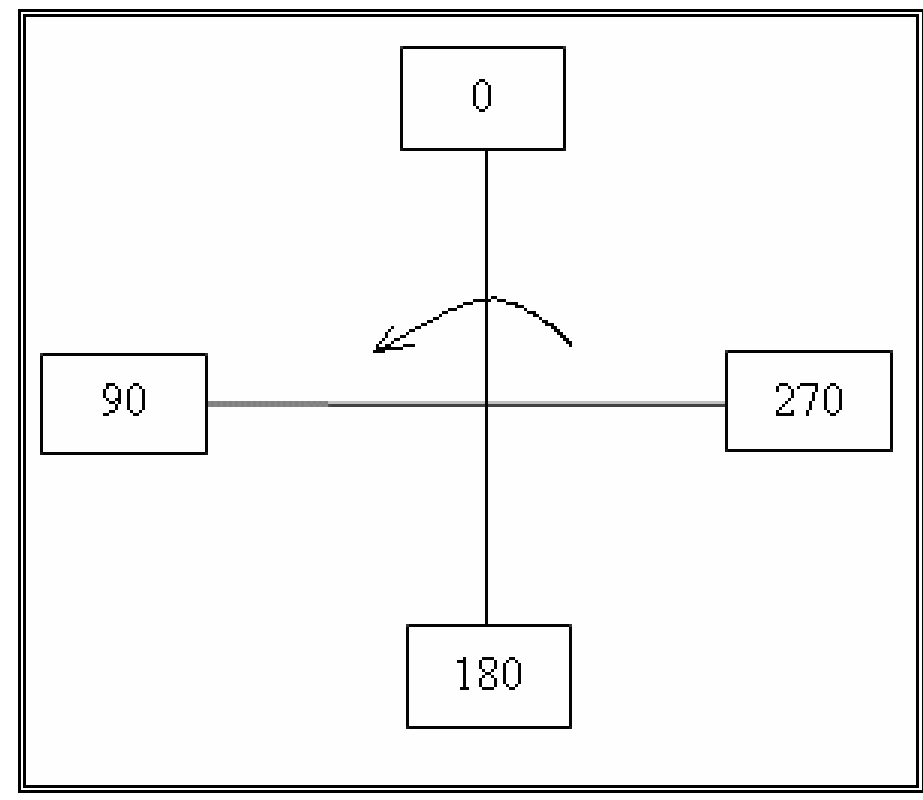

FIGURA 7.1. Ângulos utilizados nas medidas de desalinhamento do eixo

Medida do Sag:

Primeira medida

$$
\begin{aligned}
& 0=0 \mathrm{~mm} \\
& 90=160 * 0,001 \mathrm{~mm}
\end{aligned}
$$


$180=175 * 0,001 \mathrm{~mm}$

$270=30 * 0,001 \mathrm{~mm}$

Para a confirmação dos valores obtidos realizava uma segunda medida.

Segunda medida

$0=0 \mathrm{~mm}$

$90=165 * 0,001 \mathrm{~mm}$

$180=173 * 0,001 \mathrm{~mm}$

$270=30 * 0,001 \mathrm{~mm}$

O máximo valor de desalinhamento estabelecido para esta máquina é de $0,127 \mathrm{~mm}$., mas procurou-se manter o desalinhamento no abaixo de $0,1 \mathrm{~mm}$.

\subsubsection{Alinhamento utilizando-se a DEP}

Após certo tempo, utilizando a técnica anteriormente descrita foi realizado o alinhamento do eixo utilizando-se a DEP. Esta técnica mostrou-se mais adequada porque não apenas verificava o alinhamento do eixo, mas também realizava o alinhamento do conjunto pista externa, gaiola com esferas, pista interna, mancal e eixo. Esta se mostrou bastante útil para o objetivo deste trabalho, que se concentrava na identificação de defeitos em suas fases iniciais.

\subsection{Algumas características do rolamento utilizado e das condições de ensaio}

Tipo do rolamento: desmontável de esferas.

Modelo: E20

Rotação utilizada no ensaio: $1800 \mathrm{rpm}$.

Carga aplicada ao eixo: $5,9 \mathrm{~kg}$

Especificações:

número de esferas: 11

diâmetro pitch: 33,9

diâmetro das esferas: 7,938

freqüências de passagens:

pista interna: 201, 403, 605, 807, 1009, 1211, 1413, $1615 \mathrm{~Hz}$

pista externa: $125,250,375,501,626,751,877,1002 \mathrm{~Hz}$ 


\subsection{Graxa lubrificante utilizada}

Nome: Graxazul, especial para rolamentos.

Tipo: multiuso.

Fabricante: FAG.

Consistência NLGI: 2.

Base: Lítio.

Aplicação: até $120^{\circ}$.

Ponto de gota: $170^{\circ} \mathrm{C}$.

Textura: fibra média.

\subsection{Localização dos defeitos}

Neste trabalho, concentrou-se a análise de defeitos na pista externa dos rolamentos, alguns defeitos na pista interna do tipo (localizado) também foram criados e algumas avaliações foram realizadas com este tipo de defeitos, mas os estudos se concentraram nos defeitos de pista externa.

\subsection{Precisão dos instrumentos de medidas}

A precisão dos instrumentos utilizados será apresentada a seguir.

\subsubsection{Sensores utilizados}

As medidas utilizadas foram feitas com acelerômetros e amplificadores calibrados. As medidas realizadas com os dois acelerômetros que estavam sobre o mancal que continha o rolamento com defeito, foram fabricados pela Endevco, modelo 7701A-100 Anexo 1, e que possuem uma faixa de operação em frequiência de até $10 \mathrm{kHz}$ dentro de $3 \mathrm{db}$, com uma sensibilidade de 9,7 e $10 \mathrm{pC} / \mathrm{m} / \mathrm{s}^{2}$ e uma freqüência de ressonância de aproximadamente $20 \mathrm{kHz}$. Estes dois sensores estavam fixados na posição vertical e horizontal. O sensor que estava na posição axial, fabricado pela Brüel \& Kjaer, modelo 4370 Anexo 2, tem uma resposta em freqüência de $8,5 \mathrm{kHz}$ dentro de $3 \mathrm{db}$, com uma 
sensibilidade de $9,9 \mathrm{pC} / \mathrm{m} / \mathrm{s}^{2}$, e com uma freqüência de ressonância de aproximadamente $17 \mathrm{kHz}$.

No outro mancal, o que não apresentava defeito foi montado acelerômetro do tipo ICP com uma sensibilidade de $10,2 \mathrm{mV} / \mathrm{m} / \mathrm{s}^{2}$, uma faixa de frequiência de 0,5 a $10 \mathrm{kHz}$ em $\pm 3 \mathrm{~dB}$, e uma freqüência de ressonância de $25 \mathrm{kHz}$. E sobre o motor que acionava o eixo que girava os rolamentos, foi fixado um outro acelerômetro, do tipo ICP, com as mesmas características do que estava sobre o mancal do rolamento sem defeito. A figura 7.2 mostra uma foto onde se podem observar os três acelerômetros fixados ao mancal com o rolamento com defeito.

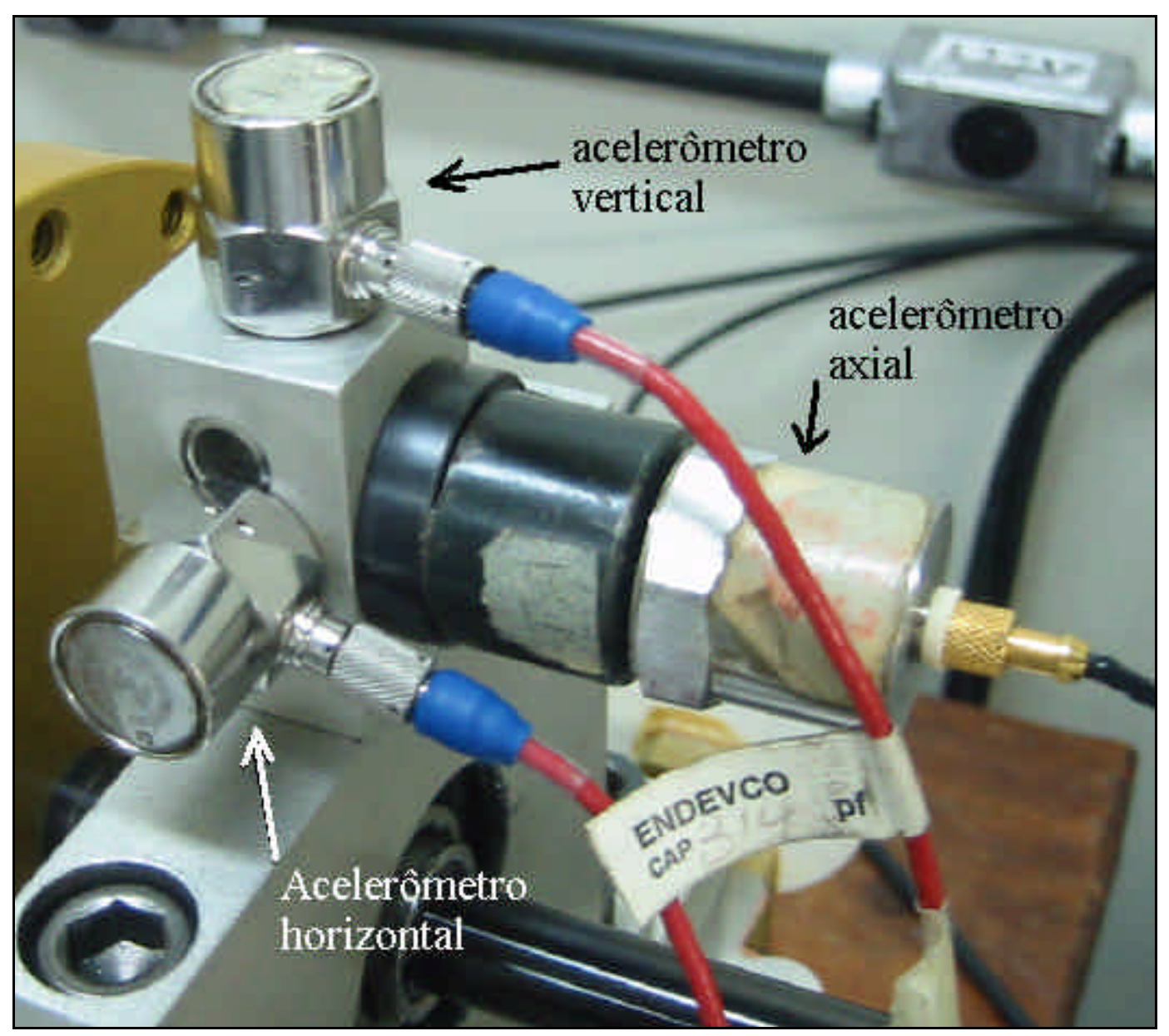

FIGURA 7.2. Detalhe mostrando os acelerômetros no mancal do rolamento sob ensaio 


\subsubsection{Amplificadores utilizados}

Os amplificadores utilizados, figura 7.3, para os sensores no mancal onde estava montado o rolamento com defeito, operam numa faixa de freqüência de $0.1 \mathrm{~Hz}$ até $100 \mathrm{kHz}$ para os sinais de aceleração, com um ruído inerente, na faixa de $2 \mathrm{~Hz}$ ate $22 \mathrm{kHz}$, de $5 \mathrm{fC}$ para um transdutor de capacitância de $1 \mathrm{nF}$, com um tempo de subida de tensão de $7.5 \mathrm{~V} / \mu \mathrm{s}$ (faixa de $100 \mathrm{kHz}$ ) e tensão máxima de “offset” de $25 \mathrm{mV}$, valor típico $2 \mathrm{mV}$, estes amplificadores são conectados aos acelerômetros vertical e horizontal. O acelerômetro axial possuí um amplificador que opera na faixa de freqüência de $0,2 \mathrm{~Hz}$ ou $2 \mathrm{~Hz}$ até $100 \mathrm{kHz}$, com um ruído inerente, na faixa de $2 \mathrm{~Hz}$ ate $22 \mathrm{kHz}$ de $5 \times 10^{-3} \mathrm{pC}$, para um

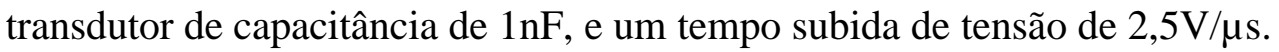

Os amplificadores para acelerômetros do tipo ICP desenvolvidos no IPEN, foram testados e calibrados conforme se pode observar na referência [52]. Apresentam uma faixa de trabalho de $1 \mathrm{~Hz}$ até $10 \mathrm{kHz}$ com ganhos de até 10000 e ruído de $100 \mu \mathrm{V}_{\mathrm{RMS}} @ 2 \mu \mathrm{V}_{\mathrm{RMS}}$.

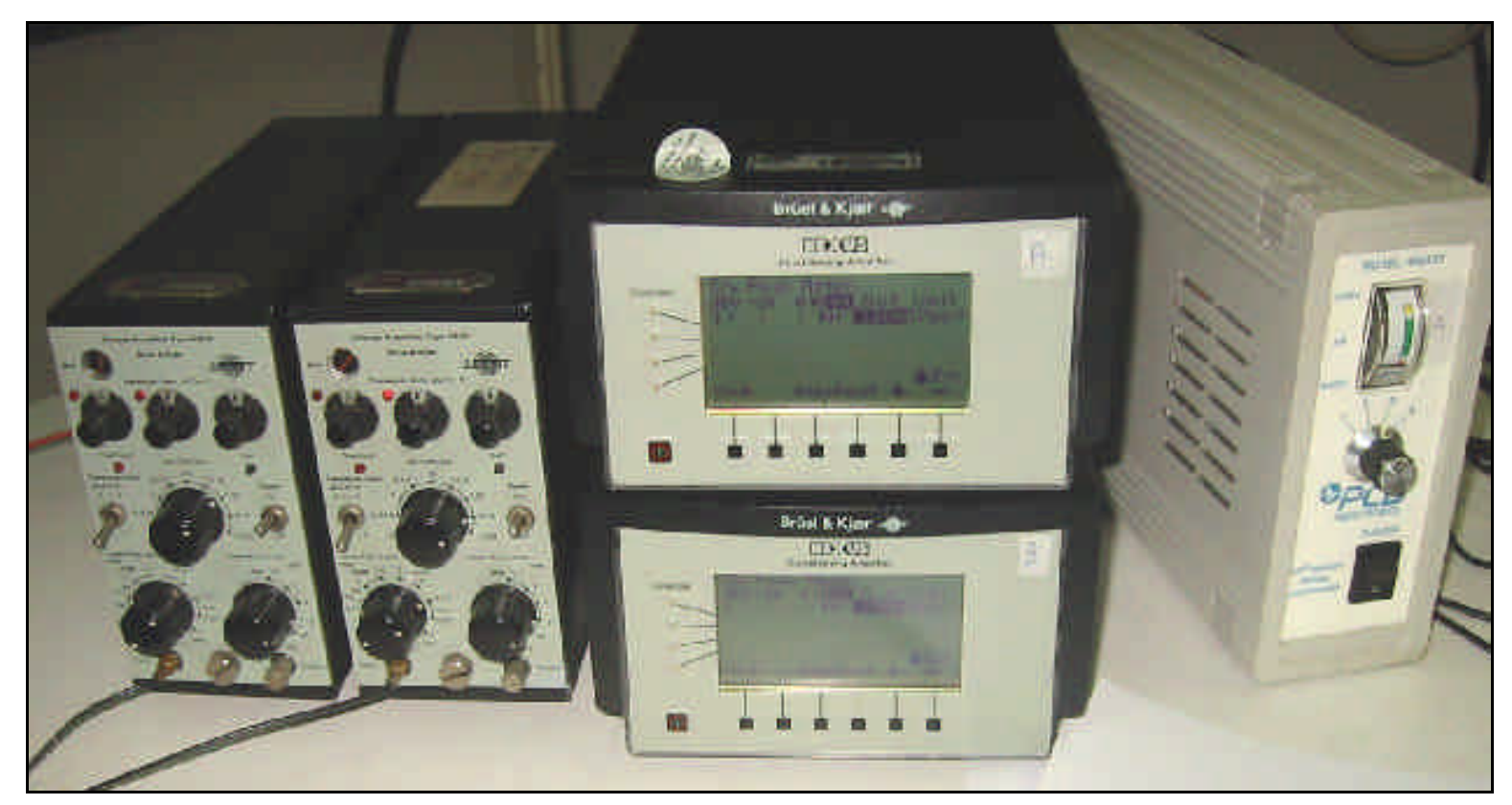

FIGURA 7.3. Amplificadores utilizados para os acelerômetros de carga

Foram projetados para serem montados em um "rack" como na figura 7.4, este "rack" contém uma fonte de alimentação e uma unidade de comando que controla até quatro amplificadores e que controla o ajuste do ganho e do filtro de cada um dos amplificadores. 


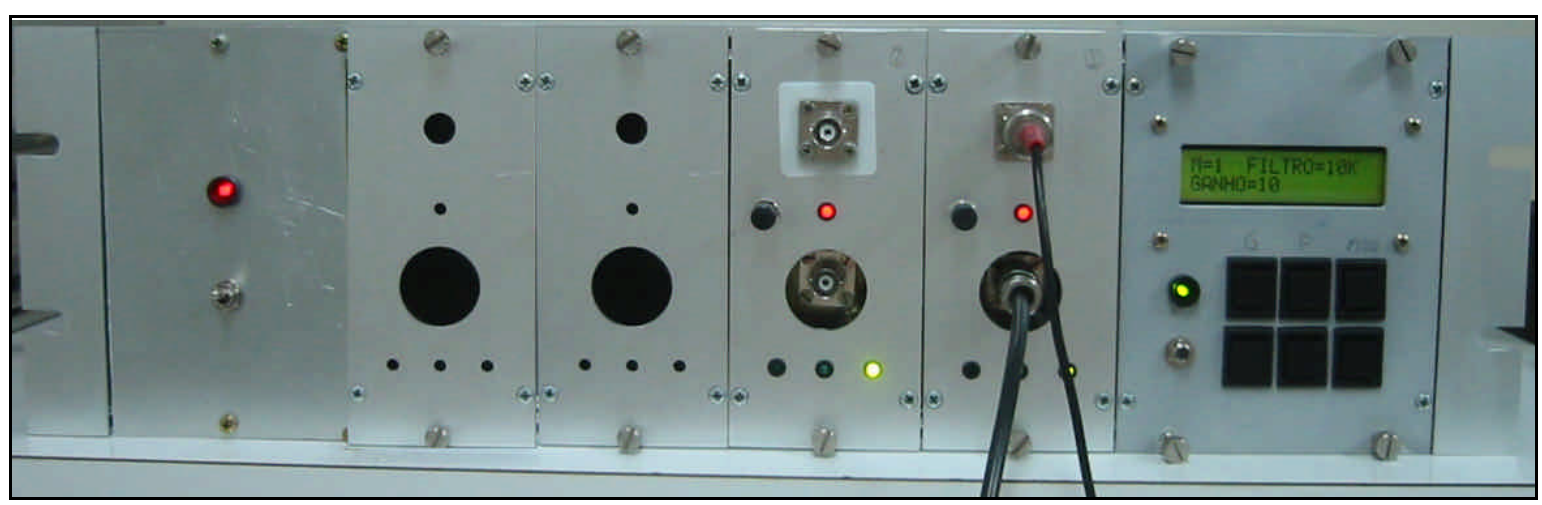

FIGURA 7.4. Conjunto de amplificadores utilizados para acelerômetros ICP

\subsubsection{Módulo de aquisição de dados}

Os amplificadores são conectados a uma caixa de conectores que transfere as tensões destes amplificadores para uma placa que digitaliza estas tensões, fabricado pela National Instruments, Este tipo de placa deve ser conectada a um micro computador de mesa (desktop). O seu modelo é 6071E, que possui 64 canais ou 32 canais no modo diferencial, 12 bits de resolução, freqüência de amostragem máxima de 1,25 MS/s com um ruído médio mais quantização de $0.84 \mathrm{mV}$. Neste trabalho as entradas de tensões das placas foram ajustadas para operarem no modo diferencial, pois foi à configuração com a menor interferência de ruído m sinal, alem de diminuir a tensão de modo comum, que pode estar presente na entrada destas placas.

A figura 7.5 apresenta a tela do programa utilizado para realizar uma pré-análise das condições do sinal obtido pelos acelerômetros e realizar o salvamento destes sinais. 


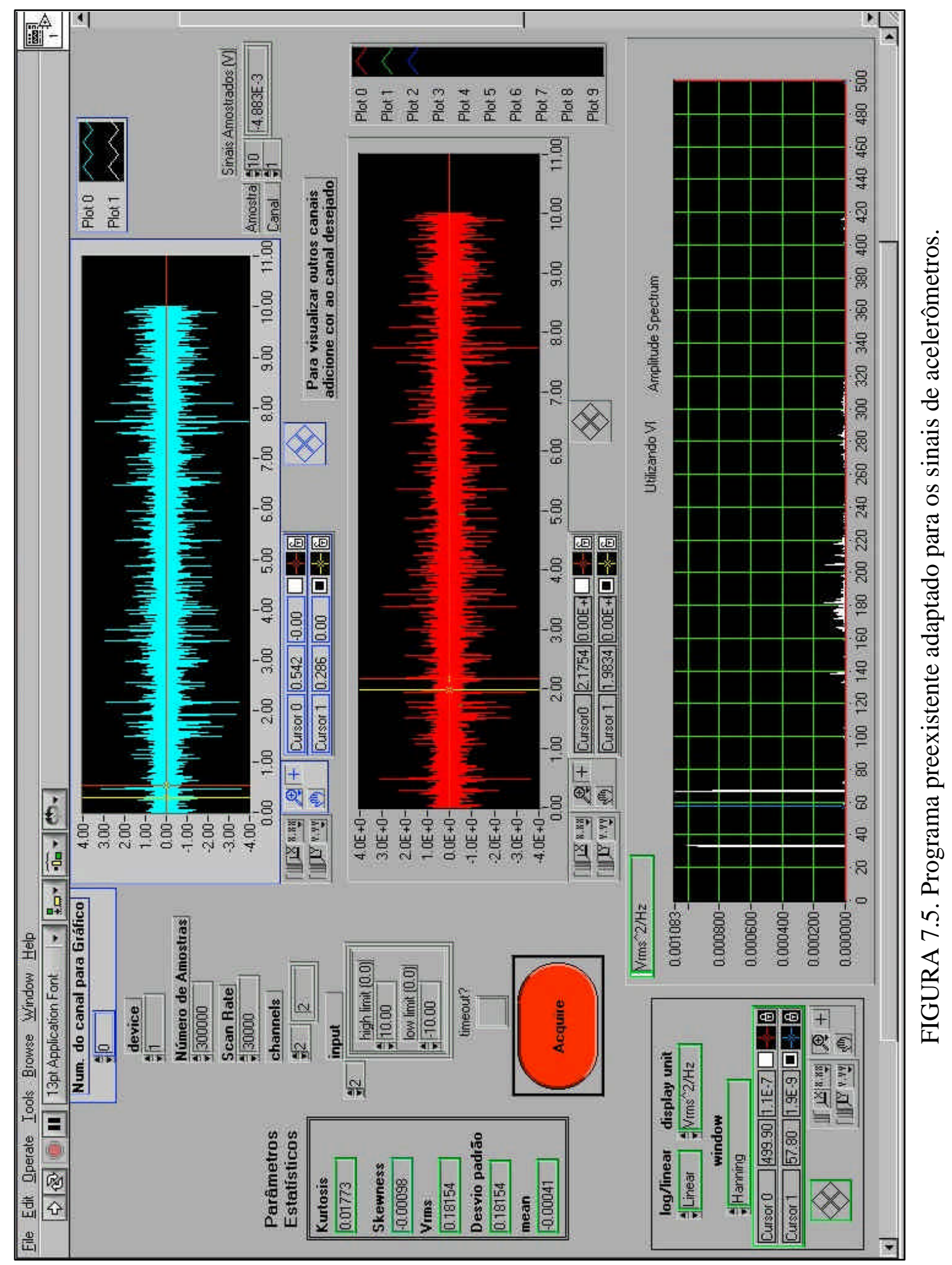




\subsubsection{Conexões elétricas, aterramento e blindagem eletromagnética}

Os amplificadores tiveram um único ponto de aterramento, evitando-se desde modo a circulação de correntes indesejáveis pelo circuito de aterramento. Foram adicionados filtros nas saídas do inversor de tensão que controla a rotação do motor, além da utilização de fios trifásicos blindados para eliminar a interferência da irradiação eletromagnética causada pelo funcionamento inversor.

Desta forma os níveis de ruído foram controlados evitando a sua interferência nas medidas efetuadas.

Com todos os cuidados com os erros nas medidas [55] causadas pelos amplificadores, sensores (acelerômetros), placas de digitalização de sinais e os ruídos eletrônicos e eletromagnéticos e erros de quantização $\left(q=10 / 2^{12}=0,0024 \mathrm{~V}\right.$ ou $\left.2,4 \mathrm{mV}\right)$, estes ficaram ao redor de 3,5\% de erro em relação ao fundo de escala, desde que os acelerômetros sejam utilizados fora da sua frequiência de ressonância (vide anexo). 


\section{APRESENTAÇÃO DOS RESULTADOS}

A tabela 8.1 apresenta o significado dos códigos que foram utilizados para identificar os defeitos criados nos rolamentos do banco de dados.

A coluna a esquerda da tabela, indica o código do tipo de defeito realizado e que são utilizados na figura 8.1 e na tabela 8.2. A figura 8.1 apresenta o valor RMS da velocidade, que é normalizado, sendo um indicador do grau de severidade dos defeitos e a tabela 8.2 possuiu para cada posição o código correspondente ao tipo de defeito realizado.

TABELA 8.1. Significado dos códigos dos defeitos utilizados

\begin{tabular}{|c|c|}
\hline TIPO DE DEFEITO & SIGNIFICADO \\
\hline \multicolumn{2}{|l|}{ SEM DEFEITO } \\
\hline SD & Rolamento Sem Defeito \\
\hline \multicolumn{2}{|l|}{ DEFEITO LOCALIZADO } \\
\hline $\mathrm{R}$ & Rolamento com defeito do tipo Localizado 1 \\
\hline $\mathrm{P}$ & Rolamento com defeito do tipo Localizado 2 \\
\hline $\mathrm{L}$ & Rolamento com defeito do tipo Localizado 3 \\
\hline $\mathrm{Q}$ & Rolamento com defeito do tipo Localizado 4 \\
\hline $\mathrm{M}$ & Rolamento com defeito do tipo Localizado 5 \\
\hline $\mathrm{N}$ & Rolamento com defeito do tipo Localizado 6 \\
\hline $\mathrm{K}$ & Rolamento com defeito do tipo Localizado 7 \\
\hline \multicolumn{2}{|l|}{$\begin{array}{l}\text { DEFEITO DISTRIBUÍDO } \\
\text { TIPO CORROSÃO }\end{array}$} \\
\hline $\mathrm{CCS}$ & Rolamento com defeito do tipo Distribuído 1 \\
\hline CCS1_im1 & Rolamento com defeito do tipo Distribuído 2 \\
\hline CCS1_im2 & Rolamento com defeito do tipo Distribuído 3 \\
\hline CCS2_im1 & Rolamento com defeito do tipo Distribuído 4 \\
\hline \multicolumn{2}{|l|}{$\begin{array}{c}\text { DEFEITO DISTRIBUIDO } \\
\text { TIPO RISCADO }\end{array}$} \\
\hline RISC2 & Rolamento com defeito do tipo Riscado 1 \\
\hline RISC3 & Rolamento com defeito do tipo Riscado 2 \\
\hline
\end{tabular}

\subsection{Valores existentes no banco de dados utilizados}

A figura 8.1 indica a progressão dos valores RMS para os vários tipos de defeitos em rolamentos. Os números indicados no gráfico estão descritos na tabela 8.2. 
Pode-se observar nesta figura que a maioria dos defeitos estão abaixo de $1,8 \mathrm{~mm} / \mathrm{s}$ ou $0,0018 \mathrm{~m} / \mathrm{s}$, indicando que os defeitos estão na região considerada de rolamentos em bom estado ou em condições aceitáveis de operação.

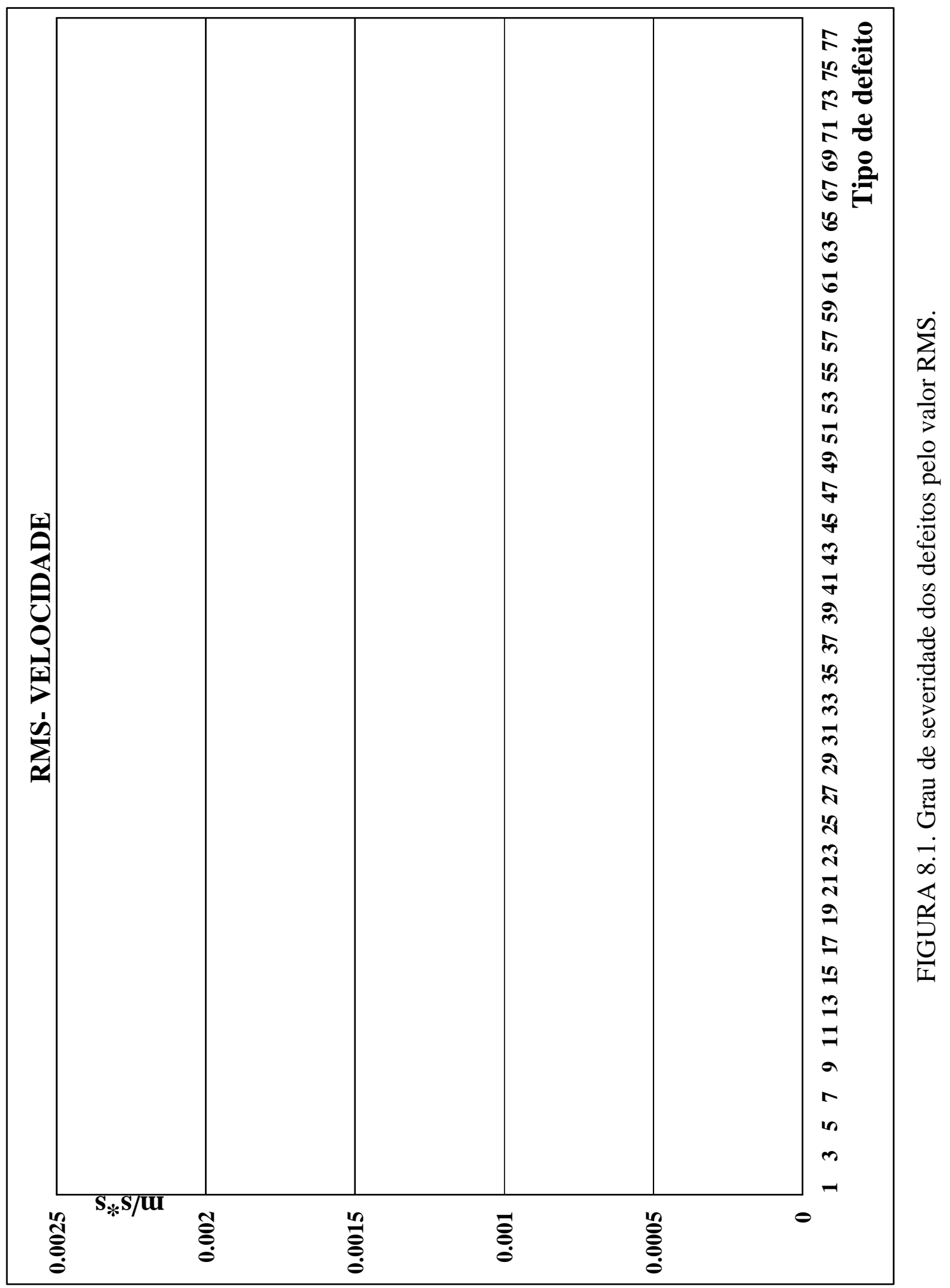


A tabela 8.2 mostra a seqüência de defeitos representados na figura 8.1, indicando o número encontrado na figura e o seu respectivo defeito.

TABELA 8.2. Código do RMS do sinal de velocidade e o defeito associado

\begin{tabular}{||c|c||c|c||c|c||}
\hline Número & Defeito & Número & Defeito & Número & Defeito \\
\hline \hline $\mathbf{1}$ & SD & $\mathbf{2 7}$ & CCS1_im1 & $\mathbf{5 3}$ & M \\
\hline $\mathbf{2}$ & SD & $\mathbf{2 8}$ & CCS1_im1 & $\mathbf{5 4}$ & M \\
\hline $\mathbf{3}$ & SD & $\mathbf{2 9}$ & SD & $\mathbf{5 5}$ & SD \\
\hline $\mathbf{4}$ & R & $\mathbf{3 0}$ & CCS & $\mathbf{5 6}$ & CCS2_im1 \\
\hline $\mathbf{5}$ & R & $\mathbf{3 1}$ & L & $\mathbf{5 7}$ & CCS2_im1 \\
\hline $\mathbf{6}$ & SD & $\mathbf{3 2}$ & CCS1_im2 & $\mathbf{5 8}$ & Q \\
\hline $\mathbf{7}$ & R & $\mathbf{3 3}$ & L & $\mathbf{5 9}$ & CCS2_im1 \\
\hline $\mathbf{8}$ & R & $\mathbf{3 4}$ & 6_I & $\mathbf{6 0}$ & N \\
\hline $\mathbf{9}$ & SD & $\mathbf{3 5}$ & CCS1_im2 & $\mathbf{6 1}$ & CCS \\
\hline $\mathbf{1 0}$ & SD & $\mathbf{3 6}$ & L & $\mathbf{6 2}$ & CCS \\
\hline $\mathbf{1 1}$ & CCS & $\mathbf{3 7}$ & L & $\mathbf{6 3}$ & CCS2_im1 \\
\hline $\mathbf{1 2}$ & CCS & $\mathbf{3 8}$ & CCS & $\mathbf{6 4}$ & CCS2_im1 \\
\hline $\mathbf{1 3}$ & SD & $\mathbf{3 9}$ & CCS1_im2 & $\mathbf{6 5}$ & CCS2_im1 \\
\hline $\mathbf{1 4}$ & P & $\mathbf{4 0}$ & CCS1_im2 & $\mathbf{6 6}$ & CCS1_iim2 \\
\hline $\mathbf{1 5}$ & CCS & $\mathbf{4 1}$ & Q & $\mathbf{6 7}$ & CCS1_iim2 \\
\hline $\mathbf{1 6}$ & CCS1_im1 & $\mathbf{4 2}$ & CCS1_im2 & $\mathbf{6 8}$ & N \\
\hline $\mathbf{1 7}$ & RISC2 & $\mathbf{4 3}$ & Q & $\mathbf{6 9}$ & 6_I \\
\hline $\mathbf{1 8}$ & RISC2 & $\mathbf{4 4}$ & CCS1_im2 & $\mathbf{7 0}$ & RISC3 \\
\hline $\mathbf{1 9}$ & P & $\mathbf{4 5}$ & M & $\mathbf{7 1}$ & P \\
\hline $\mathbf{2 0}$ & CCS1_im1 & $\mathbf{4 6}$ & M & $\mathbf{7 2}$ & 5_I \\
\hline $\mathbf{2 1}$ & CCS1_im1 & $\mathbf{4 7}$ & CCS & $\mathbf{7 3}$ & RISC3 \\
\hline $\mathbf{2 2}$ & RISC2 & $\mathbf{4 8}$ & CCS & $\mathbf{7 4}$ & RISC3 \\
\hline $\mathbf{2 3}$ & CCS1_im1 & $\mathbf{4 9}$ & CCS1_im2 & $\mathbf{7 5}$ & K \\
\hline $\mathbf{2 4}$ & SD & $\mathbf{5 0}$ & CCS1_im2 & $\mathbf{7 6}$ & K \\
\hline $\mathbf{2 5}$ & CCS & $\mathbf{5 1}$ & N & $\mathbf{7 7}$ & K \\
\hline $\mathbf{2 6}$ & CCS1_im1 & $\mathbf{5 2}$ & SD & $\mathbf{7 8}$ & K \\
\hline \hline & & & & \\
\hline
\end{tabular}




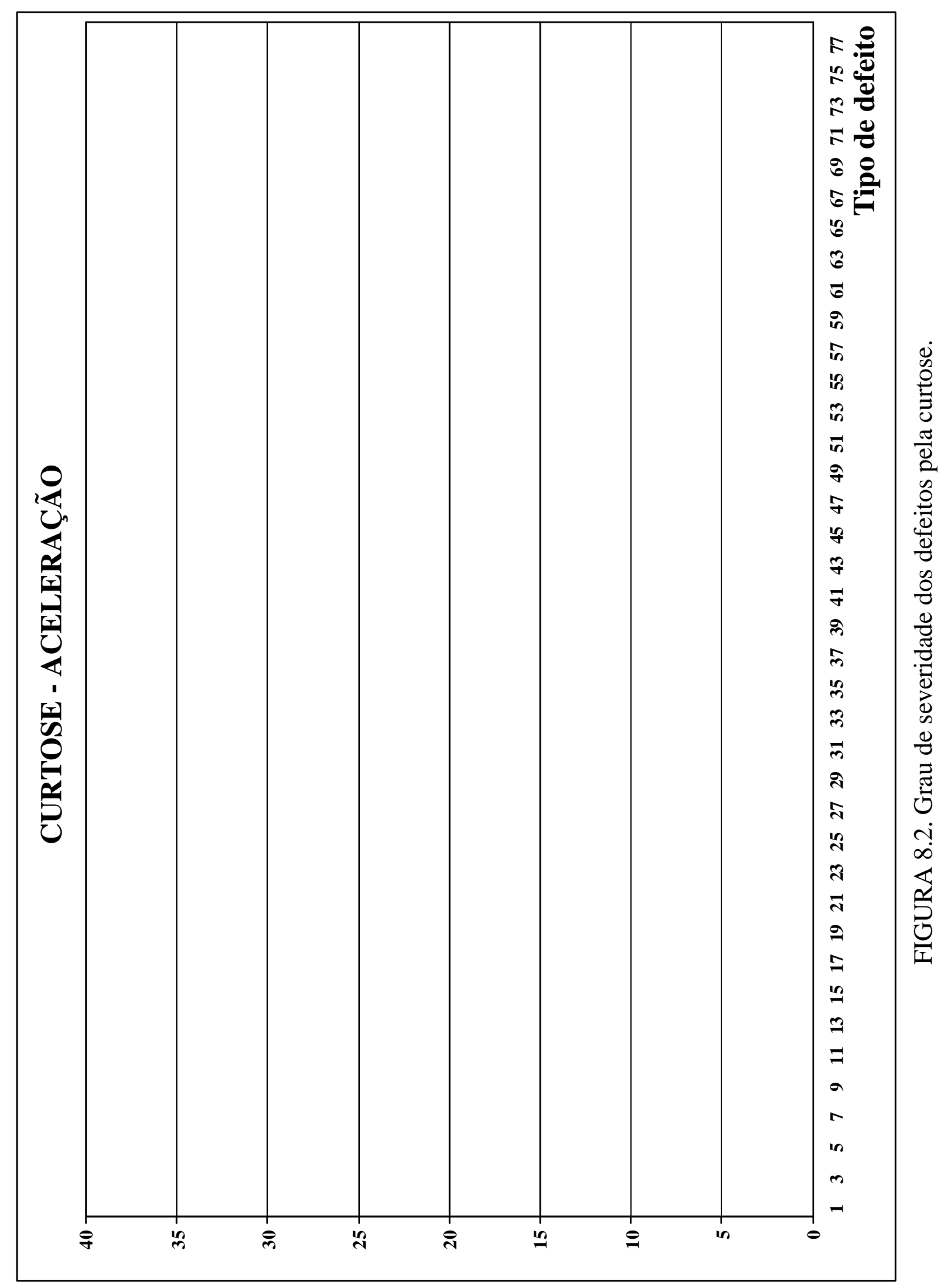


A tabela 8.3 mostra a sequiência de defeitos representados na figura 8.2, indicando o número encontrado na figura e o seu respectivo defeito.

TABELA 8.3. Código da curtose da Aceleração e o defeito associado

\begin{tabular}{|c|c|c|c|c|c|}
\hline Número & Defeito & Número & Defeito & Número & Defeito \\
\hline$\overline{1}$ & CCS & 27 & "CCS2_im1 & 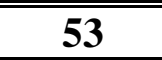 & 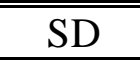 \\
\hline 2 & $\mathrm{CCS}$ & 28 & CCS1_im1 & 54 & $\mathrm{SD}$ \\
\hline 3 & CCS1_im2 & 29 & CCS2_im1 & 55 & SD \\
\hline 4 & CCS2_im1 & 30 & CCS2_im1 & 56 & $\mathrm{SD}$ \\
\hline 5 & CCS2_im1 & 31 & RISC3 & 57 & $\mathrm{~N}$ \\
\hline 6 & $\mathrm{CCS}$ & 32 & RISC3 & 58 & $\mathrm{Q}$ \\
\hline 7 & CCS1_im2 & 33 & $\mathrm{SD}$ & 59 & $\mathrm{SD}$ \\
\hline 8 & CCS2_im1 & 34 & $\mathrm{CCS}$ & 60 & $\mathrm{SD}$ \\
\hline 9 & CCS1_im2 & 35 & CCS & 61 & SD \\
\hline 10 & CCS1_im2 & 36 & RISC2 & 62 & $\mathrm{Q}$ \\
\hline 11 & CCS1_im2 & 37 & SD & 63 & $\mathrm{~N}$ \\
\hline 12 & CCS1_im2 & 38 & $\mathrm{CCS}$ & 64 & 6_I \\
\hline 13 & CCS1_im2 & 39 & RISC2 & 65 & $\mathrm{~L}$ \\
\hline 14 & CCS1_im2 & 40 & RISC2 & 66 & $\mathrm{~N}$ \\
\hline 15 & $\mathrm{CCS}$ & 41 & 5_I & 67 & $\mathrm{~L}$ \\
\hline 16 & CCS & 42 & $\mathrm{CCS}$ & 68 & 6_I \\
\hline 17 & CCS1_im1 & 43 & $\mathrm{R}$ & 69 & $\mathrm{M}$ \\
\hline 18 & CCS1_im1 & 44 & $\mathrm{R}$ & 70 & $\mathrm{M}$ \\
\hline 19 & CCS1_im1 & 45 & $\mathrm{P}$ & 71 & M \\
\hline 20 & $\mathrm{CCS}$ & 46 & $\mathrm{R}$ & 72 & $\mathrm{M}$ \\
\hline 21 & CCS1_im1 & 47 & $\mathrm{R}$ & 73 & $\mathrm{~K}$ \\
\hline 22 & CCS1_im1 & 48 & $\mathrm{SD}$ & 74 & $\mathrm{~K}$ \\
\hline 23 & CCS1_im1 & 49 & $\mathrm{P}$ & 75 & $\mathrm{~L}$ \\
\hline 24 & RISC3 & 50 & $Q$ & 76 & $\mathrm{~L}$ \\
\hline 25 & CCS1_im2 & 51 & $\mathrm{P}$ & 77 & $\mathrm{~K}$ \\
\hline 26 & CCS1_im2 & 52 & $\mathrm{SD}$ & 78 & $\mathrm{~K}$ \\
\hline
\end{tabular}

A figura 8.3, mostra a DEP típica para um defeito do tipo localizado, com as respectivas harmônicas das freqüências de passagem do rolamento com defeito.

A figura 8.4 mostra o envelope típico para um defeito do tipo localizado, com as respectivas harmônicas das freqüências de passagem do rolamento com defeito. Pode-se notar que o sinal esta bem visível, podendo-se notar ate a existência da $8^{\circ}$ harmônica. 


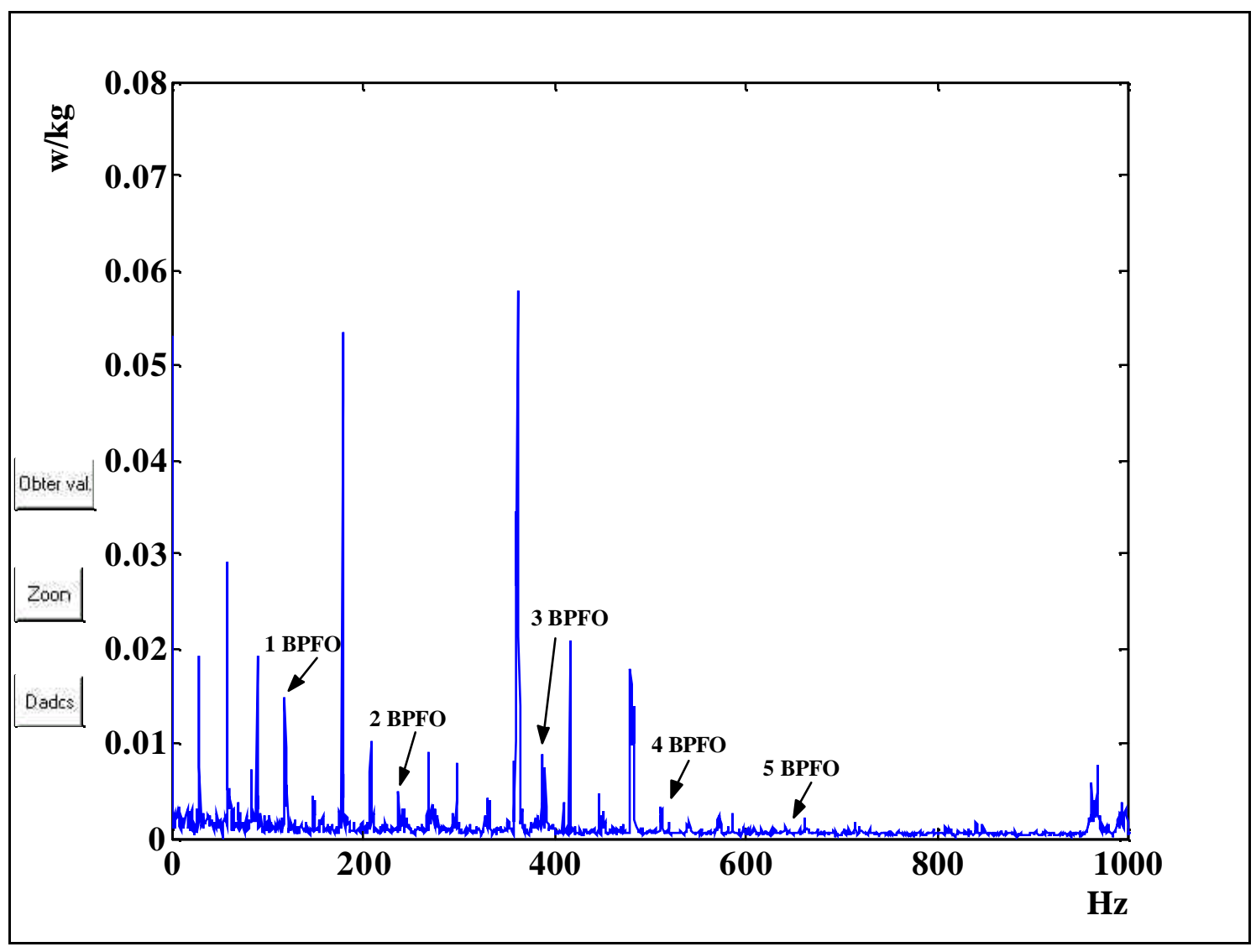

FIGURA 8.3. DEP de um sinal do tipo localizado

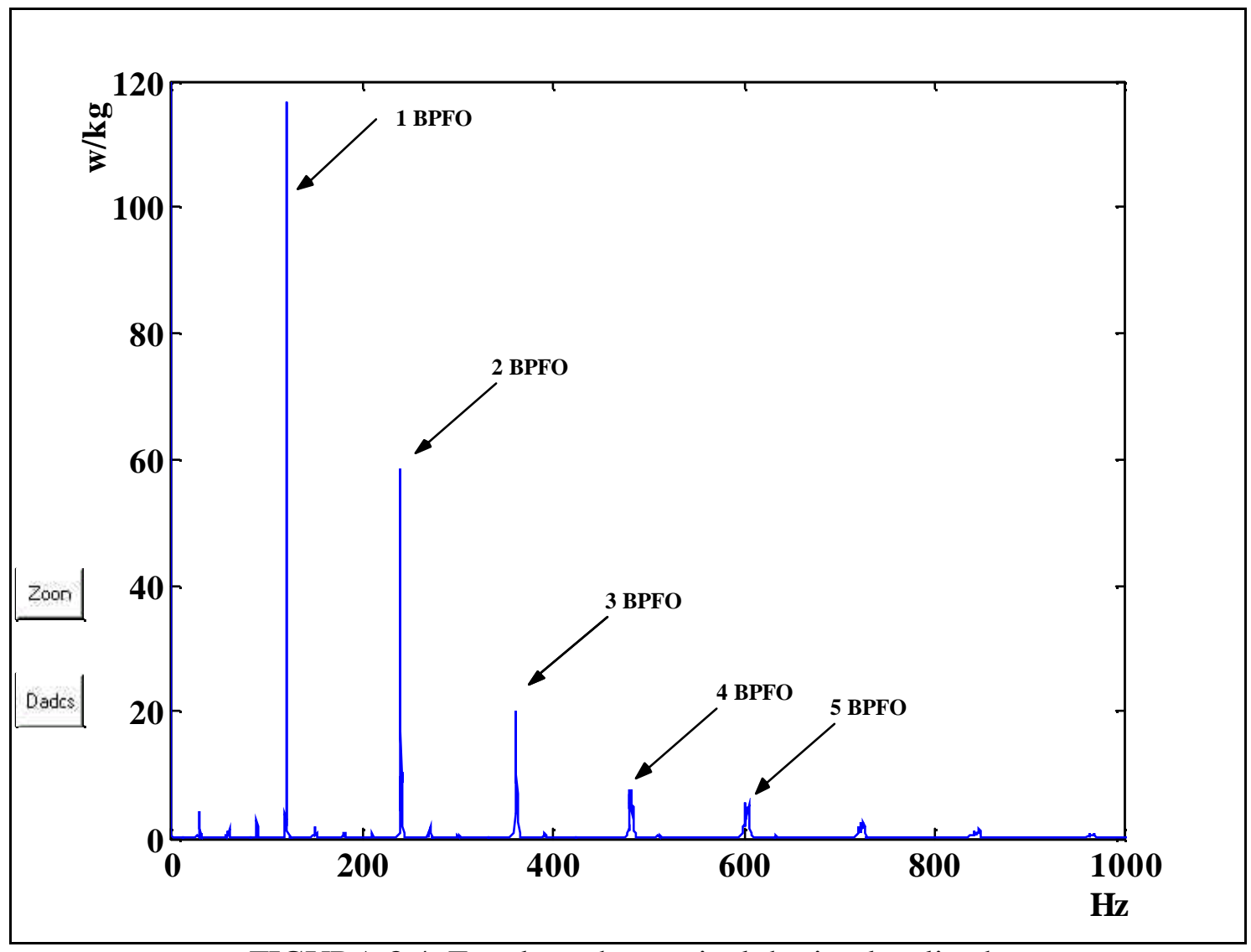

FIGURA 8.4. Envelope de um sinal do tipo localizado 


\subsection{Comportamento IWZC com a variação do limiar}

Na figura 8.5 são apresentadas as DEP para os vários níveis da transformada de wavelet. Os 10 gráficos à esquerda da tela, separado pela linha vertical preta, mostram a DEP para os 10 níveis de aproximação da transformada de wavelet, os números nos gráficos acima e a direita de cada gráfico mostra o limite superior da banda de freqüência, pois o limite inferior de todos estes gráficos é 1 . As unidades de todos os gráficos são para o eixo das abscissas em $(\mathrm{Hz})$ e das ordenadas em w/kg. À direita da linha vertical preta que divide a tela, têm-se as transformadas de wavelet de detalhe. As letras D1, D3, D5, D7 e D9 indicam a tw de detalhe dos níveis $1,3,5,7$, e 9 respectivamente, e os gráficos à direita da tela indicam os níveis da tw para os níveis 2, 4, 6, 8 e 10. Na parte superior destes gráficos estão identificados o limite inferior e o limite superior da banda de freqüência de cada um dos níveis da tw e que estão apresentados no eixo das abscissas (Hz). 


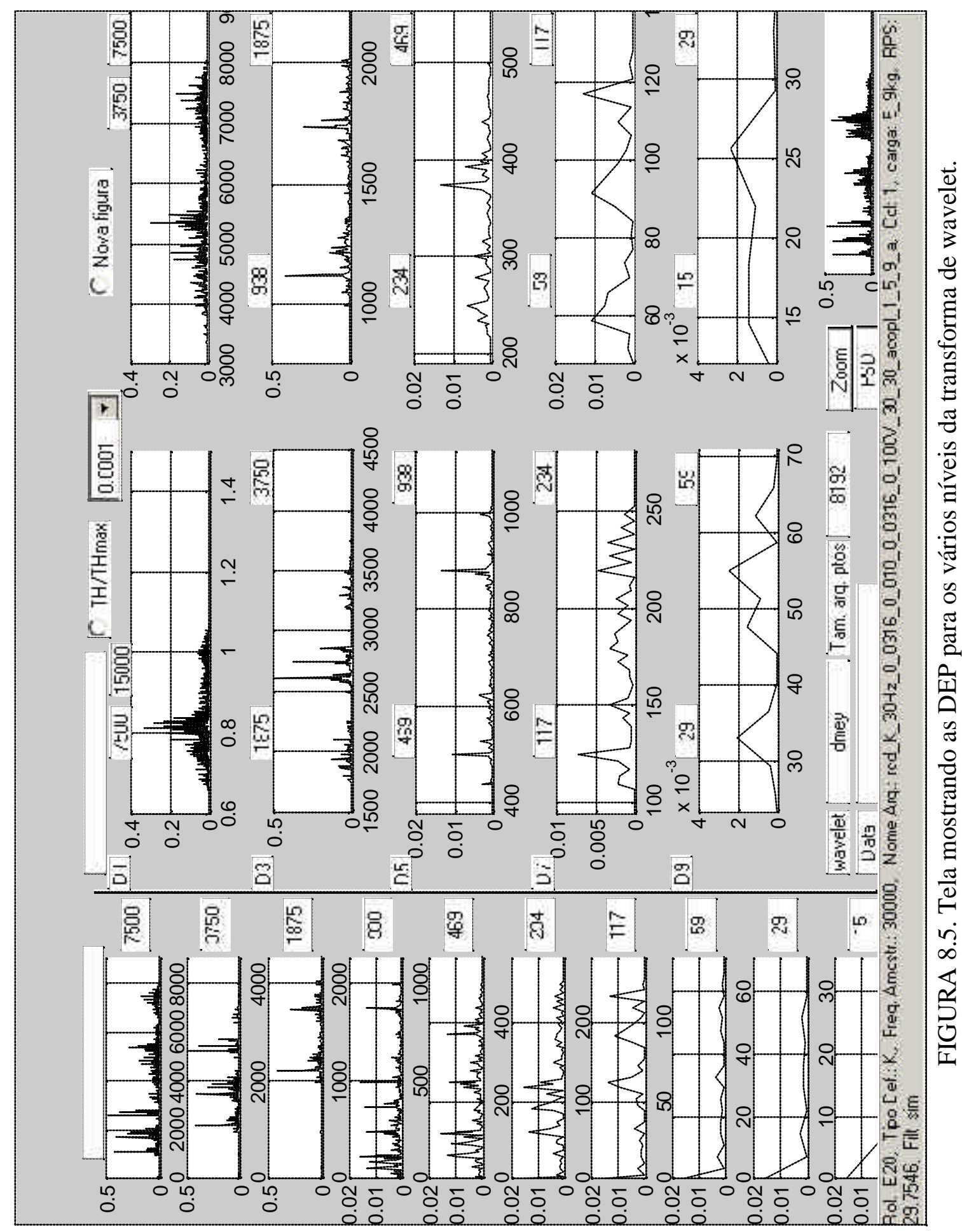

Os sinais de rolamentos nos níveis de detalhes D5, D6 e D7, contêm as freqüências de passagens dos sinais de rolamento. A ocorrência de sinais com grandes amplitudes nestes níveis é um indicativo da existência de defeito no rolamento. Estas amplitudes são mostradas pelo Zero Crossing da Transformada de Wavelet como grandes oscilações nas amplitudes dos sinais de Representação do zero crossing da transformada de wavelet, o que 
leva a grandes valores de limiar nestes níveis, indicando a possibilidade de defeitos neste rolamento.

Um dos modos para avaliar os sinais a serem analisados, utilizando o IWZC, foi construir uma curva variando o valor do limiar, desde zero até um valor a partir do qual não se observa mais contagens do número de Zero Crossing para cada um dos níveis. Desta forma, quando se compara um rolamento sem defeito com um rolamento com defeito, em um determinado nível da Transformada de Wavelet, sabe-se que o máximo valor do limiar ocorre quando o IWZC chega a zero e, portanto obtém-se a máxima amplitude do sinal. Logo, o sinal que apresentar o maior limiar também possui a maior amplitude. Como os rolamentos sem defeitos apresentam oscilações de baixa amplitude, isto leva a pequenos valores de limiar e desta forma, os valores altos de limiar são indicativos da presença de defeitos. Como o Zero Crossing da Transformada de Wavelet permite dividir estes sinais em bandas de frequiências, isto permite uma análise detalhada do sinal, facilitando a identificação de defeitos sem a influência de sinais que estão distribuídos em outras bandas, o que não ocorre com a DEP onde todas as frequiências estão presentes em um único gráfico.

Como exemplo, as 3 figuras 8.6, 8.7 e 88 apresentam as curvas do IWZC que caracterizam um rolamento sem defeito (SD) figura 8.6, ou com defeito distribuído, figura 8.7 ou com defeito localizado, figura 8.8. 


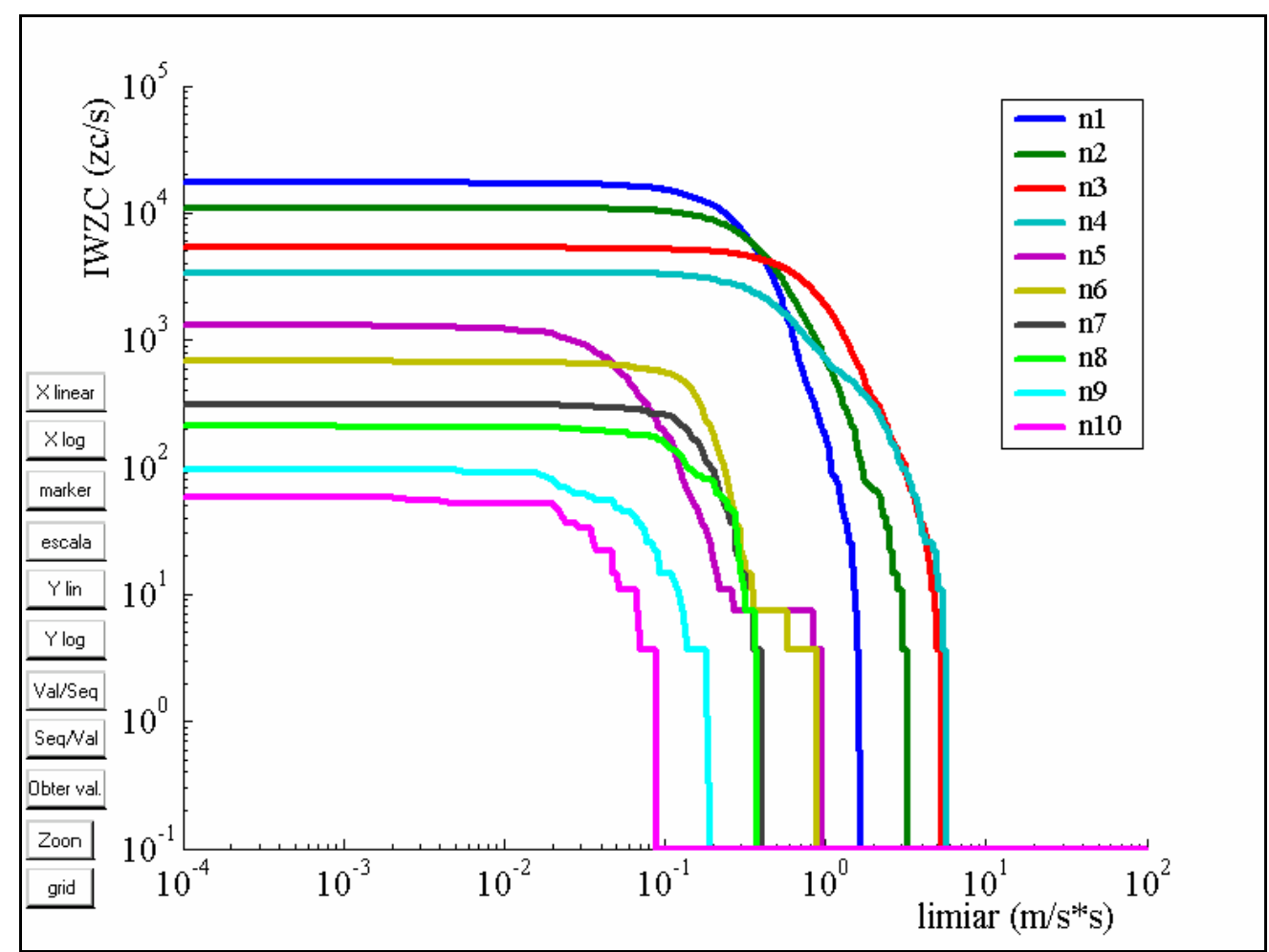

FIGURA 8.6. Curvas IWZC de um rolamento sem defeito

A figura 8.7 apresenta o IWZC obtido por um defeito tipo distribuído (corrosão). Como se pode observar no gráfico, o defeito do tipo distribuído no nível 1.

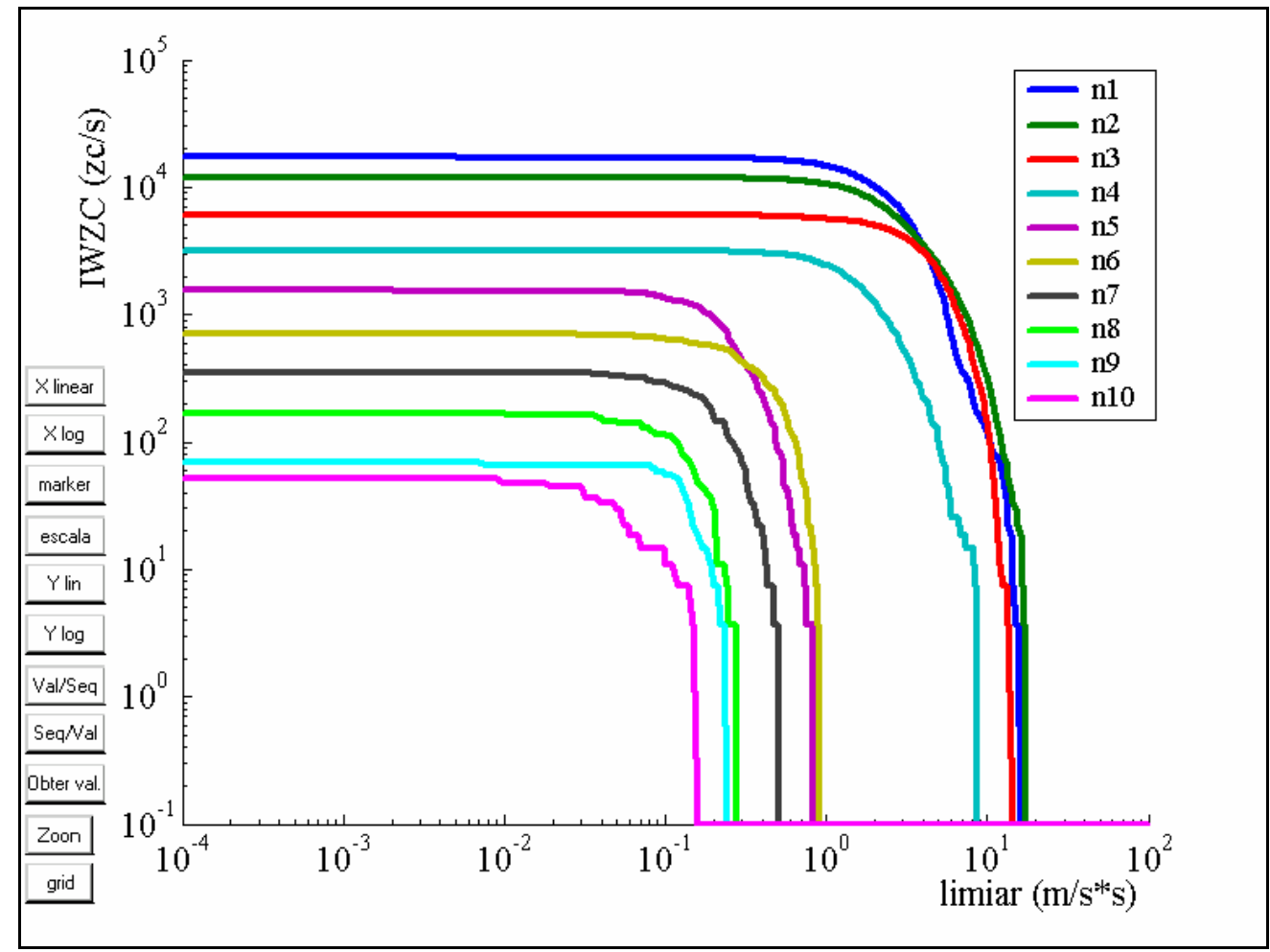

FIGURA 8.7. Curva IWZC de um rolamento com defeito distribuído 
A figura 8.8 mostra o comportamento do IWZC com a variação do limiar. É possível notar neste gráfico que o comportamento diferenciado dos níveis 1 e 2, para os quais nota-se existir uma rápida queda do sinal, e depois uma queda lenta no valor do limiar, sugerindo o comportamento de um filtro linear com dois pólos, diferentemente dos níveis 1 e 2 das figuras 8.6 e 8.7 Este comportamento é observado tipicamente nos defeitos do tipo localizado, ou seja, furos.

Desta forma, quanto mais severo for o defeito do tipo localizado, mais o decaimento do IWZC se torna suave, o que facilita bastante distinguir este tipo de defeito dos demais tipos. Ou seja, o IWZC apresenta boa capacidade para diagnosticar defeitos do tipo localizado.

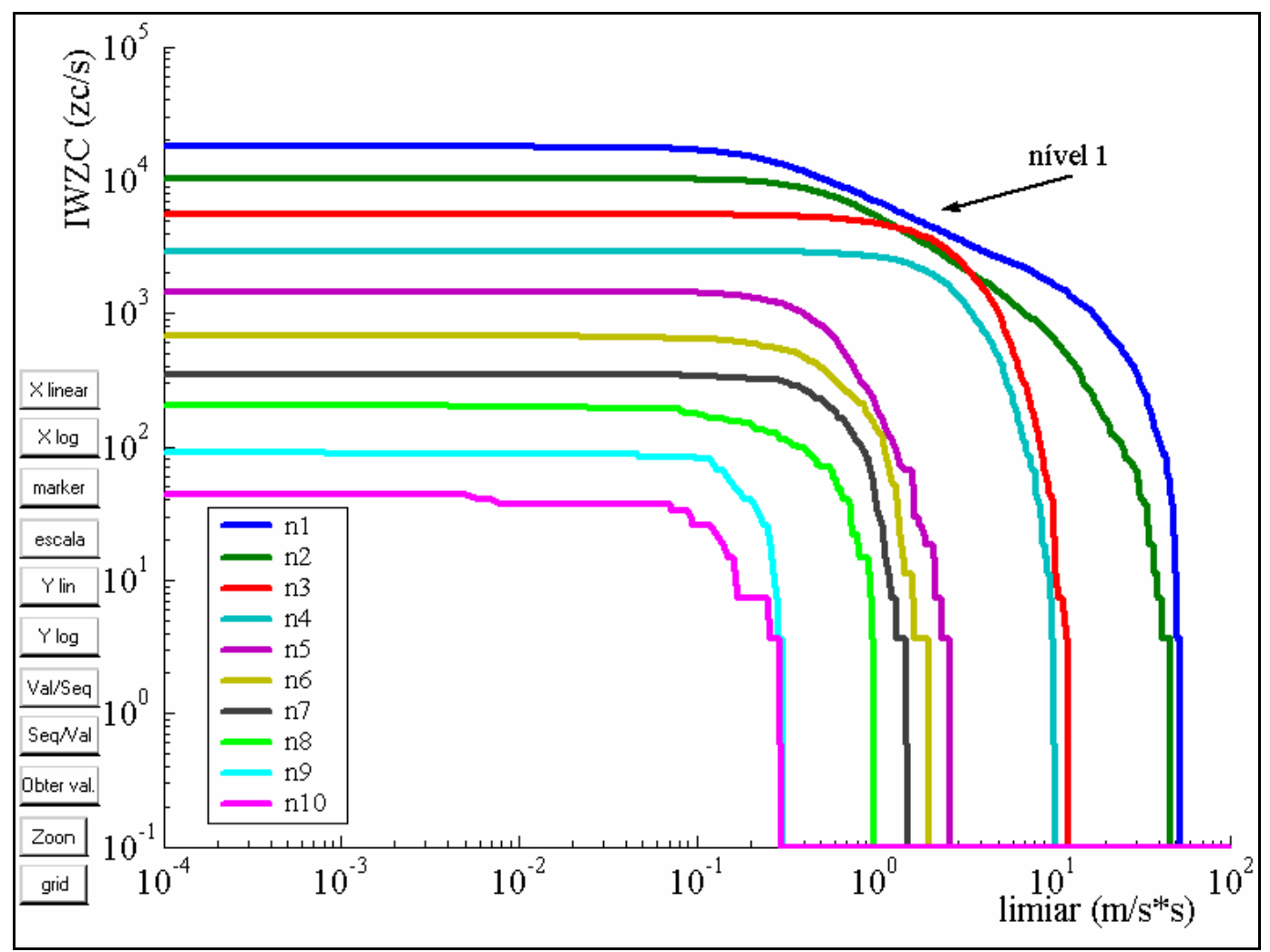

FIGURA 8.8. Curva IWZC de um rolamento com defeito localizado (furo)

Os níveis 8, 9 e 10 apresentam bandas de freqüências onde se pode observar o comportamento do desbalanceamento e do desalinhamento do eixo. A banda 8 apresenta o desalinhamento do eixo, a banda 9 apresenta o desbalanceamento do eixo e a banda 10 também apresenta o desbalanceamento do eixo, mas para rotações abaixo de $30 \mathrm{~Hz}$. 
Para os níveis 5, 6 e 7, observou-se que estes níveis poderiam separar sinais de rolamento sem defeito dos demais tipos, distribuídos ou localizados. São nestes níveis que se encontram as freqüências de passagem de um rolamento com defeito, para este tipo de rolamento, e para esta faixa de rotação. Desta forma, utilizou os valores RMS de cada um destes níveis. Estes valores foram agrupados e procurourse obter o centróide destes valores, item 8.3 .

Analisando-se os gráficos de sinal sem defeito, figura 8.6 e com defeitos do tipo localizado, ou distribuído, observou-se que a velocidade de decaimento do valor IWZC, dos rolamentos com defeitos do tipo localizado, podem ser utilizados para separá-los dos tipos, sem defeito ou distribuído, desde que analisados sempre no nível 1 (D1) ou nível 2 (D2).

Tem-se verificado que para um defeito do tipo localizado, figura 8.8, o valor do coeficiente de decaimento (Tal IWZC1) apresenta uma variação de 0,7 até 2,6, para os defeitos do tipo distribuído, figura 8.7, um valor de 2,3 até 4,05 e para os rolamentos sem defeito um valor de 2 até 2,8. Desta forma, seria possível dizer que para o coeficiente de decaimento abaixo de 2 , tem-se os defeitos do tipo localizado, pois estes defeitos apresentam uma atenuação lenta, o que leva a valores dos coeficientes de decaimento pequenos, como pode ser mostrado no figura 8.8. Para um coeficiente de decaimento acima de 3,4 ter-se-á uma indicação de um defeito do tipo distribuído, isto pode ser considerado, pois as corrosões, defeitos distribuídos, apresentam um decaimento rápido, pois suas amplitudes decaem rapidamente a partir de um determinado valor de limiar.

\subsection{Obtenção dos critérios para RMS 5, 6 e 7}

A técnica do RMS 5, 6 e 7 é utilizada a partir do cálculo de um centróide que foi associado ao rolamento sem defeito, e do cálculo do outro centróide associado ao rolamento com defeito do tipo distribuído. Desta forma, quando um novo sinal de rolamento é obtido, este é comparado com os dois centróides existentes. Se os valores rms dos níveis 5, 6 e 7 do rolamento sob análise são mais próximos de um determinado centróide, este será considerado pertencente a este grupo, sendo então classificado como sem defeito, ou com defeito do tipo distribuído, já que em uma análise previa já se verificou se o sinal analisado apresentava defeito do tipo localizado. Se o defeito é do tipo localizado, is to dispensaria a análise desta etapa, pois esta técnica de centróide mostroutse adequada apenas para a separação de rolamentos sem defeitos. 
A figura 8.9 mostra um gráfico onde se pode ver o agrupamento dos dados para um rolamento sem defeito e os dados para um rolamento com defeito. Para a obtenção destes valores utilizou-se uma amostra dos valores existentes no banco de dados, e que serviram para a se obter da região dos pontos dos rolamentos sem defeito e dos pontos dos rolamentos com defeitos. Nesta figura pode observar:

- os círculos em vermelho, os pontos relativos aos rolamentos sem defeito.

- os círculos em azul, os pontos relativos aos rolamentos com defeito.

- em preto, os centróides dos pontos dos rolamentos sem defeitos e o centróide dos pontos dos rolamentos com defeitos.

- em verde, a fronteira (plano) que delimita a região dos rolamentos sem defeitos dos rolamentos com defeito.

- em azul, a reta que une os dois centróides.

- e sobre esta reta, em marrom, o ponto que separa a região dos rolamentos sem defeito da região dos rolamentos com defeito.

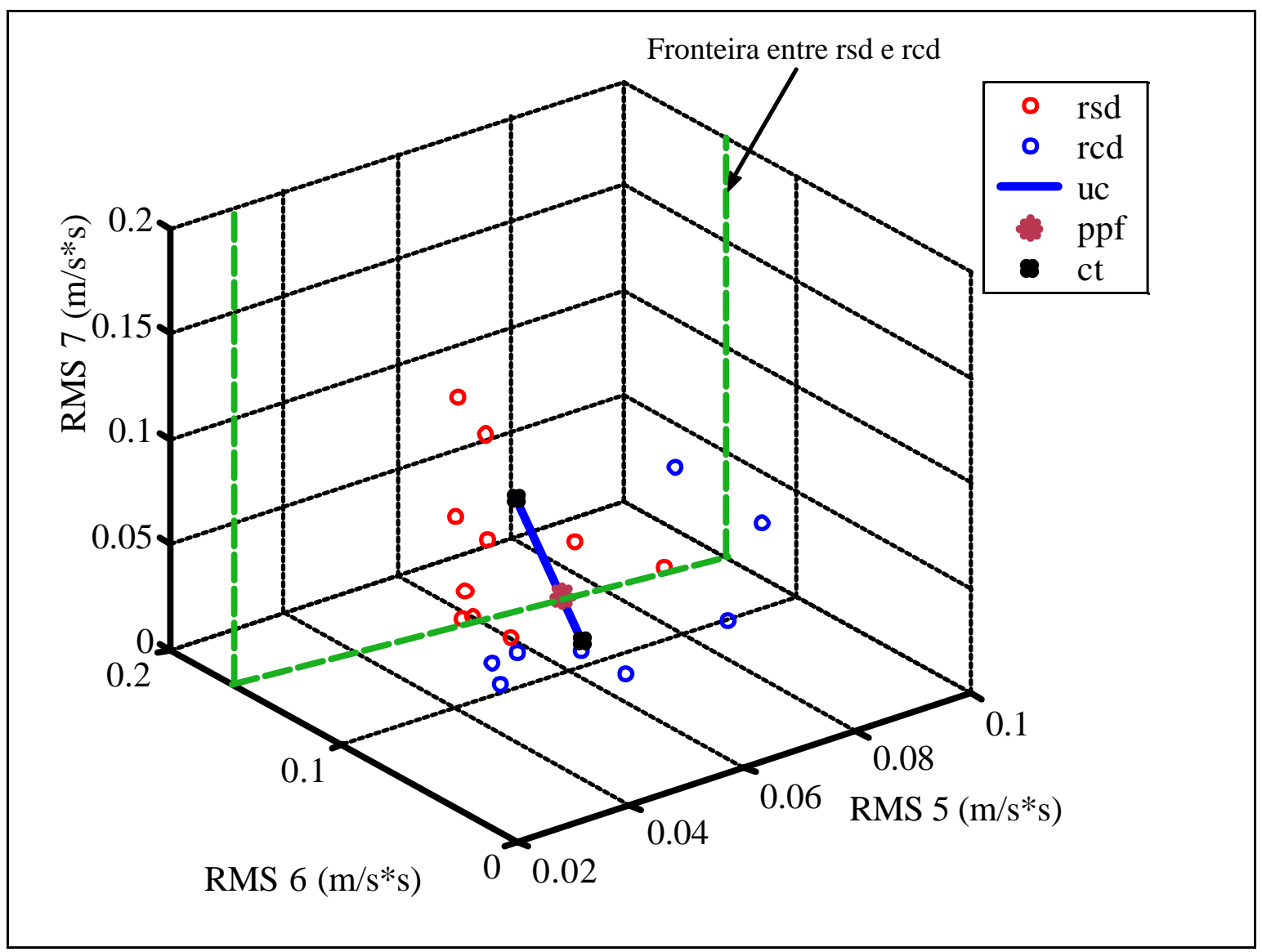

FIGURA 8.9. Agrupamentos dos dados para obtenção do critério RMS 5, 6 e 7 


\subsection{Resultado dos diagnósticos realizados do banco de dados}

Resultados obtidos pela análise dos sinais de rolamentos:

A tabela 8.4 apresenta os resultados obtidos através da lógica nebulosa paraconsistente, respondendo as proposições indicadas em negrito, alem de mostrar o tipo de defeito real, podendo confirmar as respostas das proposições indicadas. Por exemplo, é severo? a resposta será afirmativa ou ne gativa de acordo com a tabela 9.2

TABELA 8.4. Resultados para os rolamentos sem defeito

\begin{tabular}{|c|c|c|c|c|c|c|}
\hline Arquivo & Defeito & $\begin{array}{c}\underline{\mathbf{E}} \\
\text { Defeito? }\end{array}$ & \begin{tabular}{|c|}
$\mathbf{E}$ \\
Severo?
\end{tabular} & $\begin{array}{c}\text { É Pista } \\
\text { Externa? }\end{array}$ & $\begin{array}{c}\overrightarrow{\mathbf{E}} \\
\text { Envelope? }\end{array}$ & $\begin{array}{c}\text { Distribuído/ } \\
\text { Localizado }\end{array}$ \\
\hline 132700 & SD & 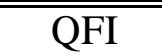 & $\overline{\mathrm{F}}$ & QPF & $\overline{\mathrm{P}}$ & Pode ser SD \\
\hline 175732 & SD & NFNP & $\mathrm{F}$ & QVP & $\overline{\mathrm{QPV}}$ & Distribuído \\
\hline 121846 & SD & NFNI & $\mathrm{P}$ & $\mathrm{P}$ & $\mathrm{P}$ & Distribuído \\
\hline 182318 & SD & NFNP & $\mathrm{F}$ & QVP & QFP & Distribuído \\
\hline 123500 & $\mathrm{SD}$ & QFP & $\mathrm{P}$ & $\mathrm{P}$ & $\mathrm{P}$ & Distribuído \\
\hline 164906 & $\mathrm{SD}$ & QFI & $\mathrm{P}$ & $\mathrm{P}$ & $\mathrm{P}$ & Localizado \\
\hline 172910 & SD & QFNI & $\mathrm{F}$ & NVNP & NVNP & Pode ser SD \\
\hline 172544 & $\mathrm{SD}$ & QFI & $\mathrm{F}$ & QFP & $\mathrm{P}$ & Pode ser SD \\
\hline 171942 & SD & QFI & $\mathrm{F}$ & $\mathrm{P}$ & $\mathrm{P}$ & Result. baixo p/ diag. \\
\hline 171424 & $\mathrm{SD}$ & NFNP & $\mathrm{F}$ & $\mathrm{P}$ & $\mathrm{P}$ & Result. baixo p/ diag. \\
\hline 205654 & SD & $\mathrm{F}$ & $\mathrm{F}$ & $\mathrm{P}$ & $\mathrm{P}$ & Pode ser SD \\
\hline
\end{tabular}

Esta tabela também mostra que muitos diagnósticos tiveram como resultado o termo Paracompleto, mas a interpretação deste termo depende da proposição efetuada e que está diretamente relacionado com os valores de $\mu_{\mathrm{A}}$ e $\mu_{\mathrm{B}}$, e que podem resultar em diferentes respostas.

Esta tabela mostra a análise efetuada para os rolamentos sem defeitos. Para a pergunta é defeito, obtêm-se a informação de que não é defeito, pois QFI, QFP, F, P, QPV, QPF, são indicativos de condição falsa, conforme definido na tabela 9.2 e a condição Distribuído/Localizado, não foi desenvolvido para detecção de rolamentos sem defeito, mas mesmo assim apresentaram resultados interessantes.

A tabela 8.5 apresenta a taxa de acerto em porcentagem de cada resultado obtido para cada proposição e o seu respectivo diagnóstico. 
TABELA 8.5. Análise estatística para os rolamentos sem defeitos em porcentagem

\begin{tabular}{||c||c|c|c|c|c||}
\hline \hline Proposição & $\begin{array}{c}\text { É } \\
\text { Defeito? }\end{array}$ & $\begin{array}{c}\text { É } \\
\text { Severo? }\end{array}$ & $\begin{array}{c}\text { É Pista } \\
\text { Externa? }\end{array}$ & $\begin{array}{c}\text { É } \\
\text { Envelope? }\end{array}$ & $\begin{array}{c}\text { Distribuído/ } \\
\text { Localizado }\end{array}$ \\
\hline \hline QFI & 36.4 & - & - & - & - \\
\hline NFNP & 27.3 & - & - & - & - \\
\hline NFNI & 18.2 & - & - & - & - \\
\hline QFP & 9.1 & - & 9.1 & 9.1 & - \\
\hline F & 9.1 & 72.7 & - & - & - \\
\hline P & - & 27.3 & 54.6 & 72.7 & - \\
\hline QPF & - & - & 9.1 & - & - \\
\hline QVP & - & - & 18.2 & - & - \\
\hline NVNP & - & - & 9.1 & 9.1 & - \\
\hline QPV & - & - & - & 9.1 & 36.4 \\
\hline Pode ser SD & - & - & - & - & 18.2 \\
\hline Resultado baixo p/ diag. & - & - & - & - & 9.1 \\
\hline Distribuído & - & - & - & - & - \\
\hline Localizado & - & - & - & & \\
\hline \hline
\end{tabular}

A tabela 8.6 indica os diagnósticos obtidos para cada proposição, podendo comparar o defeito real com o defeito diagnosticado. Neste caso para um defeito do tipo distribuído (corrosão) foi devidamente classificado pelo IWZC.

TABELA 8.6. Resultados para rolamentos com defeito distribuído tipo corrosão

\begin{tabular}{||c||c||c||c||c||c||c||}
\hline \hline Arquivo & Defeito & $\begin{array}{c}\hat{\mathbf{E}} \\
\text { Defeito? }\end{array}$ & $\begin{array}{c}\hat{\mathbf{E}} \\
\text { Severo? }\end{array}$ & $\begin{array}{c}\text { É Pista } \\
\text { Externa? }\end{array}$ & $\begin{array}{c}\text { É } \\
\text { Envelope? }\end{array}$ & $\begin{array}{c}\text { Distribuído/ } \\
\text { Localizado }\end{array}$ \\
\hline \hline 90648 & Distribuído & $\mathrm{I}$ & $\mathrm{F}$ & $\mathrm{V}$ & $\mathrm{V}$ & Distribuído \\
\hline 90528 & Distribuído & $\mathrm{I}$ & $\mathrm{F}$ & $\mathrm{V}$ & $\mathrm{V}$ & Distribuído \\
\hline 84730 & Distribuído & $\mathrm{I}$ & $\mathrm{F}$ & $\mathrm{V}$ & $\mathrm{V}$ & Result. baixo p/ diag. \\
\hline 90354 & Distribuído & $\mathrm{I}$ & $\mathrm{F}$ & $\mathrm{V}$ & $\mathrm{V}$ & Distribuído \\
\hline 90224 & Distribuído & $\mathrm{I}$ & $\mathrm{F}$ & $\mathrm{NVNI}$ & $\mathrm{V}$ & Distribuído \\
\hline 85028 & Distribuído & $\mathrm{I}$ & $\mathrm{F}$ & $\mathrm{V}$ & $\mathrm{V}$ & Distribuído \\
\hline 84852 & Distribuído & $\mathrm{I}$ & $\mathrm{F}$ & $\mathrm{V}$ & $\mathrm{V}$ & Localizado \\
\hline & & & & & & \\
\hline 164430 & Distribuído & $\mathrm{V}$ & $\mathrm{F}$ & $\mathrm{I}$ & $\mathrm{V}$ & Distribuído \\
\hline 174502 & Distribuído & $\mathrm{NVNI}$ & $\mathrm{F}$ & $\mathrm{I}$ & $\mathrm{V}$ & Distribuído \\
\hline 174342 & Distribuído & $\mathrm{V}$ & $\mathrm{F}$ & $\mathrm{V}$ & $\mathrm{V}$ & Distribuído \\
\hline 133702 & Distribuído & $\mathrm{I}$ & $\mathrm{F}$ & $\mathrm{V}$ & $\mathrm{V}$ & Distribuído \\
\hline 133520 & Distribuído & $\mathrm{V}$ & $\mathrm{F}$ & $\mathrm{I}$ & $\mathrm{V}$ & Distribuído \\
\hline 123216 & Distribuído & $\mathrm{V}$ & $\mathrm{F}$ & $\mathrm{V}$ & $\mathrm{V}$ & Distribuído \\
\hline 123052 & Distribuído & QIV & $\mathrm{F}$ & $\mathrm{V}$ & $\mathrm{V}$ & Distribuído \\
\hline
\end{tabular}




\begin{tabular}{|c|c|c|c|c|c|c|}
\hline 173824 & Distribuído & $\mathrm{V}$ & $\mathrm{F}$ & $\mathrm{I}$ & $\mathrm{I}$ & Distribuído \\
\hline 174032 & Distribuído & $\mathrm{V}$ & $\mathrm{F}$ & $\mathrm{V}$ & $\mathrm{V}$ & Distribuído \\
\hline 182848 & Distribuído & $\mathrm{V}$ & $\mathrm{F}$ & $\mathrm{I}$ & $\mathrm{I}$ & Localizado \\
\hline 190632 & Distribuído & $\mathrm{V}$ & $\mathrm{F}$ & $\mathrm{I}$ & $\mathrm{I}$ & Localizado \\
\hline 190452 & Distribuído & $\mathrm{V}$ & $\mathrm{F}$ & $\bar{I}$ & $\mathrm{I}$ & Distribuído \\
\hline 190232 & Distribuído & $\mathrm{V}$ & $\mathrm{F}$ & $\mathrm{I}$ & $\mathrm{I}$ & Result. baixo p/ diag. \\
\hline 183216 & Distribuído & $\mathrm{V}$ & $\mathrm{F}$ & $\mathrm{I}$ & $\mathrm{I}$ & Localizado \\
\hline 183048 & Distribuído & $\mathrm{V}$ & $\mathrm{F}$ & $\mathrm{I}$ & $\mathrm{I}$ & Localizado \\
\hline 145930 & Distribuído & $\mathrm{V}$ & $\mathrm{F}$ & $\mathrm{I}$ & $\mathrm{I}$ & Pode ser SD \\
\hline 145648 & Distribuído & $\mathrm{V}$ & $\mathrm{F}$ & $\mathrm{I}$ & $\mathrm{I}$ & Distribuído \\
\hline 144248 & Distribuído & $\mathrm{V}$ & $\mathrm{F}$ & $\mathrm{I}$ & $\mathrm{I}$ & Localizado \\
\hline 142802 & Distribuído & $\mathrm{V}$ & $\mathrm{F}$ & $\mathrm{I}$ & $\mathrm{I}$ & Localizado \\
\hline 131056 & Distribuído & $\mathrm{I}$ & $\mathrm{F}$ & I & $\mathrm{V}$ & Distribuído \\
\hline 130826 & Distribuído & QFI & $\mathrm{F}$ & NFNP & $\mathrm{P}$ & Distribuído \\
\hline 112702 & Distribuído & QPF & $\mathrm{F}$ & QPF & $\mathrm{P}$ & Pode ser SD \\
\hline 112434 & Distribuído & $\mathrm{I}$ & $\mathrm{F}$ & $\mathrm{V}$ & $\mathrm{V}$ & Pode ser SD \\
\hline 171046 & Distribuído & $\mathrm{I}$ & $\mathrm{F}$ & $\mathrm{I}$ & $\mathrm{V}$ & Pode ser SD \\
\hline 170748 & Distribuído & $\mathrm{V}$ & $\mathrm{F}$ & $\mathrm{V}$ & $\mathrm{V}$ & Distribuído \\
\hline
\end{tabular}

A tabela 8.7 apresenta a taxa de acerto em porcentagem de cada resultado obtido para cada proposição e o seu respectivo diagnóstico.

TABELA 8.7. Análise estatística de defeito distribuído (corrosão), em porcentagem

\begin{tabular}{||c||c|c|c|c|c||}
\hline \hline Proposição & $\begin{array}{c}\text { É } \\
\text { Defeito? }\end{array}$ & $\begin{array}{c}\text { É } \\
\text { Severo? }\end{array}$ & $\begin{array}{c}\text { É Pista } \\
\text { Externa? }\end{array}$ & $\begin{array}{c}\text { É } \\
\text { Envelope? }\end{array}$ & $\begin{array}{c}\text { Distribuído/ } \\
\text { Localizado }\end{array}$ \\
\hline \hline I & 34.4 & - & 50.0 & 34.4 & - \\
\hline V & 53.1 & - & 40.6 & 59.4 & - \\
\hline NVNI & 3.1 & - & 3.1 & - & - \\
\hline QIV & 3.1 & - & - & - & - \\
\hline QFI & 3.1 & - & - & - & - \\
\hline QPF & 3.1 & - & 3.1 & - & - \\
\hline NFNP & - & - & 3.1 & - & - \\
\hline F & - & 100.0 & - & - & - \\
\hline P & - & - & - & 6.3 & - \\
\hline Pode ser SD & - & - & - & - & 12.5 \\
\hline Resultado baixo p/ diag. & - & - & - & - & 6.3 \\
\hline Distribuído & - & - & - & - & 59.4 \\
\hline Localizado & - & - & - & - & 21.9 \\
\hline
\end{tabular}


A tabela 8.8 indica os diagnósticos obtidos para cada proposição, podendo comparar o defeito real com o defeito diagnosticado. Neste caso para um defeito do tipo distribuído (riscado) foi devidamente classificado pelo IWZC.

TABELA 8.8. Resultados para rolamentos com defeito distribuído tipo riscado

\begin{tabular}{||c||c||c||c||c||c||c||}
\hline Arquivo & Defeito & $\begin{array}{c}\dot{\mathbf{E}} \\
\text { Defeito? }\end{array}$ & $\begin{array}{c}\mathbf{E} \\
\text { Severo? }\end{array}$ & $\begin{array}{c}\hat{\mathbf{E}} \text { Pista } \\
\text { Externa? }\end{array}$ & $\begin{array}{c}\mathbf{E} \\
\text { Envelope? }\end{array}$ & $\begin{array}{c}\text { Distribuído/ } \\
\text { Localizado }\end{array}$ \\
\hline 122520 & Distribuído_RISC & V & F & I & I & Localizado \\
\hline 122154 & Distribuído_RISC & V & F & I & I & Distribuído \\
\hline 164318 & Distribuído_RISC & V & F & V & V & Distribuído \\
\hline & & & & & & \\
\hline 113512 & Dis tribuído_RISC & V & QFI & I & I & Distribuído \\
\hline 113254 & Distribuído_RISC & V & QFI & I & I & Distribuído \\
\hline 113020 & Distribuído_RISC & V & QFI & I & I & Distribuído \\
\hline
\end{tabular}

A tabela 8.9 apresenta a taxa de acerto em porcentagem de cada resultado obtido para cada proposição e o seu respectivo diagnóstico.

TABELA 8.9. Análise estatística de defeitos distribuídos (riscados), em porcentagem

\begin{tabular}{||c||c|c|c|c|c||}
\hline \hline Proposição & $\begin{array}{c}\mathbf{E} \\
\text { Defeito? }\end{array}$ & $\begin{array}{c}\mathbf{E} \\
\text { Severo? }\end{array}$ & $\begin{array}{c}\text { É Pista } \\
\text { Externa? }\end{array}$ & $\begin{array}{c}\dot{\mathbf{E}} \\
\text { Envelope? }\end{array}$ & $\begin{array}{c}\text { Distribuído/ } \\
\text { Localizado }\end{array}$ \\
\hline \hline V & 100.0 & - & 16.7 & 16.7 & - \\
\hline F & - & 50.0 & - & - & - \\
\hline QFI & - & 50.0 & - & - & - \\
\hline I & - & - & 83.3 & 83.3 & - \\
\hline Pode ser SD & - & - & - & - & - \\
\hline Resultado baixo p/ diag. & - & - & - & - & - \\
\hline Distribuído & - & - & - & - & 83.3 \\
\hline Localizado & - & - & - & - & 16.7 \\
\hline \hline
\end{tabular}

A tabela 8.10 indica os diagnósticos obtidos para cada proposição, podendo comparar o defeito real com o defeito diagnosticado. Neste caso para um defeito do tipo furo (localizado) foi devidamente classificado pelo IWZC. 
TABELA 8.10. Resultados para os rolamentos com defeito localizado tipo furo

\begin{tabular}{|c|c|c|c|c|c|c|}
\hline Arquivo & Defeito & $\begin{array}{c}\underline{\mathbf{E}} \\
\text { Defeito? }\end{array}$ & $\begin{array}{c}\hat{\mathbf{E}} \\
\text { Severo? }\end{array}$ & $\begin{array}{c}\text { É Pista } \\
\text { Externa? }\end{array}$ & $\begin{array}{c}\mathbf{E} \\
\text { Envelope? }\end{array}$ & $\begin{array}{l}\text { Distribuído/ } \\
\text { Localiza do }\end{array}$ \\
\hline 161638 & Localizado & $\overline{\mathrm{V}}$ & $\overline{\mathrm{V}}$ & 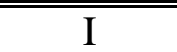 & $\overline{\mathrm{V}}$ & Localizado \\
\hline 184658 & Localizado & $\mathrm{V}$ & $\mathrm{V}$ & $\mathrm{I}$ & $\mathrm{I}$ & Localizado \\
\hline 184314 & Localizado & $\mathrm{V}$ & $\mathrm{V}$ & $\mathrm{I}$ & $\mathrm{I}$ & Localizado \\
\hline 125818 & Localizado & $\mathrm{V}$ & $\mathrm{V}$ & $\mathrm{I}$ & $\mathrm{I}$ & Localizado \\
\hline 175338 & Localizado & $\mathrm{V}$ & $\mathrm{P}$ & $\mathrm{V}$ & $\mathrm{I}$ & Localizado \\
\hline 175136 & Localizado & $\mathrm{V}$ & $\mathrm{P}$ & $\mathrm{I}$ & $\mathrm{I}$ & Result. baixo p/ diag. \\
\hline 171220 & Localizado & $\mathrm{V}$ & $\mathrm{P}$ & $\mathrm{I}$ & $\mathrm{I}$ & Localizado \\
\hline 170854 & Localizado & $\mathrm{V}$ & $\mathrm{P}$ & $\mathrm{V}$ & $\mathrm{I}$ & Localizado \\
\hline 183540 & Localizado & $\mathrm{V}$ & $\mathrm{P}$ & $\mathrm{V}$ & $\mathrm{I}$ & Localizado \\
\hline 183338 & Localizado & V & $\mathrm{P}$ & V & I & Localizado \\
\hline 181636 & Localizado & $\mathrm{V}$ & $\mathrm{P}$ & V & $\mathrm{I}$ & Localizado \\
\hline 181448 & Localizado & $\mathrm{V}$ & $\mathrm{P}$ & $\mathrm{V}$ & $\mathrm{I}$ & Localizado \\
\hline 155714 & Localizado & $\mathrm{V}$ & $P$ & $\bar{I}$ & $\bar{I}$ & Result. baixo p/ diag. \\
\hline 152256 & Localizado & $\mathrm{V}$ & QFP & $\mathrm{I}$ & $\mathrm{I}$ & Localizado \\
\hline 180954 & Localizado & $\mathrm{V}$ & QPV & $\mathrm{I}$ & $\mathrm{I}$ & Localizado \\
\hline 102354 & Localizado & QFI & $\bar{F}$ & QPV & QPV & Localizado \\
\hline 163702 & Localizado & QVI & NFNI & $\mathrm{V}$ & $\mathrm{V}$ & Pode ser SD \\
\hline 151534 & Localizado & $\mathrm{V}$ & $\mathrm{F}$ & $\mathrm{V}$ & $\mathrm{V}$ & Pode ser SD \\
\hline 123814 & Localizado & I & $\mathrm{F}$ & $\bar{V}$ & $\mathrm{~V}$ & Localizado \\
\hline 161610 & Localizado & $\mathrm{V}$ & $\mathrm{F}$ & I & $\mathrm{I}$ & Localizado \\
\hline 153352 & Localizado & $\bar{V}$ & $\overline{Q P F}$ & I & I & Localizado \\
\hline & & & & & & \\
\hline 192306 & Localizado & $\mathrm{I}$ & $\mathrm{F}$ & $\bar{V}$ & $\mathrm{~V}$ & Localizado \\
\hline 192108 & Localizado & $\mathrm{I}$ & $\bar{F}$ & $\mathrm{~V}$ & $\mathrm{~V}$ & Result. baixo p/ diag. \\
\hline 190216 & Localizado & $\mathrm{I}$ & $\mathrm{F}$ & $\mathrm{I}$ & $\mathrm{V}$ & Localizado \\
\hline 190034 & Localizado & $\mathrm{I}$ & $\mathrm{F}$ & $\mathrm{V}$ & $\mathrm{V}$ & Result. baixo p/ diag. \\
\hline 165542 & Localiz. PI & $\mathrm{V}$ & QFI & $\mathrm{I}$ & I & Pode ser SD \\
\hline 171910 & Localiz. PI & $\mathrm{I}$ & QVP & $\mathrm{I}$ & $\mathrm{V}$ & Result. baixo p/ diag. \\
\hline
\end{tabular}

A tabela 8.11 apresenta a taxa de acerto em porcentagem de cada resultado obtido para cada proposição e o seu respectivo diagnóstico. 
TABELA 8.11. Análise estatística de defeitos localizado (furo), em porcentagem

\begin{tabular}{||c|c|c|c|c|c||}
\hline Proposição & $\begin{array}{c}\text { É } \\
\text { Defeito? }\end{array}$ & $\begin{array}{c}\text { É } \\
\text { Severo? }\end{array}$ & $\begin{array}{c}\text { É Pista } \\
\text { Externa? }\end{array}$ & $\begin{array}{c}\text { É } \\
\text { Envelope? }\end{array}$ & $\begin{array}{c}\text { Distribuído/ } \\
\text { Localizado }\end{array}$ \\
\hline \hline V & 72.0 & 16.0 & 48.0 & 32.0 & - \\
\hline QFI & 4.0 & - & - & - & - \\
\hline QVI & 4.0 & - & - & - & - \\
\hline I & 20.0 & - & 48.0 & 64.0 & - \\
\hline P & - & 36.0 & - & - & - \\
\hline QFP & - & 4.0 & - & - & - \\
\hline QPV & - & 4.0 & 4.0 & 4.0 & - \\
\hline F & - & 32.0 & - & - & - \\
\hline NFNI & - & 4.0 & - & - & - \\
\hline QPF & - & 4.0 & - & - & - \\
\hline Pode ser SD & - & - & - & - & 8.0 \\
\hline Resultado baixo p/ diag. & - & - & - & - & 16.0 \\
\hline Distribuído & - & - & - & - & - \\
\hline Localizado & - & - & - & - & 76.0 \\
\hline
\end{tabular}




\section{ANÁLISE DOS RESULTADOS OBTIDOS}

\subsection{Tabela de dados}

A tabela 9.1 apresenta um resumo dos resultados obtidos para a análise dos rolamentos. Os números dentro das células indicam a taxa de acerto. Estes valores são para uma carga no eixo de $5,9 \mathrm{~kg}$ e uma rotação de 1800RPM.

TABELA 9.1. Taxa de acerto dos resultados obtidos

\begin{tabular}{|c|c|c|c|c|c|}
\hline $\mathbf{P}$ & $\begin{array}{c}\mathbf{E} \\
\text { Defeito? }\end{array}$ & $\begin{array}{c}\text { É } \\
\text { Severo? }\end{array}$ & $\begin{array}{c}\text { É Pista } \\
\text { Externa? }\end{array}$ & $\begin{array}{c}\text { É } \\
\text { Envelope? }\end{array}$ & $\begin{array}{c}\text { Distribuído/ } \\
\text { Localizado }\end{array}$ \\
\hline 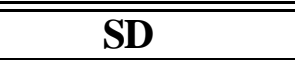 & $10100 \%$ & - & - & - & - \\
\hline Corrosão & $93,75 \%$ & $100 \%$ & $93,75 \%$ & $93,75 \%$ & $59,37 \%$ \\
\hline Furo & $96 \%$ & $60 \%$ & $96 \%$ & $96 \%$ & $76 \%$ \\
\hline Riscado & $100 \%$ & $100 \%$ & $100 \%$ & $100 \%$ & $83,30 \%$ \\
\hline Pista Interna & $\overline{100 \%}$ & $\overline{50 \%}$ & $0 \%$ & $\overline{100 \%}$ & $0 \%$ \\
\hline
\end{tabular}

O banco de dados disponível necessita ser ampliado para um detalhamento maior das fronteiras apresentadas na figura 6.14. Desta forma, como os dados disponíveis ainda são limitados, foram unidos alguns estados lógicos de saída. Assim os estados de saída V, QVI e QVP foram unidos e chamado de estado lógico V. Os estados de saída F, QFI e QFV foram unidos chamados de estado lógico F. Os estados lógicos I, QIV e QIF, foram unidos e chamados de estados lógicos I e os estados lógicos P QPV e QPF, foram unidos e chamados de estado lógico $\mathrm{P}$.

A tabela 9.2 apresenta as respostas a cada proposição efetuada. Os estados lógicos para a resposta afirmativa, estão indicados na coluna afirmação e a resposta negativa a proposição, está indicada na coluna negação. 
TABELA 9.2. Resultados dos estados lógicos de saída por proposição

\begin{tabular}{||c||c||c||}
\hline \multicolumn{1}{|c|}{ PROPOSIÇÃO } & AFIRMAÇÃO & NEGAÇÃO \\
\hline \hline É DEFEITO? & I, QIV, QIF, V, QVI e QVP & P, QPV, QPF, F, QFP, QFI, * \\
\hline \hline É SEVERO? & P, QPV, QPF, V, QVI e QVP & I, QIV, QIF, F, QFP, QFI, * \\
\hline \hline É PISTA EXTERNA? & I, QIF, QIV, V, QVI e QVP & P, QPV, QPF, F, QFI e QFP, * \\
\hline \hline É ENVELOPE? & I, QIV, QIF, V, QVI e QVP & P, QPV, QPF, F, QFI e QFP, * \\
\hline
\end{tabular}

* NFNI, NFNP, NVNI, NVNP

Os valores inconsistente ou paracompleto possuem significados de acordo com a proposição efetuada e o comportamento esperado das funções de pertinência definidas.

Neste trabalho para as proposições:

Para a análise dos resultados, distribuído ou localizado, não se utilizou a lógica nebulosa paraconsistente, e tem-se os seguintes possíveis diagnósticos:

- Localizado;

- Distribuído;

- Pode ser SD;

- Result. Baixo p/ diag.

Para os diagnósticos: "Pode ser SD" e "Result. Baixo p/ diag.", significam que o rolamento pode não possuir defeito.

Está análise é realizado pelo programa desenvolvido utilizando-se a lógica clássica. 


\section{CONCLUSÕES}

O IWZC associado com o limiar apresentou bom resultado para o diagnóstico do tipo de defeito, se é localizado ou distribuído, mostrando boa capacidade na detecção de defeito mesmo em sua fase inicial, onde o nível de ruído pode dificultar o diagnóstico do defeito.

A Zero Crossing da Transformada de Wavelet teve um bom desempenho no diagnóstico de defeitos em fase inicial como se observa através dos parâmetros Thmax 6 e Thmax 7.

Quando se compara a capacidade da transformada de wavelet em detectar defeitos utilizando os vários níveis, figura 6.26 pode-se observar o seu grande potencial no diagnóstico de defeitos, por exemplo, quando comparado como o valor RMS de cada um dos seus níveis.

A Lógica Nebulosa Paraconsistente apresentou bons resultados para a detecção de defeitos em sua fase inicial, mesmo nas situações onde as várias técnicas de extração de características apresentaram situações contraditórias, pois foi desenvolvida para tratar de situações onde ocorrem opiniões contraditórias. Esta se mostrou capaz de tomar decisões, removendo a condição de impasse de modo automático, oferecendo um diagnóstico sobre a condição de operação do rolamento.

A Lógica Nebulosa Paraconsistente mostrou-se também de fácil implementação e bastante versátil, devido a sua maleabilidade para a resolução de proposições. Pode-se observar que com o aumento do conhecimento a respeito das técnicas de extração de características, estes novos conhecimentos poderiam ser facilmente implementados nesta lógica, tornando-a mais ajustada para a realização do diagnóstico das condições dos rolamentos.

Esta tese abordou duas áreas que se mostraram bastante promissora que são as aplicações do zero crossing da transformada de wavelet na monitoração de máquinas rotativas e o uso da lógica nebulosa paraconsistente no diagnóstico das condições de operação das máquinas, que mostraram resultados satisfatórios, conforme se observou através dos diagnósticos obtidos. 
O programa de computador desenvolvido pode auxiliar na integração das diversas técnicas de extração de características utilizadas, desde o carregamento dos dados até o diagnóstico automático de defeito em rolamento, podendo posteriormente salvar os resultados para um possível histórico das condições operacionais da máquina. 


\section{TRABALHOS FUTUROS}

Como trabalhos futuros podem-se propor as seguintes realizações:

A investigação do uso da wavelet "packet" na identificação de defeitos de rolamentos, em bandas de frequiências definidas, estabelecendo a possibilidade de diagnósticos precisos dentro da banda utilizada.

Estudar a possibilidade de análise de defeito usando a transformada de wavelet para outros níveis (3 e 4).

Acrescentar no programa desenvolvido as características que permitam que este possa realizar diagnóstico de defeitos em engrenagens.

Aumentar o banco de dados acrescentado defeitos nas esferas, gaiola, e a combinação de defeito entre si.

Aplicar este estudo para os três sensores simultaneamente

Aumentar a versatilidade do programa não só para analisar defeitos em rolamentos, mas também em outros segmentos da monitoração preditiva como na avaliação de motores, peças de alto desgaste, tendo como objetivo a análise de casos e a descoberta das características próprias de um determinado defeito. 


\section{APÊNDICES}

\section{A.1 Curvas dos sensores}

As duas figuras mostram a curva dos sensores, piezelétricos utilizados neste trabalho.

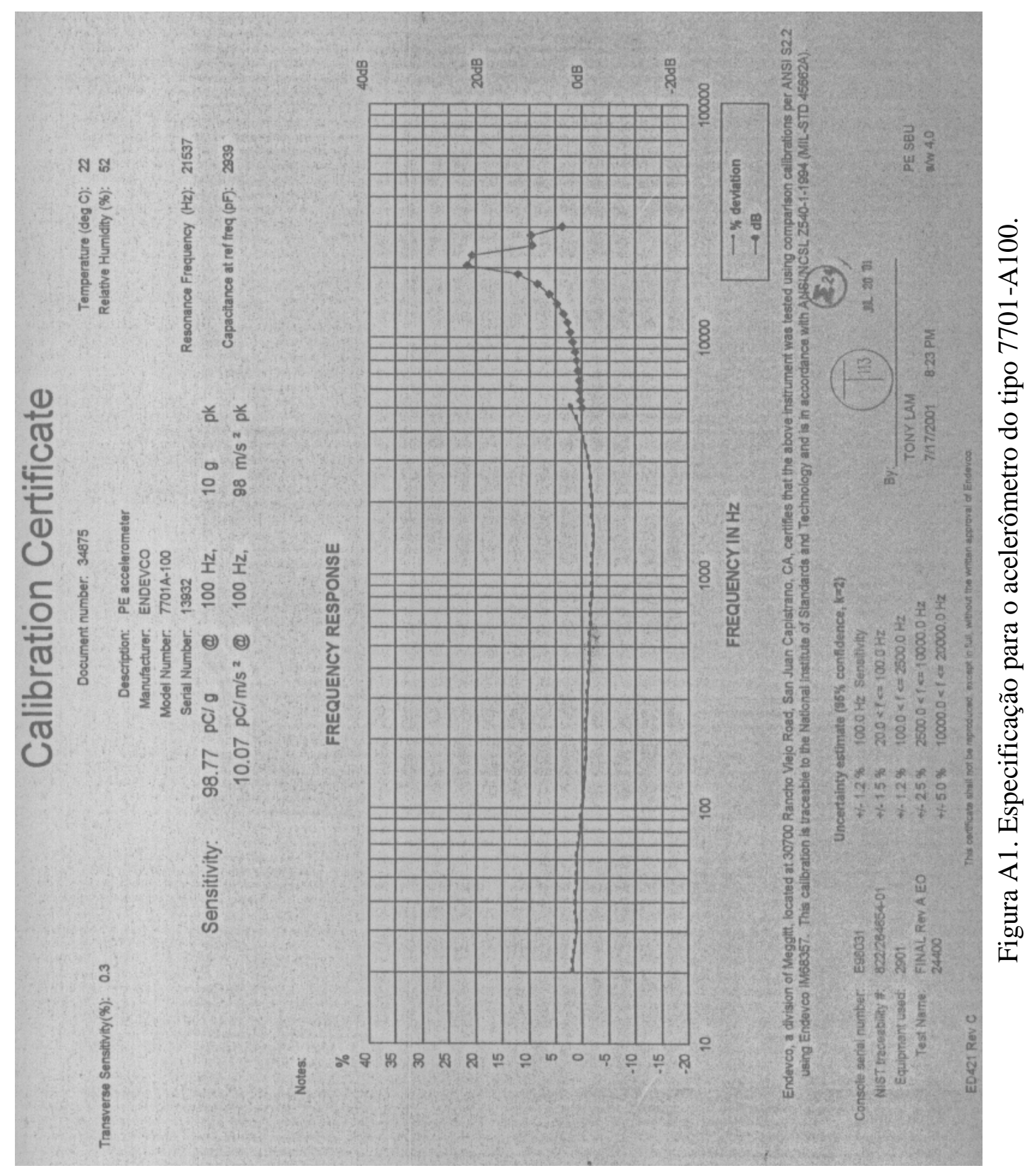




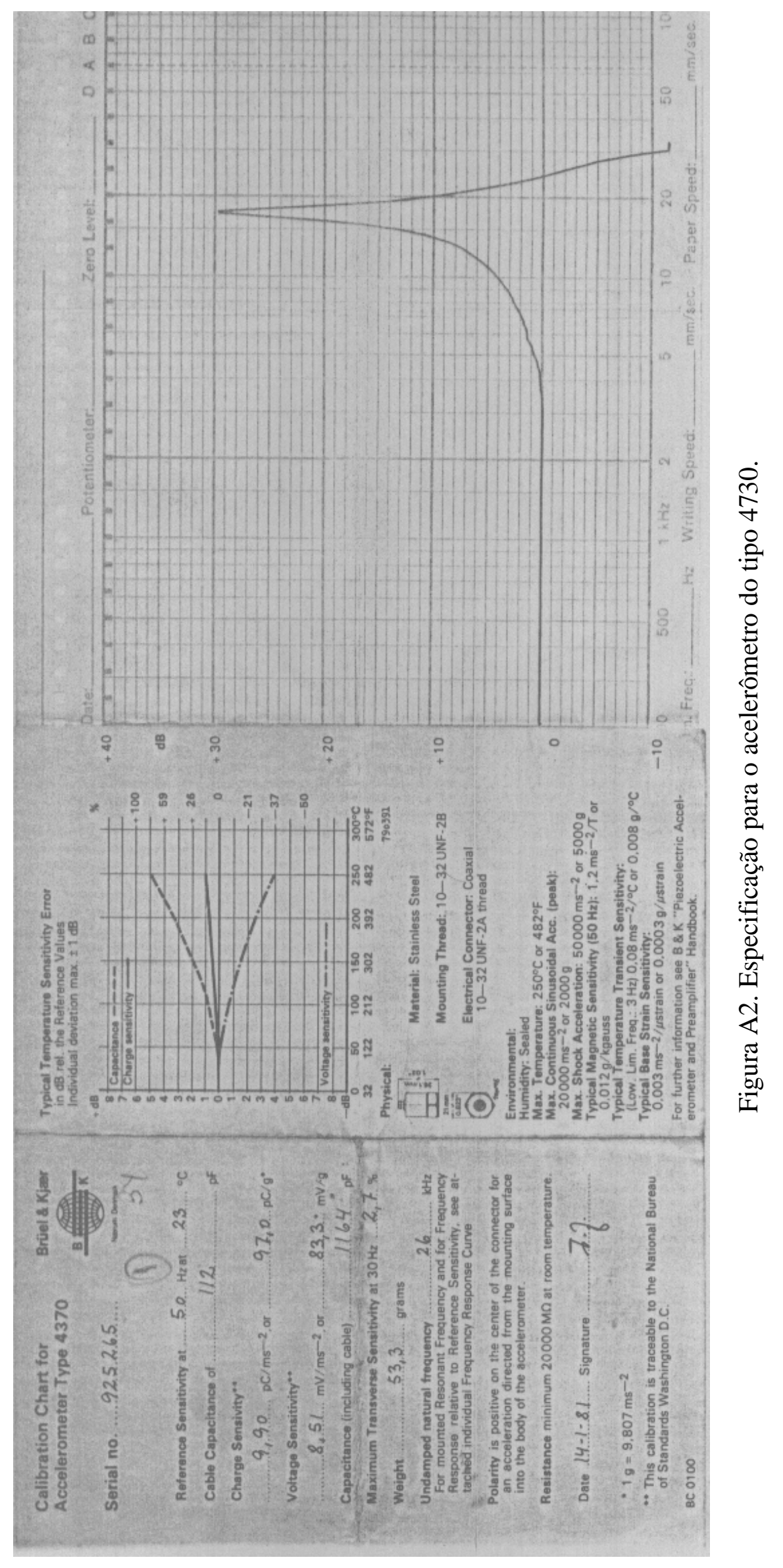




\section{REFERÊNCIAS BIBLIOGRÁFICAS}

1 - TANDON, N.; CHOUDHURY, A.; A Review of Vibration and Acoustic measurement methods for the detection of defects in rolling elements bearing, Tribology International 32, pág. 469 - 480, 1999; Elsevier Science 2000.

2 - SÜDMERSEN U.; REIMCHE W.; SCHEER C.; STEGEMANN D.; Applying Vibration Analysis To Process And Production Control systems, Institute for Nuclear Engineering and Non-Destructive Testing, Hannover, Germany.

3 - BEARING EXPERT ${ }^{\mathrm{TM}}$, Disp. em

<http://www.sourceindex.com/be/product_summary.html, revisitado em 09/05/2006.

4 - ABODE, software (Advanced Bearing optimization, Design and Evaluation - High Speed Ball and Roller Bearing Analysis), Disponível em <http://www.advancedbearing.com/examples/examples.html> revisitado em 09/05/2006

5 - LABOROTEC/ ULB RESERACH - "Labview Virtual Instrument"; Disponível em <http://www.ulb.ac.be/polytech/laborulb/index.htm>. revisitado em 09/05/2006

6 - PIRES E AlbUQUERQUE, O A L. Elementos de Máquinas Ed. Guanabara Dois S.A. 1980.

7 - NEPOMUCENO L. X. Técnicas De Manutenção Preditiva, Editora Edgard Blücher Ltda, Volume 1, $1^{\text {o }}$ Reimpressão 1999.

8 - SKF O que é Envelopamento?; Disponível em <http://www.vibra.dynamiczone.com> traduzido do artigo publicado pela SKF Condition Monitoring - Nota de aplicação - CM 3014. revisitado em 09/05/2006.

9 - SKF Identificando Estágios de Falhas em Rolamentos, Disponível em <http://www.vibra.dynamiczone.com> traduzido do artigo publicado pelo periódico Revolutions da SKF Condition Monitoring, Vol. 7, No 3. revisitado em 09/05/2006. 
10 - MISITI, MICHEL; MISITI, YVES; OPPENHEIM, GEORGES; POGGI, JEAN MICHEL; Wavelet Toolbox, User's Guide, The MathWorks, Inc 1997.

11 - SKF Early Warning Fault Detection In Rolling Element Bearings Using Microlog Enveloping, SKF Condition Monitoring - Application Note - CM 3021 Revised 2 - 96, 1996. Disponível em <http://www.skfcm.com> revisitado em 09/05/2006.

12 - BROTHERTON, TOM; E POLLARD, TOM; Application of Time-Frequency and Time-Scale Representation to Fault Detection and Classification, Proc. IEEE 4-6 Oct., 9599, 1992.

13 - YUANJIN, ZHENG; DAVID, B. H.; TAY, LEMIN LI; Signal Extraction and Power Spectrum Estimation Using Wavelet Transform Scale Space Filtering and Bayes Shrinkage, Signal Processing 80, pag. 1535 - 1549, 2000; Elsevier Science 2000.

14 - JOUAN-RIMBAUND, D.; WALCZAK, B.; POPPI, R.J.; NOORD, O. E.; E MASSART, D.L.; Application of Wavelet Transform to Extract the Relevant Component from Spectral Data for Multivariate Calibration Analytical Chemistry Vol 69, $\mathbf{N}^{\mathrm{o}} 21$, pag 4317 - 4323, Nov. 1, 1997.

15 - CHUI, CHARLES K.; An Introduction to Wavelets - Wavelet Analysis and Its Applications, volume 1, Academic Press - 1992.

16 - NEWLAND, D. E.; An Introduction to Random Vibration Spectral \& Wavelet Analysis, Addison Wesley Longman Limited, $3^{\circ}$ edição, 1996.

17 - SHIROISHI, J.; LI, Y.; LIANG, S.; KURFESS, T.; E DANYLUK, S.; Bearing Condition Diagnostics Via Vibration and Acoustic Emission Measurements, Mechanical System and Signal Processing 11 (5), pag. 693 - 705, 1997; Elsevier Science 1997.

18 - WALCZAK, B.; MASSART, D.L.; Wavelet Packet Transform Applied to a Set of Signals: A new Approach to the Best-Basis Selection, Chemometrics and Intelligent Laboratory Systems 38, pag 39 - 50, 1997; Elsevier Science 1997. 
19 - WALCZAK, B.; MASSART, D.L.; Tutorial Noise Suppression and Signal Compression Using the Wavelet Packet Transform Selection, Chemometrics and Intelligent Laboratory Systems 36, pag 81- 94, 1997; Elsevier Science 1997.

20 - MALLAT STEPHANE,; Zero-Crossing of a Wavelet Transform, IEEE Transactions on Information Theory, Vol. 37, Nº 4. pp. 1019 - 1033, July 1991.

21 - QUEK, SER-TONG, WANG Q., ZHANG L., ANG K. K.; Sensitivity Analysis of Crack Detection in Beams by Wavelet Technique, International Journal of Mechanical Science 43(2001) 2899-2910, Elsevier Science 2001.

22 - LEE, B. Y.; TARNG, Y.S.; Drill Fracture Detection by the Discrete Wavelet Transform, Journal of Materials Processing Technology 99, pag 254-255, 2000; Elsevier Science 2000.

23 - UPADHYAYA, B. R.; ERBAY, ALI S.; HÁZI G.; SUNG, KEY Y.; Eddy Current Test Data Analysis For Steam Generator Tubing Diagnosis Using Artificial Intelligence Methods. Nucl. Engin. Depart. The University of Tennessee Knoxville, Annual Report, Feb 1999.

24 - PAYA, B.A.; ESAT, I.; Artificial Neural Network Based Fault Diagnostics of Rotating Machinery Using Wavelet Transform as a Preprocessor, Mechanical Systems and Signal Processing, 11- 5, pp 751 - 765, 1997; Elsevier Science, 1997.

25 - Da COSTA, N. C. A., ABE J.M., SILVA FILHO J.I., MUROLO A.C., LEITE C. F. S.; Lógica Paraconsistente Aplicada, Editora Atlas S.A. - São Paulo, 1999.

26 - SPECTRA QUEST; - Manual de operação da Bancada de Simulação de Defeitos em Máquinas Rotativas.

27 - Da SILVA FILHO, JOÃO I.; Métodos de Aplicações da Lógica Paraconsistente Anotada de Anotação com Dois Valores-LPA2v com Construção de Algoritmo e 
Implementação de Circuitos Eletrônicos, 1999 Tese (Doutoramento) - Universidade de São Paulo, São Paulo.

28 - Da SILVA FILHO, JOÃO I. and ABE, JAIR M.; Para-Fuzzy Logic Controller I - A Hybrid Logical Controller Indicated for Treatment of Inconsistencies Designed with the Junction of the Paraconsistent and Fuzzy Logic, Proceedings of the International ICSC Congress on Computational Intelligence Methods and Applications CIMA 99 Rochester Institute of Technology, Rochester, NY, USA, June 22 - 25, 1999.

29 - Da SILVA FILHO, JOÃO I. and ABE, JAIR M.; Para-Fuzzy Logic Controller II - A Hybrid Logical Controller Indicated for Treatment of Fuzziness and Inconsistencies, Proceedings of the Inter ICSC Congress on Computational Intelligence Methods and Applications CIMA 99 Rochester Institute of Technology, Rochester, USA, June 22 - 25, 1999.

30 - INTERNATIONAL STANDARD ORGANIZATION - ISO 10816-1; Mechanical Vibration - Evaluation of Machine Vibration by Measurements on Non-rotating part 1, Fist edition, 1995.

31 - INTERNATIONAL STANDARD ISO 281; Rolling Bearing - Dynamic Load Ratings and Rating Life, STD.ISO 281: 1990/Amd2:2000(E).

32 - ANS, ANSI/ABMA STD 11; Load Ratings and Fatigue Life for Roller Bearing.

33 - TING, D.K.S.; MASOTTI, P.H.F.; MESQUITA, R.N.; Teste de Validade para um Ensaio por Eddy Current em Tubos Geradores de Vapor Usando Lógica "Fuzzy" Paraconsistente, I Congresso de Lógica Aplicada à Tecnologia, LAPTEC 2000, 11 a 15 de Setembro de 2000.

34 - SILMARA, A.S.V.; MASOTTI, P.H.F.; ALMEIDA, R.G.T.; TING, D.K.S.; PADOVESE, L.R.; Automatic Diagnosis of Defects in Bearings Using Fuzzy Logic, COBEM, XVI Congresso Brasileiro de Engenharia Mecânica, 26 a 30 Novembro 2001, Uberlândia, Minas Gerais, Brasil. 
35 - TING, D.K.S.; MASOTTI, P.H.F.; Comparing Electronic And Numerical Methods For The Integration Of Random Signals In Accelerometry, CONEM 2002, II Congresso Nacional de Engenharia Mecânica, 12 a 16 de Agosto de 2002 - João Pessoa - PB.

36 - MASOTTI, P.H.F.; TING, D.K.S.; Wavelet Zero Crossings and Paraconsistent Fuzzy Logic in the Diagnostic of Rolling Bearings, XIII ENFIR, VI ENAN, IX CGEN, INAC 2002, International Nuclear Atlantic Conference, 11 a 16 August 2002, Rio de Janeiro, Brazil.

37 - SEHGAL, R.; GANDHI, O. P.; ANGRA, S.; Reliability Evaluation and Selection of Rolling Element Bearing Reliability Engineering \& System Safety 68, pag. 39-52, Elsevier Science 2000.

38 - NAKA, MICHIHARU; Research and Development of Lubrication Greases by NSK, Basic Technology Research \& Deve lopment Center, Motion \& Control N ${ }^{0} 3$ - 1997, NSK 39 - ROCHA, LUIZ F. R; Diagnóstico de falhas através da análise de vibrações pelo método de sinais residuais na manutenção preditiva de indústrias de papel e celulose, 2003. Dissertação (Mestrado) - Escola Politécnica da Universidade de São Paulo, São Paulo.

40 - HOOPER, WESLEY C.; UPADHYAYA, B. R.; An automated Diagnostics System for Eddy Current Data Analysis of Steam Generator Tubing, Nuclear Engineering Department The University of Tennessee Knoxville, Annual Report, January 1998.

41 - TORRES, CLÁUdIO R.; ABE, JAIR M.; TORRES, GERMANO, L.; 1-Sistemas Inteligentes Paraconsistentes Para controle do Robôs Móveis Autônomos, 2-Robô Móvel Autônomo EmmyII, Série Lógica e Teoria da Ciência, $\mathrm{N}^{0} 58$, Instituto de Estudos Avançados da Universidade de São Paulo. Fevereiro 2005.

42 - KOLDITZ, J.; IAEA - Interregional Training Course on Ageing Phenomena and Diagnostics for PWR - Type Reactors, 25.11 - 13.12.96. 1996. 
43 - SKF, Basic Condition Monitoring Kit, disponível em

http://www.skf.com/portal/skf/home/solutions?paf_dm=shared\&paf_gear_id=600029\&con tentId $=0.000336 .004148 .056292 .0 .56681 .001086 .057342$, acessado em novembro 2005.

44 - FAG, Bearing Analyzer II, disponível em

<http://www.fag.com/content/media/_shared_media/library/downloads/downloads_fag_te mp/wl_80250_2_de_en.pdf>, acessado em novembro 2005.

45 - BENTLY NEVADA, Monitoring Systems, disponível em

<http://bently.com/prod/produtcts/monitoringsystems.htm>, acessado em novembro 2005.

46 - BENTLY NEVADA, Software, Plant Asset Management Software, disponível em <http://www.bently.com/prod/products/software.htm>, acessado em novembro 2005.

47 - WALKER, J.S.; Fast Fourier Transforms - second edition - CRC Press - 1996

48 - PERCIVAL B. DONALD, WALDEN T. ANDREW; Spectral Analysis for Physical Applications, Multitaper and Conventional Univariate Techniques Cambridge, 1993

49 - INMAM, DANIEL J.; Engineering Vibration Prentice Hall, 1996

50 - HAMMING, R.W.; Numerical Methods for Scientists and Engineers 2 ed. Dover Publications 1973

51 - PENHA, R. M. L.; Análise de Sinais em Regime Transiente Aplicando a Técnica de Wavelet, Dissertação (Mestrado), Instituto de Pesquisas Energéticas e Nucleares, 1999.

52 - DYRJAWOJ, N.; Desenvolvimento de um Amplificador Isolador para Análise de Sinais Dinâmicos, Dissertação (Mestrado), Instituto de Pesquisas Energéticas e Nucleares, 2003.

53 - LOU X.; LOPARO, K. A.; Bearing Fault Diagnosis Based on Wavelet Transform and Fuzzy Inference, Mechanical System and Signal Processing 18 (2004) 1077 - 1095, Elsevier, 2004. 
54 - ABE, J.M.; Introdução a Lógica Paraconsistente Anotada, Seleção Documental, Artigos Técnicos e Científicos da Área de Inteligência Artificial, Editora ParaLogike n1, anoI - Janeiro 2006.

55 - VUOLO, J. H.; Fundamentos da Teoria de Erros. $2^{\circ}$ edição revisada e ampliada, editora Edgard Blücher Ltda, 1996.

56 - LI, C. J.; MA, J.; Wavelet Decomposition of Vibration for Detection of BearingLocalized Defects, NDT\&E International Vol. 30 No 3 pp 143-149 Elsevier Science 1996.

57 - WANG C.; GAO, R. X.; Wavelet Transform With Spectral Post-Processing for Enhanced Feature Extraction, IEEE Transaction on Instrumentation and Measurement, vol 52, $\mathrm{N}^{\mathrm{0}}$ 4, August 2003.

58 - McFADDEN, P.D.; SMITH, J.D.; Model for the Vibration Produced by a Single Point Defect in a Rolling Element Bearing, Journal of Sound and Vibration (1984) 96(1), 69-82, 1984

59 - UHRIG, ROBERT E.; TSOUKALAS, LEFTIERI H.; Soft Computing Technologies in Nuclear Engineering Applications Progress in Nuclear Energy Vol $34 \mathrm{~N}^{\circ} 1$ pag 13-75 1999, Elsevier Science, 1999.

60 - NORTON, M. P.; Fundamentals of Noise and Vibration Analysis for Engineers, Cambridge University Press, 1994.

61 - HARRIS, CYRIL M.; Shock \& Vibration, Handbook, terceira edição, McGraw-Hill Book Company, 1988.

62 - CIENFUEGOS, FREDDY; Estatística Aplicada ao Laboratório, Editora Interciência Ltda, 2005. 
63 - SKEIRIK, ROBERT D.; Alignment Pitfalls - How to Identify and Eliminate Them, presented at Vibration Institute, New Orleans, 17 junho de 1997.

64 - SHIROISHI J.; LI, Y, LANG S.; DANYLUK S.; KURFESS T.; Vibration Analysis for Bearing Outer Race Condition Diagnostics. Journal of the Brazilian Society of Mechanical Sciences, vol. 21, Nº 3, Rio de Janeiro, Setembro de 1999.

65 - PRABHAKAR S.; MOHANTY A.R.; SEKHAR A.S.; Application of Discrete Wavelet Transform for Detection of Ball Bearing Race Faults, Tribology International 35, 793 - 800, Elsevier, 2002.

66 - Building GUIs with Matlab, version 5, The Mathworks Inc, MA, USA, 1997.

67 - Fuzzy Logic Toolbox for use GUI with Matlab version 5, The MathWorks Inc, MA USA, 1997.

68 - MAllAT, S.G.; A Wavelet Tour of Signal Processing. San Diego, Academic Press, 1997. 